PROGRAMA DE DOCTORADO EN ESTUDIOS INGLESES AVANZADOS: LENGUAS Y CULTURAS EN CONTACTO

TESIS DOCTORAL:

\title{
LA TEORÍA FUNCIONAL DE LA LEXICOGRAFÍA Y SU APLICACIÓN A LA CONSTRUCCIÓN DE DICCIONARIOS ESPECIALIZADOS. UNA PROPUESTA DE DICCIONARIO DE EXPRESIÓN GRÁFICA EN LA INGENIERÍA
}

Presentada por M. Angeles Esandi Baztan para optar al grado de

Doctor/a por la Universidad de Valladolid

Dirigida por:

Dr. D. Pedro Antonio Fuertes Olivera 



\section{AGRADECIMIENTOS}

Quisiera expresar mi más sincero agradecimiento a todas las personas que directa o indirectamente han contribuido durante el desarrollo de este trabajo de investigación a que esta tarea resultara más liviana, más interesante y personalmente satisfactoria.

Esta tesis no habría sido posible sin la profesionalidad y el entusiasmo por la investigación que derrocha mi Tutor Doctoral y Director de Tesis Dr. D. Pedro Antonio Fuertes Olivera. Agradezco su paciencia durante todos estos años.

El Programa de Incentivación al profesorado de la Universidad de Valladolid para Lograr el Título de Doctor que, al amparo de la Ley Orgánica de 4/2007 de 12 de abril (LOMLOU) por la que se modifica la Ley Orgánica de Universidades 6/2001 de 21 de diciembre (LOU) establece en su disposición adicional segunda, ordinal dos, lo siguiente:

Las universidades establecerán programas tendentes a favorecer que los Profesores Titulares de Escuela Universitaria puedan compaginar sus tareas docentes con la obtención del título de Doctor.

Agradezco a la Universidad de Valladolid que en Consejo de Gobierno de 15 de julio de 2016 acordó concederme el acogimiento a este programa y posterior prórroga por un total de tres cursos lectivos. Sin esta incentivación hubiera sido muy difícil compaginar docencia e investigación. 


\section{RESUMEN}

El objetivo de esta tesis es diseñar una propuesta de diccionario en línea especializado de Expresión Gráfica en la Ingeniería $(E G I)$ de orientación pedagógica en el marco teórico y metodológico de la Teoría de las Funciones Lexicográficas (TFL). El área de conocimiento Expresión Gráfica en la Ingeniería tiene, por su naturaleza, un lenguaje de comunicación propio gráfico. Este diccionario es una herramienta lexicográfica monolingüe en español.

Se concibe este diccionario como una obra de referencia, una herramienta para su consulta puntual destinada a un tipo de usuario que en una situación de aplicación práctica de conocimientos teóricos o de interpretación de Normas tiene necesidades de información. Los parámetros, que se articulan en el marco de la TFL (Tarp, 2008, 2009; Andersen y FuertesOlivera, 2009) y que se han utilizado para la construcción de este diccionario pedagógico especializado con criterios lexicográficamente relevantes como las funciones del diccionario son: los usuarios de diccionario, las necesidades específicas del usuario en situaciones específicas, la presentación de datos y la accesibilidad de los datos. Se diseña para que como resultado de la actividad lexicográfica: intervenga en un proceso para conseguir información; desempeñe una función cognitiva, operativa e interpretativa, y sea una herramienta práctica de uso y un instrumento pedagógico. Este diccionario es especializado por el tema en un dominio peculiar ya que utiliza unidades léxicas y gráficas para describir y representar conceptos en sus campos temáticos específicos.

En Expresión Gráfica en la Ingeniería se emplean técnicas y convencionalismos de representación geométrica que se aplican en dibujos de ingeniería de carácter técnico e industrial. Las características y las propiedades de los objetos que define un tecnólogo y un ingeniero no siempre pueden reducirse a descripciones verbales inequívocas. La práctica profesional de la ingeniería pone de manifiesto que existe una necesidad de fijar ideas y de representarlas gráficamente. Para lograrlo es necesario disponer de un lenguaje gráfico basado en los sistemas de representación y la normalización.

La presencia de los elementos gráficos con funciones semióticas generadas por un código gráfico diferente del lingüístico modifica las unidades de entendimiento (Esandi et al., 2007) en el ámbito de conocimiento (EGI) y transforma la noción de concepto dentro del discurso especializado. Esta modificación se debe a que existen otros sistemas de transmisión y 
representación del conocimiento en los que cada concepto se expresa a través de signos de la lengua y de símbolos de otros lenguajes o sistemas (Galinski y Pitch, 1997).

Para responder las preguntas de investigación formuladas al inicio de este trabajo se decidió: definir el perfil tipo de usuario e identificar las necesidades de información lexicográficas partiendo de las competencias a desarrollar en la vida académica del usuario universitario y realizar una sesión con expertos docentes de EGI. Los expertos aportaron información sobre el perfil del usuario, sus situaciones y sobre su percepción sobre cuáles son las necesidades de ese usuario en materias de EGI de acceso lexicográfico. Como método de prospección se utiliza con estos expertos el Método Delphi, una metodología que, mediante cuestionarios, permite en primer lugar, extraer conceptos del dominio y conceptos gráficogeométricos $y$, en segundo lugar, obtener una lista inicial de conceptos fundamentales consensuada por el grupo. Adicionalmente se recogió la opinión de los alumnos sobre los conceptos de EGI con el objetivo de optimizar, contrastar y priorizar el contenido en la propuesta de diccionario.

Finalmente se formula una propuesta concreta para el contenido, la presentación y el acceso a los datos del diccionario. El interés pedagógico del diccionario hace que se retome la noción de reformulación pedagógica. Esta reformulación, para (Pétroff, 1984), consiste en adaptar la información (en nuestro caso los datos) a una nueva situación, a un tipo específico de receptor y de acuerdo con una acción determinada. Además de ser relevante, de buena calidad, llegar en el momento correcto, en el lugar correcto, y llegar a la persona adecuada. 


\section{SUMMARY}

This thesis aims to design a proposal for a of pedagogical-oriented specialised online dictionary of Graphic Expression in Engineering (EGI) under the theoretical and methodological framework of the Theory of Lexicographic Functions (TLF). The field of knowledge Graphic Expression in Engineering has, by nature, its own graphic communication language. This dictionary would be a monolingual lexicographic tool in Spanish.

This dictionary is conceived as a reference work, a tool for occasional consultation aimed at a type of user who, in a situation of practical application of theoretical knowledge or interpretation of the Standards, has a need for information. The parameters involved, under the framework of the TFL (Tarp, 2008, 2009; Andersen and Fuertes-Olivera, 2009) and which have been used for the preparation of this specialised pedagogical dictionary with lexicographically relevant criteria such as dictionary functions are: dictionary users, the specific needs of the user in specific situations, for data display and the accessibility of the data. It is designed assuming that the lexicographic activity intervenes in a process for getting information, fulfils a cognitive, operational and interpretative function, and could lead to the design of practical tools and pedagogical instruments. This dictionary is specialised by subject in a distinctive domain that uses lexical and graphic units to describe and represent concepts in their specific thematic fields.

In Graphic Expression in Engineering, geometric representation techniques and conventions are used and applied in technical and industrial engineering drawings. The objects specifications and properties defined by a technologist and an engineer cannot always be reduced to unambiguous verbal descriptions. The professional practice of engineering shows that there is a need to fix ideas and to represent them graphically. To achieve this, it is necessary to have a graphic language based on representation systems and standardization.

The presence of graphic items with semiotic functions generated by a graphic code different from the linguistic one modifies the units of understanding (Esandi et al., 2007) in our field of knowledge (EGI) and transforms the notion of concept within specialized discourse. This modification is due to the fact that there are other systems of knowledge transmission and representation where each concept is expressed through language signs and symbols of other languages or systems (Galinski and Pitch, 1997).

To answer the research questions formulated at the beginning of this work, it was decided: firstly, to define the type of user profile and identify the needs for lexicographic information based on the competencies to be developed in the academic career of the university 
user and secondly, to hold a session with EGI teaching experts. The experts provided information on the user's profile, their situations and on their perception of what that user's needs are in terms of EGI. The Delphi Method has been used as a method of prospecting with the experts, a methodology which, by means of questionnaires, makes it possible firstly to extract domain concepts and graphical-geometrical concepts and secondly to obtain an initial list of fundamental concepts agreed upon by the group. Furthermore, the students' opinions on the concepts of EGI were collected in order to optimize, confront and prioritize the content in the proposed dictionary.

Finally, a concrete proposal is formulated for the content, presentation and access to the dictionary data. The pedagogical interest of the dictionary makes the notion of pedagogical reformulation resumed. This reformulation (Pétroff, 1984), consists of adapting the information (in our case the data) to a new situation, to a specific type of recipient and according to a specific action. Besides being relevant, of good quality, arriving at the right time, in the right place, and reaching the right person. 


\section{ÍNDICE DE CONTENIDOS}

1. INTRODUCCIÓN

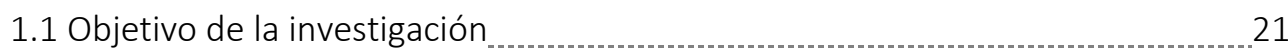

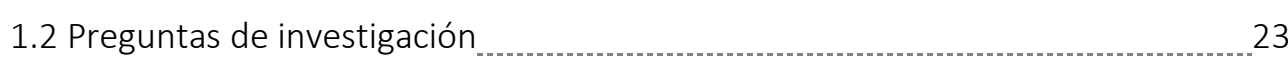

1.3 Justificación 24

1.4 Estructura del trabajo

2. CONSIDERACIÓNES TEÓRICAS. ANTECEDENTES

2.1 Introducción 29

2.2 La Lexicografía 31

2.2.1 Consideraciones científicas sobre Lexicografía _ _ $\quad 32$

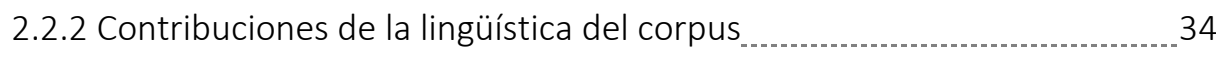

2.2.3 El criterio de relevancia $\quad 36$

2.2.4 Contribuciones tecnológicas a la lexicografía _........................ 38

2.3 Terminología y Lexicografía especializada

2.3.1 Teorías terminológicas _ 41

2.3.1.1 Teoría General de la Terminología _......................................... 41

2.3.1.2 Teoría Comunicativa de la Terminología _._. 43

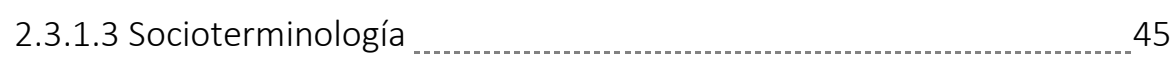

2.3.1.4 Terminología Sociocognitiva _........... 46

2.3.1.5 Terminología basada en Marcos $\quad 48$

2.3.2 Relaciones entre teorías terminológicas $\quad 50$

2.3.3 Hacia una teoría general de la lexicografía _ $\quad 52$

2.3.4 La Moderna Teoría de las Funciones Lexicográficas _...................... 54

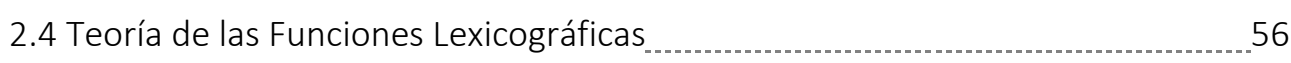

2.4.1 Las funciones lexicográficas _................ 60

2.5 Conclusiones 61

\section{LOS DICCIONARIOS ESPECIALIZADOS}

3.1 Introducción 65

3.2 El diccionario especializado 66

3.2.1 Diccionarios en línea especializados 67

3.2.2. La estructura de los artículos lexicográficos en los dicciona-

rios especializados 70

3.2.2.1. DICTER 71

3.2.2.2 Diccionarios Valladolid UVa (2017-2020) _ 75

3.2.2.3 Physical training lexicographical tools

3.2.2.4 Observaciones para la estructura del diccionario de EGI _ . $\quad 79$ 
3.3 La elaboración de diccionarios 80

3.4 El usuario del diccionario _._. 81

3.4.1 Concepto de usuario $\quad 82$

3.4.2 La teoría funcional de la lexicografía en relación con las necesidades del usuario $\ldots$

3.4.3 Métodos utilizados en lexicografía para identificar las necesidades del usuario del diccionario.

3.4.4 Investigación lexicográfica de las necesidades del usuario en el marco teórico de la TFL 90

3.4.4.1 Habilidades en el uso de diccionarios en línea. 92

3.4.5 Métodos para detectar las habilidades de referencia en el uso de diccionarios

3.4.5.1 Respecto a las habilidades de referencia en el uso de diccionarios en línea

3.5 Perspectiva orientada al usuario _ 96

3.5.1 Acceso y rutas de acceso a los datos de un diccionario en línea _......... 96

3.6 Conclusiones 97

4. EXPRESIÓN GRÁFICA EN LA INGENIERÍA

4.1 Introducción

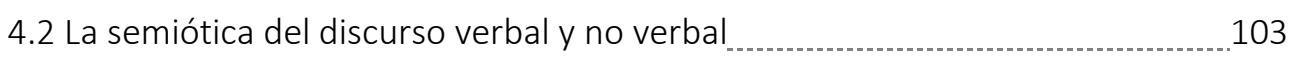

4.3 Antecedentes históricos de la Expresión Gráfica en la Ingeniería _.............. 105

4.4 La comunicación técnica mediante el dibujo industrial 113

4.5 La comunicación técnica gráfica en el ámbito académico de la ingeniería industrial.

4.5.1 La reformulación pedagógica en la adquisición de conocimiento _...... 124

4.6 Funciones de la representación gráfica en la ingeniería _...................... 125

4.7 Estudio empírico de diccionarios técnicos 126

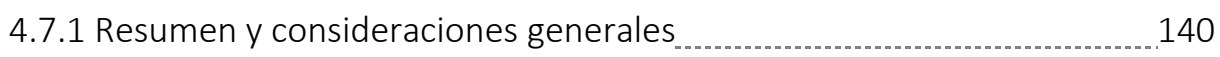

4.8 El usuario de una herramienta lexicográfica de EGI _............................. 141

4.8.1 El perfil del usuario 142

4.8.2 Las situaciones 146

4.8.3 Las necesidades de un usuario tipo en relación con el área de conocimiento 147

4.9 La selección de lemas en lexicografía especializada _...................... 148

4.10 Determinación de unidades de conocimiento en EGI _ 152

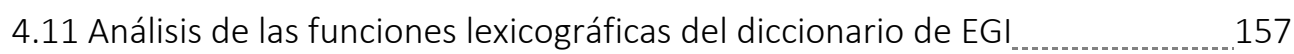

4.11.1 Función Cognitiva $\quad 160$

4.11.2 Función Interpretativa $\ldots \ldots \ldots$ 


\section{MATERIALES Y MÉTODOS}

5.1 Introducción 173

5.2 Metodología 173

5.3 Caracterización del usuario tipo 174

5.3.1 Características del perfil del usuario de un diccionario de EGI 176

5.4 Sesión de Expertos

5.4.1 Aportaciones de los expertos 178

5.5 Lista inicial consensuada de conceptos, el Método Delphi _.................... 183

5.5.1 Metodología Delphi _ 185

5.5.2 Las fuentes $\quad 185$

5.5.3 Los cuestionarios 186

5.5.4 Realización de los cuestionarios 188

5.5.5 Interpretación del consenso $\quad 189$

5.5.6 Importancia asignada al concepto 189

5.5.7 Encuesta realizada a los alumnos $\quad 189$

5.5.8 Análisis de los resultados $\quad 191$

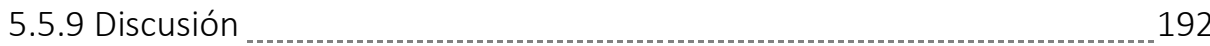

5.6 Conclusiones 197

6. PROPUESTA DE DICCIONARIO EN LÍNEA DE EGI EN EL MARCO DE LA TEORIA FUNCIONAL

6.1 Introducción 201

6.2 Aplicación de las funciones lexicográficas del diccionario de EGI _............... 202

6.3 Propuesta de concepto lexicográfico en EGI 205

6.3.1 Propuesta de definiciones para el diccionario de EGI 206

6.4 Presentación y acceso a los datos respaldando las funciones 208

6.4.1 Plantilla para la presentación de datos en el diccionario 209

6.4.2 Ejemplo de un concepto según la plantilla propuesta

6.4.3 Ejemplos de presentación de datos por funciones _

6.5 Ruta de acceso en línea

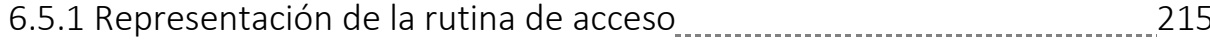

6.5.2 Ejemplo de la presentación de una consulta 218

6.5.3 Propuesta de consulta de usuarios con diferentes perfiles de conocimiento especializado

6.6 Conclusiones 224 
7. CONCLUSIONES

7.1 Conclusiones 229

7.2 Respuestas a las preguntas de investigación 233

7.3 Contribuciones al conocimiento 237

7.4 Líneas de investigación futuras 238

8. BIBLIOGRAFÍA

A. Diccionarios 243

B. Bibliografía General 244

C. Otras Referencias 263

\section{APÉNDICES}

Apéndice 1: Resultados obtenidos en la primera ronda del método

Delphi, se incluye el grado de consenso. 267

Apéndice 2: Resultados obtenidos en la segunda ronda del método Delphi 269

Apéndice 3: Comparación de los resultados con respecto a la importancia percibida por los expertos de las rondas I y II. 271

Apéndice 4: Resultados de las opiniones de los alumnos. 273 


\section{ABREVIATURAS}

Ell Escuela de Ingenierías Industriales

EGI Expresión Gráfica en la Ingeniería (área de conocimiento)

Egi Expresión gráfica en la ingeniería (asignatura y materia)

LSP Language for Special Purposes

UVa Universidad de Valladolid

TFL Teoría Funcional de la Lexicografía o Teoría de las Funciones Lexicográficas

TGT Teoría General de la Terminología

TCT Teoría Comunicativa de la Terminología

TS Terminología Sociocognitiva

TbM Terminología basada en Marcos

RAE Real Academia Española 


\section{ÍNDICE DE FIGURAS}

Figura 3.1 Plantilla del registro en la base de datos DICTER: Forma e historia 72

Figura 3.2 Plantilla del registro en la base de datos DICTER:

Clasificación semántica $\quad 72$

Figura 3.3 Plantilla del registro en la base de datos: Ejemplos e información 73

Figura 3.4 Plantilla del registro en la base de datos: Imagen $\quad 73$

Figura 3.5 Búsqueda avanzada y búsqueda semántica. DICTER 2.0 74

Figura 3.6 Búsqueda de imágenes por área de especialidad DICTER 2.0 74

Figura 3.7 Datos gramaticales básicos agrupados en la sección lema

(Diccionarios Valladolid-Uva)

Figura 3.8 Datos de la sección significado (Diccionarios Valladolid-Uva) $\quad 76$

Figura 3.9 Datos de la sección traducción y registros para

contextualizar el significado (Diccionarios Valladolid-

Uva)

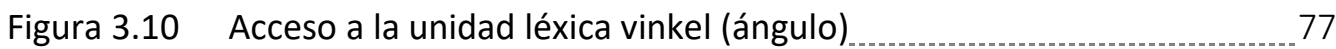

Figura 3.11 Plantilla de registro. Physical training lexicographical tools _ 78

Figura 3.12 Opciones da la cadena de búsqueda con Shoe. Physical

training lexicographical tools 79

Figura 4.1 Dos proyecciones ortográficas, Albrecht Dürer (1525)

Figura 4.2 Verdadera magnitud de un segmento, Gaspard Monge (1795) _...... 111

Figura 4.3 Figura de análisis. Recta b perpendicular al plano $\boldsymbol{\varphi}$

Figura 4.4 Representación diédrica de una recta que pasa por un

punto $\mathbf{P}$ y es perpendicular a la recta $\mathbf{a}$

Figura 4.5 Dibujo normalizado de una pieza, con acotación de

tolerancias geométricas de paralelismo y de perpendicularidad

Figura 4.6 Tolerancia de paralelismo de una superficie con respecto

a una superficie de referencia (ISO 1101:2004 p. 34)

Figura 4.7 Arco de circunferencia 129

Figura 4.8 Procedimiento para trazar el arco ACB conocida la recta

AB y la perpendicular $\quad 129$

Figura 4.9 Representación normalizada e imagen informativa 131

Figura 4.10 Representación normalizada de una rosca métrica acotada _......... 131

Figura 4.11 Representación simplificada de un proceso

Figura 4.12 Esquema eléctrico _......................................................... 131

Figura 4.13 The Application of Dimensions, indicación normalizada de la acotación 
Figura 4.14 First angle projection and true projection contrasted, representa en proyecciones diédricas, una comparación entre el primer y el tercer diedro _ _ 133

Figura 4.15 Lema: proyecto incluye dos definiciones 134

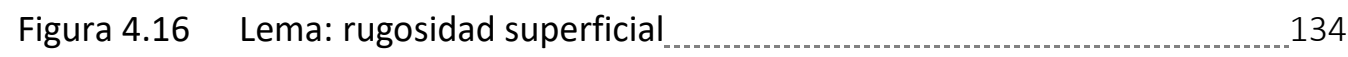

Figura 4.17 Lema: rosca 134

Figura 4.18 Lema: roscado 134

Figura 4.19 Lema: tuerca almenada 135

Figura 4.20 Lema sección transversal 135

Figura 4.21 Anilla elástica exterior e interior 136

Figura 4.22 Extremo roscado con rosca de perfil triangular 136

Figura 4.23 Símbolos normalizados de indicación de calidad superficial _ $\quad 137$

Figura 4.24 Visualización de la nomenclatura de una rueda dentada _ $\quad 137$

Figura 4.25 Lema: arco (Girava, Fineo, Geometría práctica, 1553, pág.

17) DICTER 2.0

Figura 4.26 Lema: rosca DICTER 2.0 139

Figura 4.27 Símbolo del requisito para la rugosidad. UNE-EN ISO $1302 \ldots$

Figura 4.28 Figura de análisis que representa dos rectas que se cortan

(González et al.,1982:30) 156

Figura 4.29 Representación diédrica de dos rectas que se cortan

(González et al.,1982: 30)

Figura 4.30 Imagen de tornillo prisionero DIN 6332.

Figura 4.31 Representación normalizada del tornillo de la figura 4.30. $\quad 157$

Figura 4.32 Ejemplo del cuestionario I con enunciado no estructurado, de respuesta abierta con componente verbal y gráfico $\ldots 163$

Figura 4.33 Ejemplo del cuestionario I, enunciado de la norma UNE 1-032 163

Figura 4.34 Captura de pantalla de la búsqueda por imagen 4.27 en Google _...... 168

Figura 4.35 Captura de pantalla de la búsqueda por imagen 4.28 en Google ...... 168

Figura 5.1 Ejemplo del cuestionario I, de un concepto geométrico complejo identificado en el enunciado, descrito con precisión y componentes verbal y gráfico

Figura 5.2 Ejemplo del cuestionario I, enunciado de la norma UNE 1-032 187

Figura 5.3 Ejemplo del cuestionario I, de un concepto geométrico complejo identificado en el enunciado, descrito con precisión y componentes verbal y gráfico equivalentes

Figura 5.4 Ejemplo perteneciente al cuestionario II, enunciado con

componente verbal

Figura 5.5 Ejemplo 1 de a la encuesta accesible a los alumnos vía campus virtual (UVa)

Figura 5.6 Ejemplo 2 de la encuesta accesible a los alumnos vía campus virtual (UVa)

xvi 
Figura 5.7 Estudio comparativo de la dificultad de los conceptos

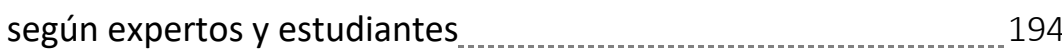

Figura 6.1 Ángulo diedro entre dos planos que se intersectan 203

Figura 6.2 Ángulo formado por el plano MNO con el plano Horizontal __._._. 203

Figura 6.3 Ángulos formados por los planos M y N; y los planos N y S ............... 203

Figura 6.4 Estructura básica de la presentación de los datos _ 209

Figura 6.5 Ejemplo de aplicación práctica. El dibujo define, con precisión, la geometría y las dimensiones de un objeto

Figura 6.6 Representación normalizada de la acotación de un elemento esférico UNE 1-039-94 211

Figura 6.7 Clave acotar, función cognitiva (BS ISO 129-1:2004) _ _ 213

Figura 6.8 Clave acotar, función interpretativa 213

Figura 6.9 Clave acotar, función operativa para la acotación en paralelo (BS ISO 129-1:2004) _........... 213

Figura 6.10 Ruta de acceso y propuesta para la interfaz de usuario _ $\quad 214$

Figura 6.11 Rutina de acceso con clave distancia y activada la función cognitiva 215

Figura 6.12 Rutina de acceso con clave distancia y activada la función operativa 216

Figura 6.13 Rutina de acceso con clave calidad superficial y activada la función operativa

Figura 6.14 Datos disponibles para la clave acotar _ 218

Figura 6.15 Datos presentados para un usuario en situación operativa _ $\quad 218$

Figura 6.16 Datos presentados para un usuario en situación interpretativa 218

Figura 6.17 Representación de la mínima distancia entre dos rectas que se cruzan 221

Figura 6.18 Por el punto 1 trazar la recta a (es paralela a s) _........................ 221

Figura 6.19 Recta perpendicular a un plano 222

Figura 6.20 Teorema de las tres perpendiculares $\quad 222$

Figura 6.21 Segmento mínima distancia entre dos rectas que se cruzan $\overline{\mathbf{5 4}} \ldots 223$

Figura 6.22 Separación mínima entre dos tuberías que se cruzan _ _ _ 223 


\section{ÍNDICE DE TABLAS}

Tabla 4.1 Resumen de problemas de perpendicularidad y aplicación a distancias. 123

Tabla 4.2 Características relativas a las funciones, el usuario, el contenido, soporte y ruta de acceso de los diccionarios técnicos analizados

Tabla 4.3 Selección del compendio de competencias profesionales establecidas por la Comisión de Elaboración de Planes de Estudio en el Ámbito de las Ingenierías Industriales y de EGI de la Universidad de Valladolid. Competencias Genéricas y Competencias Específicas

Tabla 4.4 Conceptos 'críticos' integrantes de concept inventory ordenados de mayor a menor dificultad (Sadowski y Sorby, 2015)

Tabla 5.1 Grados que determinan el nivel de consenso 189

Tabla 5.2 Grados que determinan la importancia asignada 189

Tabla 5.320 conceptos consensuados por expertos y sus valoraciones 192 
1. INTRODUCCIÓN

1.1 Objetivo de la investigación

1.2 Preguntas de investigación

1.3 Justificación

1.4 Estructura del trabajo 


\section{INTRODUCCIÓN}

El trabajo de investigación que se presenta es una propuesta de diccionario pedagógico en línea de Expresión Gráfica en la Ingeniería (en adelante EGI) dirigido a estudiantes y profesionales con el interés y la necesidad de adquirir nuevos conocimientos y ponerlos en práctica ayudados por una herramienta pedagógica para su consulta en línea.

El programa de doctorado en "Estudios Ingleses Avanzados: Lenguas y Culturas en Contacto" tiene un carácter, intercultural e interdisciplinar. Es un programa de doctorado conjunto de la Universidad de Salamanca y la Universidad de Valladolid. Nuestro interés reside en las líneas de investigación relacionadas con Lexicografía Especializada e Inglés para Fines Específicos y Lenguajes de Especialidad.

\subsection{Objetivo de la investigación}

El objetivo final de esta tesis es formular una propuesta de diccionario pedagógico en línea. Partiendo de la metodología de la Teoría de las Funciones Lexicográficas para la elaboración de diccionarios se propone una metodología que aúne los logros en este marco teórico lexicográfico y desarrolle el aspecto lexicográfico de la Expresión Gráfica en la Ingeniería. El usuario potencial tiene o ha tenido un contexto académico universitario y está familiarizado con la documentación gráfica técnica pero no dispone de una herramienta de consulta lexicográfica puntual que satisfaga sus necesidades.

Las situaciones en las que se encuentra el usuario potencial requieren la adquisición de conocimiento, la definición geométrica en la resolución de problemas e interpretación de símbolos, conceptos y objetos normalizados. El diccionario, por tanto, debe comprender los contenidos, el método y las actividades de aprendizaje necesarios para alcanzar el objetivo de la consulta. El contexto es de tipo práctico extralexicográfico, bien académico, bien profesional que requieren un rigor científico-técnico.

Nos planteamos una aproximación lexicográfica, inicialmente a materias académicas de EGI, - un subdominio de conocimiento especializado en el ámbito de la ingeniería gráfica EGI- y 
que, en el futuro, debe concretarse en una herramienta lexicográfica al alcance de alumnos y profesionales de la ingeniería industrial que requieran información puntual sobre los fundamentos geométricos del dibujo técnico, la geometría descriptiva, la representación normalizada y el dibujo asistido por ordenador.

La motivación principal para realizar este trabajo es la oportunidad de diseñar un diccionario destinado a facilitar la adquisición de conocimiento de alumnos y profesionales basándonos en la experiencia docente de expertos. Teniendo en cuenta que los signos y símbolos no lingüísticos relacionados con problemas de información que surgen en el ámbito de la EGI hasta el momento no están incorporados a las obras de referencia y nos proponemos incorporarlos. Un diccionario en línea es un formato que permite el tratamiento lexicográfico y gráfico de conceptos y lemas con muy buena calidad.

La Teoría Funcional de la Lexicografía (en adelante TFL) (Bergenholtz \& Tarp, 2003; Tarp, 2008; Fuertes-Olivera \& Tarp, 2014) constituye el marco teórico de nuestra propuesta de diccionario en línea. En este marco teórico las obras de referencia son concebidas como herramientas accesibles cuyo propósito es satisfacer las necesidades puntuales de información de tipos de usuarios concretos en situaciones extralexicográficas concretas (Fuertes-Olivera, 2013: 330). Se desarrollan en base a una teoría lexicográfica moderna y una tecnología que utiliza opciones avanzadas de búsqueda y visualización.

Para lograr esta propuesta contamos, por una parte, con la experiencia lexicográfica publicada sobre los diccionarios especializados en línea con funciones predeterminadas y, por otra parte, con la experiencia docente en materias de EGI y el conocimiento en este campo especializado del experto. Es necesario alcanzar unos objetivos que consideramos intermedios y que consisten en: la identificación de conceptos; el análisis de las unidades de información; la determinación del perfil y las necesidades del usuario potencial; la configuración de las entradas para cada concepto con los datos relevantes para cada situación; la determinación de los datos contenidos de los cuales extraer la información necesaria, y la adaptación del acceso y la presentación de los datos a las funciones que desempeña el diccionario.

Con anterioridad a este trabajo de investigación, en el estudio realizado sobre el discurso de la EGI en el Trabajo de Investigación Tutelado (Esandi, 2006: 59-60) se plantearon, en aquel momento, futuras líneas de investigación interesantes para el 'futuro', entre ellas: 
- El análisis de las unidades terminológicas o de las unidades de significación especializada. ¿Existen este tipo de unidades con componente verbal y gráfico?

- Si existen este tipo de unidades, ¿responden a una necesidad de hacer más comprensible o más eficaz la comunicación en un entorno académico y/o profesional (industrial)?

\subsection{Preguntas de Investigación}

La reducida, aunque relevante, investigación lexicográfica en el ámbito pedagógico de la EGI junto con la posibilidad de obtener una herramienta de aprendizaje asistido y apoyo al docente orientan la realización de este trabajo. La investigación preliminar mencionada en el apartado anterior puso de manifiesto la lejanía entre la Lexicografía y la Expresión Gráfica en la ingeniería. Después de una revisión de la relación entre ambas disciplinas, se formulan una serie de preguntas de investigación que se pretende responder. Son las siguientes:

P 1. ¿Cómo debe ser la aproximación pedagógico-lexicográfica a la expresión gráfica en la ingeniería que dé como resultado un diccionario en línea?

P 2. ¿Por qué el marco teórico de la Teoría Funcional de la Lexicografía (TF) es válido para nuestra propuesta de desarrollo de un diccionario de EGI?

P 3. ¿Cómo debe guiarnos la TF a la hora de diseñar una herramienta lexicográfica sobre los fundamentos geométricos, gráficos y técnicos en el ámbito de la Expresión Gráfica en la Ingeniería?

P 4. ¿Qué datos debe contener una herramienta lexicográfica de contenido gráfico industrial en el marco de la TFL?

P 5. ¿Qué funciones lexicográficas son necesarias en un diccionario pedagógico online de EGI?

P 6. ¿Qué implicaciones futuras puede tener esta propuesta de diccionario? 


\subsection{Justificación}

Desde que comenzamos el programa de doctorado en "Estudios Ingleses Avanzados: Lenguas y Culturas en Contacto", nuestro interés se centró, en primer término, en las líneas de investigación de Lenguajes de Especialidad y posteriormente en Lexicografía Especializada.

El enfoque lexicográfico de la EGI en el marco de la TFL supone una aproximación lexicográfica a un contenido especializado con contenido gráfico industrial y se plantea que el soporte sea en un medio digital y el acceso en línea. Es necesario el análisis de las unidades de conocimiento de EGI desde un punto de vista lexicográfico y el tratamiento de los datos que incluyen una representación gráfica para satisfacer las necesidades del futuro usuario que tenemos en mente y que se encuentra en una situación de adquisición y de aplicación práctica de conocimiento técnico especializado. Contamos con la experiencia en estudios lexicográficos y proyectos de diccionarios especializados basados en la metodología de la TFL que han concluido en obras lexicográficas como: English-Spanish Accounting Dictionary (Bergenholtz, Nielsen \& Mourier, 2007); el proyecto de la base de datos The Danish Internet Dictionary (Bergenholtz, 2002-2009), utilizado en la producción de seis diccionarios diferentes y, el portal lexicográfico de diccionarios denominado Diccionarios Valladolid-UVa (Fuertes-Olivera, 2019) que incluye distintos diccionarios digitales.

La escasez de herramientas lexicográficas especializadas EGI y de desarrollo del tratamiento de imágenes técnicas imprescindibles para definir conceptos geométricos, hacen que esta tesis en Expresión Gráfica en la Ingeniería y Lexicografía esté, en nuestra opinión, plenamente justificada ya que puede:

- Contribuir a dar solución a las necesidades de información de un tipo de usuario de EGI

- Identificar las unidades de conocimiento fundamentales y críticas para un aprovechamiento satisfactorio del diccionario y elaborar una técnica y un método que permite ampliar el repositorio inicial y el alcance del proyecto actual

- Disponer de un uso eficaz de las unidades verbales válido para adquirir conocimiento gráfico

- Profundizar en las posibilidades de la función interpretativa de la TFL 


\subsection{Estructura del trabajo}

El Capítulo 1 está dedicado a la introducción del problema que se está tratando en este proyecto, el objetivo final es una propuesta de una herramienta lexicográfica de utilidad para estudiantes de materias de Expresión Gráfica en la Ingeniería (EGI). Se expone cómo se va a tratar el problema, el enfoque personal del trabajo de investigación, las preguntas de investigación planteadas y la contribución de esta tesis e importancia del estudio.

El resto de la tesis se ha dividido en una serie de capítulos que forman parte de tres apartados generales: los antecedentes, el núcleo y las conclusiones. En los antecedentes se trata la historia relevante; el estado de la cuestión en teoría y práctica de Lexicografía y de EGI y las opiniones de otros investigadores. Este apartado esta formado por los capítulos 2, 3 y 4 . El núcleo de la tesis aborda los métodos elegidos, las innovaciones planteadas para responder las preguntas de investigación que nos hemos planteado y se realiza una propuesta concreta de diccionario. Los capítulos 5 y 6 constituyen este apartado. En el apartado de conclusiones, capítulo 7, en el que se exponen las conclusiones y se plantean las líneas futuras de investigación. Por último, se incluye un capítulo de referencias bibliográficas.

El Capítulo 2 trata los antecedentes teóricos actuales: la lexicografía especializada, las teorías terminológicas y la Teoría de las Funciones Lexicográficas. Nos hemos detenido en las contribuciones que recibe la lexicografía de la lingüística del corpus, en el criterio de relevancia en la TFL y en el impacto tecnológico en la lexicografía. Estos antecedentes terminológicos y lexicográficos tienen intereses compartidos, a veces muy pequeños, que invitan a un estudio conjunto.

En el Capítulo 3 se tratan los diccionarios en línea especializados y la perspectiva orientada al usuario de la teoría funcional. Se revisan los antecedentes de la práctica lexicográfica buscando la estructura de los artículos lexicográficos y se han elegido tres proyectos de lexicografía especializada creados con el objetivo de organizar y presentar los datos, estos son: DICTER, Diccionarios Valladolid UVa y Physical training lexicographical tools. Por último, se plantea el punto de vista del usuario, sus características, sus habilidades de referencia y los métodos utilizados en lexicografía para identificar las necesidades del usuario en la teoría funcional. 
En el Capítulo 4 se estudian los antecedentes históricos de Expresión Gráfica en la Ingeniería para entender la importancia y la función que desempeña en el desarrollo tecnológico actual y se describe la semiótica del discurso técnico no verbal. Se presentan los resultados cualitativos del análisis empírico de una serie de diccionarios técnicos. Centrados en el usuario de una herramienta lexicográfica de EGI, se traza el perfil del usuario, las situaciones en las que se encuentra y sus necesidades de información para ajustar las funciones cognitiva, interpretativa y operativa del diccionario. El experimento preliminar llevado a cabo por Sadowski y Sorby (2012, 2014 y 2015) en el campo de la Expresión Gráfica en la Ingeniería, se resume en este capítulo. Este estudio constituye un referente destacado tanto por el método Delphi utilizado como por los resultados alcanzados en la obtención de un inventario de conceptos de ingeniería gráfica.

En el capítulo 5 se define el perfil tipo del potencial usuario y se identifican sus necesidades de información partiendo de las competencias generales y específicas a desarrollar en el período académico; se resume la sesión con expertos en docencia de EGl; se describe el proceso del método Delphi utilizado para obtener una lista consensuada de conceptos, y finalmente se comparan las opiniones de expertos y estudiantes sobre la importancia de conceptos de EGI.

En el capítulo 6 se define una propuesta de concepto lexicográfico en EGI adaptadas al usuario; una propuesta de definiciones para el diccionario de EGI, la presentación de datos en una plantilla sencilla y la ruta de acceso a los mismos respaldando las funciones del diccionario. Por último, se define que la ruta de acceso en línea permita dos opciones al usuario: avanzar de forma dirigida (por el experto) o avanzar en modo libre decidida por el alumno. Estas dos vías de acceso permitirán al usuario explorar varias funciones del diccionario, según sus necesidades, y retornar a una opción previa caso de ser necesario.

El capítulo 7 se tratan: las conclusiones, se responden las preguntas de investigación, la contribución al conocimiento y se apuntan las líneas de investigación futuras.

La Bibliografía de detalla en el capítulo 8. Se han agrupado en tres apartados: Diccionarios, Bibliografía General y Otras Referencias. Este último incluye normas UNE e UNEEN ISO. 


\section{CONSIDERACIÓNES TEÓRICAS. ANTECEDENTES}

2.1 Introducción

\subsection{La Lexicografía}

2.2.1 Consideraciones científicas sobre Lexicografía

2.2.2 Contribuciones de la lingüística del corpus

2.2.3 El criterio de relevancia

2.2.4 Contribuciones tecnológicas a la lexicografía

2.3 Terminología y Lexicografía especializada

\subsubsection{Teorías terminológicas}

2.3.1.1 Teoría General de la Terminología

2.3.1.2 Teoría Comunicativa de la Terminología

\subsubsection{Socioterminología}

\subsubsection{Terminología Sociocognitiva}

2.3.1.5 Terminología basada en Marcos

2.3.2 Relaciones entre teorías terminológicas

2.3.3 Hacia una teoría general de la lexicografía

2.3.4 La Moderna Teoría de las Funciones Lexicográficas

2.4 Teoría de las Funciones Lexicográficas

2.4.1 Las funciones lexicográficas

2.5 Conclusiones 


\section{CONSIDERACIÓNES TEÓRICAS}

\subsection{Introducción}

El objetivo de este apartado es un repaso al estado de la cuestión de las obras Lexicográficas en el contexto de lenguas occidentales, empezando por la lexicografía en español. En un apartado posterior presentamos las teorías terminológicas. La parte interesada de la breve historia de la lexicografía en este trabajo son las obras de referencia de la lexicografía en español, parte integrada en todas las corrientes internacionales. Se destacan los aspectos más generales unas veces y los matices otras de manera que se aprecie claramente la trayectoria y la situación actual de teoría y práctica lexicográfica, en especial de la lexicografía especializada, en relación con el objetivo final del proyecto que nos ocupa: una propuesta de diccionario especializado en EGI de orientación pedagógica en el marco teórico y metodológico de la Teoría de las Funciones Lexicográficas o Teoría Funcional de la Lexicografía.

Se conservan evidencias desde la época medieval sobre la lexicografía en español. Han Ilegado hasta nuestros días: las Glosas Emilianenses (cf. Wolf \& Ruhstaller,1996) y Glosas Silenses (cf. Menéndez Pidal, 2018), anotaciones en lengua romance peninsular sobre textos en latín que escribían los monjes con el objetivo, en unos casos, de servir de ayuda a estudiantes de latín y en otros para facilitar el entendimiento de algunos pasajes por algunos frailes; Glosarios del latín al castellano, de los siglos X y XI comentados por Manuel Díaz y Díaz (1981), los de los siglos XIV y XV publicados en 1991 por Américo Castro dedicados a la enseñanza del latín con agrupación de las entradas por categorías gramaticales.

Se considera alcanzada la mayoría de edad de la lexicografía en español con la publicación de la gramática y los dos diccionarios de Antonio de Nebrija el Lexicón Latino-Español y el Vocabulario Español-Latino (1492 y 1495). Obras con rigor en el método, objetividad científica y el mérito reconocido de ser el primer léxico bilingüe concebido de una forma moderna que 
contiene una lengua viva. Es destacable su trascendencia en la lexicografía posterior al ser una autoridad y fuente lexicográfica del español en los siglos XVII y XVIII.

En la publicación del Diccionario de la Lengua Castellana (1726-1739) por la Academia Española se utiliza la metodología más avanzada del s. XVIII adoptando: el principio de la prescripción, la documentación en destacados escritores, el ideal del uso de la corte del diccionario académico francés, las variedades dialectales y niveles populares de la lengua y las notas de uso. En su disertación sobre lexicografía, Vicente Salvá, lexicógrafo y editor, en la introducción del Nuevo Diccionario de la Lengua Castellana en 1846, expuso su método no académico en cuanto a la estructura de la obra y a los artículos y a la intensa preparación necesaria para acometer este tipo de obras. Esteban de Terreros publicó en 1767 un diccionario general de castellano que abrió nuevas perspectivas a la lexicografía, diccionario que según Alvar Ezquerra (2002: 43) estaba «enriquecido con cuantos términos específicos de las artes, ciencias y técnicas pudo allegar el autor».

Ramón Joaquín Domínguez, autor, impresor y editor publica entre 1846-47 un diccionario que incluye como novedad 86.000 voces técnicas. En $1853-55$ se publica el Diccionario Enciclopédico en un tono objetivo y equilibrado, norma de la lexicografía moderna y concebido como un proyecto de empresa (Gaspar y Roig) y realizado por un equipo bajo la dirección de Eduardo Chao. El Diccionario enciclopédico hispano-americano de literatura, ciencias y artes editado por Montaner y Simón 1887-1898, redactado por especialistas en distintas materias en las entradas léxicas y que incluye, a modo de autoridad, citas 'ilustradoras y garantes de los sentidos explicados en las definiciones'.

La lexicografía en España en el s. XIX se centraba, bien en diccionarios de lengua, bien en diccionarios enciclopédicos. Hasta el diccionario actual sólo el Diccionario PLANETA de la lengua española usual (1982) dirigido por Francisco Marsá, de orientación didáctica y con aportación sistemática de ejemplos (inventados) en todas las entradas. Los diccionarios ilustrados se publican en España en el s. XX como el Larousse ilustrado (1912), Diccionario Manual Ilustrado de la Lengua Española RAE 1914, VOX Diccionario General Ilustrado de la Lengua Española (1945).

Lexicógrafos como Menéndez Pidal y Julio Casares manifestaron la necesidad de la fundamentación teórica previa de los repertorios léxicos. Las ideas novedosas de Casares en 
cuanto a la práctica lexicográfica se refieren a la catalogación del léxico, especialmente las locuciones y construcciones pluriverbales, por campos de similitud semántica (muy útil, hoy en día, en la recogida de material asistida por ordenador). Su obra Introducción a la lexicografía moderna, (1951) es considerada el primer tratado sobre teoría lexicográfica hecho en España. En ese momento cualquier diccionario que aspirase a ser 'moderno' se sustentaba en un proyecto previo que le dotase de una metodología científica rigurosa.

\subsection{La Lexicografía}

La lexicografía es la disciplina científica que se dedica esencialmente a la concepción, producción y estudio de los diccionarios. Una disciplina cuya actividad y desarrollo teórico se nutre de colaboraciones con otras disciplinas en función de proyectos concretos.

La práctica lexicográfica se inició hace casi 25 siglos con evidencias en forma de repertorios lexicográficos. Los inicios en lenguas europeas se remontan a autores griegos; Pródico (465-395 a. de C.) realizó estudios sobre la sinonimia; Aristófanes de Bizancio (257- 180 a. de C.) bibliotecario de Alejandría trabajó en repertorios de textos homéricos. Existen numerosos glosarios medievales, léxicos alfabéticos renacentistas y diccionarios modernos, pero por su importancia en la lexicografía española merece especial mención el Tesoro de la lengua castellana o española de Sebastián de Covarrubias (1611). En lexicografía inglesa JK's A New English Dictionary (1739) y Universal Dictionary of Trade and Commerce de Malachy Postlethwayt (1774).

La controversia existente acerca de la teoría de la lexicografía denota discrepancias significativas y reafirma distintos puntos de vista de los lexicógrafos: los que piensan que es una práctica que no puede describirse teóricamente como Atkins y Rundell (2008) y los que sí admiten la teoría lexicográfica (Bergenholtz y Tarp 2003, Tarp 2008, Fuertes-Olivera y Tarp 2014). Unos consideran que depende de teorías lingüísticas, inciden en esta dependencia y desarrollan sus postulados teóricos parciales como parte de la lingüística aplicada como Meyer (2001) o como arte y artesanía Landau (2001); y otros destacan su independencia como Wiegand (1989) y Tarp (2008a) y realizan un importante trabajo metalexicográfico y pertenecen 'a thriving metalexicographic community' (Atkins \& Rundell 2008). Es necesario destacar la 
contribución al desarrollo de teorías generales de la lexicografía las reflexiones y publicaciones de Scerba (1940), Wiegand (1998) y Bergenholtz y Tarp $(2002,2003)$.

En cuanto a la práctica y diseño de recursos lexicográficos existen dos tradiciones consolidadas con metodologías y técnicas de configuración de diccionarios centradas, una en analizar los datos empíricos del uso de la lengua y la lingüística del corpus; otra en el perfil de los usuarios y en sus necesidades.

A continuación, se plantean cuestiones teóricas y prácticas que contribuyen a la situación lexicográfica actual como: las consideraciones científicas sobre lexicografía; las contribuciones de la lingüística del corpus y el criterio de relevancia.

\subsubsection{Consideraciones científicas sobre Lexicografía}

"Good practice in lexicography is a brilliant balancing act, accuracy and comprehensiveness against space, cost and clarity. That should be the centre of the study, and not remain a harsh reality that exists conveniently outside the ivory tower. » (Sinclair 1984: 3)

La lexicografía, tanto práctica como teórica, tiene una larga historia anterior al desarrollo de la lingüística moderna, esto no es óbice para que la relación de dependencia o independencia entre Lexicografía y Lingüística no esté consensuada entre los expertos.

Entre las figuras destacadas que hizo aportaciones teóricas sobre lexicografía en español está Julio Casares que en 1951 reconoce el carácter científico que debería tener la lexicografía, que este carácter es un indicio de modernidad y considera que la disciplina ya había superado la etapa precientífica:

La lexicografía empieza a ser moderna en el momento en que, rebasada la primitiva etapa, puramente literaria, y superada luego la preocupación selectiva (aceptación de unos hechos lingüísticos y repulsa de otros), aparece el criterio científico según el cual todos los materiales léxicos han de merecer la misma atención. (Julio Casares, 1951, citado por Espejo, 1999: 415)

EI DRAE desde 1984 incluye las dos acepciones: lexicografía práctica que aborda la técnica de confección, de la compilación de diccionarios, vocabularios, léxicos, glosarios, etc., y 
lexicografía teórica o metalexicografía, que aborda los criterios teóricos y metodológicos que debe manejar un equipo lexicográfico.

Se consolidan varias tendencias teniendo en cuenta la lexicografía como ciencia y su independencia de la lingüística. La Lexicografía es considerada lingüística aplicada por unos y una ciencia independiente con su propio núcleo independiente y vocación interdisciplinar, por otros. Entre los investigadores que consideran que la lexicografía no es una disciplina independiente fundamentan, unos como Meier (2003: 307) y Hartmann (1989) defiende que es "an instance of applied linguistics"; otros investigadores como Landau (2001) consideran que es "art and craft"; Béjoint (2010) niega la existencia de teorías lexicográficas y por último los que creen que son los fundamentos teóricos lingüísticos los que tienen el potencial de ayudar a lexicógrafos para realizar su trabajo con más efectividad y seguridad (Atkins y Rundell, 2008: 4).

Sinclair considera que en lexicografía se produce el encuentro entre La Tecnología de la Información y la Lingüística, "It is clearly an applied science or craft, rather than a pure one. That is to say, it relies for a theoretical framework on external disciplines" Sinclair (1984: 6). Pone en consideración la lexicografía como estudio académico aplicado para la formación de lexicógrafos profesionales.

Los investigadores que aceptan la concepción científica de la lexicografía y que abordan la teoría y la práctica de los diccionarios siguen orientaciones bien diferenciadas: los que la consideran una rama científica subordinada a la lingüística que trata la presentación y descripción de unidades léxicas de lenguajes naturales en los diccionarios (Kudashev, 2007:159) y los que la consideran una disciplina independiente diferenciando lexicografía "scientific practice" y metalexicografía "scientific research area" (Wiegand 1984) y Sorokoletov (1982, citado en Fuertes-Olivera y Tarp, 2014:21).

Tarp (2008), Fuertes-Olivera y Tarp (2014) y Tarp (2018) consideran la lexicografía una ciencia independiente con su propio núcleo independiente y una vocación interdisciplinar que debe ser considerada: "an independent discipline with its own theory, own tasks and own methods" (Tarp 2018: 20). Desde este último punto de vista se apunta que la lexicografía subordinada a la lingüística sólo puede obedecer a una visión parcial y selectiva de la realidad empírica (ibid., p. 21), ya que la lexicografía es algo más que lingüística aplicada "lexicography is, at all events, more tan the application of linguistic theories and methods or the utilization of 
linguistic and philological findings." (Wiegand 1984: 13). Tarp afirma que 'Lexicography is the science of dictionaries', teniendo en cuenta la definición de ciencia del diccionario filosófico PHILOSOPHISCHES WÖRTERBUBUCH:

A science is a system of knowledge growing out of social practice and developing on an ongoing basis, comprising the acknowledgement of the most important properties, casual connections and legal considerations of nature, society and philosophy; rooted in the form of concepts, categories, defined goals, laws, theories and hypoyheses, and constituing the basis of Man's growing mastery of his natural and social environment. A science also consists of its own history, pretheoretical ideas, contributions to methodology, directions for practical action etc. (cf. Philosophisches Wörterbuch: 1083, 1169, citado en Tarp, 2008: 4).

La Investigación y las publicaciones, de las últimas décadas en el marco de la Teoría Funcional de la Lexicografía, refuerzan la consideración científica de la Lexicografía y la presentan "como la ciencia de los diccionarios dotada de formulaciones teóricas y herramientas prácticas adecuadas para diseñar, construir y actualizar herramientas de información especializada de calidad" (Fuertes-Olivera y Tarp, 2014). Estos autores argumentan que la lexicografía tiene mucho en común con la ciencia de la información ya que la realidad empírica de los diccionarios especializados evidencia su pertenencia a un dominio más amplio que tiene mucho en común con otras disciplinas de la información. En esta dirección avanza el desarrollo de la lexicografía electrónica y los diccionarios electrónicos ocupan un lugar destacado entre los recursos de referencia en internet (ibib. 2014: 30).

\subsubsection{Contribuciones de la lingüística del corpus.}

La lingüística del corpus utiliza una metodología empírica basada en evidencias reales de producciones del lenguaje para la producción de obras de referencia y se utiliza en lexicografía desde los años 80 en formato electrónico mediante el almacenamiento y análisis de corpus por ordenador. Estrictamente hablando, un corpus es un cuerpo de texto con una muestra amplia de lenguaje que se reúne sistemáticamente de acuerdo con un conjunto específico de criterios y se organiza de forma coherente con un fin particular (Bowker 2003: 160). Esta autora se refiere al término corpus "Now, the term corpus is typically understood to refer to a relatively large 
collection of authentic texts that have been gathered in electronic form according to a specific set of criteria. There are four important characteristics to note here: large, authentic, electronic and specific criteria." (ibid. 2010: 161). El método de compilación de dichos recursos es un factor crucial y los metadatos son relevantes para decidir qué corpus es adecuado para encontrar ciertos fenómenos, hoy en día solo se concibe el corpus digitalizado. Faaß (2017: 124) indica las características que ha de tener un corpus actual son: ser representativo, ser reutilizable, contener anotaciones y facilitar el acceso a los datos. Algunas de las propiedades específicas que para Faaß ha de tener un corpus:

- Debe contener expresiones escritas y habladas (transcritas).

- Debe ser legible por una máquina, todos los caracteres que contenga.

- Cuanta más información se tiene de las fuentes, más útil es el corpus.

- Los metadatos, que describen el recurso como tal, han de almacenarse y ser legibles por máquinas.

- Las anotaciones lingüísticas deben describir, con el mayor detalle posible, los contenidos del corpus, de forma que pueda ser reutilizable en el futuro.

- Un corpus debe ser representativo, es decir, contener el uso de un grupo o tipo de usuarios.

- El material de corpus es prácticamente ilimitado.

- La informatización de la compilación, debe poder analizarse con un software que permita ordenar gran cantidad de datos y extraer con rigor información sobre el uso de palabras, significados, patrones de gramática, relaciones y eventos del lenguaje que son frecuentes y están dispersos en textos.

Los diccionarios producidos con esta metodología generalmente comparten otras características: son generalmente sincrónicos, es decir, se refieren a un único período cronológico de uso del lenguaje, suele referirse al período en el que se producen, están típicamente destinados a un mercado masivo y están producidos por editoriales comerciales. La perspectiva diacrónica de un diccionario histórico produce desafíos estructurales y de presentación que son bastante diferentes de los de los diccionarios sincrónicos, por lo que se pueden identificar métodos y procedimientos que distinguen ampliamente la 'lexicografía diacrónica' de la 'lexicografía sincrónica'. (Durkin, 2016:1). 


\subsubsection{El criterio de relevancia}

La relación entre la lexicografía y las ciencias de la información desde el punto de vista de la lexicografía es doble: por una parte, las obras lexicográficas son herramientas para ser consultadas y obtener información y por otra, se aplica el criterio de relevancia lexicográfica para la toma de decisiones en proyectos de diccionarios. Esto tiene como consecuencia que, estas dos disciplinas la lexicografía y las ciencias de la información, con origen y desarrollo distanciados, comparten el interés por proporcionar acceso a datos; por facilitar información; y por aplicar el criterio de relevancia en el diseño y evaluación de los sistemas de trasmisión de información. La lexicografía podría, en este caso, integrarse en las ciencias de la información (cf. Tarp 2009; Bothma, 2011: 74).

La implicación de las ciencias de la información en la lexicografía se ha materializado en que las obras lexicográficas que se planifican y producen de acuerdo con criterios similares a esta (Bothma y Tarp, 2012: 105). En particular con la aplicación del criterio de relevancia, base de todo sistema de recuperación de información (Schamber y Eisenberg, 1988: 4) y con la presentación de datos en herramientas de información en línea (cf. Bothma, 2011; Bergenholtz y Bothma, 2011) adaptada a las necesidades del usuario.

El criterio de relevancia, dentro de las ciencias de la información, admite: que la relevancia es un concepto multidimensional basado en el proceso de juicio humano; que depende de factores internos (cognitivos) y externos (situacionales), y que es intersubjetivo, pero sistemático y mensurable (Schamber y Eisenberg 1988: 3). Estos investigadores proponen un nuevo paradigma de recuperación de la información, un modelo cognitivo centrado en el usuario, en el que el usuario es el determinante central y activo de las dimensiones de la relevancia.

Ingwersen y Järvelin (2005) distinguen dos tipos de fuentes de información 'objects or humans' y dará lugar a dos tipos de relevancia, la relevancia objetiva (relevancia algorítmica o relevancia de sistema) y la relevancia subjetiva basado en el usuario: 
Relevance. The assessment of the perceived topicality, pertinence, use-fulness or utility, etc., of information sources, made by cognitive actor(s) or algorithmic devices, with reference to an information situation at a given point in time. It can change dynamically over time for the same actor. Relevance can be of a low order objective nature or of higher order, i.e., of subjective multidimensional nature. (Ingwersen y Järvelin 2005: 21)

Los términos relevancia y pertinencia no son siempre equivalentes ya que el usuario decide si lo relevante es también pertinente. Por ello, en el contexto del presente trabajo, este concepto se entiende como 'relevancia basada en el usuario'. En un sistema de trasmisión de información es el usuario quien evalúa la relevancia de un documento en base a la información necesitada y no el propio sistema. Las categorías de relevancia basadas en usuario son (cf. Borlund 2000, Cosijn y Ingwersen 2000, Borlund 2003, Cosijn 2003, Cosijn y Bothma 2005 and Ingwersen y Järvelin 2005, citado en (Bothma y Tarp, 2012: 96) (traducido por nosotros):

- relevancia o actualidad temática;

- relevancia o pertinencia cognitiva;

- relevancia situacional;

- relevancia sociocognitiva;

- relevancia motivacional o afectiva.

El criterio de relevancia se ha desarrollado en el entorno de las ciencias de la información y se ha aplicado en lexicografía (Cosijn y Bothma, 2005, Bothma y Tarp, 2012) en el diseño y evaluación de los sistemas de recuperación de información. Desde el punto de vista del diseño lexicográfico, la relevancia se utiliza para optimizar la presentación de datos adaptados a las necesidades del usuario en herramientas de información en línea, teniendo en cuenta el factor tiempo de la consulta (desde que se accede a los datos hasta que se obtiene la información) y desde el punto de vista de la evaluación, para determinar los datos a incluir en un diccionario teniendo en cuenta las necesidades de información de los usuarios en cada situación. La teoría de la relevancia y las dimensiones de la relevancia descritas en Bothma y Tarp (2012: 96-98) ayudan a los lexicógrafos en el análisis de las necesidades de información de los usuarios y son aplicables en el proceso lexicográfico tal y como se entiende en el marco de la teoría funcional, teoría que se detalla más adelante en este capítulo. 


\subsubsection{Contribuciones tecnológicas a la lexicografía}

El trabajo del lexicógrafo es a veces, introspectivo, conservador y resistente a la innovación, en un contexto de avance imparable de una tecnología muy relevante para la lexicografía, " $A$ professional group which resists outside interference is always in danger of narrowing down its range of expertise, and reducing its flexibility. The existence of high, self-maintained standards is no guarantee of adaptability and relevance in the future" (Sinclair 1984: 5).

Los hitos tecnológicos que han marcado los avances de la lexicografía son la imprenta en el siglo XV y los ordenadores en el siglo XX. Ambos avances tecnológicos presentan innovaciones equiparables en cuestiones como: las evidencias, los recursos, la compilación y la divulgación (Hanks 2010: 1004). Todos estos avances supusieron, inicialmente una mejora para el trabajo lexicográfico y para la obtención, como resultado de este trabajo, de una obra de referencia de mayor calidad que finalmente repercute en el usuario. Por último, los corpus electrónicos, la diseminación de información en línea y los motores de búsqueda han abierto las posibilidades para las descripciones y el significado de unidades léxicas especializadas, la presentación de un lexicón para usuarios humanos o máquinas, la compilación de datos con distintos criterios alfabético, cognitivo...,

"In the 16th century, the index card was invented, and used to compile lexicographical information and sort data into alphabetical order. Now, the computer has freed lexicographers from the tyranny of alphabetical order. [...] At the present time, this whole technology is being superseded by on-line dissemination of information." (Hanks, Dykstra \& Schoonheim 2010: 1004).

La lexicografía computacional aparece a finales de los años 80, abarcaba los temas relacionados con diccionarios legibles por 'máquinas' que estaban disponibles en CD-ROM, es decir, eran corpus cerrados de textos en formato electrónico con la única finalidad lexicográfica que evolucionaría con el tiempo a bases de datos de lenguaje dinámicas y multifuncionales (Kruyt 1995: 118). La digitalización de datos lingüísticos ha supuesto un punto de inflexión y se recordará como un hito destacado en la Historia de la Lexicografía, así como los cambios relacionados con el 'espacio físico' que requiere el trabajo lexicográfico. Durante un tiempo los 
diccionarios impresos en papel se convirtieron a formato electrónico, hoy en día, muchas obras de referencia se producen en formato electrónico y sin soporte físico. "Computer-assisted compiling and online dictionaries offer the lexicographer the opportunity of creating a much fuller, more accurate and easier to use dictionary, whether it is monolingual or bilingual" (Atkins 1996: 15).

Actualmente los lexicógrafos cuentan con una serie de tecnologías para realizar búsquedas en corpus en línea y registrar los datos del diccionario en una base de datos relacionable y estructurada: ordenadores personales con gran capacidad de almacenamiento, procesadores potentes y conexiones rápidas a internet; datos de corpus tratados con aplicaciones desarrolladas con algoritmos de aprendizaje automático para el procesamiento de lenguajes naturales; software para introducir y gestionar textos y bases de datos, técnicas de big-data, etc. Las mejoras en hardware y las aportaciones de expertos en lingüística computacional permiten hacer mejores diccionarios y, una vez compilado el diccionario, la tecnología ofrece una serie de opciones para hacerlo accesible al usuario final (Atkins y Rundell 2008: 3-4).

Es necesario conocer algunos términos utilizados hoy en día en la investigación lexicográfica utilizando ordenadores e internet ${ }^{1}$. El primero de ellos es la Web Semántica: es una extensión de la World Wide Web en la que el significado de la información y de los servicios está definido de forma que permite "entender" y satisfacer las peticiones de las personas y de las máquinas que utilizan el contenido web. Los pilares de la Web Semántica son las ontologías y las anotaciones. Más recientemente aparece el concepto de la Web de datos enlazados, un mecanismo que permite hacer datos en lenguaje RDF públicamente disponibles mediante la utilización del protocolo HTTP. La combinación de la Web Semántica y la Web 2.0 ha dado lugar al término Web3.0, o Web Semántica Social.

Los avances de las tecnologías transforman la manera en que se realiza la investigación científica. El análisis y almacenamiento de datos ha pasado de ser una actividad manual a una actividad informatizada. Como resultado de esto, se procesa diariamente una gran cantidad de datos científicos utilizando ordenadores. Se cree que ninguna organización de investigación

\footnotetext{
${ }^{1}$ Información consultada. Ontology Engineering Group, Escuela Técnica Superior de Ingeniería Informática de la Universidad Politécnica de Madrid. < https://www.oeg-upm.net/ >
} 
individual tiene el poder de cómputo para procesar tantos datos, ni los suficientes recursos para procesarlos, por lo que la recogida de datos y procesos de almacenamiento están distribuidos y dispersos en diferentes lugares. La colaboración entre científicos de diferentes disciplinas es más necesaria que nunca para analizar y procesar la gran cantidad de publicaciones científicas y, garantizar una mayor eficacia y mejor calidad en la investigación.

Las nuevas exigencias derivadas de este nuevo enfoque de la investigación científica requieren, en algunos casos, la definición explícita del significado de los datos sobre diferentes dominios. Los modelos y los métodos de reproducción pueden jugar este papel que las semánticas explícitas y sus tecnologías asociadas, en el contexto de lo que se conoce como eCiencia semántica. Su foco está, entre otros, "en la aplicación de la semántica explícita sobre la infraestructura de la e-Ciencia para aumentar la interpretación precisa de la información, los análisis científicos más eficientes y mejor colaboración entre los científicos".

La Ingeniería Lingüística facilita la comunicación del hombre con la máquina y es fundamental para la Web Semántica. El conocimiento se representa mediante ontologías que pueden ser compartidas entre usuarios y ordenadores. Se relaciona con disciplinas como la terminología, la lingüística computacional, etc. para orientar y mejorar sus aplicaciones de extracción de información y análisis de contenido multilingüe que permiten combinar y explotar recursos lingüísticos disponibles en la web (lexicones, corpus, servicios de traducción, etc.), o en la web de datos 'enlazados' (linked data).

Por último estaría la integración de datos en el contexto de redes sociales (Big Data). Internet está ampliando su alcance en el mundo real RWI (Real World Internet) a través de innovaciones del llamado 'Internet de las Cosas' (IoT - Internet of Things). Los dispositivos móviles y la proliferación de redes inalámbricas permitirán a todos el acceso permanente a internet en todo momento y en todo lugar e integrar el mundo real en internet.

\subsection{Terminología y Lexicografía especializada}

A continuación, se describen brevemente las teorías terminológicas y las contribuciones que más influencia han tenido en los investigadores lexicográficos en las últimas décadas y que se consideran de interés para nuestro trabajo. Se pretende analizar la influencia de aspectos 
teóricos, tecnológicos, metodológicos sobre el receptor y principal beneficiario de la labor y del producto lexicográfico: el usuario. De forma que sirvan de hilo conductor para conocer la evolución de la Lexicografía y la situación de la investigación lexicográfica actual.

\subsubsection{Teorías terminológicas}

El primer uso históricamente registrado de "terminología" es el referido a colección de términos o vocabulario técnico (Sager, 1990: 3). Hoy en día terminología tiene tres significados: práctica, disciplina y producto. Es un conjunto de prácticas y métodos utilizados para coleccionar, describir y presentar términos; es una disciplina con una teoría en base a un conjunto de premisas, razonamientos y conclusiones requeridas para explicar las relaciones entre conceptos y términos; $y$ es el vocabulario de una esfera de actividad determinada o de un discurso temático (Boulanger 1995).

Para Sager (1990: 1-2) es un area de conocimiento con raíces en la lingüística y la semántica: "We see terminolgy as a number of practices that have evolved around the creation of terms, their collection and explication and finally their presentation in various printed and electronic media". Este autor no reconoce su estatus como disciplina independiente, pero coincide con E. Wüster en su carácter interdisciplinar y en este sentido, la terminología pone en relación la lingüística, la lógica, la ontología y las ciencias de la información con cualquier otra esfera de actividad (Sager 1990: 2).

Las teorías y propuestas teóricas terminológicas de mayor impacto en los trabajos de investigación y sus principales impulsores son por una parte, la teoría tradicional de terminología o Teoría General de la Terminología atribuida a Wüster y por otra parte, los nuevos enfoques en terminología son: la Teoría Comunicativa de la Terminología propuesta por Cabré; la Socioterminología propuesta de Gaudin y la Terminología Sociocognitiva propuesta por Temmermann y la Terminología basada en marcos propuesta por Faber.

\subsubsection{Teoría General de la Terminología}

A mediados del s. XX la ciencia y la tecnología y el discurso especializado adquieren una importancia y un impacto social creciente, por ello tiene razón de ser una profesión de 
especialistas en información y comunicación técnica que contribuyen a superar los obstáculos en la comunicación verbal en estos campos, 'obstáculos creados' por el contacto de lenguas. Las ideas y el trabajo sobre normalización terminológica de Eugen Wüster se sitúan en este contexto junto con el esfuerzo notable de organizaciones internacionales por crear bancos de datos para sus traductores.

Basándose en su experiencia terminológica y para contribuir a una comunicación eficaz y sin ambigüedad entre profesionales, Wüster publica en 1968 el diccionario de términos normalizados The Machine Tool. An Interlingual Dictionary of Basic Concepts. Sus objetivos eran: normalizar la terminología; crear una herramienta que facilitase la comunicación en lenguajes técnicos; convencer a usuarios de lenguajes técnicos de los beneficios de la Normalización de términos a pesar de su carácter prescriptivo y; considerar la terminología como disciplina con el estatus de ciencia. Plantea tres líneas de trabajo principales (Cabré, 2003: 165):

- El desarrollo de principios internacionales para la descripción y el registro de términos.

- La formulación de los principios generales de terminología, como campo de estudio autónomo, no como una rama de la lingüística aplicada (no lo denomina Teoría).

- La creación de un centro internacional Infoterm para recopilar, diseminar y coordinar información sobre terminología.

Sus seguidores (entre ellos H. Felber) realizaron contribuciones al modelo de Wüster y postularon la denominada Teoría General de la Terminología (en adelante TGT) añadiendo y manteniendo unos criterios que resultaban determinantes:

- Se acepta la sinonimia.

- Pueden existir unidades terminológicas fraseológicas pluriverbales.

- Se introduce la descripción de procesos, haciendo el modelo más dinámico.

- Se introduce la representación de estructuras conceptuales no ordenadas jerárquicamente.

- Se mantiene la prioridad del concepto sobre la designación.

- Se mantiene el carácter monosémico del concepto porque le confiere precisión.

- Se mantiene la concepción semiótica, es decir, las designaciones pueden incluir signos. 
Los principios de la llamada Escuela de Viena (enfoque de Wüster) no ofrecen una explicación para los términos en contexto ni su polisemia, por lo que fueron criticados en base a investigaciones empíricas. Entre ellos, Sager en 1990 añadió al análisis terminológico conceptual un análisis lingüístico y comunicativo basado en corpus de texto en $A$ Practical Course in Terminology Processing y posteriormente Cabré (1999) lo desarrolla. El enfoque estructural de la teoría de la lingüística que prevalecía en la época de Wüster se demostró demasiado restrictivo y completamente orientado hacia aspectos formales de los lenguajes para poder explicar y justificar la especificidad de los aspectos semánticos de los signos especializados (Cabré 2003: 166).

Temmerman (2000) critica que el enfoque de la Escuela de Viena no se mostrara interesado en el lenguaje como herramienta cognitiva sino sólo en el potencial denominador del lenguaje. Critica este enfoque onomasiológico consistente primero en identificar "un concepto", luego darle un lugar en una estructura (basado en relaciones lógicas (IS_A) o (PART_OF)), después definir el concepto en una definición aristotélica, es decir, basado en un conocimiento empírico y finalmente elegir un término para denominar el concepto. Esta crítica parece razonable en el ámbito de los estudios de traducción e interpretación, sus alumnos (lingüistas) necesitaban información textual para comprender un tema especializado y hacer un análisis terminológico en textos en los que encontraban ambigüedad, sinonimia, vaguedad y tomaban cada vez más conciencia de que "the advancement of understanding and the negotiation of meaning go together". Temmerman (2014) concluye que la terminología debe ser descriptiva y que el carácter prescriptivo es más útil para expertos en la materia que para traductores o intérpretes ${ }^{2}$.

\subsubsection{Teoría Comunicativa de la Terminología}

Cabré trabaja, desde 1996, en una concepción teórica que pueda abarcar un abanico más amplio de ideas sobre los términos y consolidar los cimientos de una teoría de base lingüística cuyo objeto de estudio son las unidades terminológicas dentro del marco general de la comunicación

2 J. de Sousa entrevista a R. Temmerman. 2014 <http://termcoord.eu/2014/02/interview-rita-temmerman/> 
especializada, la Teoría Comunicativa de la Terminología (en adelante TCT). Su punto de partida son dos hipótesis iniciales:

1. la terminología es simultáneamente un conjunto de necesidades, un conjunto de prácticas destinadas a resolver estas necesidades y un campo de conocimiento unificado;

2. el objeto central de la terminología son las unidades terminológicas.

En referencia a la primera hipótesis, considera que todas las actividades relacionadas con la representación y transferencia de conocimiento especializado necesitan una terminología; al mismo tiempo, la terminología es un conjunto de utilidades o aplicaciones que permiten el desarrollo de productos idóneos específicamente orientados a la solución de necesidades específicas. y, por lo tanto, debe tener en cuenta sus destinatarios y sus actividades y son las circunstancias de cada situación las que determinan el tipo de aplicación (glosario, léxico, diccionario, etc. en uno o varios idiomas), la información que deben contener (terminología, fraseología, definiciones, variantes, contextos, representación fonética o fonológica, equivalentes de lenguas extranjeras, ilustraciones, etc.), su representación e incluso sus medios de difusión. Por último, considera que la terminología es un campo de conocimiento, es decir, un reto intelectual relacionado con un objeto de estudio o investigación y, como tal, es un conjunto organizado de elementos básicos sobre un objeto de conocimiento (Cabré, 2003: 182183). Una teoría de la terminología debe describir este objeto y proporcionar un marco metodológico suficientemente amplio que incluya las prácticas destinadas a la satisfacción de las diversas necesidades.

Respecto a la segunda hipótesis, considera que las unidades terminológicas, objeto de su estudio, son al mismo tiempo unidades de conocimiento, unidades de lenguaje y unidades de comunicación de un área de conocimiento específico, por tanto, su descripción debe incluir los componentes cognitivo, lingüístico y sociocultural que la integran. El carácter específico de las unidades terminológicas, sus diferencias respecto a otras unidades de la lengua y de otras unidades que expresan conocimiento especializado, se legitima y reside en el hecho de que cumplen condiciones restringidas en cada uno de sus componentes constitutivos cognitivos, gramaticales y pragmáticos (ibid., p. 183). 
Las unidades terminológicas como conjunto de unidades pertenecientes al lenguaje natural tienen, por una parte, la función de representar el conocimiento especializado de un área temática y por otra, constituyen el vehículo para la comunicación profesional espontánea o natural. Esta doble función de 'representación y transferencia' no presupone una relación unívoca (Cabré, 1999: 80), en contraposición al postulado reduccionista de Wüster (sin variación formal ni conceptual de los términos).

Considera que las unidades terminológicas son multidimensionales y es posible aproximarse a ellas desde la semiótica y desde la lingüística. El concepto es independiente y precede a una designación que puede incluir signos lingüísticos y no lingüísticos, por tanto, las unidades terminológicas se conciben como combinaciones léxicas, indivisibles en forma y contenido. Cabré formula un modelo, para reconciliar estas dos aproximaciones, que denomina the theory of doors (Cabré, 2003: 186), que hace referencia a un espacio multidimensional en el que la terminología está en el centro y al que se accede desde diversos puntos o 'puertas': concepto, término o situaciones. Para acceder a las unidades es necesario declarar el punto de acceso y documentar en detalle el proceso descriptivo o explicativo que se debe seguir para llegar al centro de este espacio (ibid., p. 193).

Afirma que el conocimiento especializado y las unidades terminológicas, pueden representarse y por tanto incorporar un componente simbólico no lingüístico (Cabré, 1999: 103). Este último componente será especialmente relevante en el trabajo de investigación que nos ocupa.

\subsubsection{Socioterminología}

La aparición de tres revistas universitarias dedicadas a las orientaciones sociales de la terminología primeramente la de los Cahiers de 'Linguistique sociale' en 1991 y cuyo tema era el de Terminologie et sociolinguistique; después Le Langage et l'homme, en 1993 y cuyo tema era Socioterminologie; finalmente META en junio de 1995, con el título Usages sociaux des termes: Théories et terrains (Santos et al., 2001: 661) y la tesis doctoral de François Gaudin en el año 1993, suponen hitos relevantes en el desarrollo de una corriente de orientación social que abre una nueva etapa en el campo de la terminología, la socioterminología, e introduce la 
terminología en el discurso en cuanto a práctica social. La socioterminología delimita un objeto en situación, reconoce el papel cognoscitivo de los términos y su enraizamiento social, se afirma empírica y analiza su relación con la semántica cognoscitiva y la sociolingüística (Santos et al., 2001: 662).

La socioterminología se sirve de otras disciplinas al abordar los términos espontáneos: la sociología; la sociolingüística; la semántica cognoscitiva; la etnografía de la palabra (circunscribe la naturaleza de las situaciones y pone de relieve la posición de los hablantes en y por sus enunciados); la lexicometría (enfoque aplicado a la redefinición de conceptos e identificación de unidades temáticas (cf. Romero-Pérez et al.,2018)); la editología; la semiótica narrativa (implica comprender mejor cómo se fabrica el texto y que papel representa en él la terminología). Se plantea tres objetivos: el análisis de las necesidades, los usos según los actores (técnicos, traductores, redactores, enseñantes, investigadores...) y las relaciones entre ciencia, técnica y producción; la comprensión de las condiciones y dificultades de los procesos de transmisión de conocimiento y, por último, la profundización en la evolución de la terminología vinculada a los medios técnicos y a la transformación del conocimiento como una parte más de la historia de las ciencias (Santos et al., 2001: 662-663).

\subsubsection{Terminología Sociocognitiva}

La terminología ha experimentado una evolución desde la llamada terminología tradicional (orientada a la estandarización y centrada en conceptos) hacia un enfoque orientado a la comunicación y centrado en el discurso (Cabré, 1999 y 2000, Temmerman, 2000). Temmerman desarrolla la teoría de la Terminología Sociocognitiva (en adelante TS) basada en el estudio empírico de los procesos de categorización y lexicalización en un corpus de publicaciones científicas sobre las ciencias de la vida (tecnología de ADN) y cuestiona la validez de la teoría terminológica tradicional.

Temmerman (2000) bajo la premisa de que 'comprender más y mejor es la base de la creación y extensión del conocimiento', destaca la importancia de la experiencia humana y el papel del lenguaje en este proceso. Esta experiencia es un motor cognitivo en muchos dominios de la existencia humana y el lenguaje actúa como herramienta cognitiva con impacto en la 
comprensión y la creación de la terminología en dominios especializados. Según Temmerman (2000: 219-232), la misión de la Terminología es intentar describir la relación entre las tres perspectivas de las unidades de comprensión: la nominal, la mental y la real, es decir, relacionar los términos con la idea que nos evoca en la mente y con el referente en el mundo externo.

En la terminología sociocognitiva los términos (en lugar de los conceptos) se convierten en el punto de partida para el análisis terminológico y cambia la noción de concepto por unidad de comprensión y categoría (que puede tener una estructura prototipo).

Temmerman realiza tres propuestas: respecto a conceptualización-categorización, la hipótesis de una estructura prototipo es viable para estructurar y comprender una categoría; respecto a la denominación, en lenguajes de especialidad la monosemia es, a veces, funcional pero también lo son la polisemia y la sinonimia; respecto a modelos metafóricos, que relacionan el sistema de lenguaje con el mundo de la experiencia y el funcionamiento de la mente (Temmerman, 2000: 43-44).

La termontografía es una metodología (para algunos investigadores una herramienta) para la gestión y representación del conocimiento en dominios de experiencia específicos que combina a partir de textos, la experiencia en un dominio con la información provista en lenguaje natural y supone la unión del trabajo terminográfico con las ontologías (Temmerman y Kerremans, 2003; Kerremans et al., 2005). En primer lugar, se desarrolla un marco inicial de categorías y relaciones intercategoriales, en colaboración con los especialistas del dominio de conocimiento que se somete al análisis ontológico (análisis descendente), este marco de categorización sirve como una plantilla para la extracción manual y semiautomática del conocimiento en un corpus. Este primer marco inicial evoluciona a una red de relaciones semánticas enriquecida, reflejando categorizaciones específicas de la cultura, ya que el conocimiento obtenido a través del material textual se confronta con el marco categórico (análisis ascendente). Los resultados de este análisis se reflejan en una base de datos termontológica, que puede utilizarse como recurso para la ingeniería del conocimiento formal (Temmerman y Kerremans, 2003: 4-5).

Sobre Terminología e Ingeniería del Conocimiento Temmerman ve el futuro del ediccionario basado en agentes de software autónomos que accedan a datos lexicográficos a fuentes y/o repositorios web distribuidos semánticamente, en lugar de una base de datos 
lexicográfica y que llevan a cabo tareas de razonamiento para decidir qué datos, en función del perfil del usuario, son relevantes y cómo se deben presentar. Una de las hipótesis del presente trabajo sostiene que son imprescindibles otros sistemas de representación de conocimiento.

\subsubsection{Terminología basada en Marcos}

La terminología basada en marcos (Faber, Márquez y Vega, 2005; Faber et al., 2006; Faber, León, Prieto y Reimerink, 2007) utiliza una versión modificada y adaptada de marcos de Fillmore junto con premisas de la Lingüística Cognitiva para configurar dominios especializados sobre la base de patrones de definición y para crear representaciones situadas de conceptos de conocimiento especializados (Faber, 2012: 117). Con esta base se estructuran dominios especializados y se crean una representación esquemática de un sistema de conceptos relacionados de forma que un único concepto activa todo el sistema conceptual. Un marco es un sistema que se configura formando un conjunto de categorías estructuradas y conformadas -motivadas- a partir de un contexto. En el caso de textos especializados como contexto, estas configuraciones representan el significado conceptual que subyace en dichos textos y facilitan la adquisición de conocimiento especializado (Faber, 2009: 121).

Al igual que el enfoque lingüístico cognitivo constituye un modelo de estructura cognitiva basado en la experiencia que proporcionan el conocimiento previo y la motivación para la existencia de léxico en una lengua, así como la forma en que este léxico se utiliza en el discurso, con la ventaja de que los marcos anticipan el comportamiento potencial semántico y sintáctico de las unidades de lenguajes especializados (Faber, 2009: 123).

Hay dos puntos de vista sobre el concepto de dominio en Terminología; por dominio se refiere al área de conocimiento en sí; o a las categorías de conceptos dentro del campo especializado. Este segundo enfoque motiva la búsqueda de un modelo de categorías y una estructura de categorías que pueda ser aplicada de forma realista al lenguaje en sentido amplio (Faber, 2009: 121). El estudio y la utilización de las unidades terminológicas en contexto requieren conocer el dominio conceptual de especialidad y la estructura de categorías de conceptos especializados. 
Las redes conceptuales, en la terminología basada en marcos, se fundamentan en un inventario cerrado de relaciones semánticas y en un evento subyacente en el dominio que genera patrones para las acciones y los procesos que tienen lugar en el campo especializado y para las entidades que participan en ellos (ibid., p. 124). La descripción de los dominios especializados se basa en eventos que tienen lugar en dichos dominios y pueden ser representados (cf. Grinev y Klepalchenko, 1999), cada área de conocimiento tiene su propio patrón de eventos.

La terminología basada en marcos considera el rol de las imágenes en la representación de conceptos especializados. La relación entre la descripción lingüística y la gráfica de entidades especializadas evidencian la naturaleza multidimensional de conceptos, así como las relaciones conceptuales dentro de un dominio (Faber et al., 2007). Propone la descripción conceptual multimodal en la que la información estructurada en definiciones terminográficas se asocia con la información en imágenes para una mejor comprensión de sistemas de conceptos complejos.

Los textos científicos y técnicos parecen idóneos para la metodología basada en marcos, por el contenido elevado de unidades de lenguaje especializado. Sin embargo, se cuestiona la posibilidad de comprender el comportamiento lingüístico basándose en patrones de definiciones y la creación de representaciones de conceptos de conocimiento especializado, con el objetivo final de adquirir conocimiento especializado. En este sentido Faber (2010: 89) opina que los traductores especializados deben alcanzar el umbral mínimo imprescindible de conocimiento especializado.

En los proyectos terminológicos basados en marcos (ej. proyecto Ecolexicon) la presentación final a la que accede un usuario es una representación de la base de datos constituida por conceptos relacionados entre sí mediante líneas de concordancia, con una representación y un aspecto visual dinámico para la contextualización de conceptos. Con el objetivo de constituir un recurso terminológico útil para la adquisición de conocimiento, pero la multidimensionalidad de los términos presentados puede causar sobreinformación. 


\subsubsection{Relaciones entre teorías terminológicas}

Existe cierta controversia entre las diferentes teorías terminológicas y la lexicografía y a su vez, una relación de convivencia y complementariedad posible que se exponen a continuación.

La Teoría Tradicional da la Terminología tiene el mérito de ser la primera propuesta teórica y por ello, ser un punto de referencia de teorías terminológicas actuales y a la vez, objeto de sus críticas. Sin embargo, cabe destacar, desde nuestro punto de vista, el esfuerzo normalizador realizado en terminología que facilitó la comunicación especializada entre profesionales que no compartían la lengua natural.

Temmerman considera que las deficiencias de la terminología tradicional son: la perspectiva onomasiológica; la proposición de que los conceptos son obvios; la asignación de definiciones terminológicas a conceptos; el reclamo de univocidad y la prevalencia de la sincronía.

Desde la Teoría Comunicativa de la Terminología, apoyándose en consideraciones de las ciencias cognitivas, la sociolingüística y las ciencias de la comunicación, se critica la Teoría Terminológica Tradicional por limitarse a los lenguajes especializados y a los términos técnicos normalizados. Esto supone separar el conocimiento especializado del conocimiento general y no considerar la contribución del conocimiento general a la adquisición de conocimiento especializado y al papel del interlocutor que crea el discurso y percibe la realidad basándose en la experiencia personal y cultural adquirida. La lingüística del corpus crea modelos que integran ambas teorías y que se extienden más allá de los límites de los modelos de la lingüística estructural y de los modelos generativos estándar de las oraciones. Por último, se cuestiona a la TGT que con un único esquema pueda representar distintos escenarios de comunicación, incluida la comunicación especializada (Cabré, 2003: 171).

Con la aparición de la Terminología Sociocognitiva (Temmerman) y la Terminología Basada en Marcos (Faber), queda patente el giro definitivo de la Terminología hacia la Lingüística cognitiva, a favor de la descripción de conceptos especializados, de la representación del conocimiento y del lexicón mental, ya que las estructuras lingüísticas reflejan la estructura conceptual, la primera a través de prototipos y la segunda a través de marcos. Desde el enfoque socioterminológico se rechaza la invariabilidad en la normalización terminológica, ya que se 
debe tener en cuenta el aspecto social y la situación en la comunicación especializada dando lugar a la variación del término.

La Terminología basada en Marcos comparte algunos de los presupuestos teóricos de la Teoría Comunicativa de la Terminología (Cabré) como son las unidades terminológicas que representan diferentes dimensiones: la cognitiva, la lingüística y la comunicativa; de la Terminología Sociocognitiva (Temmerman) acepta la Teoría de prototipos, la idea de que los conceptos y términos evolucionan con el tiempo y la necesidad de usar ontologías en el proceso de creación de recursos terminológicos (López Rodríguez et al., 2010).

Riggs (1989: 89-110) se refiere a los modos de trabajo en disciplinas lexicográficas y la Terminología que dan lugar respectivamente, a obras de referencia de carácter descriptivo, con un orden alfabético de las entradas, esto es, diccionarios y obras de carácter prescriptivo, con un orden no alfabético, orden "systematic, logical, taxonomic, classificatory, semantic", obras de referencia terminológicas que Riggs denomina "glosarios conceptuales". Riggs (ibid. p. 93) recoge una tendencia creciente hacia un modelo descriptivo para el trabajo terminológico, desarrollado por "social scientists" sobre la base de principios onomasiológicos. Son académicos que escriben con tradición humanística "social and information scientist, linguists and lexicographers" y que se alejan de la estandarización de métodos terminológicos y vocabulario técnico recomendados por ISO/TC37.

La Terminología basada en Marcos (Faber) tiene un enfoque cognitivo, que comparte muchas premisas con la TCT y la terminología sociocognitiva. Por ejemplo, sostiene que la mejor manera de estudiar unidades de conocimiento especializadas es estudiando su comportamiento en los textos. Debido a que la función general de los textos lingüísticos especializados es la transmisión de conocimiento, dichos textos tienden a ajustarse a las plantillas para facilitar la comprensión y generalmente se caracterizan por una mayor repetición de términos, frases, oraciones...

La Terminología, hoy en día se ha convertido en una ciencia multidisciplinar que para algunos investigadores ha alcanzado un grado elevado de madurez gracias a las contribuciones de diferentes escuelas lingüísticas: computacional, del corpus, variacional, sociocognitiva, sociocomunicativa, semántica basada en prototipos, semántica basada en marcos, y a las contribuciones de desarrolladores informáticos de ingeniería y lenguaje formal. Con enfoques 
que abarcan desde lo estandarizado y prescriptivo hasta enfoques basados en el usuario y orientados al usuario, que ofrecen recursos para buscar, extraer y analizar terminología en corpus en línea y que generan bases de términos que contribuyen a una comunicación eficaz entre expertos. Probablemente, esta fusión de la Terminología con la Lingüística permite una reflexión madura y multidimensional sobre los fenómenos terminológicos, que genere aplicaciones futuras que aún no han sido probadas en lenguaje natural (Kockaert y Steurs, 2015).

La convergencia entre terminología y lexicografía se pone, recientemente, de manifiesto al incorporar recursos terminológicos en un portal de diccionarios en línea que se está construyendo en la UVa y que contiene varios tipos de diccionarios. El tipo de elementos léxicos incluidos, bien sean palabras o términos se integran sin dificultad en un tipo de herramienta caracterizada por los recursos técnicos y tecnológicos para abordar los aspectos informáticos y lingüísticos (Fuertes-Olivera y Esandi-Baztan, 2020, en revisión).

\subsubsection{Hacia una teoría general de la lexicografía}

Scerba (también escrito Shcherba o Ščerba) en 1940 consciente de que no existe una teoría lexicográfica que guíe la práctica lexicográfica enuncia los principios de una teoría que pueda dar cuerpo a un trabajo continuado durante siglos de compilación de diccionarios. Tipifica los diccionarios según características opuestas y entre los criterios que utiliza destacan: el colectivo usuario al que va dirigido; la coincidencia en el tiempo y situación geográfica de los usuarios, y una conciencia lingüística compartida por el colectivo de usuarios. Sobre el propio diccionario destaca el hecho de que su contenido pueda constituir o no, un único sistema expresivo integral y que está condicionado por el colectivo usuario. Define y describe las características de los diccionarios que provisionalmente denomina Informative dictionaries:

Thus, under the type informative dictionary can be grouped all kinds of technical dictionaries, containing words from different specialties because the specialists in these fields frequently do not understand each other... what characterizes the informative dictionary is that its words do not form a single, integral expressive system... or it contains only a part of the words forming a unified system. (Scerba, 1940 [1995]: 316 (traducido por Farina)) 
Wiegand perfila el inicio de una teoría general de la lexicografía partiendo de lo que denomina lexicografía lingüística. Desarrolla una teoría general, dividida en cuatro partes: sección general; teoría de la organización del trabajo en tres campos de la actividad; teoría de la investigación lexicográfica de la lengua y teoría de la descripción lexicográfica de la lengua.

All types of works made with the aim of providing not only, but above all, information on linguistic expressions should be classified as linguistic lexicography .... Linguistic lexicography is scientific practice aimed at producing reference works on language, in particular dictionaries of language. (Wiegand, 1984: 13-14)

Esta teoría denominada general, sin embargo, no abarca todo tipo de obra lexicográfica sólo la producida desde la lexicografía lingüística.

A general theory of lexicography must systematically process and explain the reasons for the knowledge required to enable lexicographers to carry out their work appropriately and as well as possible. (Wiegand, 1984:14-15)

Entre sus aportaciones más destacadas por sus repercusiones en la teoría de las funciones lexicográficas Wiegand (1998) está la consideración del diccionario como utility product con 'genuine purpose' y su oposición a considerar la lexicografía parte de la lingüística aplicada, lexicología o semasiología.

Wie alle Gebrauchsgegenstände, so haben auch Nachschlagewerke genuine Zwecke. (Wiegand 1998:52)

[Like all utility products, reference Works also have a genuine purpose.] (Bergenholtz y Tarp 2003:179)

La reinterpretación de Scerba, los postulados y debates de Wiegand contribuyeron a la formación de una teoría basada en las funciones lexicográficas que incorpora nuevas aportaciones. 


\subsubsection{La Moderna teoría de las Funciones Lexicográficas}

It was not until the appearance of the "modern theory of lexicographic functions" that a theory was developed that takes the users, the user needs and the user situations as the starting point for all lexicographic theory and practice. (Bergenholtz \& Tarp 2003:172)

La moderna teoría de las funciones lexicográficas es el resultado de la investigación continuada y de las publicaciones de: Bergenholtz \& Tarp, 1995; Tarp 2003, 2007, 2008; BergenholtzKaufmann 1997, Bergenholtz-Nielsen 2002, Bergenholtz-Tarp 2003. Se basa en dos postulados: la lexicografía es una disciplina independiente y los diccionarios se configuran como 'productos de utilidad', son productos con un carácter práctico y útil que cumplen su cometido al satisfacer ciertas necesidades humanas. Es una teoría lexicográfica en desarrollo que se centra en determinar, para un tipo de usuario en un tipo de situación, las necesidades que le surgen y que serán satisfechas mediante la consulta de datos lexicográficos en un diccionario. Las funciones son los elementos básicos de teoría y práctica lexicográficas y constituyen 'the leading principle' de los diccionarios (Bergenholtz y Tarp, 2003: 177). El siguiente esquema puede ilustrarnos este proceso primario de diseño:

$$
\text { human activity } \leftrightarrow \text { human needs to be satisfied } \leftrightarrow \text { Utility product }
$$

El lexicógrafo al decidir el propósito acreditado ('genuine purpose') y las funciones del diccionario decide crear un 'producto de utilidad' cuyo proceso se inicia analizando de entre las actividades humanas aquellas en las que surgen necesidades, de entre estas, las que son susceptibles de ser satisfechas mediante la consulta a un diccionario. Crear determinado diccionario como producto de utilidad conlleva identificar el perfil del grupo de usuarios potencial determinado por ciertas características comunes del grupo y las situaciones en las que se encuentra. Fijar estas variables permite determinar las funciones y el objetivo concreto del diccionario.

Las situaciones en que pueda encontrarse el usuario potencial se corresponden con las funciones del diccionario y se agrupan en dos: knowledge-orientated y communicationorientated (ibid. p.176) y se diferencian en el modelo de comunicación. En las situaciones denominadas knowledge-orientated, se produce una comunicación directa entre el lexicógrafo 
y el usuario, el usuario demanda conocimiento y el lexicógrafo lo proporciona. En las situaciones denominadas communication-orientated, la comunicación se produce entre dos o más personas, tiene que ver con la recepción, producción y traducción de textos, es decir, se planifica una comunicación escrita u oral donde los problemas de comunicación se resuelven mediante consultas al diccionario (el lexicógrafo es un interlocutor indirecto).

Identificadas las características del perfil del usuario y sus situaciones, es posible anticipar una tipología de necesidades de información que el lexicógrafo debe planificar y satisfacer en cada proyecto. A grandes rasgos, estas necesidades comprenden categorías de información como (ibid. p. 175):

- Information about the native language

- Information about a foreign language

- Comparison between the native and a foreign language

- Information about culture and the world in general

- Information about the special subject field

- Comparison between the subject field in the native and foreign language

- Information about the native LSP

- Information about the foreign LSP

- Comparison between the native and foreign LSP

Bergenholtz y Tarp definen la función lexicográfica como la asistencia que proporciona un tipo específico de diccionario que puede tener una o varias funciones:

A lexicographic function of a given dictionary is to provide assistance to a specific user group with specific characteristics in order to cover the complex of needs that arise in a specific type of user situation. A concrete dictionary can have one or more functions, i.e. it can be mono- and multifunctional. As any other utility product, dictionaries also have a genuine purpose. This genuine purpose is made up by the totally of functions of a given dictionary and the subject field(s) that it covers. (Bergenholtz \&Tarp 2003:176)

Las funciones son los elementos básicos de la teoría y la práctica lexicográfica por lo que tanto contenido como la forma del diccionario se planifican teniendo en cuenta estas funciones. 


\subsection{Teoría de las Funciones lexicográficas}

La teoría Funcional de la Lexicografía o Teoría de las Funciones Lexicográficas (en adelante TFL) supone el reencuentro entre la teoría y la práctica lexicográficas en el campo de los diccionarios especializados, entre sus objetivos principales está el de dirigir la actividad lexicográfica. El concepto de función lexicográfica (Tarp, 2008a) o función de un diccionario y una nueva metodología (Fuertes Olivera- Tarp, 2008: 80) permitirán de antemano en cada propuesta de diccionario decidir los conceptos, determinar las categorías de datos específicos que se van a incluir y a presentar. Bajo la perspectiva del colectivo de usuarios al que se dirige, sus características, sus situaciones extralexicográficas y sus necesidades lexicográficamente relevantes. Tanto el colectivo de lexicógrafos como de usuarios potenciales de un diccionario están condicionados en su trabajo, en la forma de relacionarse y en la forma de comunicarse por el hecho de convivir en la llamada sociedad de la información y del conocimiento.

La teoría funcional de la lexicografía está motivada inicialmente por el trabajo y las publicaciones de lexicógrafos singulares como: Shcherba (1940); Hausmann (1977); Kromann et al. (1984) y Wiegand $(1984,1998,2002)$ que se han mencionado.

Los primeros enunciados TFL se formulan en la tesis doctoral de Sven Tarp en 1992 y sus inicios tienen lugar en un contexto integrado por académicos en el Centro de Lexicografía del Aarhus School of Business, dirigidos por Henning Bergenholtz y Sven Tarp. Estos expertos lexicógrafos han contribuido desde entonces a su difusión, desarrollo y notable avance teórico y práctico, entre ellos en nuestro contexto, los investigadores integrantes del equipo investigador de Lexicografía Especializada del Instituto de Estudios Europeos de la Universidad de Valladolid dirigidos por el profesor Pedro A. Fuertes Olivera.

La TFL comparte los dos postulados iniciales con la teoría general de la lexicografía de Wiegand (1983): el considerar a la lexicografía una disciplina independiente de la lingüística cuyo objeto de actividad son los diccionarios; y consideran que los diccionarios son 'productos de utilidad' creados para satisfacer ciertas necesidades de los usuarios ${ }^{3}$. Wiegand reconoce la

\footnotetext{
${ }^{3}$ Desde el punto de vista de diseño de producto, el producto de utilidad se crea para satisfacer necesidades del usuario lo que implica ciertas funciones asociadas al producto que les permiten ser 'usables y útiles' de otro modo, las funciones se convierten en superfluas para el usuario y para el producto.
} 
independencia de la lexicografía respecto de la lingüística aplicada lo que evidencian los distintos diccionarios técnicos, pero a pesar de esto desarrolla y se centra en la lexicografía lingüística (cf. Wiegand 1983).

El desarrollo y las distintas actualizaciones de la TFL demuestra que sus impulsores y sus seguidores asumen, hasta nuestros días, todas las consecuencias teóricas y prácticas de estos dos postulados iniciales (Bergenholtz and Tarp, 2003: 172).

El hecho de diseñar un diccionario como producto de utilidad supone, a grandes rasgos, estudiar las actividades humanas con el fin de detectar necesidades que puedan ser satisfechas con consultas al diccionario. Para poder identificar las necesidades del usuario previamente es necesario definir el perfil de usuario y el tipo de situaciones en que se encuentra. Bergenholtz and Tarp (2003: 173) enumeran y Fuertes Olivera y Tarp (2008: 80) completan en forma de preguntas las características que comparten el tipo de usuarios potencial y que el lexicógrafo puede tener en cuenta para configurar el perfil del grupo:

1. ¿Cuál es su lengua materna?

2. ¿A qué nivel domina la lengua materna?

3. ¿A qué nivel domina la lengua extranjera?

4. ¿Cuál es su experiencia como traductor?

5. ¿A qué nivel dominan su propia cultura?

6. ¿A qué nivel dominan la cultura relacionada con la lengua extranjera?

7. ¿A qué nivel dominan el lenguaje especializado en su lengua materna?

8. ¿A qué nivel dominan el lenguaje especializado en la lengua extranjera?

9. ¿A qué nivel dominan la disciplina o ciencia dada?

10. ¿A qué nivel dominan la disciplina o ciencia en su propia lengua?

11. ¿A qué nivel dominan una disciplina o ciencia en la lengua extranjera?

Las necesidades del usuario surgen en situaciones concretas en las que se demanda información knowledge orientated que pueden ser sobre un tema concreto, o sobre el proceso de aprendizaje de una lengua, y un tercer grupo de situaciones en el que surge un problema de comunicación oral o escrita communication orientated (Bergenholtz y Tarp 2003: 175) (cf. 2.3.4). 
Sven Tarp (2014:16) añade que tan determinante para identificar las necesidades lexicográficamente relevantes como las características del usuario, es la situación extralexicográfica en la que se producen. The range of possible functionally relevant social situations is a core element of the function theory (Fuertes-Olivera y Tarp 2008a: 78). Las categorías fundamentales de situaciones lexicográficamente relevantes son:

- Situaciones comunicativas

- Situaciones cognitivas

- Situaciones operativas

- Situaciones interpretativas

De acuerdo a la teoría funcional, la necesidad de información puntual que tiene un usuario que consulta un diccionario se satisface mediante el aporte de un conjunto de datos lexicográficos que han sido seleccionados, preparados y presentados de forma accesible para su consulta, bajo la supervisión de un lexicógrafo.

Para producir obras lexicográficas de calidad, según Bothma y Tarp (2012: 92), es necesario que las técnicas y métodos de análisis utilizados se basen en criterios de relevancia condicionados por el tipo específico de información necesitada. Para estos investigadores el proceso lexicográfico se compone de tres fases y se inicia con anterioridad a la consulta a una obra de referencia:

1- Fase prelexicográfica: un usuario con características y en situación extralexicográfica específicas, tiene necesidad de información, toma conciencia de esa necesidad y decide iniciar una consulta lexicográfica.

2- Fase intralexicográfica: el usuario selecciona una herramienta para la consulta, accede a los datos relevantes, verifica que ha encontrado los datos relevantes y recupera la información a partir de dichos datos.

3- Fase postlexicográfica: el usuario con la información obtenida bien resuelve un problema comunicativo, cognitivo, operativo o interpretativo.

Es frecuente que en proyectos terminográficos se utilice el procesado automático de las colecciones electrónicas de textos, este proceso devuelve a los investigadores información sobre la frecuencia y da cuenta de la existencia de la variación y de la relevancia objetiva, pero no 
informa sobre la relevancia subjetiva (basada en el usuario) lo que implica que esta actividad práctica no es aconsejable, en primera instancia, para la toma de decisiones finales en un proyecto de lexicografía especializado, dado que frecuencia y variación son contrarios a la naturaleza de la comunicación especializada (Fuertes-Olivera 2011: 105).

La teoría funcional se ha ido perfilando como una teoría transformadora, concebida en sí misma como una 'herramienta teórica' capaz de guiar la práctica lexicográfica mediante los siguientes enunciados axiomáticos fundamentales, (adaptado Tarp 2015: 34):

- Cualquier diccionario debe ser una herramienta de uso que permita una consulta rápida y fácil con el fin de satisfacer necesidades puntuales de información, a tipos específicos de usuarios en tipos específicos de situaciones extralexicográficas.

- Las necesidades de información de los usuarios se satisfacen dando acceso a datos lexicográficos preparados, de los cuales los usuarios pueden extraer la información requerida y emplearla con propósitos relacionados con las situaciones en las que se produjeron.

Se puede comprobar que la teoría de las funciones lexicográficas o teoría funcional de la lexicografía constituye un modelo teórico de utilidad para el lexicógrafo y el experto en un ámbito de conocimiento especializado, que tiene el suficiente cuerpo teórico y que supone un progreso notable para afrontar la concepción y producción de diccionarios capaces de cumplir satisfactoriamente con las necesidades de los usuarios (Hernández 1991: 191, énfasis añadido).

Un diccionario en línea es una compleja herramienta lexicográfica electrónica y su concepto no es puramente lingüístico. No está enfocado hacia la lingüística y las categorías lingüísticas, sino hacia las funciones que pueden tener los diccionarios cuando son consultados por los usuarios (Nielsen, 2011: 197). Contiene datos adaptados para satisfacer necesidades de usuarios en situaciones que pueden no estar relacionadas exclusivamente con la lingüística y están condicionados por un medio desarrollado por la informática y la tecnología. Esta tecnología permite planificar diccionarios especializados que facilitan datos con contenido lingüístico y gráfico que directamente respaldan las funciones para las que han sido diseñados.

Tarp, en 2014 en el simposio internacional sobre «El futuro de los diccionarios en la era digital» en la RAE, indica la metodología para desarrollar un concepto de diccionario, en el marco de la TFL, que se centra en cuatro ejes: el tipo de usuario con ciertas características; el tipo de 
situación extralexicográfica, que a su vez determina las características del usuario que son relevantes para el proyecto; el proceso de deducción de los tipos posibles de necesidades relevantes de los usuarios en estas situaciones, y la conclusión de las necesidades y de los tipos de datos a incluir en un proyecto lexicográfico.

Nuestra propuesta con este trabajo, es aunar la confluencia de intereses entre las necesidades lexicográficamente relevantes que, de forma general tiene lugar en la sociedad y en nuestro entorno académico en particular y los diccionarios como productos culturales. La relación causal entre necesidades y productos (Fuertes Olivera- Tarp 2008:77) en este marco teórico adquiere un sentido que esperamos materializar en una propuesta lexicográfica de EGI.

\subsubsection{Las funciones lexicográficas}

Para Sven Tarp (2015a: 35-36) una teoría lexicográfica transformadora debe servir de herramienta teórica capaz de guiar la concepción y la compilación de las obras lexicográficas. Define la función lexicográfica como "la asistencia que presta una obra lexicográfica para satisfacer los tipos específicos de necesidades de información puntual que pueda tener un tipo específico de posible usuario en un tipo específico de situación extralexicográfica." La asistencia mencionada se refiere a que hay una intención facilitadora al preparar y presentar los datos en un diccionario, en clara referencia al hecho mismo de la consulta. La función lexicográfica que da nombre a la TFL, y es considerada "the heart and soul of lexicography" es la satisfacción de tipos específicos de necesidades de información que pueden surgir a tipos específicos de usuarios potenciales en tipos específicos de situaciones extralexicográficas (Fuertes-Olivera y Tarp 2014: 62). Según la teoría funcional hay varios tipos de funciones lexicográficas que cubren las situaciones de uso y las diferentes necesidades de los usuarios. Estos investigadores clasifican las funciones lexicográficas según las situaciones extralexicográficas como: funciones comunicativas, cognitivas, operativas e interpretativas.

- Las funciones comunicativas son las que asisten al usuario en la resolución de problemas de recepción, producción y traducción de textos. 
- Las funciones cognitivas son las que asisten al usuario que requiere aumentar su conocimiento enciclopédico y de cultura general, específico de un área y lingüístico. (Bergenholtz and Tarp, 2003: 176).

- Las funciones operativas son las que asisten al usuario que necesita instrucciones para realizar una acción física, cultural o mental.

- Las funciones interpretativas son las que asisten al usuario para interpretar un signo, señal, símbolo o sonido que no es lingüístico, Tarp (2015: 35).

\subsection{Conclusiones}

Concluimos con los aspectos de la teoría de las funciones lexicográficas que contribuyen al objetivo de orientar nuestra propuesta lexicográfica (cf. 2.3.4, 2.4 y 2.4.1):

- la TFL supone el reencuentro entre la teoría y la práctica lexicográficas en el campo de los diccionarios especializados, entre sus objetivos principales está el de dirigir la producción lexicográfica;

- planificar un diccionario como utility tool conlleva identificar el perfil del grupo de usuarios potencial determinado por ciertas características comunes del grupo y las situaciones en las que se encuentra para así, poder identificar las necesidades de información del usuario y definir las funciones del diccionario;

- las necesidades humanas no deben verse como algo abstracto, sino que se desarrollan en contextos y en situaciones reales;

- los lexicógrafos estudian, o deben estudiar, las actividades humanas para detectar posibles necesidades que puedan satisfacerse mediante un diccionario;

- todas las consideraciones teóricas y prácticas deben basarse en la determinación de estas necesidades;

- los lexicógrafos, deben legitimar un perfil del grupo de usuarios previsto y una tipología de las situaciones de los usuarios en las que pueden surgir problemas o necesidades que pueden resolverse proporcionando datos lexicográficos en un diccionario. 
A nuestro entender,

- la función lexicográfica existe solamente durante el acto de uso del diccionario, que es un objeto de uso práctico definido;

- los diccionarios en línea 'solo existen' en el momento de la consulta, hasta entonces y después, son un 'proyecto' de obra de referencia, es decir, adoptan el aspecto de un diccionario en cada consulta (a diferencia de los diccionarios en papel);

- la Teoría Funcional de la Lexicografía constituye un modelo teórico y metodológico de utilidad en un ámbito de conocimiento especializado y que supone un progreso notable para afrontar un proyecto de diccionario especializado de EGI. 


\section{LOS DICCIONARIOS ESPECIALIZADOS}

3.1 Introducción

3.2 El diccionario especializado

3.2.1 Diccionarios en línea especializados

3.2.2 La estructura de los artículos lexicográficos en los diccionarios especializados

\subsubsection{DICTER}

3.2.2.2 Diccionarios Valladolid UVa (2017-2020)

3.2.2.3 Physical training lexicographical pools

3.2.2.4 Observaciones para la estructura del diccionario de EGI

3.3 La elaboración de diccionarios

3.4 El usuario del diccionario

\subsubsection{Concepto de usuario}

3.4.2 La teoría funcional de la lexicografía en relación con las necesidades del usuario

3.4.3 Métodos utilizados en lexicografía para identificar las necesidades del usuario del diccionario

3.4.4 Investigación lexicográfica de las necesidades del usuario en el marco teórico de la TFL

3.4.4.1 Habilidades en el uso de diccionarios en línea

3.4.5 Métodos para detectar las habilidades de referencia en el uso de diccionarios

3.4.5.1 Respecto a las habilidades de referencia en el uso de diccionarios en línea 3.5 Perspectiva orientada al usuario

3.5.1 Acceso y rutas de acceso a los datos de un diccionario en línea 3.6 Conclusiones 


\section{LOS DICCIONARIOS ESPECIALIZADOS}

\subsection{Introducción}

El diccionario es una obra de referencia concebida como herramienta para consulta puntual y destinada a un tipo de usuario que en un momento determinado tiene unas necesidades de información. El hecho de considerarlo una herramienta supone que desde el inicio se diseña para que facilite o intervenga en un proceso y para que desempeñe una función. Los parámetros que intervienen en el diseño de la herramienta, se fijan con una intención determinada de forma que se puede predecir, en términos generales, la utilización de la misma. En nuestro proyecto se considera que el diccionario es una herramienta práctica de uso, pero también un instrumento pedagógico resultado de la actividad lexicográfica.

Desde un punto de vista formal coinciden las nociones básicas de términos lexicográficos en un diccionario con las definiciones de Haensch y Omeñaca (2004: 45-46): unidad léxica es una palabra aislada o una macrounidad que corresponde a una unidad conceptual; macroestructura es la ordenación del conjunto de elementos que forman el cuerpo de un diccionario y que se divide en artículos; microestructura es la ordenación de los elementos que configuran un artículo; artículo o entrada es la unidad autónoma correspondiente a cada unidad léxica registrada en un diccionario y lema el elemento que encabeza un artículo y representa a una unidad léxica univerbal o pluriverbal.

La conciencia lingüística subyacente de un colectivo o comunidad de hablantes específico en un determinado momento es la base de ciertos diccionarios, pero no de todos (Scerba, 1940: 135). Si el diccionario está dirigido a colectivos diferentes o distanciados en el tiempo o geográficamente o bien porque contienen sólo una parte del vocabulario que forma un sistema unificado, resulta difícil compartir la misma conciencia lingüística. Incluso puede que no 
constituyan ningún tipo de 'sistema'. En este sentido los diccionarios técnicos pueden contener lemas pertenecientes a diferentes especialidades, es decir, permiten la comunicación entre especialistas de campos diferentes que no constituyen un mismo sistema.

Como se ha mencionado, el objetivo final del presente trabajo es configurar una propuesta de diccionario en el marco teórico de la Teoría Funcional de Lexicografía (TFL), integrado en internet, pedagógico, especializado en Expresión Gráfica en la Ingeniería (EGI) industrial. En nuestro proyecto, los diccionarios especializados son diccionarios especializados por el tema, también llamados diccionarios de dominio especial y utilizan unidades léxicas y gráficas para describir y/o representar conceptos en campos temáticos específicos.

\subsection{El diccionario especializado}

Why dictionaries are used, to what end and by whom...?

(Bergenholtz \& Tarp, 2003: 179)

Los diccionarios especializados se centran en el lenguaje para fines específicos y utilizan, por regla general, elementos léxicos para describir conceptos en campos temáticos específicos que están dirigidos a usuarios con cierto conocimiento previo de dicho campo (Bergenholtz y Tarp, 1995), bien como resultado de un proceso de autoaprendizaje, bien por estar inmersos en un proceso de enseñanza reglada. Son especializados en tanto que transmiten un conocimiento 'experto'.

Bowker (2003) entiende que los diccionarios especializados monolingües se ocupan principalmente del significado (definición e información enciclopédica) y que, por regla general, cuanto más especializado es el diccionario, menos información general contiene porque está dirigido a usuarios expertos en el tema. Considera que los estudiantes de un campo especializado son semiexpertos (situados entre los 'verdaderos expertos' y los no expertos).

La tipología del diccionario especializado debe estar basada en las funciones lexicográficas y no a partir del tipo de datos incluidos. Para Gouws (2007:79) esta tipología, desde un enfoque funcional, debería al menos hacer visibles las funciones previstas de un diccionario, bien como 
un subtítulo en la portada, en la página de título de un diccionario impreso o en la pantalla inicial de un diccionario electrónico.

El diccionario especializado es una herramienta de información que se puede definir con una o varias funciones determinadas para satisfacer tanto las necesidades lingüísticas como conceptuales de un usuario potencial. En este caso se tienen en cuenta las relaciones que existen entre los conceptos de un dominio o área de conocimiento, la categorización del dominio y se contrasta la viabilidad de un diccionario especializado en el marco de la teoría de las funciones lexicográficas.

Los diccionarios especializados ofrecen ayuda para cubrir la necesidad de un 'experto o futuro experto' de fijar, difundir o comunicar el conocimiento especializado (de una forma ordenada, agrupada, procesada, relacionada...) o una demanda de información especializada. En ambos casos, el diccionario es una herramienta que facilita un proceso y que presta una ayuda. La cooperación interdisciplinaria en el proceso de concepción de diccionarios especializados redunda en un incremento de la calidad del diccionario y optimiza, por una parte, la carga semántica y por otra, en nuestro caso, la carga semiótica ofreciendo datos más ajustados al significado en cada entrada del diccionario.

Los diccionarios especializados pueden ser culturalmente dependientes o culturalmente independientes. Es posible que un usuario de un diccionario de EGI tenga distintas referencias culturales o geográficas (p. ej., Los sistemas de primer y tercer diedro, utilizados en Europa y Estados Unidos respectivamente) se tienen en cuenta como un factor a considerar, aunque estas diferencias no existen a nivel conceptual, pero sí a nivel de representación gráfica.

\subsubsection{Diccionarios en línea especializados}

Los ordenadores y el acceso a internet han cambiado significativamente las condiciones para la producción y recepción de diccionarios. Para los editores de diccionarios académicos, internet no solo es una fuente de inspiración, sino que también genera desafíos y retos como: facilitar a los usuarios un acceso más fácil a los diccionarios académicos y desarrollar un enfoque común de la lexicografía electrónica (https://www.elexicography.eu/). 
Los diccionarios en línea especializados son aquellos publicados en diferentes tipos de medios electrónicos, compilados y accesibles en línea, susceptibles de actualizaciones y fundamentalmente caracterizados por ser «a work in progress» en el sentido que expresa Fuertes-Olivera (2013: 335) «... an online dictionary is always in progress, not only because it can be corrected and updated on a regular basis but also because it allows the inclusion of new dictionary data that are based on new lexicographic thinking, that is, the application of a transformative approach to lexicography. »

Respecto a las nociones básicas lexicográficas de un diccionario mencionadas son necesarios algunos matices. En los diccionarios en línea especializados la definición tradicional de lema no se ajusta ni a la estructura, ni a la consulta y posterior presentación de datos del diccionario, p.ej. un lema asociado a un signo no lingüístico y la presentación de estos datos en la pantalla de un dispositivo. Tarp (2008: 110-113) introduce los términos invisible lemma y unmentioned lemma en referencia a los casos en los que el lema no aparece en los datos que se presentan después de una consulta a un diccionario en línea y Agerbo (2019: 213) intuye que el lema es redundante en algunos casos y puede no ser obligatorio en la presentación de datos lexicográficos en este tipo de diccionarios.

Un diccionario especializado en un medio electrónico tiene el efecto de desdibujar el concepto tradicional de macroestructura y la ordenación de elementos en el diccionario ya no es visible. El acceso a las entradas es directo mediante los sistemas de búsqueda previstos o por vínculos con entradas relacionadas, por lo que cambia también la noción de ordenación de las mismas (Bowker, 2003: 158-160).

Entre los estudios históricos que avalan la necesidad de diseñar diccionarios en formato digital con acceso en línea está la revisión de más de 35 trabajos de investigadores sobre el uso de diccionarios electrónicos o digitales que realiza Töpel (2014). El período analizado va desde 1993 hasta 2012 y se centra en la comparación de diccionarios electrónicos y en papel. La conclusión deducida es confirmar que los usuarios utilizan cada vez más los diccionarios electrónicos; el acceso a la información requerida es más fácil y más rápido que en diccionarios impresos; la actitud positiva de los encuestados respecto a los diccionarios electrónicos y que, a menudo, el nivel de satisfacción de los usuarios con el diccionario electrónico es mayor. Los participantes destacan como ventajas de los diccionarios electrónicos la velocidad de acceso, así 
como la accesibilidad y la utilidad. Potencialmente, todos pueden tener una versión personalizada de los datos que muestran y cómo se muestran. La falta de habilidades en el uso de diccionarios electrónicos supone una desventaja cada vez menor. Para los lexicógrafos una ventaja de los diccionarios en línea, y de los diccionarios electrónicos en general, es que son más dinámicos, pero los usuarios esperan que un diccionario en línea resuelva de forma inmediata su consulta (Müller-Spitzer, Koplenig y Töpel, 2011).

Los medios informáticos con los que cuenta el compilador de diccionarios en la actualidad han minimizado las dificultades del pasado y planteado nuevas opciones a los investigadores. Por ejemplo, combinar aproximaciones semasiológicas y onomasiológicas (Bowker, 2003: 155) es posible en un diccionario especializado electrónico. Los nuevos sistemas informáticos de representación de diccionarios permiten tratar onomasiológicamente el léxico con un modelo de registro y almacenamiento de conceptos y elementos léxicos (y elementos gráficos) facilitándose así el acceso del usuario final. La noción de onomasiología electrónica de Van Sterkenburg (2003: 137) hace referencia al carácter dinámico de los diccionarios en los que al realizar una búsqueda mediante una palabra clave el sistema devuelve todos los registros en los que aparece esta palabra clave, incluidas las definiciones, los ejemplos etc., esto puede producir sobreinformación o información muy útil. Esta forma de utilizar los conceptos para encontrar las palabras clave que tienen relación con el concepto expresado en la definición, permite utilizar el diccionario electrónico como un diccionario onomasiológico.

Un diccionario electrónico en línea permite potenciar y aprovechar la posibilidad de organizar dinámicamente subconjuntos de unidades léxicas, de forma que el usuario las puede seleccionar por marcas sin que exista un orden alfabético de las unidades, aunque pueden incluir uno o varios índices. La presentación de datos se simplifica si inicialmente se ofrece una ruta lógica de acceso y a continuación, se ofrece la información completa en casos en que exista ambigüedad, pero con la posibilidad de seleccionar intuitivamente u obedeciendo a criterios del usuario. También es posible elegir entre las distintas opciones que ofrece la descripción y representación de un concepto, lo que en lexicografía general y especializada se conoce como equivalencia. En nuestro caso la equivalencia se produce entre la definición o descripción verbal y la figura de trazado gráfico y el símbolo y la 'figura de análisis'. La posibilidad de incluir 
Por último, se reseña que el presente y futuro de los diccionarios en línea está ligado al uso de ordenadores y de dispositivos móviles. La aparición de sistemas operativos más potentes para dispositivos móviles, la velocidad de acceso a internet y los navegadores web (p.ej. opera web mobile) han permitido presentar el mismo contenido de una web sin realizar variaciones técnicas y manteniendo el estándar en maquetación. En estos dispositivos se instalan aplicaciones móviles APP (application) que permiten interactuar con contenidos alojados en un servidor web (https://www.fundeu.es/).

Con lo anteriormente expuesto se entiende que nuestra propuesta solo se ajusta parcialmente a la definición de diccionario semasiológico, sí en su esencia, puesto que procede del significante al significado, siendo un significante especializado. Ciertas unidades son alfabetizables, pero las unidades gráficas no lo son por sí mismas, por lo que es necesario un orden onomasiológico por áreas de significado en lugar de un orden alfabético.

Se decide que el formato de nuestra propuesta sea electrónico (digital) con conexión activa en red, con disponibilidad simultánea y generalizada, que permita ofrecer diferentes rutas de acceso y que permita adaptar la presentación de datos, se define un diccionario en línea.

\subsubsection{La estructura de los artículos lexicográficos en los diccionarios especializados}

Los antecedentes de la práctica lexicográfica constituyen un punto de referencia para nuestra propuesta de diccionario. En este apartado se trata de exponer brevemente diferentes estructuras de artículos lexicográficos creadas con el objetivo de organizar y presentar los datos ante una eventual consulta puntual. Se eligen tres ejemplos de diccionarios representativos de distintas propuestas independientes o integradas en plataformas, que son el resultado de diferentes trabajos de investigación al amparo de la teoría funcional y de la lingüística del corpus, en ambos casos con un contenido especializado. Nos interesa el punto de vista de la tarea del lexicógrafo en cuanto a la definición de la ficha de registro para la base de datos de los artículos del diccionario de acceso a los datos. Los diccionarios tomados como referencia son:

1. DICTER (1999-2012) con actualizaciones posteriores.

2. Diccionarios Valladolid UVa (2017-2020).

3. Physical training lexicographical tools, Agerbo Pedersen, (2019). 


\subsubsection{DICTER}

Es un diccionario en línea que se enmarca en el proyecto «El diccionario de la Ciencia y de la Técnica del Renacimiento (DICTER)» bajo la dirección de Mancho Duque y en la que han contribuido numerosos investigadores. Se cita, una pequeña parte de este proyecto, a los redactores Sánchez Martín (2008, 2009) (Metrología, Geometría) y Molina Sangüesa (2017, 2018) (Matemáticas-aritmética y álgebra) y sus aportaciones a la estructura de los artículos campos que relacionados con la geometría y la metrología. El corpus textual de DICTER se conforma a partir de 74 textos de la ciencia y de la técnica del siglo XVI y primer cuarto del XVII. Se accede a los fragmentos textuales en <http://dicter.eusal.es/?idContent=elenco_obras> (Mancho Duque, 2014: 337). Los ejes del proyecto son «la elaboración de glosarios parciales en áreas temáticas concretas» y «el análisis y estudio de las características específicas del léxico especializado».

La estructura de los artículos de los lemas, acepciones y subentradas tiene el siguiente contenido y orden (según el caso):

- Lema;

- Variantes;

- Etimología;

- Familia léxica;

- № de acepción;

- Categoría gramatical;

- Marcas gramaticales, si las hubiera;

- 1a datación del corpus: Autor, Título de la obra, año. Marcación diatécnica, si la hubiera;

- Marcación diatópica, si la hubiera;

- Definición, con las fuentes lexicográficas, si las hubiera;

- Sinónimos, si hubiera;

- Antónimos, si hubiera;

- Ejemplos, entre paréntesis: Autor, Título de la obra, año, foliación o paginación numeradas como en el texto (romana o arábiga);

- Imagen, si hubiera;

- Información referente a la imagen, si hubiera;

- Información enciclopédica, si hubiera y Remisiones de unidades pluriverbales al lema en el que se desarrollan, si las hubiera (ibid., p. 337-338).

La ordenación de los elementos que componen el articulo lexicográfico en el inventario de DICTER (Molina Sangüesa, 2017: 54-57) se presenta en cuatro bloques de acceso diferenciado 
mediante 'pestañas' independientes: Forma e historia (figura 3.1), Clasificación semántica (figura 3.2), Ejemplos e información (figura 3.3), e Imagen (figura 3.4). Estas opciones incluyen información sobre: lema; variantes gráficas; etimología y primera documentación; la categoría gramatical, el género y el numero; la marcación temática o diatécnica; la definición; acepciones; un máximo de tres ejemplos; las relaciones semánticas y genéticas (sinonimia, antonimia, familias léxicas); información enciclopédica sobre el concepto e llustraciones.

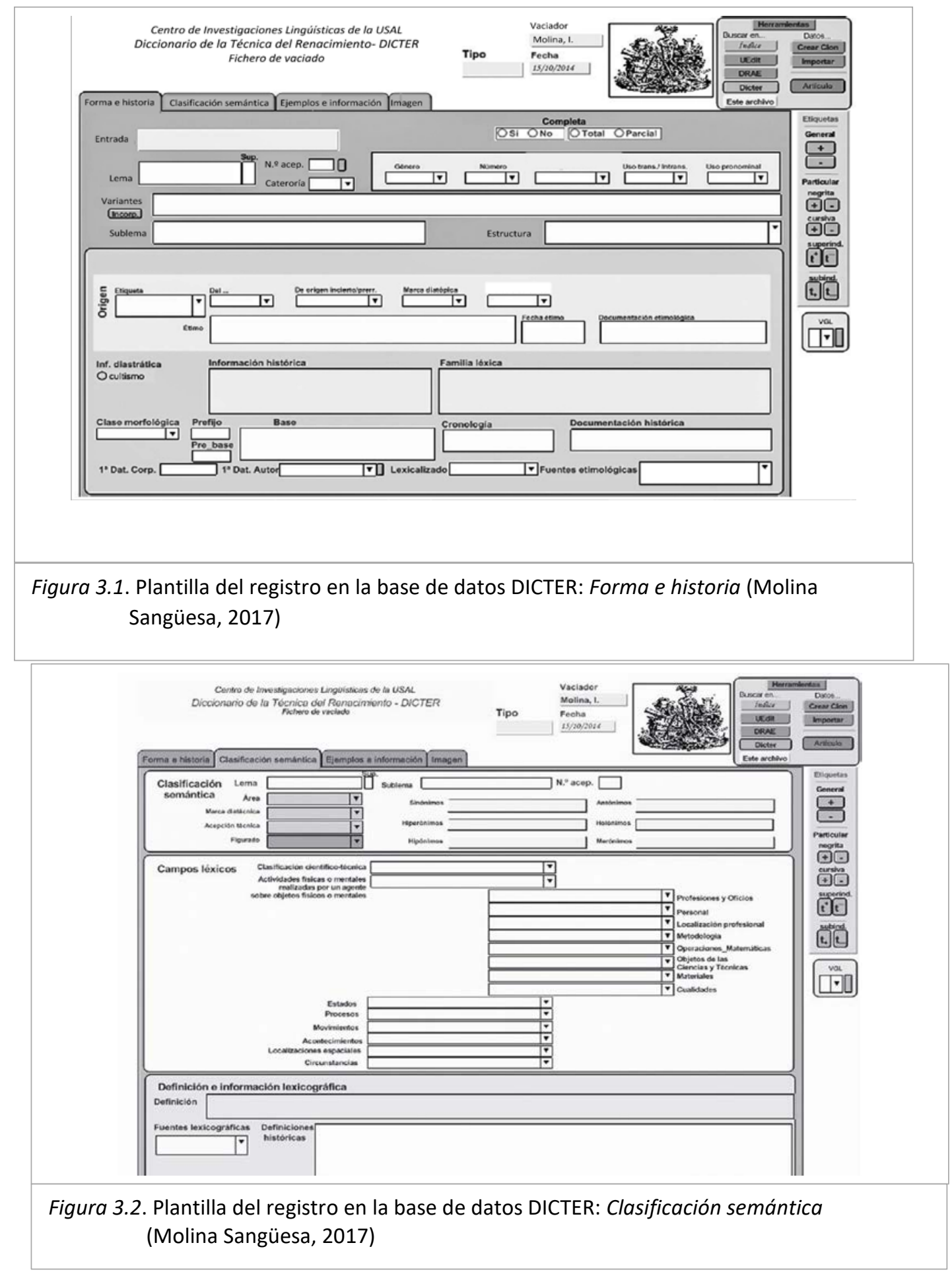




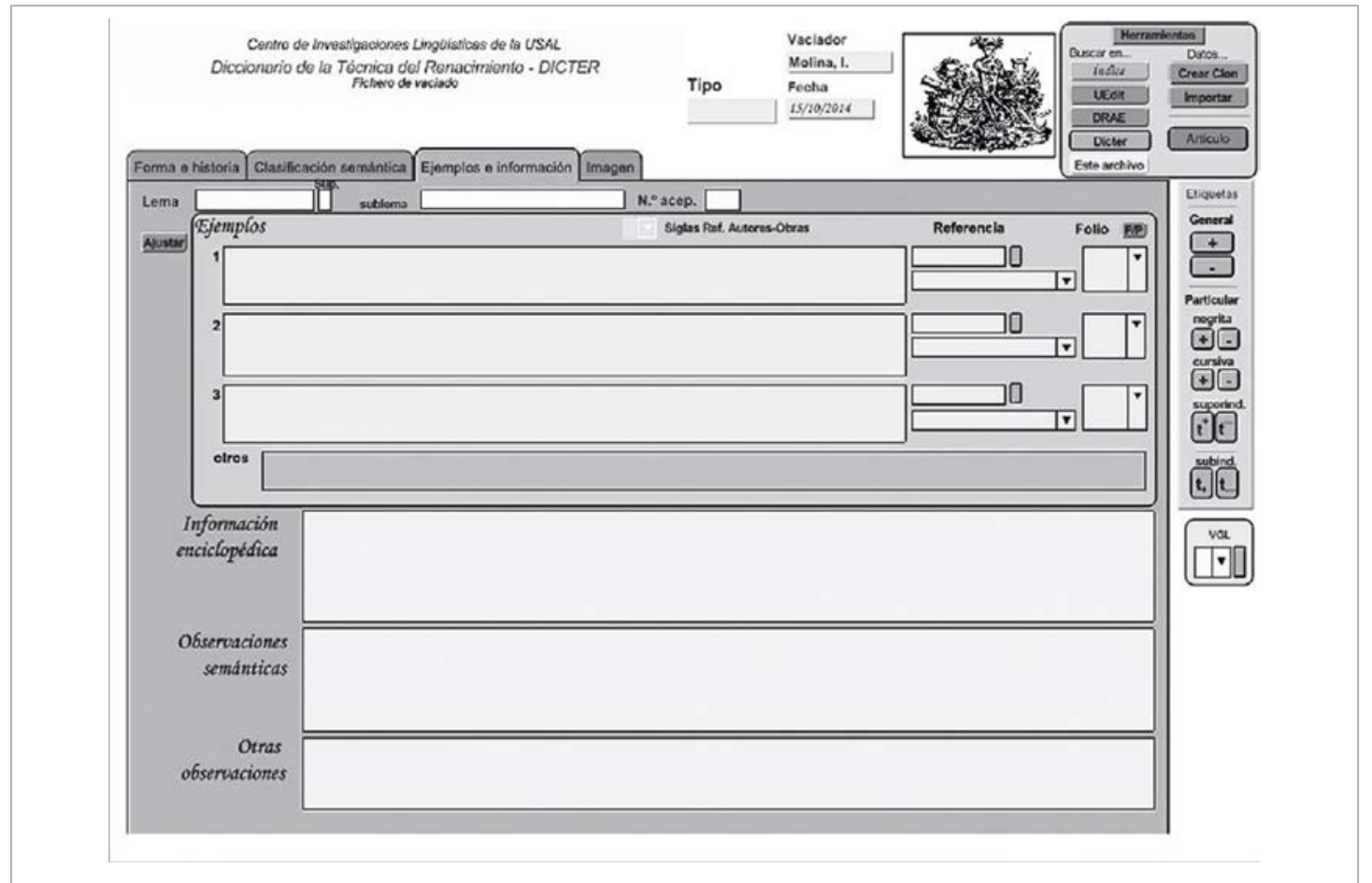

Figura 3.3. Plantilla del registro en la base de datos DICTER: Ejemplos e información (Molina Sangüesa, 2017)

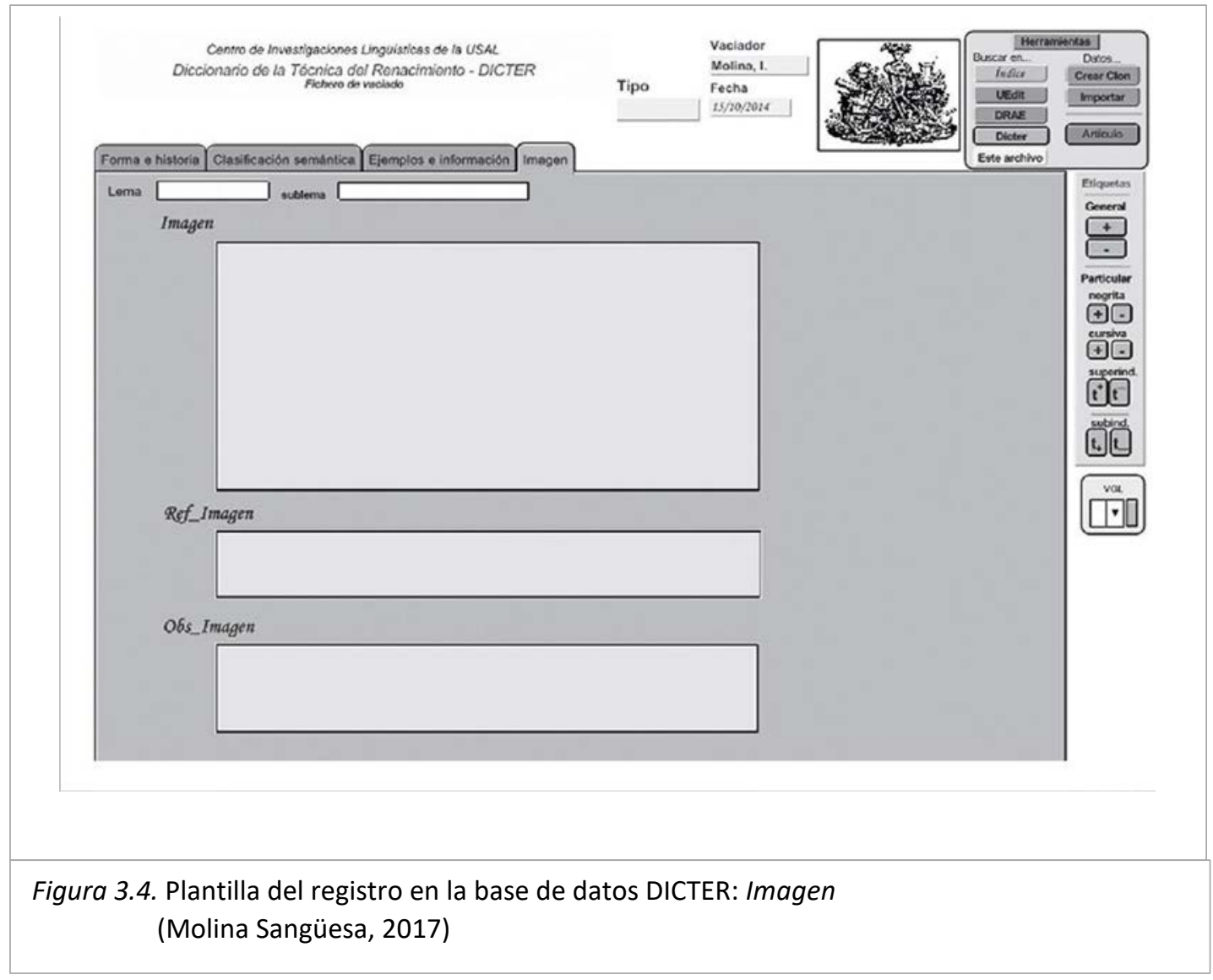


En cuanto al proceso de búsqueda DICTER permite un inicio de búsqueda:

- por palabra, exacta o por aproximación;

- búsqueda avanzada y búsqueda semántica (figura 3.5);

- Acceso a imágenes por orden alfabético;

- Acceso a imágenes por áreas de especialidad p.ej. geometría (figura 3.6).

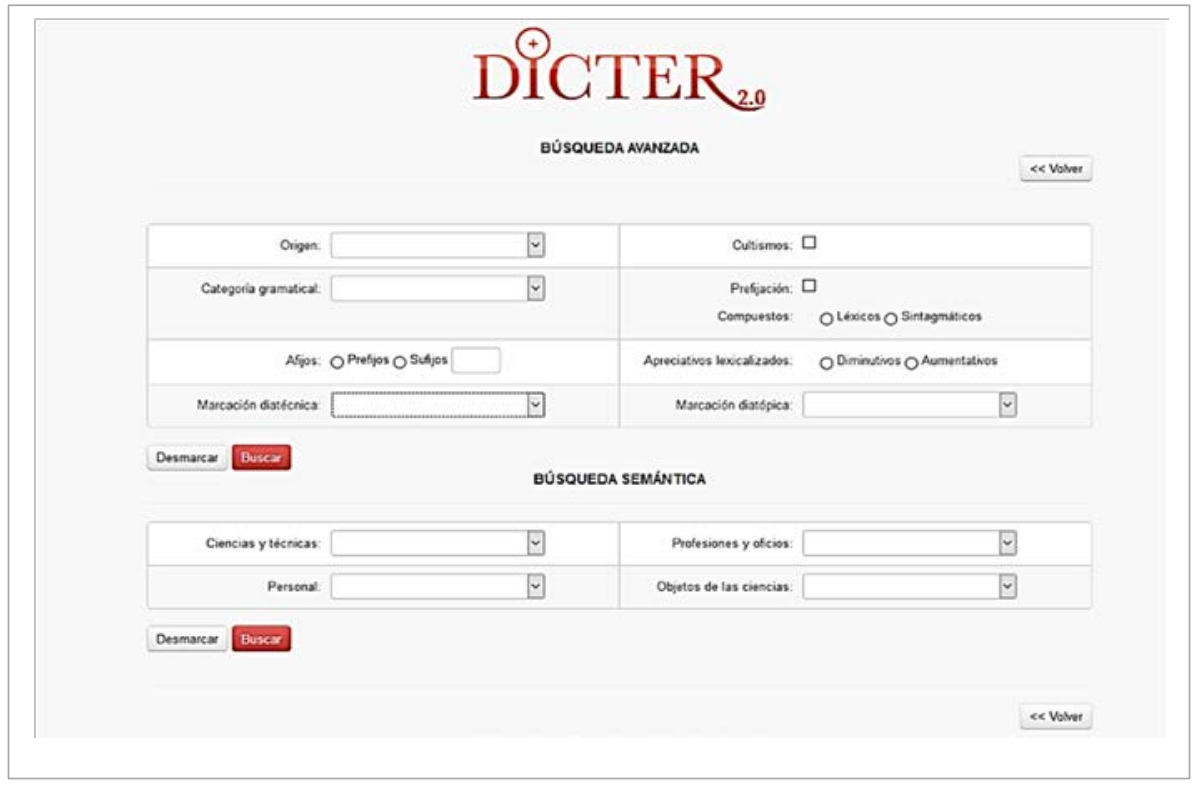

Figura 3.5. Búsqueda avanzada y búsqueda semántica. DICTER 2.0

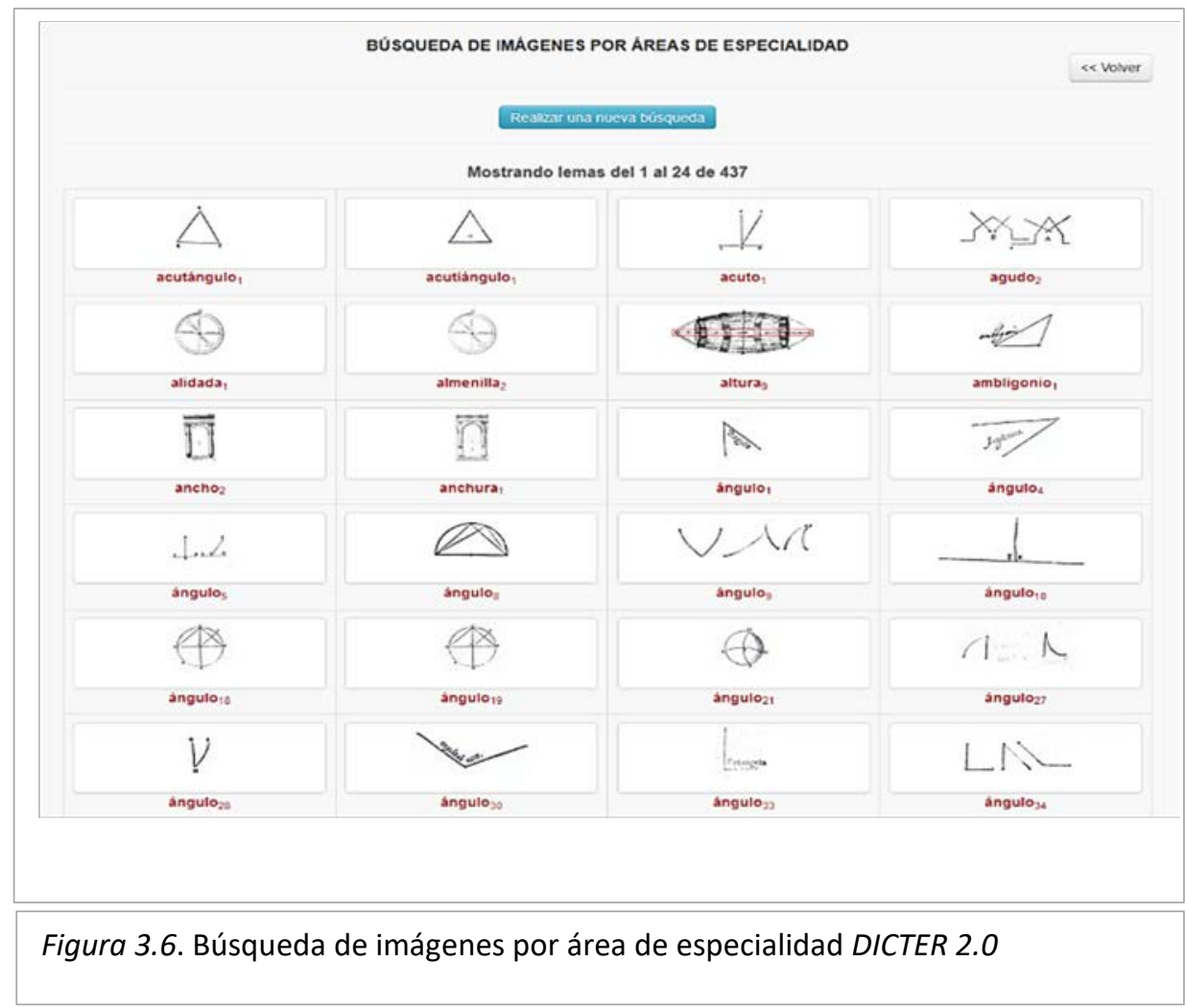




\subsubsection{Diccionarios Valladolid UVa (2017-2020)}

Es un proyecto lexicográfico en línea en el marco de la teoría funcional que crea una base de datos lexicográfica bilingüe que sustenta dos productos destinados a usuarios nativos de español: un diccionario en línea inglés-español-inglés (que se incluiría en el portal Diccionarios Valladolid-Uva), y un asistente de escritura español-inglés (Write Assistant (2019)). En la actualidad Write Assistant es una herramienta que asiste en danés, alemán, inglés y español.

Utiliza el concepto de corpus lexicográfico (Fuertes-Olivera, 2012: 51) como repositorio de datos, como base empírica inicial del corpus lexicográfico y minitextos obtenidos mediante búsquedas con Google (Tarp y Fuertes-Olivera, 2016; Fuertes-Olivera, Niño Amo y Sastre Ruano, 2019: 88). Las funciones relevantes para este diccionario son la asistencia en la recepción de textos en inglés y en la traducción inglés-español. Las funciones que comparte con Write Assistant son la asistencia a los usuarios españoles a escribir textos en inglés y a traducir del español al inglés (Fuertes-Olivera, Tarp y Sepstrup, 2018: 158). Estas funciones lexicográficas determinan las categorías de datos requeridas de la base de datos y el servicio personalizado en la presentación al usuario determina la provisión de la cantidad exacta y el tipo de datos para satisfacer las necesidades del usuario en cada consulta concreta (Fuertes-Olivera y Tarp, 2014: 64).

La metodología del proyecto permite una asistencia con 'recorridos' en sentidos inversos tomando como punto de partida la lengua destino en lugar de la lengua nativa del usuario. Comienza con una selección y descripción de lema en inglés, automáticamente se realiza una inversión simultánea y estos equivalentes en español, de uno o más lemas en inglés, se convierten en nuevos lemas con sus equivalentes en inglés con la ventaja de que han utilizado las definiciones breves en español para discriminar el significado (Fuertes-Olivera, Tarp y Sepstrup, 2018: 160). Esta metodología implica que el usuario nativo de español debe tener ciertos conocimientos de la lengua inglesa.

Las plantillas utilizadas en la primera fase del proyecto contienen el trabajo de la sección inglés-español del proyecto y está dividida en cuatro pasos. En el primer paso, el editor recibe los archivos de registro y decide los lemas más buscados a incluir. 
En el segundo paso se completan los datos gramaticales básicos en todas las situaciones y registros y los datos administrativos en la plantilla 'Lemma' (figura 3.7). En esta figura además aparecen desplegadas a la izquierda las opciones creadas después de la evaluación para encontrar el mejor equivalente en inglés posible para el lema español que corresponden a una fase posterior.

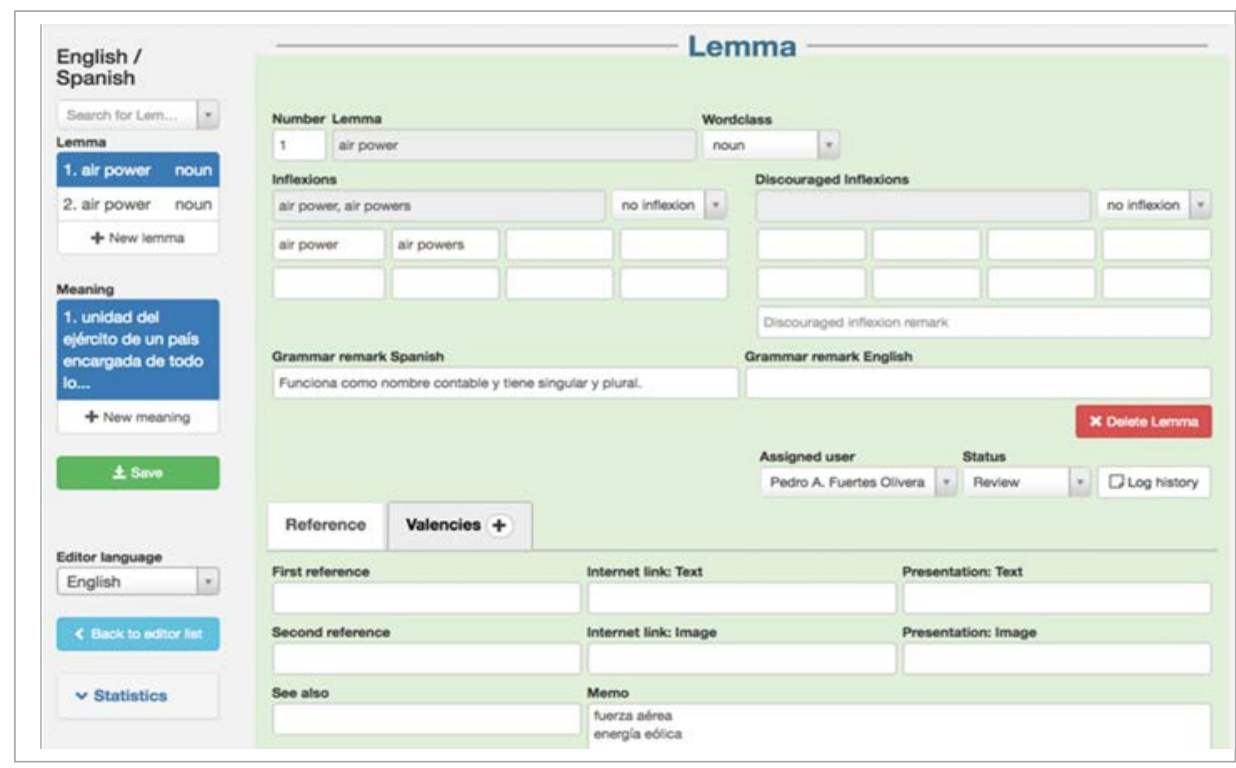

Figura 3.7. Datos gramaticales básicos agrupados en la sección lema (Diccionarios Valladolid-Uva)

En el tercer paso se completan los datos en la plantilla 'Meaning' (figura 3.8), el número asignado agrupa y vincula los datos de esta plantilla para cada significado del mismo lema.

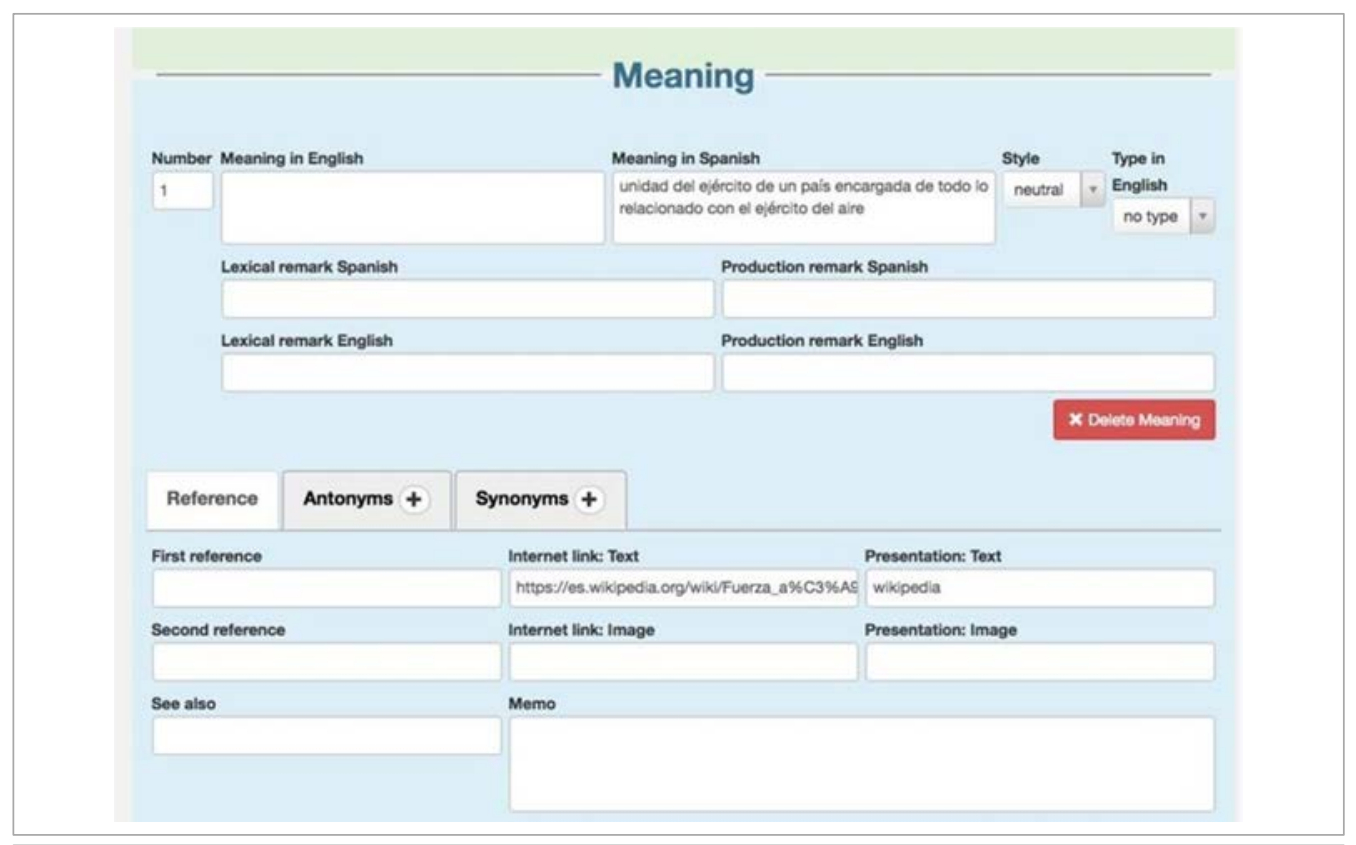

Figura 3.8. Datos de la sección significado (Diccionarios Valladolid-Uva) 
En el cuarto paso se completan los datos en la plantilla 'Translations' (figura 3.9) con campos relacionados con el equivalente en español y el significado y, la función del lema y su equivalente en contexto. Se incluye una opción para crear un lema (a utilizar en la fase 3) y acceso a registro de colocaciones, ejemplos y formación para contextualizar el significado del lema en diferentes situaciones de traducción.

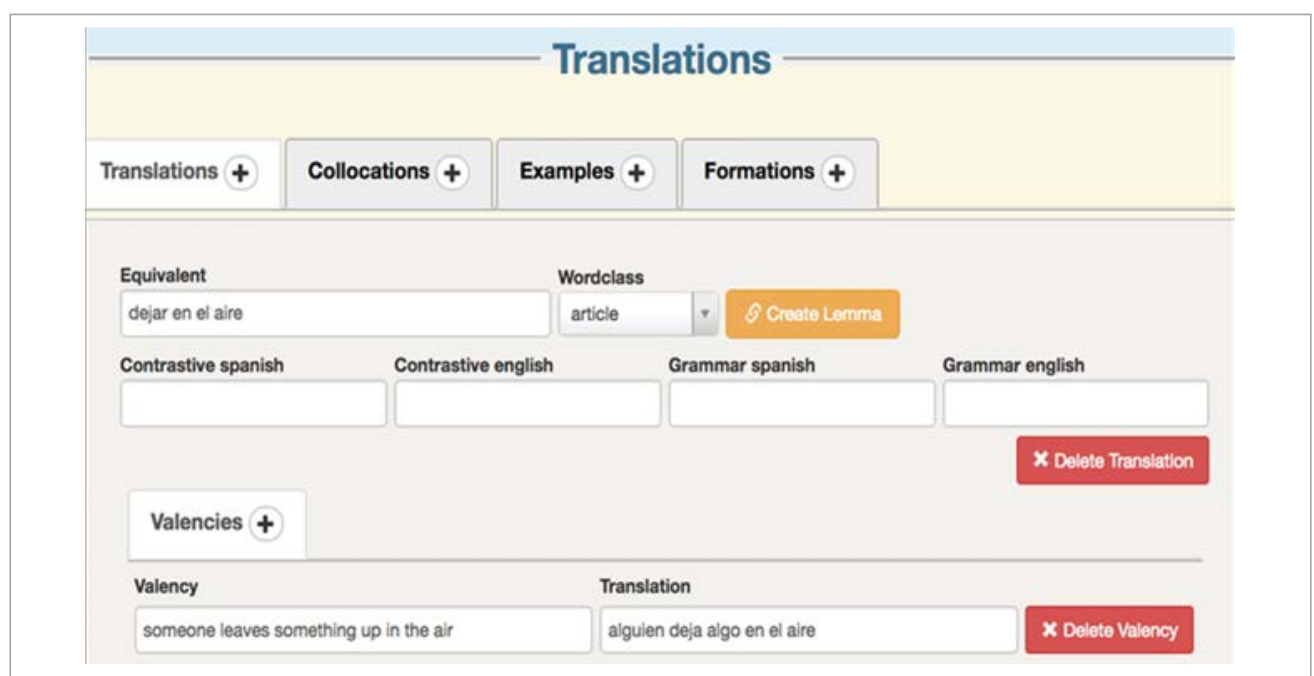

Figura 3.9. Datos de la sección traducción y registros para contextualizar el significado (Diccionarios Valladolid-Uva)

En la fase dos se revisan las entradas del diccionario de la fase uno. En la fase tres el editor verifica el equivalente en español compilado en la fase 1 y puede decidir convertir el equivalente en un lema en español (opción crear lema) o dejarlo solo como equivalente. Si acepta el equivalente como lema, mediante la opción crear lema, esta opción pasa a abrir lema y se accede a la plantilla inicial de lema del Dictionary Writing System correspondiente a españolinglés. Acceso p. ej. vinkel (ángulo) en lemma.com (figura 3.10)

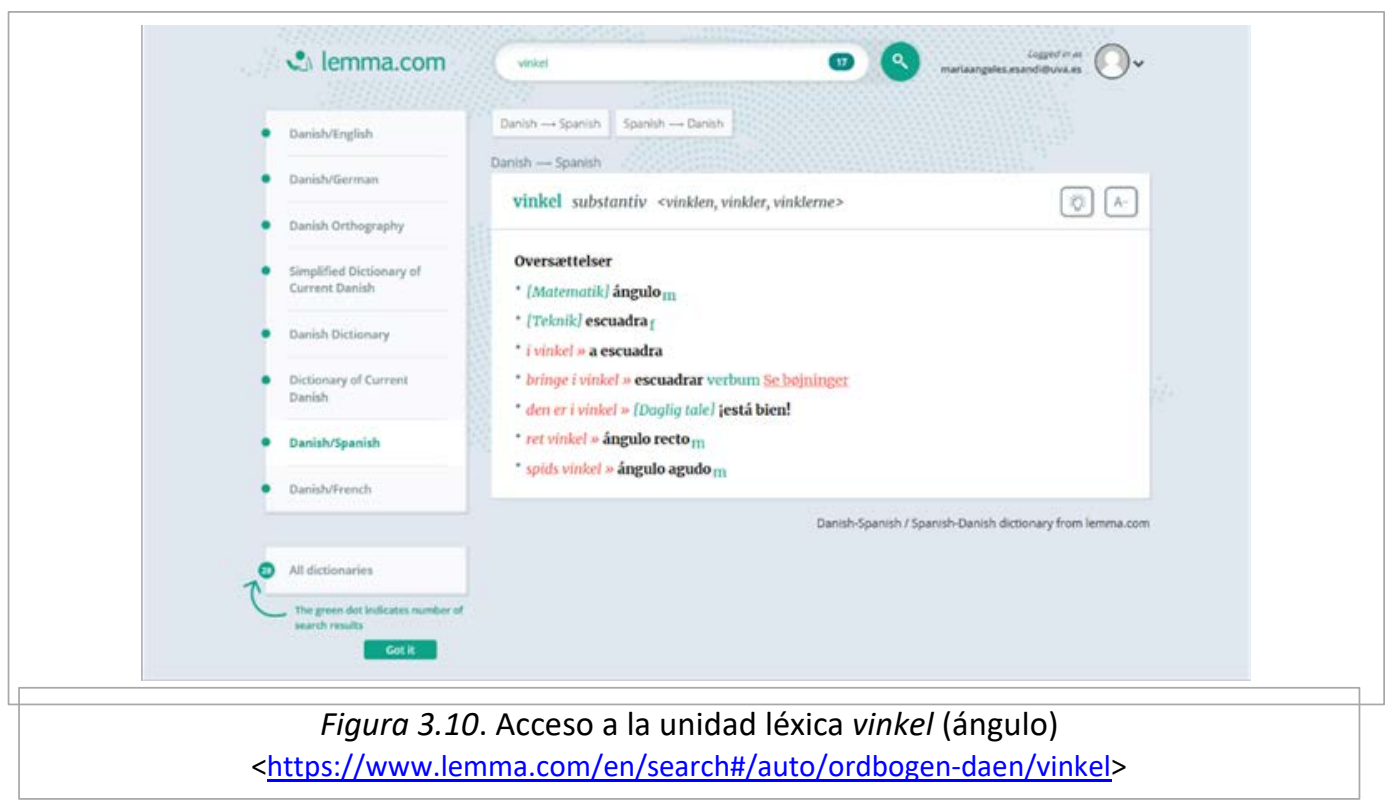




\subsubsection{Physical training lexicographical tools}

La investigación y las conclusiones de Agerbo sobre la función operativa de la teoría funcional conducen a una nueva definición (provisional) del concepto lexicográfico de lema denominándolo acción asociado a palabras y también a signos no lingüísticos. Este nuevo punto de vista tiene diferentes consecuencias y cambia la tipología de las funciones de diccionario: comprender, actuar (comunicativa y no comunicativa) y cognitiva (Agerbo, 2019: 225). Desde el punto de vista de la tarea del lexicógrafo, articula la información de las plantillas para la base de datos alrededor de un núcleo y una o más acciones que son representaciones de la misma necesidad operativa.

Un artículo del diccionario contiene una única acción (independientemente de que esté asociado a varias) y las búsquedas realizadas con acciones sinónimas pueden conducir a entradas similares, es decir, pueden conducir a los mismos datos relevantes para el usuario. Cada plantilla de registro de la base de datos tiene la estructura de la figura 3.11:

\begin{tabular}{|l|l|}
\hline \multicolumn{2}{|c|}{ Data base card } \\
\hline Nucleus & $\ldots$ \\
\hline Action(s) & $\ldots$ \\
\cline { 2 - 2 } & $\ldots$ \\
\hline Instruction & $\ldots$ \\
\hline Level of difficulty & $\ldots$ \\
\hline Equipment & $\ldots$ \\
\hline Etc. & $\ldots$ \\
\hline
\end{tabular}

Figura 3.11. Plantilla de registro. Physical training lexicographical tools

«Nucleus: an abstraction in the form of a word to which one or more actions are connected Action: an abstraction that represents the operative need that the user wants to satisfy and which functions as the name of the article that contains the relevant data» (Agerbo, 2019:223)

La figura 3.12 muestra cinco 'cadenas de búsqueda' diferentes (zapatilla; zapatilla de correr; limpiar; zapatilla de correr y limpiar; ¿Cómo limpio mis zapatillas de correr?) como ejemplo de los diferentes resultados que se obtienen en estas búsquedas (traducción nuestra). 
"Search string: what the user types in the search field in the tool, i.e. word(s) and/or image(s), perhaps combined with Boolean operators» (Agerbo, 2019:223).

El resultado del proyecto de investigación de Agerbo Pedersen (2019) consta de nueve herramientas lexicográficas independientes que se extraen de una misma base de datos.

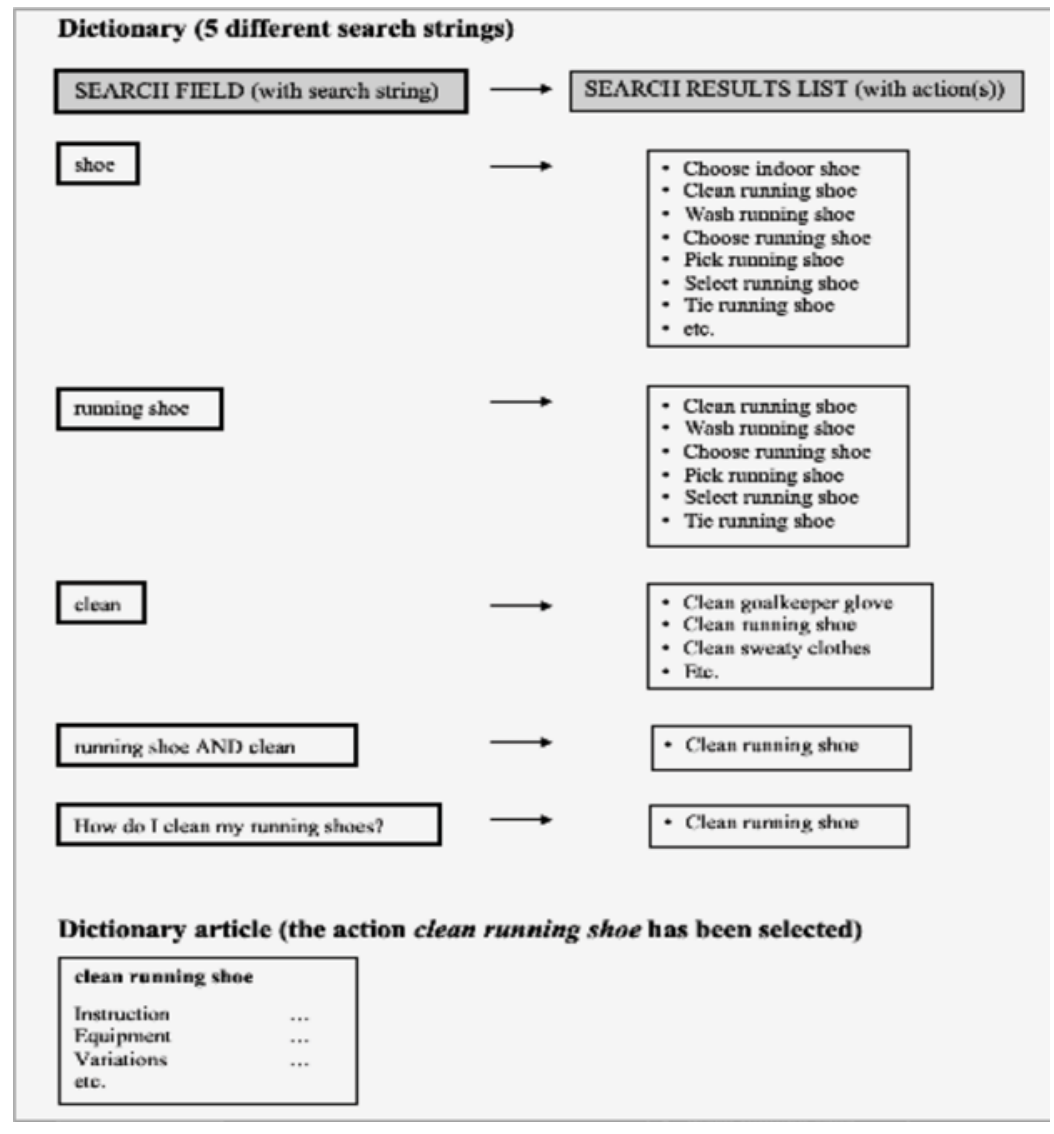

Figura 3.12. Opciones da la cadena de búsqueda con Shoe. Physical training lexicographical tools

\subsubsection{Observaciones para la estructura del diccionario de EGI}

La propuesta de estructura de datos del diccionario de EGI «debe crearse y organizarse con el fin de dotarle de valor lexicográfico» (Fuertes-Olivera, Niño Amo y Sastre Ruano, 2019:82) para satisfacer las necesidades de información de un usuario que no son necesidades genéricas, sino concretas. Su estructura de datos debe estar sujeta o condicionada a la tecnología disponible que permita y facilite el acceso y la presentación de los recursos necesarios con interés lexicográfico para la consecución de nuestro objetivo, permitir que un usuario en un entorno académico o profesional recabe la información que precisa para adquirir conocimiento técnico o resolver trazados geométricos o interpretar simbología técnica. 
Al igual que Molina Sangüesa (2017: 63) se considera necesaria la información complementaria y el aporte de ilustraciones porque «las ilustraciones sirven, en algunos casos, de apoyo a la óptima comprensión de la información lexicográfica» esto implica acoger elementos no lingüísticos como apoyo a la información lexicográfica en un contexto de lenguas especializadas.

\subsection{La elaboración de diccionarios}

Los métodos utilizados en investigación lexicográfica y diccionarios son: métodos lingüísticos para la recopilación de datos lingüísticos; los métodos que provienen de las ciencias sociales (como análisis de datos cuantitativos, métodos empíricos sistemáticos, estudio de casos); los métodos filológicos enfocados hacia la competencia personal del lenguaje y, los métodos de comprensión e interpretación que se adaptan a los textos y a todos los datos empíricos (Schierholz, 2015: 327-328). La pluralidad de métodos de investigación es una de las características de la investigación lexicográfica.

Wiegand (1998, citado en ibid., p.328) distingue las siguientes fases del proceso lexicográfico de creación de un diccionario: preparación; adquisición; tratamiento; evaluación del material y de los datos; preparación del proceso de impresión, y la fase de desarrollo adicional, como el mantenimiento, reprocesado y postproducción. Las decisiones que se toman en las distintas fases condicionan, a su vez, las decisiones sobre los métodos a utilizar. De las fases y los métodos que propone (ibid., p.328-336), cabe centrarse en las fases de aplicación a un diccionario en línea, sin embargo, es interesante el detalle de los métodos a utilizar en las distintas fases teniendo en cuenta que unos métodos están orientados o son de aplicación en teorías lexicográficas como la Teoría Funcional. Las decisiones a tomar en las distintas fases previo a la elección de uno o varios métodos son:

- en la fase de preparación se ha de valorar el coste en términos económicos y de volumen de trabajo; la oportunidad de mercado; el tipo de diccionario y sus funciones;

- en la fase de adquisición de material el trabajo lexicográfico para recoger datos se basa en la experiencia, el conocimiento y las rutinas de búsqueda. Estos procesos proporcionan las fuentes para la construcción de la base del diccionario y la 
recopilación de estos datos debe realizarse de forma sistemática para que esta base sea fiable;

- en la fase de tratamiento del material la extracción o selección de candidatos a lemma en el caso de diccionarios especializados procede de textos especializados y de conocimiento experto;

- en la fase de evaluación de material y de los datos de los artículos del diccionario se redactan sobre la base del material recopilado y preparado (cf. Wiegand 1998). La tarea principal durante la elaboración de artículos de diccionario es la redacción de especificaciones individuales de diferentes tipos de elementos;

- en la fase de preparación de la publicación el lexicógrafo tiene que hacer la revisión editorial de todos los artículos. En un diccionario electrónico también se revisan los enlaces implementados, los elementos multimedia etc.

- en la fase de actualización, mantenimiento, reprocesado y postproducción de los diccionarios en línea deben tenerse en cuenta los siguientes aspectos relacionados con los métodos: los criterios de actualización para la inspección periódica de los artículos publicados; si se actualizará el corpus (dado el caso) y con qué criterios; si los usuarios del diccionario tienen la oportunidad de retroalimentar directa, indirecta o adicionalmente, y si almacenamiento de los datos se realizará de forma 'sostenible', es decir con un software independiente.

Hay tres aspectos que condicionan los métodos a utilizar en cada una de las fases: la utilización del ordenador, el tipo de diccionario y la función del diccionario. La selección del lema, la elección y la formulación de elementos, la relevancia de los datos, la preparación y el uso de los elementos lexicográficos, están dirigidos por las funciones del diccionario que, a su vez, están orientadas a las necesidades del grupo de usuarios previsto (ibid., p. 337).

\subsection{El usuario del diccionario}

Desde el punto de vista del trabajo lexicográfico en un proyecto de diseño de un diccionario la denominada 'perspectiva del usuario' por Hartmann (2001) en la investigación de diccionarios implica el uso de técnicas que permiten la identificación de las necesidades y las habilidades de 
referencia de los usuarios dando lugar a diferentes perfiles de uso, que permiten optimizar el diseño de diccionarios. Esto implica el análisis de las necesidades 'An analysis of user's needs should precede dictionary design', de las habilidades lexicográficas del usuario y la consideración de que diferentes usuarios tienen distintas razones para realizar una consulta 'Different user groups have different needs' (Hartmann 1989: 103) que un diccionario debe y puede atender y satisfacer. El usuario es una variable esencial en el proceso de diseño de una obra lexicográfica o de un tipo de obra de referencia.

\subsubsection{Concepto de usuario}

La demanda de diccionarios pensados para el usuario es una inquietud planteada desde siempre por los lexicógrafos. Samuel Johnson, en 1747, anticipó los problemas que preocupan a los lexicógrafos de hoy en día:

The value of a work must be estimated by its use: It is not enough that a dictionary delights the critic, unless at the same time it instructs the learner; as it is to little purpose, that an engine amuses the philosopher by the subtilty of its mechanism, if it requires so much knowledge in its application, as to be of no advantage to the common workman. (The Plan of a Dictionary of the English Language, Samuel Johnson 1747: 5).

El interés del trabajo e investigación lexicográfica centrado en el usuario y sus necesidades, pudo tener su origen en "Conference on Lexicography Indiana University 1960". Los conferenciantes expresan un acuerdo muy general en varios puntos: "I (1) Dictionaries should be designed with a special set of users in mind and for their specific needs [...] (2) All entries should be as accessible as possible" (Householder 1967: 279). "III (4) Both Barnhart and Haas called attention to the importance of having all technical vocabulary checked by specialists" (Householder 1967: 281).

Comparten este interés distintas tradiciones lexicográficas, por citar las aportaciones que pueden ser interesantes para este trabajo: Householder and Saporta (en Householder, 1967); Hartmann (1989); Bergenholtz y Tarp (2003); Atkins y Rundell (2008) y Fuertes-Olivera (2011). En la lexicografía de tradición anglosajona basada en la lingüística del corpus, los lexicógrafos analizan datos empíricos del uso de la lengua para determinar 'lo que es probable que sea 
relevante para los usuarios del diccionario' (Rundell, 2012: 60), y muestran con ejemplos el comportamiento de una o más lenguas a partir de colecciones de textos compilados con criterios lingüísticos.

La investigación empírica del usuario de diccionario señala distintas propuestas que Hartmann recoge en seis perspectivas para abordar el uso del diccionario diccionarios o seis métodos de obtener el perfil del usuario: lexicografía pedagógica, tipos de diccionario, perspectiva sociológica, análisis de necesidades de referencia, estrategias o habilidades necesarias para una consulta eficiente e instrucción dirigida en habilidades de referencia (Hartmann 2001: 80-83).

Al referirnos al usuario se debe diferenciar 'addressee', Gelpi (2007: 5) y 'target-user' de 'user' (Hartmann, 2002). Los dos primeros se refieren al mismo grupo o individuo potencial al (a los) que el que el autor y/o el editor destina el diccionario, sería el usuario ideal del diccionario. El tercero, 'user', se refiere al individuo que realiza una consulta concreta. La tecnología utilizada hoy en día para la presentación y el acceso a los datos en un diccionario permite tanto la evolución de un objetivo como la satisfacción de las necesidades de grandes tipos de usuarios, grupos pequeños e individuos, teniendo en cuenta que las razones para el uso del diccionario surgen en el contexto inmediato del uso del diccionario y que es el usuario el que tiene que aportar ciertas habilidades para extraer la información requerida (Hartmann, 2001: 80-81).

El lexicógrafo planifica y toma las decisiones oportunas con un potencial usuario ideal en mente. Esto implica conocer de antemano quien lo va a utilizar y cuál es su contexto inmediato (Hartmann, 2002).

Tarp (2009: 293) en la investigación sobre el usuario avanza hacia la multidisciplinariedad, formula objetivos claros e incorpora los métodos científicos utilizados por las ciencias sociales modernas. Finalmente, la investigación se basa en una teoría avanzada de lexicografía capaz de establecer categorías científicas con respecto a las necesidades del usuario, tipología del usuario, situaciones del usuario, situaciones de uso, rutas de acceso, etc., que se deben considerar al planificar y realizar proyectos de investigación. Fuertes-Olivera y Tarp (2014) proponen una metodología alternativa a la de la Lingüística de corpus para extraer conocimiento especializado: la estrecha colaboración con el experto. 
Parece razonable, la consideración de un usuario con habilidades lexicográficas y extralexicográficas, no sólo condicionado por el formato y la tecnología utilizada sino, como se expone más adelante, también por el contenido.

Online dictionaries are the tools used by people who are active participants in information retrieval. [...] Online dictionaries are a response to the needs of users to retrieve information by means of downloading. [...] we (lexicographers) produce innovative reference tools including dictionaries (Gouws, 2011:28-29).

El usuario es un individuo motivado con habilidades y conocimiento necesarios para hacer un buen uso funcional del diccionario. El objetivo se alcanza si el usuario es capaz de interpretar los datos presentados, recabar información de estos, procesar esta información y demostrar que ha incrementado su conocimiento de tal forma que es capaz de colmar la necesidad y/o resolver el problema de forma satisfactoria.

Los diccionarios no contienen información como tal, sino datos lexicográficos seleccionados y preparados con cierta intención a partir de los cuales el usuario puede recuperar la información necesaria a través de un proceso mental para el que requiere habilidades lingüísticas (en términos del lenguaje) y conocimiento enciclopédico del tema en cuestión (Wiegand, 2002; Tarp, 2007). Estas variables intervienen y conforman la propuesta de diccionario objeto de nuestro proyecto.

Una de las principales hipótesis de nuestro estudio es demostrar que el marco teórico más adecuado para determinar las variables usuario, situación, necesidad, consulta y actuación es el marco teórico de las funciones lexicográficas.

\subsubsection{La teoría funcional de la lexicografía en relación con las necesidades del usuario}

La clasificación tradicional de diccionarios basada en criterios de la lingüística aplicada no es adecuada en Lexicografía (Fuertes-Olivera y Tarp, 2011: 145); Tarp (2008, 2009); Andersen y Fuertes-Olivera (2009) abogan por una clasificación lexicográfica que incluya información sobre la orientación general del diccionario y que aplique criterios lexicográficamente relevantes como las funciones del diccionario, los usuarios de diccionario, las necesidades específicas del usuario en situaciones específicas, la presentación de datos, la accesibilidad de los datos, etc. Estos son 
parámetros lexicográficos que se articulan para la construcción de un diccionario pedagógico especializado en el marco de la TFL.

La teoría funcional de la lexicografía es una teoría orientada al usuario de la obra lexicográfica, basándose en las necesidades que se le presentan en situaciones extralexicográficas específicas (Bergenholtz y Nielsen, 2006: 281). Aplica una metodología que proporciona un reconocimiento de las necesidades reales de los usuarios y permite determinar qué datos se incluirán en un diccionario (Fuertes-Olivera y Tarp, 2014: 46). Así que, previamente a determinar las necesidades hay que conocer las situaciones de uso; estas situaciones, identificadas en la TFL, en las que se encuentra el usuario pueden ser: comunicativas, cognitivas, operativas e interpretativas.

El concepto "user situation" de Wiegand, referido principalmente a la situación durante el acto de consulta se amplía en este marco teórico, con aquellas situaciones en las que, por alguna razón, el usuario siente una necesidad (de comunicación, de adquisición de conocimiento...) que puede ser satisfecha mediante la consulta a una obra de referencia lexicográfica (Bergenholtz y Tarp, 2003: 191). Esto implica considerar, por una parte, el proceso intralexicográfico de consulta y por otra parte el proceso extralexicográfico que ocurre inmediatamente antes y después de la consulta (Fuertes-Olivera y Tarp, 2014: 87).

En las situaciones que la TFL denomina extralexicográficas y es a partir de estas situaciones que se determinan, de entre las características de los usuarios potenciales, las 'características relevantes', es decir, las que 'precisen soluciones lexicográficas diferenciadas' (Fuertes-Olivera y Tarp, 2008: 80).

La concepción actual de un diccionario como utility tool, implica una interacción usuarioobjeto. En un contexto lexicográfico, esta interacción tendrá lugar, con la necesaria adecuación, entre las necesidades lexicográficas de un sujeto y los datos contenidos en el diccionario. La TFL, en relación con los diccionarios en línea se define como «la teoría y práctica de las herramientas de uso que se caracterizan por su capacidad para facilitar un acceso rápido y fácil al tipo específico de datos de los cuales, un tipo específico de usuarios pueden extraer el tipo específico de información que les permita satisfacer el tipo específico de necesidades (lexicográficamente relevantes) que tengan en un tipo específico de situación social extralexicográfica» (Bergenholtz y Tarp, 2003; Fuertes-Olivera y Tarp, 2014; Tarp, 2008; Niño Amo \& Fuertes Olivera, 2017: 146). 
A partir del estudio de las situaciones sociales y de las características de los usuarios, la teoría funcional permite establecer una tipología de necesidades que pueden producirse y determinar la correspondiente asistencia que pueden prestar los diccionarios a un usuario que demanda información. Las categorías de información (cf. 2.3.4) coinciden con los criterios que para Tarp (2008: 54-55), generan las necesidades primarias que son las que motivan una situación de uso del diccionario y que siempre son necesidades de información para resolver problemas o adquirir conocimiento. Las necesidades secundarias (Tarp, 2008: 57) están relacionadas con el uso general o específico del diccionario y en alguna medida son necesidades de información, pero también de instrucción y de educación e involucran necesidades de:

- educación general en lexicografía,

- instrucción general en el uso de diccionario,

- instrucción en diccionarios de especialidad,

- instrucción en el uso diccionarios de especialidad.

Una comprensión adecuada de la relación entre el conocimiento del idioma, las habilidades del lenguaje y la comunicación conducen a la construcción de mejores diccionarios para el alumno ya que esta relación ofrece pistas sobre las necesidades lexicográficamente relevantes del alumno (Fuertes-Olivera y Tarp, 2011: 146).

Es preciso la identificación en un contexto lexicográfico de la TFL los siguientes parámetros: las situaciones extra-lexicográficas, los perfiles de usuarios y las necesidades que un diccionario puede satisfacer y, en consecuencia, diseñar la herramienta con unas funciones determinadas. Por una parte, se identifican las situaciones extralexicográficas previas a y las posteriores a la consulta; el perfil de un usuario tipo (se piensa en un usuario humano) constituido por su conocimiento, sus competencias y sus habilidades; las necesidades que en el ámbito lexicográfico un diccionario puede satisfacer. Estos parámetros son dependientes entre sí ya que unos intervienen en alguna medida para determinar a los otros, en consecuencia, se deben establecer las relaciones entre ellos y su influencia mutua. Por otra parte, hay que tener en cuenta el papel que tiene un diccionario en línea destinado a un potencial tipo de usuario, definido por unas funciones que se le han determinado, que contiene unos datos específicos y que presenta y facilita el acceso a aquellos datos que satisfacen la consulta. 


\subsubsection{Métodos utilizados en lexicografía para identificar las necesidades del usuario del diccionario}

El punto de partida de un proceso que finaliza con la consulta motivada de un usuario al diccionario es una persona en una situación que precisa ayuda puntual para satisfacer una necesidad por medio de una obra de referencia. Este tipo de ayuda que demanda un usuario permite describir y/o completar las características de la situación, "The crucial point in this theory is that it is the situation that leads to the need for an information tool, and it is the nature of the help that is required that is essential for the description of the situation", (Bergenholtz y Bothma, 2011: 61). La determinación, en la mayor medida posible, de las necesidades potenciales del usuario permite crear modelos concretos de necesidades de usuario relacionadas con las situaciones en la que se encuentre y como consecuencia se puede vincular el ámbito extralexicográfico relativo a la necesidad de información, con el ámbito intralexicográfico relativo a los datos contenidos en un diccionario (Tarp, 2008: 69).

Para identificar las necesidades potenciales del usuario se puede utilizar el método inductivo o el método deductivo. El primero consiste en utilizar encuestas centradas en usuarios potenciales en situaciones extralexicográficas y confeccionadas para identificar los problemas lexicográficamente relevantes que tienen los usuarios. El segundo implica probar una hipótesis y hacer deducciones a partir de los resultados de pruebas basadas las categorías de información adaptadas a fines lexicográficos. Siempre que sea posible, la utilización de ambos métodos de forma complementaria puede conducir a la identificación de las necesidades de los usuarios con mayor precisión. Para Tarp el segundo método es suficiente para mostrar que la teoría de las funciones puede utilizar un análisis de las necesidades del usuario potencial como origen a partir del cual iniciar una síntesis y recrear una 'imagen nítida' de los elementos principales en las funciones lexicográficas.

Otros investigadores requieren un enfoque empírico para basar juicios en hechos establecidos en lugar de en suposiciones, por lo cual las condiciones del uso del diccionario deben determinarse mediante una observación empírica precisa. Entre los parámetros a investigar están los tipos de diccionarios consultados por los tipos de usuarios durante (varios tipos de) actividades que requieren (varios tipos de) estrategias (Hartmann, 2001: 81). 
En investigación lexicográfica, se han utilizado varios métodos para realizar investigaciones empíricas sobre el uso del diccionario y deducir las necesidades de los usuarios y, los más comunes: los cuestionarios, las entrevistas, la observación directa, los protocolos, los experimentos, los test, los archivos de registro, seguimiento ocular y protocolos en tareas relacionadas pero independientes de cualquier consulta de diccionario. Estos métodos no producen resultados sobre las necesidades del usuario en situaciones extra lexicográficas ya que se centran en la situación de uso del diccionario y no incluyen las situaciones previas y posteriores a la consulta.

En las propuestas de diccionarios se pueden combinar distintos métodos para determinar las necesidades del usuario. La utilidad de unos u otros puede venir condicionada por los medios y el tiempo disponible y porque precisan utilizar la obra de referencia o un prototipo terminados. Entre estos métodos: Bussines as usual, Personal knowledge, User research y Functional approach (Fuertes-Olivera y Tarp, 2014:46).

a. Bussines as usual, consiste en crear nuevos diccionarios partiendo de los conceptos existentes en otros diccionarios previos. Este método solo es aconsejable si cubre las necesidades de los futuros usuarios.

b. Personal knowledge, se puede utilizar cuando el lexicógrafo tiene conocimiento personal cercano de las necesidades del usuario potencial. Puede darse el caso de que el lexicógrafo tenga comunicación directa con el usuario real del futuro diccionario lo cual es muy valioso.

c. User research, consiste en la utilización de protocolos en los que el usuario registra conscientemente la actividad y/o cierta información mientras realiza una consulta motivada o en una entrada piloto; en la utilización de "Log Files " que son ficheros de registro de actividad de un dispositivo; en la observación de los usuarios mediante cuestionarios, entrevistas, protocolos, test, observación directa del proceso de consulta mediante el estudio de ficheros de registro o por seguimiento visual.

d. Functional approach, la TFL define grupos de usuarios potenciales de diccionarios con distinto grado de conocimiento de su propio campo específico y de su lengua y plantean una serie de preguntas pertinentes al tema para elaborar un perfil con las características del usuario.

Para obtener una aproximación a las necesidades de información relevantes de un potencial usuario, es necesaria información sobre su perfil lexicográfico en relación al uso de las obras de referencia. En Fuertes-Olivera y Tarp (2014: 49-50) y Tarp 20015 se definen una lista 
abierta de preguntas para elaborar una lista de características de usuario lexicográficamente relevantes (para la función y/o para la consulta) y crear un perfil de usuario de un diccionario determinado:

- ¿Cuál es su lengua materna?

- ¿A qué nivel dominan su lengua materna?

- ¿Con qué método aprende el usuario la lengua materna o primera lengua?

- ¿A qué nivel dominan una lengua extranjera?

- ¿Con qué método aprende el usuario una lengua extranjera?

- ¿Cuál es el nivel cultural y enciclopédico general del usuario?

- ¿Cuál es su experiencia en traducción?

- ¿A qué nivel dominan la disciplina o ciencia en cuestión (lego, semiexperto o experto)?

- ¿A qué nivel dominan la disciplina en su propia cultura?

- ¿A qué nivel dominan la disciplina especializada en una cultura extranjera?

- ¿A qué nivel dominan el lenguaje especializado en su lengua materna?

- ¿A qué nivel dominan el lenguaje especializado en la lengua extranjera?

- ¿Cuál es su experiencia en la traducción especializada?

Para obtener características del usuario relevantes para la consulta:

- ¿Cuál es la experiencia del usuario en las consultas lexicográficas?

- ¿El usuario es ciego, sordo o tiene alguna otra discapacidad que pueda limitar el uso de tipos específicos de herramientas lexicográficas?

- ¿El usuario tiene electricidad y luz eléctrica?

- ¿El usuario tiene un dispositivo con acceso a Internet?

Los estudios sobre el uso de diccionarios electrónicos se han ocupado principalmente de documentar y evaluar el comportamiento de los usuarios. El método más utilizado en la investigación sobre el uso de diccionarios electrónicos es el análisis de archivos de registro (De Schryver \& Joffe (2005); Bergenholtz \& Johnsen (2005); Verlinde \& Binon (2010); Lorentzen (2012) y Hult (2012)), también se utilizan las observaciones utilizando estudios de seguimiento ocular (Tono, 2011), y una combinación de encuesta y un cuestionario con un diseño experimental (Winkler, 2001) (cf. Töpel, 2014: 47). 


\subsubsection{Investigación lexicográfica de las necesidades del usuario en el marco teórico de la TFL}

Los trabajos de investigación lexicográfica recientes en el marco teórico de la TFL constituyen una fuente de información y de análisis sobre aspectos metodológicos para futuras propuestas de diccionarios especializados. Los diccionarios de lenguajes especializados en línea comparten una serie de características que el análisis y la crítica de dichos trabajos pueden ayudar a identificar.

Niño Amo (2015) en el Diccionario español de contabilidad, bajo la premisa de que el usuario, en una situación cognitiva, tiene una necesidad real de conocimiento sobre una materia en la que no es experto y planifica la introducción sistemática como un componente externo a modo de manual o guía al usuario no experto entendiendo que "La Introducción Sistemática es un texto integrado en un diccionario que se construye como herramienta capaz de proporcionar al usuario conocimiento sobre un área o materia específica, de una forma organizada y con el propósito de poder acceder a una información de calidad y de la forma más eficiente posible" y atendiendo a las necesidades lingüísticas y conceptuales del usuario potencial (Niño Amo y Fuertes-Olivera, 2017: 149).

García Llamas (2016) pone en duda la efectividad de permitir que el usuario defina un perfil de usuario o adapte la herramienta a sus necesidades previamente a la consulta. En su propuesta de Diccionario de Comercio Internacional considera la opción de 'dosificar la información' para ayudar al estudiante a personalizar la búsqueda y aumentar los datos ofrecidos mediante la activación de vínculos; dado el caso, recomienda que un profesor imparta una sesión de formación teórico-práctica sobre el uso del diccionario al estudiante. Es el propio usuario el que facilita la información necesaria sobre su perfil para adaptar los datos ofrecidos a sus necesidades lexicográficas (García Llamas, 2016: 47).

Agerbo (2019) menciona dos métodos poco utilizados, pero con un potencial a explorar y considerar en investigación lexicográfica: web research y videotape recordings. La investigación en la web tiene la ventaja de trabajar con datos digitales procedentes de redes sociales, fórums, etc., para el análisis directo de las necesidades analizadas. Las grabaciones de cintas de vídeo se basan en la observación directa del usuario durante la consulta, y se centra en cómo se utilizan los diccionarios y nunca se han utilizado para analizar las necesidades de información del usuario en determinadas situaciones (cf. Agerbo, 2019: 159-160). 
Otros autores apoyan un proceso de formación del usuario del diccionario para que este facilite el reconocimiento de sus propias necesidades de información y la correcta formulación de las mismas. La capacitación y formación de un usuario implica que esta formación adquiera una dimensión significativa para él (Monfasani y Curzel, 2006: 91-92).

Para conseguir la individualización en la satisfacción de las necesidades Tarp (2011:67) propone tres métodos a llevar a cabo en un entorno informativo y tecnológico: el método interactivo, el método activo y el método pasivo, los tres requieren de unas habilidades tecnológicas en distinto grado.

- En el método interactivo el usuario, con unas habilidades mínimas, completa la información o responde a preguntas en la herramienta (e-tool) de forma que esta le asiste para configurar su perfil personal y si además indica la situación y/o la actividad en la que surge la necesidad de información esta le ayuda a identificar el tipo de necesidad. Con estos parámetros fijados la herramienta electrónica adapta y presenta los datos según las necesidades individuales en función del perfil de usuario y la situación indicada.

- En el método activo a cada usuario con habilidades avanzadas se le da la opción de diseñar su propio 'master article' en base a los datos que busca y la presentación en pantalla. La herramienta es capaz de adecuar los datos relevantes y presentarlos con la disposición elegida por el usuario.

- En el método pasivo el usuario realiza distintas consultas y es la herramienta la que registra las consultas. En base a ellas, crea y memoriza un perfil de datos que el usuario suele demandar y es capaz de volver a presentarlos en posteriores consultas, pero sin diferenciar el tipo de situaciones previas. No obstante, "If consultation of the e-tool is made one day in one situation and the next day in a different one, then the needs will be of a completely distinct nature. For this, the best solution might be some kind of combination of all three methods mentioned, with the possibility to reset and change at any moment" (Tarp, 2011: 68).

Sea cual sea el formato de la obra de referencia, su contenido viene determinado por las necesidades de información del usuario percibidas o anticipadas por el lexicógrafo. En formatos cerrados la categorización de un dominio es muy amplia y está dirigida a un grupo genérico en 
el que es difícil tener en cuenta las necesidades de información de un individuo. La denominada e-lexicography y los formatos 'abiertos y dinámicos' permiten, por una parte, que las necesidades de información percibidas de grupo potencial de usuarios, lo más grande posible, se pueda abordar en cualquier e-diccionario específico y por otra, es posible presentar datos personalizados al usuario obtenidos mediante tecnologías de filtrado y adaptación basadas en el perfil del usuario (Bothma, 2011: 73).

Fuertes-Olivera (2016: 227) involucrado en proyectos de diccionarios en línea especializados, recoge la idea de trabajo en equipo con expertos planteada con anterioridad. El equipo de expertos estaría formado por expertos en lexicografía, en el campo de especialidad y en internet. Cuando se realiza una consulta directa a los usuarios potenciales se realiza para distinguir entre las necesidades y preferencias que el usuario manifiesta y las necesidades que el lexicógrafo cree que tiene, sin dejar de lado las recomendaciones de los expertos.

\subsubsection{Habilidades en el uso de diccionarios en línea}

Los diccionarios de calidad para su uso en la educación superior indican dos oportunidades de mejora, la consecución de diccionarios de calidad electrónicos (en línea) y la capacitación en el uso de estos diccionarios. Nesi (1999) presenta un listado de las habilidades como parte de un proyecto de investigación con informantes de varias universidades de Reino Unido y de fuera de Reino Unido que son estudiantes de idiomas de nivel universitario. Este listado está dividido en seis bloques o etapas: antes del estudio; antes de consultar los diccionarios; localización de la información de entrada; interpretación de la información de entrada; registro de información de entrada, y comprensión de los problemas lexicográficos.

Entre los usuarios de diccionarios en línea se puede identificar dos grandes grupos: los usuarios de diccionarios impresos en papel que 'migran' bien a diccionarios electrónicos, bien a diccionarios electrónicos que se ofrecen en línea (digital immigrants acuñado por Prensky 2001) y los usuarios que esperan que un diccionario sea únicamente en línea. Las habilidades de referencia del primer grupo han evolucionado para adaptarse de un medio impreso a un medio digital, mientras que las habilidades del segundo grupo son las propias de 'nativos digitales' usuarios de obras de referencia. Lew (2013: 29) plantea un enfoque hacia nuevas técnicas de búsqueda, la utilización de unidades pluriverbales y fragmentos de texto en las búsquedas y el 
alejamiento del modelo basado en palabras implícito en la lexicografía impresa como componente destacado y relevante en las habilidades de uso de diccionarios en la era electrónica.

\subsubsection{Métodos para detectar las habilidades de referencia en el uso de diccionarios}

Las habilidades de referencia de un diccionario requieren habilidades del lenguaje, conocimiento sobre las convenciones propias del diccionario, habilidades de resolución de problemas y habilidades de procesamiento de información (Tono, 2011:149). El diccionario es un instrumento pedagógico fundamental y vertebrador de la enseñanza de la lengua y una adecuada metodología de uso, permite a los usuarios seguir enriqueciendo autónomamente su competencia lingüística (Hernández, 1991: 194). Sin embargo, no todos los estudiantes que acceden a la universidad tienen habilidades en el uso de diccionarios.

Nuestra propuesta sustenta la hipótesis de que el diccionario sería una buena herramienta complementaria a otras labores docentes para esto es preciso conseguir un uso eficaz y eficiente del diccionario. 'There are two direct routes to more effective dictionary use: the first is to radically improve the dictionary: the second is to radically improve the users' (Atkins y Varantola 1997:1). Para lo cual, añaden, es imprescindible saber en detalle cómo se utilizan los diccionarios en el 'presente'. Hartmann (1987:12) destaca que la falta de información empírica sobre las necesidades y las habilidades de referencia del usuario puede dar lugar a una falta de correspondencia entre la información que facilita un diccionario y la ayuda requerida por el usuario del diccionario. Puesto que no es posible recabar información sobre el uso y habilidades de referencia en diccionarios técnicos de EGI, las investigaciones llevadas a cabo en diccionarios de otros ámbitos nos ayudan a identificar las habilidades de referencia comunes.

El estudio realizado por Tono en 1991 sobre el usuario del diccionario reconoce que la innovación en proyectos de diccionarios implica que los lexicógrafos deben tener mayor conciencia sobre el usuario, - con anterioridad Stein (1984:4) había especificado que era necesario considerar las necesidades, las expectativas y los prejuicios del usuario- Realiza un estudio bajo una cuidadosa observación directa del usuario para investigar las diferencias entre los usuarios e identificar las características del 'buen usuario'. El método consistió en un 
cuestionario sobre adquisición de lenguaje y uso de diccionarios, y una entrevista con el investigador para realizar ciertas tareas.

Los resultados revelaron que un buen usuario obtiene la información que necesita más rápido, entiende mejor las normas del diccionario, tiene suficiente dominio del idioma para comprender el contenido de la entrada y parece saber qué palabras buscar. También destacan las diferencias en el número de búsquedas, en el tiempo que utilizaron y en los estilos de búsqueda de distintos usuarios. En el caso de diccionarios en línea, Tono aplica metodologías de seguimiento ocular para analizar el proceso de búsqueda en diccionarios en línea y realiza un experimento para examinar procesos de interacción del usuario con la información presentada mediante un grabador de marcas oculares (Tono, 2011:125).

Nesi (1999: 66) destaca la necesaria formación en habilidades de referencia del diccionario para estudiantes universitarios y lamenta la supresión de esta formación en los planes de estudio. Sus informantes otras muestran el entusiasmo por este tipo de capacitación, especialmente los usuarios de diccionarios electrónicos (como ROBERT ÉLECTRONIQUE) y los que presentan material multimedia adicional de auto-acceso. "far from being unpopular, the students really enjoy this quite detailed research task, the discoveries they make, and the feeling that, with a dictionary close by, they do not need to have previously heard a new, or "difficult" word before being able to pronounce it".

\subsubsection{Respecto a las habilidades de referencia en el uso de diccionarios en línea}

En la actualidad, estas habilidades ponen en relieve que los usuarios potenciales son nativos digitales. Se denomina así a los nacidos a partir de 1980 (Thompson, 2013: 12; Prensky, 2001) que crecen y viven inmersos en la tecnología digital, tanto que se ha planteado ya la hipótesis de que la tecnología digital ha motivado el cambio de los patrones de pensamiento y posteriores generaciones de estudiantes (Prensky, 2001: 1).

Digital Natives are used to receiving information really fast. They like to parallel process and multi-task. They prefer their graphics before their text rather than the opposite. They prefer random access (like hypertext). They function best when networked. They thrive on instant gratification and frequent rewards. (Prensky, 2001: 2). 
Sin embargo, el trabajo realizado por Thompson (2013) para comprobar la relación entre los patrones de uso de la tecnología, las características digitales y los hábitos de aprendizaje entre los estudiantes de primer año de universidad, puede ser útil para observar patrones y tendencias. En este estudio se refleja la relación compleja y no homogénea entre el uso de tecnologías, las características digitales y los hábitos de aprendizaje productivo. El debate sobre los nativos digitales se fundamenta en dos supuestos:

1- tienen un conocimiento sofisticado de las tecnologías de la información y unas habilidades derivadas de su uso;

2- tienen preferencias o estilos de aprendizaje particulares que difieren de las generaciones anteriores de estudiantes como consecuencia de su contacto con la tecnología.

Estos supuestos se han presentado durante años con una evidencia empírica limitada (Bennett et al. 2008: 777). No obstante, los estudiantes nativos digitales pueden mejorar en autosuficiencia, pero requieren apoyo docente para la utilización efectiva y el control de las distracciones intrusivas de la tecnología. Thompson (2013: 23) concluye que "Technology is indeed an important influence in students' lives, but it is one influence among many, and teachers still have an opportunity to help their digital native students navigate successfully through the promises and pitfalls of learning in the digital world.".

El estudio realizado por Margaryan et al. (2011) relativo al uso de tecnologías digitales por parte de estudiantes universitarios de Ingeniería de dos universidades británicas cuenta con dos tipos de informantes: estudiantes y profesores. Los materiales de recogida de datos utilizados constan de un cuestionario en papel y una entrevista personal. Entre sus conclusiones se destaca que:

- los educadores pueden suponer que todos los jóvenes estudiantes son nativos digitales para apoyar y mejorar su aprendizaje;

- los estudiantes hacen uso limitado, en su mayoría recreativo o social, de las tecnologías digitales.

- los hallazgos apuntan a un nivel bajo de uso y familiaridad con las herramientas de creación de conocimiento en colaboración, como wikis, publicación web personal y otras tecnologías emergentes; 
- su aprendizaje parece estar influenciado por los enfoques adoptados por sus profesores;

- algunos profesores reconocen el valor educativo de las tecnologías digitales, otros lo ven como una 'moda' pasajera;

- es una competencia esencial para un profesional, la capacidad de crear y compartir conocimiento de manera colectiva, más allá de los grupos y comunidades inmediatas;

- es una competencia esencial para un profesional, la capacidad de estar informado de los nuevos conocimientos de su campo.

\subsection{Perspectiva orientada al usuario}

La denominada 'perspectiva del usuario' (Hartmann 2001) en la investigación de diccionarios se basa en técnicas que permiten la identificación de las necesidades y las habilidades de referencia de los usuarios dando lugar a diferentes perfiles de uso, que finalmente permiten innovar en el diseño de diccionarios.

\subsubsection{Acceso y rutas de acceso a los datos de un diccionario en línea}

La consulta satisfactoria a un diccionario es un requisito previo para que se cumplan las funciones lexicográficas de un diccionario. La recuperación óptima de información es un requisito para lograr una función lexicográfica prevista y para satisfacer la necesidad de un usuario. Gouws (2009:12-13) avanza estos planteamientos en el contexto de una teoría lexicográfica funcional que no había descrito un procedimiento de consulta de éxito que cumpliera una función determinada por las restricciones de la macro y micro estructuras de los diccionarios impresos. La lexicografía (TFL) actual y la ingeniería cognitiva comparten el interés por proporcionar datos y facilitar el acceso a esos datos al usuario.

Cuando se trata de un diccionario electrónico en línea con un contenido dinámico, es de la máxima importancia definir la secuencia de acceso de un usuario con necesidades puntuales de información hasta llegar a los datos relevantes y nada más. Acceder a los datos relevantes en una obra de referencia ante una necesidad de información requiere el diseño del proceso de acceso a esos datos. Bergenholtz, Bothma y Gouws (2015: 9) plantean este proceso de acceso a 
los datos en tres fases: prelexicográfica, intralexicográfica y postlexicográfica. Del mismo modo, muestran la secuencia de acceso al utilizar una herramienta de información en distintas situaciones:

- "communicative situations: text $\rightarrow$ information source $\rightarrow$ act in the text $\rightarrow$ meta-reflections;

- operative situations: knowledge problem how to act $\rightarrow$ information source $\rightarrow$ act in the world after having got the needed information $\rightarrow$ meta-reflections;

- interpretative situations: acting problem reacting to a sign or a symbol $\rightarrow$ information source $\rightarrow$ act or not act in the world after having obtained the needed information $\rightarrow$ meta-reflections;

- cognitive situations: knowledge interest $\rightarrow$ information source $\rightarrow$ no acting but storing the found information in the brain (forever or for a short period) $\rightarrow$ meta-reflections."

Es en la fase postlexicográfica (la tercera fase), en la que se aprecian las opciones marcadas por las situaciones comunicativas, operativas, interpretativas y cognitivas que a su vez representan las cuatro funciones de la teoría funcional moderna.

Cada paso, cada interacción con el software en un proceso de selección de opciones en un diccionario en línea, debe ser fruto de la reflexión (meditada o inmediata) pero no de una intuición que no tiene lugar en una ciencia. Lo razonable o lógico es que la reflexión esté fundamentada y sea consciente, pero esto no siempre ocurre y puede conducir a un fracaso en la consulta.

\subsection{Conclusiones}

La tipología del diccionario especializado debe estar basada en las funciones lexicográficas que pueden ser visibles en la pantalla de un diccionario electrónico de tal forma que activarán el contenido presentado. Para consultar diccionarios con imágenes no alfabéticas, los estudiantes deben comprender su estructura, interpretar encabezados temáticos y predecir conjuntos léxicos subordinados que un diccionario electrónico en línea permite potenciar y organizar dinámicamente. El usuario puede seleccionar por marcas los subconjuntos de unidades léxicas sin que exista un orden alfabético de las unidades.

La propuesta de estructura de datos del diccionario de EGI debe tener valor lexicográfico para satisfacer las necesidades de información de un usuario utilizando la tecnología disponible 
que permita y facilite el acceso y la presentación de datos con interés lexicográfico para la consecución del objetivo. Se considera necesario aportar elementos no lingüísticos junto con la información lexicográfica en el contexto EGI de lenguas especializadas.

La interacción usuario-objeto en cualquier utility tool, se puede entender unas veces como la interacción entre las necesidades lexicográficas de un usuario y los datos contenidos en un diccionario y otras, como la interacción funciones-datos. Se requieren ciertas habilidades para utilizar una herramienta con la finalidad con la que ha sido diseñada, desde las habilidades de referencia en un formato determinado hasta las habilidades y destrezas que requiera el ámbito de conocimiento.

Se recuerda que la TFL relaciona todos los parámetros que intervienen en un diccionario en línea especializado: "es la teoría y práctica de las herramientas de uso que se caracterizan por su capacidad para facilitar un acceso rápido y fácil al tipo específico de datos de los cuales, un tipo específico de usuarios pueden extraer el tipo específico de información que les permita satisfacer el tipo específico de necesidades (lexicográficamente relevantes) que tengan en un tipo específico de situación social extralexicográfica".

Para conseguir la individualización en la satisfacción de las necesidades se puede ofrecer al usuario la decisión sobre la ruta de acceso y cada paso, cada interacción con el software en un proceso de selección de opciones en un diccionario en línea, debe ser fruto de la reflexión meditada o inmediata. Es posible decidir el formato, identificar el perfil de usuario, determinar su contenido y la presentación y, facilitar el acceso a los datos con el objetivo final de que el usuario real obtenga la información pertinente a partir de los datos presentados.

Nuestra propuesta sustenta la hipótesis de que el diccionario sería una buena herramienta complementaria a otras labores docentes para esto es preciso conseguir un uso eficaz y eficiente del diccionario. 


\section{EXPRESIÓN GRÁFICA EN LA INGENIERÍA}

\subsection{Introducción}

4.2 La semiótica del discurso verbal y no verbal

4.3 Antecedentes históricos de la Expresión Gráfica en la Ingeniería

4.4 La comunicación técnica mediante el dibujo industrial

4.5 La comunicación técnica gráfica en el ámbito académico de la ingeniería industrial

4.5.1 La reformulación pedagógica en la adquisición de conocimiento 4.6 Funciones de la representación gráfica en la ingeniería

4.7 Estudio empírico de diccionarios técnicos

4.7.1 Resumen y consideraciones generales

4.8 El usuario de una herramienta lexicográfica de EGI

4.8.1 El perfil del usuario

4.8.2 Las situaciones

4.8.3 Las necesidades de un usuario tipo en relación con el área de conocimiento

4.9 La selección de lemas en lexicografía especializada

4.10 Determinación de unidades de conocimiento en EGI

4.11 Análisis de las funciones lexicográficas del diccionario de EGI

4.11.1 Función Cognitiva

4.11.2 Función Interpretativa

4.11.3 Función Operativa

4.12 Conclusiones 


\section{EXPRESIÓN GRÁFICA EN LA INGENIERÍA}

\subsection{Introducción}

La denominación «expresión gráfica en la ingeniería», en nuestro contexto, hace referencia a las técnicas y convencionalismos de representación geométrica que se utilizan en los denominados dibujos de ingeniería y a su carácter técnico e industrial. Ciertas características y cualidades de los objetos en los que piensa un tecnólogo y un ingeniero no pueden reducirse a descripciones verbales inequívocas, de hecho, son tratadas en su mente mediante un proceso visual no verbal, Eugene Ferguson (1977) justifica así el pensamiento no verbal del tecnólogo. Añade que buena parte de los objetos que nos rodean tienen su origen en una imagen mental, una visión más allá de la geometría. Barnard, investigador interesado en el origen del pensamiento simbólico en el marco de la antropología social, hace referencia a la comunicación interna en un contexto de símbolos "Of course, symbolism communicates too, but it communicates 'internally' through sets of symbols that are ordered consciously and culturally." (Barnard, 2012: 86).

La práctica profesional de la ingeniería prueba que existe una necesidad de fijar ideas y de representarlas como parte de un proceso de comunicación técnica. Este capítulo trata sobre la comunicación gráfica en Expresión Gráfica en la Ingeniería (EGI), los lenguajes o sistemas de representación y los convencionalismos que se utilizan, y los parámetros a tener en cuenta para configurar una herramienta lexicográfica.

Entre las características del registro científico-técnico destaca la presencia de los elementos gráficos, que pueden tener funciones semióticas generadas por un código gráfico. Se trata de un mecanismo, diferente del mecanismo verbal, utilizado para la comunicación (Sevilla Muñoz y Sevilla Muñoz, 2003). Es posible entonces, que las unidades de entendimiento (Esandi et al., 2007) en nuestro ámbito de conocimiento (EGI) puedan hacer variar la noción de concepto dentro del discurso especializado ya que existen otros sistemas de transmisión y representación 
del conocimiento donde cada concepto se expresa a través de signos del lenguaje o de símbolos de otros lenguajes o sistemas (Galinski y Pitch, 1997).

Para autores como Rondeau (1983) el discurso científico-técnico tiene un carácter unitario y los textos científico-técnicos constituyen el caso más claro de texto de lenguaje de especialidad (Cabré, 1993: 143). Los textos presentan rasgos comunes que se pueden agrupar en:

- el componente semántico global: son textos concisos, es decir, poco redundantes; precisos, sin ambigüedad; y despersonalizados;

- las construcciones sintácticas tienden a ocultar el agente, como la pasivización, la nominalización y las formas impersonales (Fuertes-Olivera, 2007);

- el aspecto formal en cuanto a estructura de los textos especializados: apariencia óptica (aspecto del conjunto), medios tipográficos y organización del contenido para ello recurren a la descripción, la definición, la clasificación, la enumeración, el cálculo, el razonamiento, la argumentación, la citación, la referencia, etc. que condiciona su apariencia formal (Arntz y Picht, 1995).

Las descripciones de productos o estructuras complejas deben comunicarse por medio de dibujos como parte de un proceso visual, no verbal. La imagen se crea, revisa y modifica en la mente para posteriormente comunicarla a otros por medio de procesos visuales y gráficos. Los partícipes en este proceso requieren las habilidades visuales, el conocimiento visual y la codificación y decodificación de ese conocimiento exigidos por la profesionalización de la ingeniería (Henderson, 1998: 15). En el proceso de formación del futuro ingeniero industrial, el primer paso para la representación de un objeto es el reconocimiento, o cierto grado de reconocimiento, mediante la codificación de la estructura geométrica del mismo. Es necesario tener en cuenta que los objetos industriales son tridimensionales y se requiere la adquisición de ciertas habilidades y destrezas para su representación mediante sistemas de representación para mejorar la comprensión de conceptos específicos (Marti, 2003).

Hegarty y Kozhevnikov (1999) distinguen dos tipos de representaciones espacio-visuales: las representaciones esquemáticas que codifican las relaciones espaciales que determinan un objeto y representaciones 'pictóricas', o de aspecto tridimensional, que codifican la apariencia 
visual de los objetos. Se denomina dibujo técnico a la representación profesional de objetos para producción industrial, que forma parte del proyecto de diseño de un objeto con una función instrumental, está sometido a determinadas leyes o convenciones gráficas y se sirve de sistemas de representación geométrica que garantizan su objetividad (Cabezas y Ortega, 2002: 30).

Esandi et al., $(2006,2007)$ plantean la existencia de un lenguaje de la expresión gráfica en la ingeniería, con un código y unas reglas de carácter gráfico propias, un significado convencional asociado y que permite la comunicación entre especialistas que pertenecen al mismo ámbito. Este «lenguaje de especialidad es un subconjunto de la lengua general utilizado por profesionales, entendido como una variante fundamentalmente pragmática del lenguaje general». Responde a la necesidad de «describir de forma exacta un objeto de producción industrial; una situación comunicativa aplicada, es decir, de adquisición de conocimiento; y dota a los usuarios de un sistema de carácter gráfico que coopera con la lengua natural en la transmisión de conocimiento especializado dentro de un ámbito técnico e industrial.» (ibid.,p. 16-17). Tanto las necesidades como las situaciones mencionadas son ampliadas y pormenorizadas en el presente estudio desde el marco teórico y metodológico de la teoría funcional.

\subsection{La semiótica del discurso verbal y no verbal}

Entre las diferentes doctrinas del signo y del significado, destacamos las de Saussure y Peirce, ya que pueden aportar un punto de vista que mejore la comprensión de ciertos fenómenos comunicativos en EGI. Para Saussure el signo es diádico, tiene dos caras (significante y significado) y para Peirce el signo es triádico, tres partes interrelacionadas (el signo, el objeto, 'interpretant'). El significante se refiere a una forma significativa, mientras que significado designa el concepto que evoca esa forma.

Para Saussure la 'cosa real o imaginada', al cual el signo remite, no es cognoscible lingüísticamente y el conocimiento del sistema en el cual el signo toma lugar no nos suministra ninguna información sobre la realidad designada por lo que califica de arbitraria la relación entre ambos. Para Fontanille (2017) excluir el referente es procurar a la lingüística su propio objeto en cuanto a ciencia y su autonomía en cuanto a disciplina. El proyecto de semiología de Saussure 
englobaría la lingüística donde se encontrarían significantes y los signos -con relación no necesaria o convencional, p.ej. los sistemas de signos visuales-. El signo para Peirce consta de una parte de- signo en tanto a significante, es decir, la parte del signo responsable de la significación limitada a los elementos esenciales para su funcionamiento como significante; el objeto 'whatever is signified', 'lo que sea que signifique'(traducción nuestra) teniendo en cuenta que solo ciertas características de un objeto permiten que un signo lo signifique o son relevantes para significación - 'el objeto determina el signo'-; the interpretant, el efecto mental o pensamiento generado por la relación signo-objeto (virtualmente puede ser equivalente a significado). Según Atkin (2013) la característica más innovadora y distintiva del relato de Peirce es la importancia del 'interpretante' ya que la significación no es una simple relación diádica entre signo y objeto, un signo solo significa al ser interpretado.

Silverman (1983: 15-17) considera que las diferencias entre el esquema semiótico de Saussure y el de Peirce radican en que Peirce pone su atención en el referente y su confianza en dos tríadas entrelazadas: la primera, ya mencionada, sign-interpretant-object y la segunda iconsindices-symbols. El signo icónico «comparte una cualidad representativa con su objeto de semejanza o de similitud, ya sea de cualidades (imágenes), de relaciones (diagramas), o de un paralelismo (metáforas)»(Redondo, 2009: 205); un índice o sema (indexical sign) es un representamen, la representación está fundamentada al estar modificada por el objeto en una relación existencial causa-efecto (el virar de una veleta); un símbolo es un signo que se refiere al objeto que denota en virtud de una ley o una asociación de ideas, que opera para hacer que el símbolo se interprete como una representación del objeto. Hay «un tercero o una regla que determina que su interpretante representa al signo representando a su objeto.» (ibid., p.209).

La semiótica de Peirce pone su acento sobre el "recorrido interpretativo" de los signos y distingue la semántica (la significación de las unidades); la sintaxis (las reglas de disposición de las unidades) y la pragmática -la manipulación de las unidades y de su organización por sujetos y para sujetos individuales y colectivos-, en situación de comunicación.

Para Fontanille (2017) la teoría de la significación adopta la perspectiva de la semiótica del discurso y de los conjuntos de significantes. Elige la significación en acto porque el objeto del ejercicio empírico de la semiótica es el discurso y la «unidad de análisis es un texto verbal y no verbal». Para este autor las cuatro propiedades de la significación que se derivan de las 
teorías del signo que hemos expuesto son: la coexistencia del mundo interior de los significados y del mundo exterior de los significantes y la significación como sistema de valores (Saussure); el interpretante que "orienta la mirada sobre el sentido» y los límites de un dominio de pertinencia para entender la significación (Peirce).

Las unidades verbales y no verbales en expresión gráfica en la ingeniería, desde el punto de vista de la Semiótica, constituyen un 'sistema con signos' en el que podemos apreciar estas cuatro propiedades de la significación. El concepto, el significado en forma de definición, el código de emisión y recepción del mensaje, el interpretante al que hay que formar para orientarle hacia un sentido pertinente, preciso, unas veces arbitrario y otras referencial. Un discurso en el que el 'mensaje' está sujeto a un conjunto de convenciones gráficas, o código, siendo el emisor el que codifica el signo y el receptor o intérprete el que lo decodifica. Entre las características de la comunicación gráfica en ingeniería destaca su función esencialmente referencial para describir o comunicar una forma o idea en forma objetiva, mono-sémica y con una única interpretación correcta o viable, (Ashwin, 1984: 46). Los dibujos de producción industrial, tienen el objetivo de transmitir al receptor o intérprete una información de manera precisa e inequívoca de forma que se eviten las lecturas alternativas y las ambigüedades en el mensaje codificado. En la formación de los ingenieros industriales los alumnos han de adquirir cierto nivel de 'alfabetización gráfica', graphicacy, concepto que Boardman (1990) aplica a la geografía y los mapas en edades tempranas, pero que es extrapolable a EGI. En el caso que nos ocupa la alfabetización gráfica consiste en que los alumnos aprenden a dominar el registro de la representación de equivalentes similares y el conjunto de códigos puramente simbólicos.

\subsection{Antecedentes históricos de la Expresión Gráfica en la Ingeniería}

Se conservan evidencias de la intención y de la necesidad de plasmar y representar las formas corpóreas que impresionan al ser humano desde las pinturas rupestres hasta nuestros días. No es objeto del estudio que nos ocupa realizar una exposición pormenorizada de la evolución de la representación gráfica, pero sí es necesario destacar algunos de los hechos y personajes más influyentes (Ortega Valin, 1992) que pueden contribuir a desvelar el objetivo de uno de los dos pilares del estudio que nos ocupa que no es otro que la representación gráfica de la realidad y 
los elementos y técnicas que se utilizan en la comunicación gráfica técnica con este fin. Gaspard Monge en el prefacio de su tratado sobre geometría descriptiva (1795) define la geometría de la descripción después de advertir de la necesidad que tiene la nación francesa de independizarse industrialmente de otras naciones (Inglaterra), para ello ve necesario actuar en educación y redirigir el aprendizaje hacia materias como la geometría descriptiva que tiene dos objetivos principales y que siguen vigentes en la actualidad:

"Cet art a deux objets principaux:

Le premier est de représenter avec exactitude, sur des dessins qui n'ont que deux dimensions, les objects qui en ont trois, et qui sont susceptibles de définition rigoureuse. Sous ce point de vue, c'est une langue nécessaire à l'homme de génie qui conçoit un project, à ceux qui doivent en diriger l'exécution, et enfin aux artistas qui doivent eux-mêmes en exécuter les différentes parties.

Le second objet de la Géométrie descriptive est de déduire de la description exacte des corps tout ce qui suit nécessairement de leurs formes et de leurs positions respectives. [...] Elle est non-seulement propre à exercer les facultés intellectuelles d'un grand peuple, et à contribuer par là au perfectionnement de l'espèce humaine, mais encore elle est indispensable à tous les ouvriers dont le but est de donner aux corps certaines formes déterminées;》 (Monge, 1822: XIV)

El dominio del lenguaje gráfico-formal de los ingenieros se basa en tres disciplinas fundamentales y en este orden: la Geometría, los Sistemas de Representación y la Normalización. Estas disciplinas se han desarrollado a lo largo de la historia en diferente medida en función y debido a las aportaciones de disciplinas como las matemáticas, la pintura, la arquitectura, la filosofía, la informática etc.

En la antigüedad el hombre, una vez agrupado en sociedades complejas, tiene la necesidad de herramientas matemáticas que le permitan delimitar y medir terrenos y realizar obras civiles. Los pueblos mesopotámicos y los egipcios crearon los rudimentos de la aritmética y la geometría. Herodoto menciona a Sesostris un personaje de leyenda, el primero en realizar una partición de tierras (el primer geómetra).

Los griegos fueron los creadores de la matemática y muy particularmente de la geometría como ciencia, al transformar unos conocimientos inconexos en una estructura mucho más sencilla, abstracta y racional. Aplicaron el método deductivo racional y realista que permite, 
por primera vez, separar las proposiciones verificables y al mismo tiempo permite afirmar algo mediante la argumentación y el recurso de la experiencia. La separación de la ciencia de la técnica hasta la época moderna, dio a todas las ciencias un fuerte carácter abstracto y originó la creencia de que el orden del universo se puede deducir en todos sus detalles por puro razonamiento. La falta del apoyo en la observación y la experimentación supuso que la primera tarea de la ciencia moderna, a partir del Renacimiento, fue mostrar lo erróneo de parte de las conclusiones científicas a las que llegaron los clásicos.

Cabe distinguir tres períodos en el desarrollo científico griego: jónico, ateniense y helenístico con figuras muy relevantes en cada uno de ellos. En el periodo jónico se establecieron las bases con trabajos sobre proporcionalidad, distancias, proyectividad e incidencia; destaquemos a: Thales (S. VII a VI a. C.) y Pitágoras (582 a 500 a.C.). En el periodo ateniense aparece la geometría métrica: Hipócrates de Quíos (c. 450 a. C.), Platón (427-347 a. C.) y Eudox (408-355 a. C.). El periodo helenístico se inicia con la creación en el 330 a. C. en Alejandría del Museo por Ptolomeo y abarca hasta el final de la época romana. La escuela de Alejandría siguió la línea de estudio de la naturaleza iniciada por Aristóteles, pero se siguió la línea platónica de las matemáticas en lugar de tomar como método la lógica aristotélica y se potenció el procedimiento geométrico frente al cálculo numérico, considerado inferior y disfrazado, caso de ser necesario, de geometría. Los cálculos se hacían gráficamente y se mantuvo esta particularidad a lo largo de la historia de la ciencia hasta bien entrado el siglo XVII con el desarrollo del cálculo infinitesimal y los cálculos analíticos. No existía una disociación entre la noción de número de las de segmento o distancia. Los conocimientos geométricos de esta época son válidos hoy en día casi en su totalidad y son la base de la enseñanza matemática y del desarrollo de la capacidad gráfica de la persona. A este periodo helenístico pertenece Euclides (S. IV y III a.C.) figura principal de la geometría y la matemática griega que compiló todos los conocimientos geométricos de su época en varios volúmenes los Elementos.

Hasta finales del siglo XVIII no se alteró ninguno de sus axiomas y la demostración de la falsedad de su 5o principio dio lugar a una nueva geometría, la geometría no-euclídea. El modo de pensar griego se adaptaba extraordinariamente a la geometría, la cual ordena el espacio, según un orden formal, proporcionado, geométrico, y elegante, que aparece repetidamente en la naturaleza y en las realizaciones humanas. Representa el núcleo de la concepción ordenada y 
abstracta del pensamiento occidental con respecto a cualquier realización material del hombre. El valor de la geometría no radica exclusivamente en ser una herramienta de estudio sino en ser una disciplina que condiciona la concepción de la realidad.

Desde el período helenístico hasta el Renacimiento hay pocas aportaciones al conocimiento de la geometría. Cuando se separó del álgebra y de la aritmética tiene un desarrollo teórico propio, se refuerzan la geometría proyectiva y la geometría descriptiva.

Hasta el siglo XVII la comunidad científica se encuentra muy familiarizada con la geometría métrica p.ej. Newton demuestra la Teoría de la Gravitación de modo geométrico por estar los científicos más acostumbrados a este 'lenguaje'. El desarrollo del álgebra, el cálculo, la trigonometría y la aritmética tuvo como consecuencia el casi abandono de la geometría métrica como instrumento de cálculo. Los conocimientos de geometría métrica siguen siendo fundamentales pero el desarrollo científico y matemático siguen otros caminos, poco o nada gráficos, hasta la llegada de la geometría proyectiva.

En el Renacimiento se produjo un cambio en la concepción del mundo y del hombre y la revalorización de la función del artesano y del artista. El estudio de las formas que hasta entonces había estado en manos de científicos y filósofos pasa a estar en manos de artistas y artesanos y a tener unos fines distintos a los teóricos clásicos. La divulgación de las aplicaciones de conocimientos prácticos y científicos, gracias a la imprenta, propició la necesidad de expresión de las nuevas aplicaciones tecnológicas y la geometría dirigió su atención hacia la representación de aparatos, proyectos, mapas, etc. Los avances más importantes en el campo de la representación vinieron de las artes visuales como el estudio de la visión y de la perspectiva, que son los pilares de cualquier Sistema de Representación. La gran revolución científica que tuvo lugar durante el Renacimiento no provino de un cambio de mentalidad o filosofía, sino de la racionalización de la mirada (Ivins, 1985 [1938]: 35) con el descubrimiento de la perspectiva. Si bien ya estaba presente antes de este período (Alberti en 1435-1436) no permitía preservar las propiedades internas del objeto y las proporciones variaban en la representación gráfica dependiendo de la ubicación. Sin embargo, la nueva perspectiva representada en el Renacimiento permite preservar estas propiedades y, por lo tanto, mover el objeto libremente en la representación. Esto permite ver el objeto desde diferentes ángulos, evitando el inconveniente de recalcular las proporciones. 
"Le système de perspective conçu par Alberti en 1435-1436 marqua le véritable début du remplacement de la conscience tactile de l'espace (qui provient d'Euclide) par une conscience visuelle, car son nouveau procédé de projection et de section centrales non seulement fit se rejoindre automatiquement en des points de fuite logiquement déterminables les droites parallèles, mais fournit une base à la grammaire ou aux règles jusque-là manquantes qui devaient établir à la fois des relations logiques au sein du système de symboles utilisé et une correspondance métrique réciproque ou à double sens entre les représentations par l'image des objets et leurs formes tels qu'ils sont situés dans l'espace» (Ivins, 1985 [1938], p. 35). (Citado en Maton, 2007: 57)

Los artistas del Renacimiento eran hombres con un conocimiento enciclopédico que estudiaron anatomía, pintura, matemáticas, óptica, mecánica, metalurgia, ciencias naturales. En contacto directo con la técnica abarcaban, además del campo artístico, la arquitectura y la ingeniería civil y militar a los que trasladaron sus métodos de trabajo y de representación formal. Debido al marcado carácter artístico de los técnicos renacentistas, la geometría descriptiva se dirigió más hacia la representación imitativa de la percepción visual (la perspectiva) que a una representación de la realidad en la que prime la información dimensional de manera que se facilite la definición geométrica de un determinado cuerpo tridimensional. Tampoco se preocuparon de crear sistemas de conocimientos ordenados y coherentes, no eran matemáticos: se limitaron a definir unos métodos de obtención de representaciones y serie de pautas útiles para una representación pictórica

Leonardo da Vinci (1452-1519) es considerado arquetipo del hombre renacentista y artista genial. Estudió a fondo la perspectiva apoyándose en conocimientos profundos de geometría y óptica. En sus tratados metodizó los sistemas de representación, particularmente la perspectiva cónica mostrando el concepto métrico del espacio tridimensional. No publicó sus aportaciones a la técnica, ya que no se concedía importancia a los proyectos técnicos, pero aportó ideas, dibujos y proyectos de máquinas, unos acompañados de ilustraciones otros, acompañados de croquis, planos de detalle, planos de edificios y mecanismos dibujados a escala. Destaca su aportación al análisis de casos concretos y de los dibujos que los acompañan con la intención manifiesta del autor de facilitar la comprensión de su pensamiento. 
Alberto Durero (1471-1528) es autor de una obra fundamental Instrucción sobre la medida en compás y regla, (Nuremberg 1525). La primera obra de ciencia aplicada dirigida a los técnicos (también a pintores, arquitectos y artesanos) considerado un tratado de Expresión Gráfica en lengua vulgar, no en latín como era costumbre. No era un tratado teórico, pero a todos los preceptos y reglas les adjuntaba una demostración, a veces, gráfica. Trata sobre la construcción de curvas, polígonos regulares, poliedros regulares etc. Utiliza para la construcción de cónicas y hélices el método de dobles proyecciones ortogonales (Figura 4.1) siendo el precursor de la Geometría Descriptiva y del Sistema Diédrico utilizados hasta nuestros días.

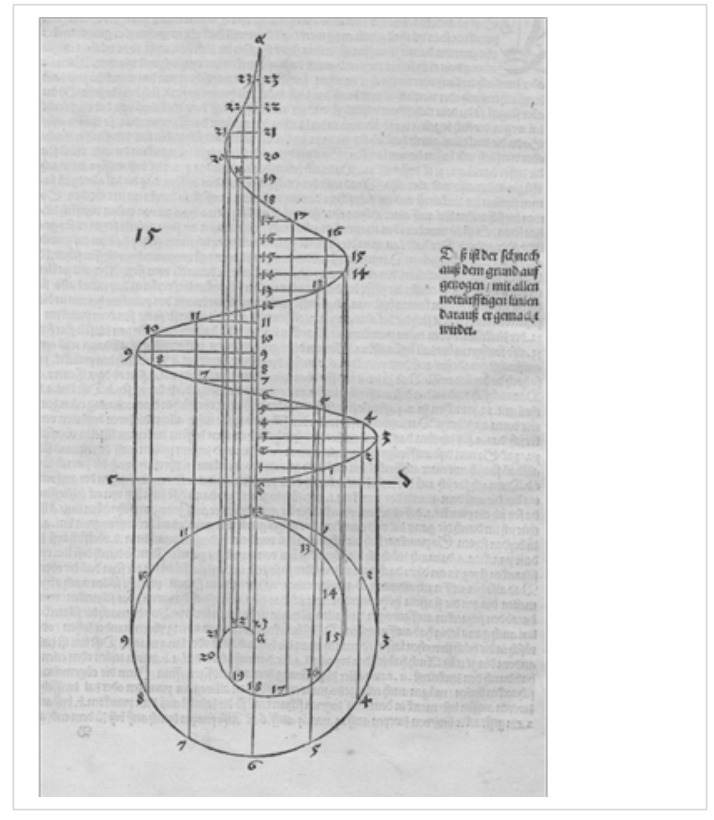

Figura 4.1. Dos proyecciones ortográficas Albrecht Dürer (1525) https://digital.slub-dresden.de/werkansicht/dlf/17139/5/

A finales del siglo XVIII se producen dos renovaciones en geometría métrica: la discusión del 5 o postulado de Euclides y el avance en el estudio de la perspectiva dando lugar a nuevas ramas, la geometría no-euclídea y la geometría proyectiva (que es objeto de nuestro interés). El matemático Gaspard Monge (1746-1818) publica en 1795 el tratado Géométrie Descriptive, publicación tardía de su trabajo desarrollado durante décadas. El método de la doble proyección ortogonal se había utilizado con anterioridad, pero ningún autor supo precisar los principios de esta técnica, desarrollar sus métodos y mostrar sus aplicaciones en el campo de la Geometría Métrica, en el de la Geometría Diferencial y extender la Geometría Cartesiana a las tres dimensiones. Para Monge la Geometría Descriptiva era sólo un aspecto más de la doctrina de las proyecciones, un instrumento útil en expresión gráfica con interés geométrico. Para Monge: 
"The objectives of descriptive geometry are two: first, to give an understanding of the methods representing objects which in nature have three dimensions on a two-dimensional surface. The second objective is to teach the way to determine the forms of objects and to deduce all the properties resulting from their respective representations» (Cvetković et al., 2019: 334).

Cabe destacar el gran esfuerzo que realizó en el campo de la educación y su gran labor como docente, en este sentido racionalizó su nuevo método geométrico y el dibujo fue materia de estudio en la Escuela militar de Mézières y en la Escuela Normal y en la Escuela Politécnica de Paris. Ya en esta época se utilizaba el dibujo con dos objetivos, en primer lugar, para representar objetos tridimensionales y en segundo lugar para obtener información consustancial a los dibujos de representación que no es directamente 'accesible' (Booker, 1961: 18). Desde nuestro punto de vista, la característica esencial de la obra de Monge es la relación que plantea entre los fundamentos analíticos con las construcciones derivadas de la geometría (Figura. 4.2) con la aplicación práctica de cada problema devolviendo el rigor y la utilidad a los estudios geométricos.

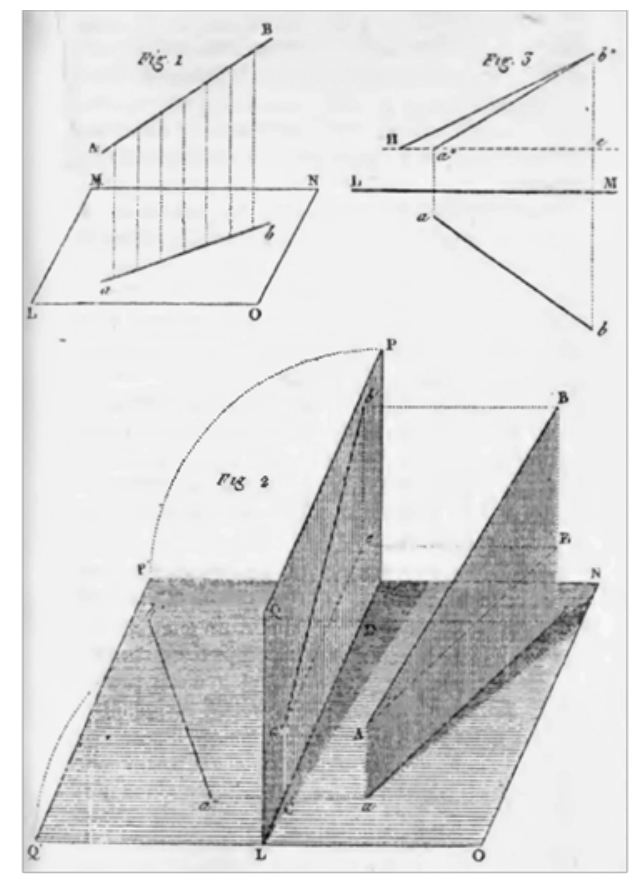

Figura 4.2. Verdadera magnitud de un segmento Gaspard Monge (1795)

Fig. 1: Representación de la proyección cilíndrica ortogonal

Fig. 2: Justificación del Sistema Diédrico, considerando dos planos ortogonales para evitar errores en la determinación de un punto y el abatimiento de un plano sobre otro.

Fig. 3: Representación del concepto 'Verdadera magnitud de un segmento' (Monge, 1822). https://archive.org/details/darstellendegeo03hausgoog/page/n15/mode/2up 
Los estudios de la perspectiva y la polaridad se completaron en la primera mitad del siglo XIX y bajo su influencia se desarrolló la Geometría Proyectiva. Poncelet (1788-1867) publicó su Tratado de las propiedades proyectivas de las figuras, estudió las propiedades geométricas que se conservan mediante proyección cilíndrica o central y aplicó su trabajo al estudio de las diversas transformaciones geométricas. Mobius (1790-1868) en su obra Cálculo baricéntrico aportó la noción general de transformación homográfica y la demostración de que la semejanza y la afinidad son casos particulares de esta. Steiner (1796-1863) completó el estudio de la geometría proyectiva.

Los avances posteriores en geometría gráfica se limitan a la revisión puntual de alguno de los procedimientos de la Geometría Descriptiva y del sistema ideado por Monge. Adam V. Millar fue el primero en concebir el Método Directo en el Sistema Diédrico de Representación y publicó, junto con Maclin en 1919, el nuevo método que incluye proyecciones auxiliares. En 1926 George Hood (George Jüssen) publicó Geometry of Engineering Drawing: Descriptive Geometry by the Direct Method. La geometría por el método directo se centra en el objeto tridimensional en sí mismo. Fomenta una actitud mental objetiva, los métodos naturales utilizados por el ingeniero, desarrolla y libera del entorno físico la capacidad de visualización espacial y la interpretación de dibujos (Hood, 1926).

El Método Directo supone la integración completa de todos los conocimientos geométricos en un sistema conceptualmente estricto donde no existen entidades distintas de las fundamentales (p. ej. línea de tierra). La proyección ortogonal está ligada a la dirección de proyección, sin la consideración de un plano fijo de proyección (p. ej. cualquier plano paralelo al vertical, cualquier plano paralelo al horizontal...) y no hay elementos distintos de los existentes en geometría que son considerados estrictamente necesarios: el punto, la recta, el plano y las relaciones métricas ortogonales entre ellos.

La geometría Descriptiva «dicta las leyes y establece las normas por las que: una forma concebida por una persona se transmite mediante el dibujo, con toda fidelidad, a otra, para su exacta asimilación» (Taibo, 1966:11). La geometría proyectiva continúa siendo importante en matemáticas $y$, aunque sea de forma básica, en cualquier disciplina que requiera la representación gráfica de formas, como en el caso de la Geometría Descriptiva, estando fuera de discusión su valor pedagógico y estético. Tanto el Sistema Diédrico ideado por Monge como 
el Método Directo del Sistema Diédrico se continúan utilizando de forma profesional e impartiendo, hoy en día, en escuelas universitarias de arquitectura e ingeniería.

La aparición a finales del s. XIX de la figura del ingeniero moderno procedente de las escuelas técnicas, es decir, con formación, contribuye a la mejora de los métodos de producción. Desde mediados del s. XVII hasta finales del s. XX se produce en Europa y Norteamérica la llamada Revolución Industrial considerada una contribución de la revolución Científica del siglo XVII. El crecimiento industrial conlleva la aparición de grandes empresas con grandes producciones en serie, de empresas muy especializadas y la necesidad de una normalización industrial en lo referente a los objetos y a su representación.

En expresión gráfica en la ingeniería se hizo necesaria la normalización para la representación, fabricación y montaje de piezas debido a la diversificación de mercados y proveedores, a la fragmentación y deslocalización del trabajo y a la fabricación a gran escala de piezas intercambiables. Las primeras normas se editaron en Alemania para la industria eléctrica y poco después la Normalización Industrial se generalizó. La normalización tiene una incidencia simplificadora en la representación de elementos al fijar el empleo de un sistema de representación y reglamentado su uso. Contribuye con normas precisas y concretas al ‘lenguaje de expresión técnica', y ha conseguido que el plano sea un documento de información completa sobre el elemento en él representado.

\subsection{La comunicación técnica mediante el dibujo industrial}

«Un privilège enviable des langues naturelles est que tout peut s'y dire. En revanche, tout ne s'y représente pas commodément.» (Lerat, 1995: 41)

En la década de 1970 se produjo una diferenciación y subdivisión de los lenguajes de especialidad según las tareas o usos específicos, esto supuso ampliar el concepto de lenguaje de especialidad que hasta entonces solo significaba especialidad de dominio. Sager (2007: 111-113) entiende que estos cambios se producen debido a factores como: «los contactos de la ciencia con la industrialización de la producción... el uso extendido de expresiones altamente técnicas... la globalización de la producción y distribución de productos». Con anterioridad Sager et al. (1980), citado en Cabré (1999: 62) proporcionan algunas claves sobre los lenguajes de 
especialidad: «special languages are semi-autonomous, complex semiotic systems based on and derived from general language; their use presupposes special education and is restricted to communication among specialists in the same or closely related fields». Son lenguajes dependientes de la lengua general con cierta autonomía que incluyen signos de referencia no lingüística, ligados al conocimiento de un nuevo marco conceptual y que se desarrollan en el seno de una comunidad lingüística. Constituyen sistemas semióticos complejos y el colectivo de usuarios requiere una formación especial para poderlos utilizar en un dominio determinado. Utilizan designaciones precisas y desarrollan un sistema de referencias que permite organizar y estructurar algunas nociones de campos específicos como: propiedades, parámetros cuantitativos, procesos, método de los procesos, conceptos gráficos etc. Kocourek (1991:12) en la misma línea que Sager plantea el lenguaje de especialidad como sistema que incluye subsistemas extralingüísticos con dependencia necesaria de las lenguas naturales «Pour nous la langue de spécialité sera une sous-langue de la langue dite naturelle, enrichie d'éléments brachygraphiques, à savoir, abréviatifs et idéographiques, qui s'intègrent à ses servitudes grammaticales».

Lerat (1995: 40-41) considera que si se admite que la lengua especializada no es otra cosa que la lengua «en la especialidad» por lo que es compatible con el carácter funcional de los enunciados que les faculta para incluir signos no lingüísticos de forma sustitutiva o adicional (traducción nuestra).

Con el objetivo de ser efectivos en la comunicación de información, los ingenieros han desarrollado un lenguaje especializado basado en elementos visuales, lenguaje gráfico o lenguaje de la representación gráfica. Los lenguajes especializados entendidos como sistemas de comunicación en EGI, pueden tratarse desde dos puntos de vista: desde su relación con las lenguas naturales y desde su convivencia con la semiótica. En ingeniería la comunicación gráfica se considera un lenguaje, en tanto que es un sistema de representación con una semántica, es decir, una relación inequívoca de significantes y significados y una sintaxis, a saber, un conjunto de reglas para construir nuevos significados mediante la disposición de los significantes (Maton, 2007: 14). El lenguaje de la representación gráfica utiliza dibujos técnicos y símbolos como un medio de comunicación preciso con reglas definidas que influye en la manera de pensar y en la 
forma en que el ingeniero aborda los problemas (pensamiento gráfico) y que además tiene la intención clara de influir en la percepción de quien recibe la información.

El lenguaje de la representación gráfica se puede abordar desde dos puntos de vista: atendiendo a la estructura de la representación gráfica, es decir, su forma y sus componentes; y atendiendo a las diferentes funciones que se les asignan. Según el primero, los diferentes signos visuales que se utilizan, su significado y su sintaxis hacen referencia a la relación entre el lenguaje gráfico y una referencia externa que en el caso de EGI puede ser un elemento geométrico, o un objeto de producción industrial (cf. Esandi, 2006). Para entender los distintos tipos de representación gráfica se debe identificar el significado atribuido a cada signo, la sintaxis utilizada entre los signos y la referencia a elementos externos representados con mayor o menor grado de fidelidad (iconicidad).

El lenguaje gráfico surge de la necesidad de establecer una referencia visual entre la representación y el objeto que designa. La capacidad cognitiva requerida, el modo de razonamiento y el método de ejecución de una representación gráfica depende del modo y de la intención en la representación.

Es posible la representación gráfica de conceptos y de vínculos entre estos conceptos en un espacio plano sin las reglas secuenciales del lenguaje donde pueden coexistir elementos con diferentes significados permitiéndose un procesamiento conjunto de la información. En este sentido se manifiestan Sadoski et al. (1991):

"Information in the verbal system is organized in a way that favors sequential, syntactic processing, whereas nonverbal information (especially in the visual modality) is organized more in the form of holistic nested sets with information available for processing in a synchronous or parallel manner. Interconnections between the systems allow for great variety in cognitive activity " (Sadoski et al., 1991: 473).

El segundo punto de vista se centra en las funciones de la representación gráfica, en todo caso son referencias a las funciones de las representaciones gráficas ubicadas junto a un texto. Las aportaciones de los aquellos autores y las funciones, que mejor representan la casuística de nuestro ámbito de conocimiento, focalizan este trabajo puesto que el campo de la representación gráfica es muy amplio y diverso. Según Macdonald-Ross (1977: 70) los objetivos 
de la representación gráfica científica y técnica son cuatro y no son excluyentes entre sí (traducción nuestra):

- icónico, el propósito es mostrar el aspecto objeto, e identificar y etiquetar partes clave;

- visualización de datos, el propósito es mostrar los resultados de las observaciones empíricas;

- explicativo, el propósito es mostrar las relaciones lógicas entre ideas clave;

- operacional, el propósito es ayudar al lector a realizar alguna tarea bien especificada.

El lenguaje gráfico proporciona una base para la gramática o las reglas que deben establecer relaciones lógicas dentro del sistema de símbolos utilizado y una correspondencia métrica recíproca o bidireccional entre las representaciones de los objetos, que se encuentran en el espacio, y sus formas. Las relaciones lógicas permiten basar la intuición visual en reglas científicas y como resultado se obtienen intuiciones visuales, pero con valor científico.

Se entiende por información contenida en un documento científico o técnico a la relación que se establece entre un elemento y el 'todo' en el que se inserta. Los elementos que 'transportan' la información tienen bien, una disposición lineal o bien, una disposición gráfica. Esta disposición de las unidades de información en el caso de ser lineal, operan secuencialmente ordenadas, pero en el caso de las representaciones gráficas, se utiliza el espacio como vector y toda la información se presenta simultáneamente en un único espacio tipográfico (Pétroff 1984:57-58). Los documentos científicos y técnicos, producidos por investigadores e ingenieros, tienen una disposición conjunta de textos -combinaciones lineales- y de representaciones gráficas que ocupan el espacio según un orden lógico. Para Bertin (1977) una característica importante de las unidades gráficas es la simultaneidad que da al receptor la posibilidad de tener información global y sintética al estar todos los elementos organizados en un único espacio y con un mismo sistema de referencia.

Los documentos y la información producida en el ámbito de conocimiento de la expresión gráfica en la ingeniería tienen un componente especializado visual destacado. En los dibujos de ingeniería o dibujos técnicos la información aportada está formada, por una parte, por la representación de elementos geométricos y de elementos topológicos en clara referencia a un referente externo y por otra, por símbolos. Estos símbolos tienen dos características, ser o no, arbitrarios y ser reversibles. En EGI se utilizan signos con significado arbitrario y signos con 
significado descriptivo. Cuando el significado del signo es arbitrario (Lerat, 1995: 34) no pretende la asignación de un significado a un significante lingüístico, sino de un signo no lingüístico a una noción. Cuando el signo es descriptivo pretende siempre una especificación geométrica precisa de un objeto. El signo en EGI es reversible, es posible que un referente externo que sólo existe en la mente de un ingeniero se represente gráficamente (se fabrique y exista) y que un objeto físico (que ya existe) se represente gráficamente. A partir de una representación plana de un objeto se puede obtener información precisa de un objeto real, esto se lo deben los ingenieros del s. XXI a la contribución de Gaspard Monge (figura 4.2).

Según Saussure (1974 [2011]), la naturaleza arbitraria del signo lingüístico, cuyo significado solo existe en un contexto de símbolos, se puede aplicar en ingeniería a la relación que se establece entre unidades léxicas y símbolos y entre símbolos y otros símbolos. Existe un sentido metafórico del símbolo que permite interpretar el significado, utilizar la analogía o ser creativo (Barnard, 2012: 9). Los símbolos que adquieren su significado completo en una representación gráfica en la ingeniería, en un contexto en relación a otros símbolos, lo hacen mediante las especificaciones normalizadas que editan los organismos competentes.

Bertin (1973 [1967]) aprecia varios tipos de dibujos: dibujos de inventario, dibujos simplificados y dibujos de procesamiento. La función de los dibujos de inventario es registrar la información íntegramente. La función principal de los dibujos simplificados es de comunicación, este tipo de dibujos contiene datos que están ordenados y para facilitar la retención de la información, la hacen visible presentando los elementos con distinto tratamiento (algunos son más visibles debido a una trama más gruesa u otros métodos visuales). La función de los dibujos de procesamiento es conservar una objetividad en relación con los datos presentados y la interpretación de los signos da lugar a un único significado posible.

Hoy en día los dibujos de ingeniería o dibujos técnicos se utilizan para fijar y/o transmitir información técnica en los documentos y proyectos técnicos. Este tipo de dibujo es un medio de expresión no verbal que permite el procesamiento, la comunicación y el almacenamiento de información técnica vinculada a una representación gráfica de objetos. Se considera un instrumento gráfico de pensamiento y comunicación profesional tanto en tareas de diseño como de fabricación. Esto implica que el dibujo es una representación funcional operativa dirigida hacia la acción, en las tareas de diseño, el dibujo técnico es un medio para reducir la 
incertidumbre de procesamiento gráfico. En las tareas de fabricación, es una representación del objetivo a alcanzar y una guía de acción, puesto que las indicaciones que especifica dirigen, en parte, el modo de fabricación.

Para Weil-Fassina y Rabardel (1985: 302) los campos conceptuales que caracterizan su contenido son:

- el código gráfico definido como el conjunto de significantes, significados y sus relaciones, así como todas las reglas de escritura;

- la tecnología entendida como el conocimiento de los objetos y los sistemas técnicos y las técnicas y los modos de producción;

- la geometría del dibujo o relaciones geométricas intrínsecas que determinan el método de representación y regula las relaciones del objeto con los planos de proyección, así como los planos de proyección entre ellos.

El dibujo técnico es un medio de comunicación necesario como instrumento para generar un modelo o una representación gráfica de un objeto real o de una idea. En ambos casos se necesitan conocimientos y habilidades especiales para poder representar ideas técnicas con suficiente precisión (p.ej. para que un objeto sea fabricado en serie). Por lo tanto, se trata de un verdadero código profesional y no una simple imagen. Es un conjunto de elementos significantes, con los cuales se asocia, de manera convencional, un conjunto de significados, con reglas de aplicación y composición. Las descripciones de productos o de estructuras complejas se comunican mediante dibujos que forman parte de un proceso visual, no verbal.

La representación gráfica de ciertas entidades (conceptos y objetos) tiene ventajas sobre su representación verbal (Pitch, 2011:229):

- tienen mayor precisión;

- ocupan menos espacio;

- son independientes el lenguaje (en casi todas las culturas);

- permiten una lectura no lineal;

- puede ser obligatorio su uso;

- dan al receptor la posibilidad de tener una información global, sintética y simultánea porque todos los elementos están organizados en un mismo espacio. 
Desde el punto de vista formal, en el lenguaje verbal, los signos individuales (palabras) se combinan en una secuencia lineal que permite analizar tanto el significado de cada signo como su posición dentro de la sintaxis de la secuencia (Ashwin, 1984: 52). Por esta razón, la comunicación verbal ha sido descrita como un sistema discursivo. La comunicación gráfica generalmente presenta, en lugar de secuencias, múltiples conjuntos de signos, y el receptor debe componer mentalmente su propio orden de la presentación, pudiendo atender primero al todo y luego a cada una de sus partes, o viceversa; repitiendo este proceso tantas veces como sea necesario para la comprensión completa de la información. Por esta razón los sistemas gráficos han sido descritos como sistemas de representación, a diferencia de los discursivos.

Los tipos de representaciones gráficas abordados en nuestro trabajo son de cuatro tipos: figuras de análisis que representan conceptos teóricos, representaciones diédricas (de conceptos teóricos o de problemas), dibujos técnicos de objetos y símbolos normalizados. Las figuras de análisis que representan conceptos teóricos ( $p$. ej. perpendicularidad, figura 4.3) requieren un nivel de abstracción menor pues son representaciones que indican un procedimiento, no requieren instrumentos de precisión para su elaboración, representan un razonamiento en perspectiva y requieren una capacidad de visualización espacial.

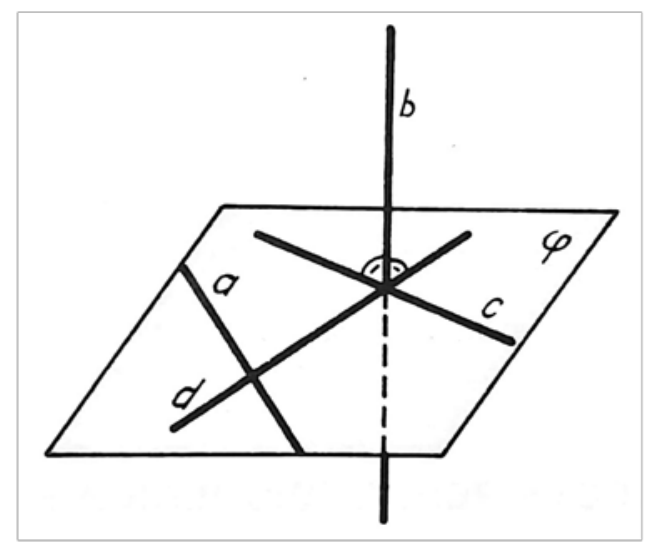

Figura 4.3. Figura de análisis. Recta $\boldsymbol{b}$ perpendicular $\boldsymbol{a}$ plano $\boldsymbol{\varphi}$ (González et al., 1982)

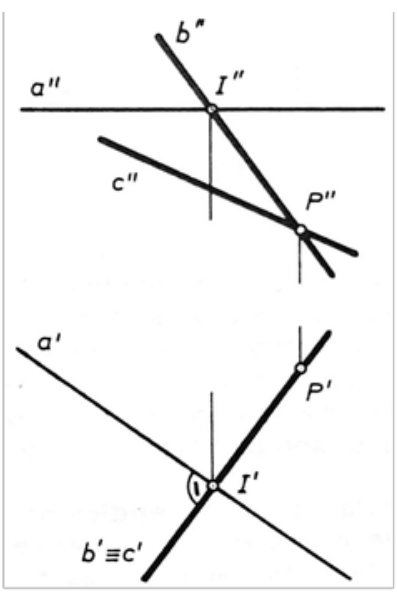

Figura 4.4. Representación diédrica de una recta perpendicular a la recta $\boldsymbol{a}$ y pasa por un punto $\mathbf{P}$ (González et al., 1982)

Las representaciones diédricas requieren mayor nivel de abstracción, son representaciones secuenciales que establecen relaciones o propiedades geométricas que permiten llegar a la solución de un problema, representan un proceso gráfico reversible entre datos y solución, requieren trazados precisos, representan relaciones métricas (recta perpendicular a plano, fig.4.4) y requieren formación para su interpretación. 
Los dibujos normalizados o dibujos técnicos requieren un nivel de abstracción elevado; son representaciones no ambiguas de objetos; aportan la información completa para la definición formal y la fabricación del objeto. Son representaciones convencionales, es decir,
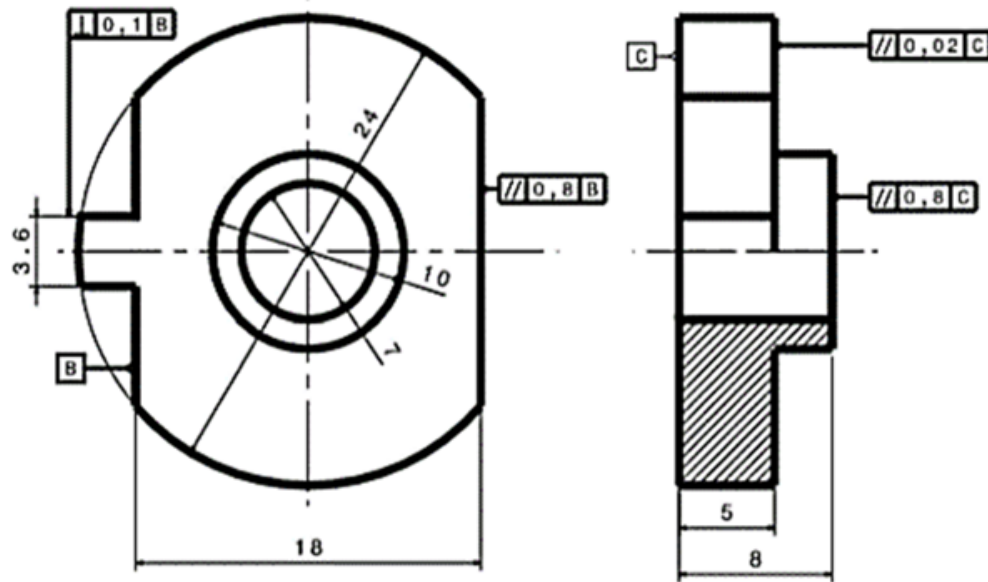

Figura 4.5. Dibujo normalizado de una pieza, con acotación de tolerancias geométricas de paralelismo y de perpendicularidad (símbolos normalizados)

atienden a las normas internacionales de representación y pueden, a su vez, incluir símbolos normalizados; requieren formación para su correcta interpretación y pueden trazarse con instrumentos de dibujo o a mano alzada (figura 4.5). Es un ejemplo de utilización de un medio eficaz para comunicar ideas y soluciones a problemas técnicos utilizando la geometría, las técnicas de representación gráfica y la normalización.

Por último, los símbolos normalizados son representaciones que requieren un nivel de abstracción elevado. Especifican elementos de acotación que están referidos a diferentes campos técnicos que informan sobre el proceso de fabricación; su Figura 4.6. Tolerancia de paralelismo de una superficie con respecto a una superficie de referencia (ISO significado es arbitrario y

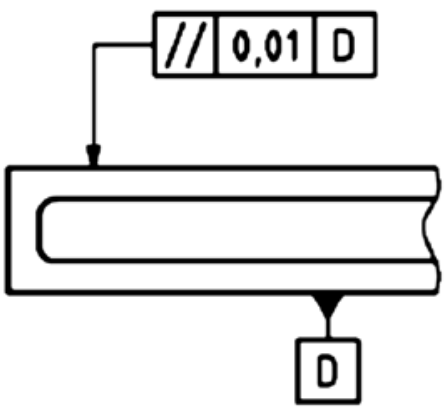
convencional, pero reconocido internacionalmente; requieren formación para su correcta interpretación; tienen una disposición normalizada y pueden trazarse con instrumentos de dibujo o a mano alzada (figura 4.6.). 
La representación gráfica combinada con la representación verbal aumenta la expresividad al tiempo que conserva las ventajas comunicativas tanto de la imagen (Pitch, 2011:232) como del texto. En algunos casos los dos componentes son independientes y permiten una aproximación independiente a un concepto o a un proceso, aunque a veces sesgada y en todos los casos constituyen un tándem comunicativo. En términos generales las imágenes ayudan a comprender los conceptos y las designaciones referenciales en los ámbitos científico y tecnológico. El uso de la representación gráfica está justificado desde un punto de vista cognitivo enfatizando su papel en todo el procesamiento de la información.

Es necesario tener en cuenta el referente visual, la estructura y las funciones de la representación gráfica en nuestra propuesta de diccionario, su relación funcional con la parte verbal con la que se complementan y su influencia a la hora de determinar la o las funciones del diccionario.

\subsection{La comunicación técnica en el ámbito académico de la ingeniería industrial}

El período de formación de futuro ingeniero industrial, con algunas diferencias entre las distintas especialidades, incluye la consulta de distintos materiales documentales, como libros de texto, manuales, normas, etc. En este trabajo de investigación se debe identificar los conceptos que formarán parte de nuestra propuesta de diccionario y elegir el material que se considera más adecuado en el entorno académico de EGI en la Ell de la UVa. Una disciplina de larga tradición en las escuelas de ingeniería industrial de toda España y entre las que se comparten metodologías y se utilizan recursos didácticos similares. Las publicaciones elegidas para este estudio y futuras ampliaciones, son: tratados sobre el método directo del Sistema Diédrico, colecciones de prácticas de la asignatura Expresión gráfica en la ingeniería (cf. 5.5) que abarcan los fundamentos geométricos del dibujo técnico, los sistemas de representación, la representación normalizada de objetos y las normas UNE (según el caso, las equivalentes internacionales vigentes) que se mencionan a continuación:

- UNE 1032:1982. Dibujos técnicos. Principios generales de representación (ISO 128, Technical drawings); 
- UNE 1039, Dibujos técnicos. Acotación. Principios generales, definiciones, métodos de ejecución e indicaciones especiales. (ISO 129-1:2018, Technical drawings -- Indication of dimensions and tolerances -- Part 1: General principles);

- UNE-EN ISO 1302, Especificación geométrica de productos (GPS) Indicación de la calidad superficial en la documentación técnica de productos;

- UNE-EN ISO 6410-1, Dibujos técnicos. Roscas y piezas roscadas. Parte 1: Convenios generales;

- UNE 1120:1996, Dibujos técnicos. Tolerancias de cotas lineales y angulares;

- UNE-EN ISO 1101:2017, Especificación geométrica de productos (GPS). Tolerancia geométrica. Tolerancias de forma, orientación, localización y alabeo (ISO 1101:2017).

En lo que se refiere a la parte lingüística de los textos que frecuentemente manejan profesores y alumnos de éste área de conocimiento en Bertoline y Medal (1999) se destacan como ejemplos representativos:

- descripciones precisas de detalles: «Por lo general, el texto de la dimensión tiene una altura de $3 \mathrm{~mm}$ ० 0,125 " con un espacio entre las líneas del texto de $1,5 \mathrm{~mm}$ ० 0,062"» (ibid. p.686)

- información escueta: «Tolerancia. Es la variación en magnitud permitida para una dimensión en particular» (ibid. p.705)

- la concisión en la selección verbal: «Dimensión más y menos. Variación positiva y negativa permisible de la dimensión especificada.» (ibid. p.705).

En estos manuales especializados de EGI también es frecuente la indicación del o de los métodos de resolución de problemas y de las aplicaciones directas de los conceptos gráficogeométricos. El objetivo, al facilitar este tipo de información, es de carácter operativo y cognitivo. El alumno ha de 'saber hacer' y ser capaz de demostrar la adquisición de conocimiento mediante su aplicación práctica a la resolución de problemas, que pueden ser casos teóricoprácticos o casos de ámbito profesional. A modo de ejemplo González et al., (1982: 90) presentan en una tabla resumen los casos tipo de problemas en perpendicularidad y sus aplicaciones directas en la resolución de las distancias entre elementos geométricos en sistema diédrico y figuran en el manual a modo de resumen como el de la Tabla 4.1. Es frecuente encontrar ejemplos de este modo de proceder, según el nivel de conocimiento, en las publicaciones recomendadas a los alumnos. 


\begin{tabular}{|c|c|c|c|}
\hline & PERPENDICULARIDAD & \multicolumn{2}{|c|}{ DISTANCIAS } \\
\hline \multirow[b]{2}{*}{$\begin{array}{l}\text { Perpendicularidad } \\
\text { entre rectas }\end{array}$} & \multirow{2}{*}{$\begin{array}{l}\text { Trazar por... } \\
\text {... un punto, una recta perpendicular a } \\
\text { otra dada. (Infinitas soluciones, cuyo } \\
\text { lugar geométrico es el plano } \\
\text { perpendicular a la recta dada). }\end{array}$} & De punto a recta & \multirow[b]{2}{*}{$\begin{array}{l}\text { Utilizando } \\
\text { proyecciones } \\
\text { auxiliares }\end{array}$} \\
\hline & & Entre rectas paralelas & \\
\hline \multirow{5}{*}{$\begin{array}{l}\text { Perpendicularidad } \\
\text { entre recta y plano }\end{array}$} & \multirow{3}{*}{$\begin{array}{l}\text { Trazar por... } \\
\text {... un punto, una recta perpendicular a un } \\
\text { plano dado. }\end{array}$} & De punto a plano & \multirow{3}{*}{$\begin{array}{l}\text { Utilizando o } \\
\text { no, } \\
\text { proyecciones } \\
\text { auxiliares }\end{array}$} \\
\hline & & Entre planos paralelos & \\
\hline & & $\begin{array}{l}\text { Mínima distancia } \\
\text { entre dos rectas que } \\
\text { se cruzan }\end{array}$ & \\
\hline & \multirow{2}{*}{$\begin{array}{l}\text { Trazar por... } \\
\text {... un punto, un plano perpendicular a una } \\
\text { recta dada. }\end{array}$} & De punto a recta & \multirow{2}{*}{$\begin{array}{l}\text { Sin utilizar } \\
\text { proyecciones } \\
\text { auxiliares }\end{array}$} \\
\hline & & Entre rectas paralelas & \\
\hline \multirow{3}{*}{$\begin{array}{l}\text { Perpendicularidad } \\
\text { entre planos }\end{array}$} & $\begin{array}{l}\text { Trazar por... } \\
\text {... un punto, un plano perpendicular a otro } \\
\text { dado (Infinitas soluciones) }\end{array}$ & & \\
\hline & $\begin{array}{l}\text { Trazar por... } \\
\ldots \text { una recta, un plano perpendicular a } \\
\text { otro dado }\end{array}$ & & \\
\hline & $\begin{array}{l}\text { Trazar por... } \\
\ldots \text { un punto, un plano perpendicular a } \\
\text { otros dos dados. }\end{array}$ & & \\
\hline
\end{tabular}

Tabla 4.1. Resumen de problemas de perpendicularidad y aplicación a distancias. González et al., (1982)

La información contenida en este resumen muestra las posibles opciones en casos generales, indica el modo de proceder y por último indica la aplicación práctica y el método posible a utilizar.

Los documentos que publica AENOR e ISO relativos a los principios, las técnicas de representación y la simbología gráfica aplicables a dibujos técnicos son recomendaciones publicadas para facilitar la lectura y la comprensión de dibujos y pueden afectar a diferentes campos de aplicación como: mecánico, eléctrico, ingeniería civil, arquitectura, etc. A pesar de no tener un carácter prescriptivo se consideran de obligado cumplimiento entre el colectivo de profesionales de la ingeniería industrial a fin de asegurar el intercambio de dibujos y la comunicación precisa de información técnica dada la globalización del diseño, la fabricación y el montaje de componentes y productos industriales. En algunas normas (p. ej. UNE 1039 (ISO 129)) las figuras simplificadas en el texto no pretenden reflejar ninguna situación real, según se indica en la propia norma. Esto obliga a una interpretación dirigida e inequívoca del significado. 


\subsubsection{La reformulación pedagógica en la adquisición de conocimiento}

La información científica y técnica para ser relevante, «debe ser de buena calidad, llegar al momento correcto, en el lugar correcto, y llegar a la persona adecuada» (Pétroff, 1984: 53). Como destaca el autor estos criterios de relevancia de la información científica y técnica son condiciones necesarias, pero insuficientes si la formulación de esta información no se adapta al destinatario previsto, en este sentido se habla de la reformulación en el discurso científico y técnico.

La reformulación, para este autor, consiste en adaptar la información a una nueva situación, a un tipo específico de receptor y de acuerdo con una acción determinada. Todas las unidades, tanto las unidades lingüísticas como las gráficas, constituyen un sistema susceptible de sufrir reformulaciones

La documentación utilizada y producida en el ámbito de la Expresión Gráfica en la Ingeniería es un ejemplo de discurso que se caracteriza por la simultaneidad de las relaciones que se establece entre los elementos o unidades de información y que constituyen una malla o red entre las unidades de información. En EGI la malla está formada por relaciones visuales entre elementos de información textuales y gráficos. Cualquier reformulación dirigida a modificar esta red de conocimiento se expresa mediante unidades adicionales de anticipación o retroalimentación, actualización o profundización del conocimiento (Pétroff, 1984: 65).

Para Pétroff (1984: 66-67) la reformulación es un acto pedagógico y describe la progresión en el aprendizaje como «spirale de l'intelligence». Viene al caso, especialmente en EGI, este símil con un 'movimiento en espiral' o una espiral. Dice el autor que la adquisición de conocimiento no es un movimiento rectilíneo, es un movimiento en espiral que 'retrocede o vuelve a dirigir la atención' sobre antiguos logros, pero cada vez a una distancia mayor del origen, abarcando un campo de visión mayor y a un nivel superior. El movimiento en espiral se compone de dos movimientos: uno rectilíneo (de avance) y uno de rotación (de retorno a puntos de vista anteriores). Si imaginamos un punto haciendo este recorrido compuesto, un observador podría percibir un movimiento de retroceso al volver a pasar por puntos similares, y en parte es correcta esta apreciación, 'se vuelve sobre antiguos logros', pero realmente se está en un nivel superior y el campo de visión es mayor. 
El carácter pedagógico de nuestra propuesta lexicográfica se enmarca en estas consideraciones que se han expuesto y se pretende materializar una acción lexicográfica premeditada que facilite el acceso a datos como un paso previo en el avance de la adquisición de conocimiento. Además, se pretenden definir las necesidades de tipo cognitivo lexicográficamente relevantes que surgen en situaciones extralexicográficas en el proceso formativo del usuario. Por último, la propuesta de un diccionario pedagógico pretende el desarrollo de una cultura lexicográfica que mejore la competencia léxica del estudiante.

\subsection{Funciones de la representación gráfica en la ingeniería}

Los documentos de ingeniería gráfica están intrínsecamente vinculados al pensamiento visual, desde las primeras etapas conceptuales hasta la producción final. En este contexto y a lo largo de este proceso la representación gráfica cumple tres funciones: el registro de información, la comunicación de información y el procesamiento de información (Bertin, 1973 [1967]) y los distintos tipos de dibujos se adaptan para cumplir cada una de estas funciones.

La primera función de las representaciones gráficas es la de registrar información. Esto evidencia el vínculo entre la representación gráfica y la necesidad de una memoria externa del individuo (expansión de la memoria), que pueda proporcionar un inventario de información conveniente y exhaustivo (Maton, 2007: 72). Los dibujos y los croquis iniciales representan un medio de acumular conocimiento sobre objetos que solo se asemejan a una forma descriptiva escrita y representan elementos que permiten aumentar la memoria de las técnicas y asegurar la transmisión de las ideas. Esta función permite la utilización de dibujos y de figuraciones complejas con múltiples imágenes, limitadas solo por reglas de legibilidad.

La segunda función es la de comunicación de la información. El análisis técnico, la ingeniería de fabricación y el diseño funcional requieren la producción y lectura de información gráfica como parte de un proceso que comienza con la habilidad para visualizar, identificar un problema técnico y las soluciones posibles. Las primeras ideas se registran mediante croquis, después se crean los modelos geométricos normalizados, los dibujos de detalle y finalmente los modelos tridimensionales que contienen todos los datos necesarios en el proceso de producción. En ingeniería, se estima que el 92 por ciento del proceso de diseño se basa en la información gráfica, el 8 por ciento se divide entre las matemáticas y las comunicaciones escritas 
y verbales. La redacción y la documentación, junto con el modelado de diseño, comprenden más del 50 por ciento del tiempo del ingeniero y son actividades puramente visuales y gráficas (Bertoline et al., 2002).

La tercera función consiste en facilitar el procesamiento de la información. En primer lugar, se constata que, para resolver un problema gráfico, es necesario tener cierto conocimiento especializado y dominar ciertas reglas. Por otra parte, los dibujos deben adaptarse a las capacidades de la memoria y deben proporcionar los medios para retener información utilizando la memoria visual. Se consideran acertados los argumentos de Larkin y Simon (1987:99) -a pesar de su especial interés en diagramas gráficos- sobre «una economía de naturaleza cognitiva, referida a la noción de eficiencia de la información», a la facilidad y velocidad de los enlaces entre los datos disponibles consecuencia de la disposición espacial de la información. Los datos se procesan de manera diferente dependiendo de si es una presentación verbal o una representación gráfica.

El psicólogo Gardner (1984) considera que el procesamiento de la imagen visual no es el resultado de una mera intuición, sino que requiere una inteligencia espacial (Henderson, 1998: 29). La inteligencia espacial tiene las siguientes características:

- la habilidad de reconocer instancias de los mismos elementos;

- la habilidad para transformar o reconocer la transformación de un elemento en otro;

- la capacidad para evocar imágenes mentales y después transformarlas;

- la capacidad para producir una imagen gráfica de la información espacial.

\subsection{Estudio empírico de diccionarios técnicos}

En las áreas de conocimiento en las que es necesaria la comunicación no verbal se observan distintos tipos y distinta frecuencia de uso de las representaciones gráficas.

En el ámbito de la comunicación gráfica técnica se utilizan distintos tipos representaciones: imágenes, figuras, dibujos técnicos o planos. El papel que desempeñan y las características de estas representaciones gráficas varía en función del objetivo del mensaje a comunicar y requieren distinto nivel de abstracción y distinto tipo de convencionalismos.

Las condiciones tecnológicas actuales de publicación y, en particular, todo lo relacionado con la presentación, la posibilidad de introducir fácilmente fotografías, bocetos, dibujos, etc., 
han cambiado la percepción que se tiene de un texto científico y técnico. De hecho, la imagen y las unidades gráficas ya no son ilustraciones periféricas, sino unidades de información por derecho propio que contribuyen directa o indirectamente a la producción de significado (Pétroff, 1984:56).

El análisis de algunos diccionarios de ámbitos técnicos que incluyen un componente gráfico adjunto a la definición o descripción de las entradas al diccionario evidencian la importancia o necesidad otorgada a las representaciones gráficas que incluyen los dos sistemas de representación, verbal y gráfico, con distinto grado de dependencia. Se entiende que son dependientes cuando es necesario leer el texto para entender el significado de la figura y viceversa. Es interesante para nuestro trabajo la identificación del destinatario (si estuviera declarado), sus necesidades, habilidades y situación; el formato del diccionario; el análisis del valor lexicográfico; el tipo de diccionario en función del idioma monolingüe-bilingüe... y el análisis del componente no verbal gráfico y su ausencia.

Los diccionarios técnicos que a continuación se analizan, a modo de ejemplos representativos, pueden contribuir a identificar la aportación al significado de las representaciones no verbales (Pitch, 2011). Los diccionarios seleccionados son:

1. Toms, W. H. \& Devoto, J. (1734). The Builder's Dictionary: or, Gentleman and Architect's Companion.

2. Robb, L. A. (1979). Diccionario para ingenieros: español-inglés e inglés-español

3. Schwartz, V. et al. (1984) Illustrated Dictionary of Mechanical Engineering: English, German, French, Dutch, Russian.

4. Follows, G. H. (1906). Universal Dictionary of Mechanical Drawing. Engineering news publishing Company.

5. Real Academia de Ingeniería (España). (2014). Diccionario Español de Ingeniería. Real Academia de Ingeniería.

6. Atkins, T., \& Escudier, M. (2013). A dictionary of mechanical engineering. Oxford University Press.

7. 9TDICTER9T. 9TDiccionario de la ciencia y de la técnica del Renacimiento. 9TMa Jesús Mancho Duque (dir.), Ediciones Universidad de Salamanca.

1. THE BUILDER'S DICTIONARY: OR, GENTLEMAN AND ARCHITECT'S COMPANION, (1734)

- Diccionario: monolingüe en inglés.

- Soporte: papel, copia digitalizada de acceso en línea.

- Contenido: términos de arquitectura, arte y oficios; teoría y práctica para constructores. 
- Objetivo: la exposición ordenada de conocimiento, «and may be referred to with ease and pleasure».

- Destinatario: expertos y profanos que estudian la parte mecánica de los edificios.

- Necesidades: necesidad de información para resolver problemas.

- Situación: adquisición de conocimiento, recordar conceptos teóricos y prácticos y resolver problemas prácticos.

- Habilidades: se requieren conocimientos básicos de aritmética, geometría, perspectiva, cálculo...

- Ejemplo de lema: Arch

- Contenido lexicográfico, en orden alfabético.

- Información gramatical: etimológica [of Arcus, L.].

- Inflexiones: arch, arches.

- Definición 1: is a Part of any Curve Line, e.gr. as of a Circle, an Ellipsis, and the like.

- Definición 2: ARCH [in Architecture] is a concave Building, rais'd with a Mould bent in the Form of the Arch of a Curve, and ferving as an inward Support of any Structure.

- Colocaciones: arch of a circle, equal arches, semicircular arches.

- Ejemplo 1: The Base or Line that joins the two Extremes of the Arch, is called the Chord; and the Perpendicular raised in the Middle of that Line, is the Sine of the Arch, as A and B in the Figure.

- Ejemplo 2: Every Circle is supposed to be divided into 360 Degrees, and an Arch is estimated according to the Number of these Degrees it takes up: Thus, an Arch is said to be 20, 30, 5-0, 80, 100 Degrees.

- Ejemplo 3: How to describe a Scheme Arch, when the Base and Perpendicular are given. First: draw the Line A B, then draw a Line at Right Angles with it, through the Middle $D$, at Pleasure, and set up the Height you desire to rise from $D$ to $C$, and draw the Line $C A$; then open your Compasses to any convenient Distance, set one Foot in C, and strike the Arch FE; with the same Opening of the Compasses, set one Foot in $A$, and strike the Arch from $G$ to $H$, at Pleasure; then take the Radius EF in your Compasses, and set it on the Arch $G H$, as at I, and draw a Right Line from $A$ through $I$, to cut the Perpendicular, as at $K$; then is $K$ he Centre to strike the Arch ACB, Which was to be done.

- Representación no verbal:

- Tipo: dibujo o figura de análisis, imagen de objeto y de mecanismo.

- Forma parte de la definición: refuerza la definición y concreta la interpretación.

- Frecuencia: en total incluye más de 200 figuras, en número de entradas con componente gráfico es inferior al $10 \%$.

- Ejemplos de figuras:

- Ejemplo 1, el componente gráfico representa un concepto (ver figura 4.7).

- Ejemplo 3, el componente gráfico representa un procedimiento (ver figura 4.8). 


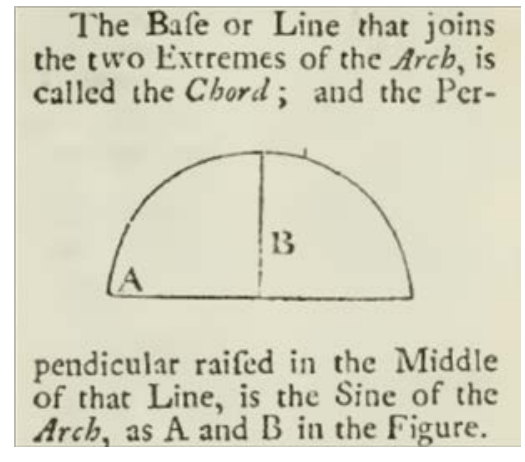

Figura 4.7. Arco de circunferencia

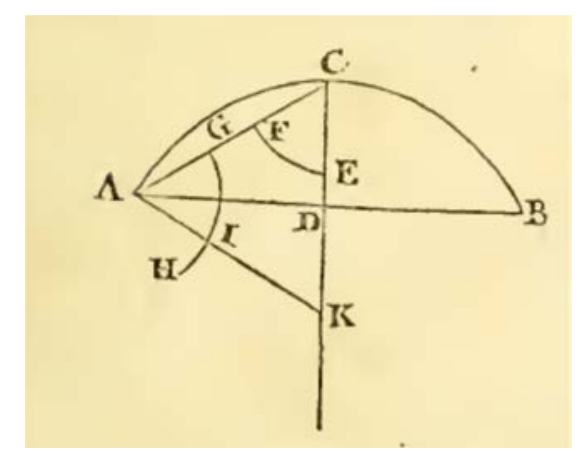

Figura 4.8. Procedimiento para trazar el arco $\mathrm{ACB}$ conocida la recta $\mathrm{AB}$ y la

2. DICCIONARIO PARA INGENIEROS: ESPAÑOL-INGLÉS E INGLÉS-ESPAÑOL, (1979).

- Diccionario: bilingüe, español- inglés e inglés-español.

- Soporte: papel.

- Contenido: términos de ingeniería civil con referencias a la química, geología y metalurgia; ingeniería eléctrica y mecánica; minería, arquitectura naval; incluye glosarios oficiales de las sociedades de ingeniería; incluye el registro de significados pluriverbales y equivalentes de locuciones pluriverbales (arandela de empaque o de guarnición, packing washer).

- Objetivo: incluir los términos más importantes, sus equivalentes y «proporcionar información que no se encuentra en otra parte».

- Destinatario:

- Necesidades: necesidad de información orientada a la comunicación, términos equivalentes aceptados en español (no descripciones).

- Situación: un técnico analiza documentación (gráfica) de una maquinaria donde los componentes a piezas están identificados en inglés. Los dibujos técnicos se utilizan para identificar componentes o piezas y comprender el funcionamiento de los mecanismos.

- Habilidades: no se especifican, pero se deduce que son personas iniciadas en el ámbito profesional con conocimientos técnicos.

- Ejemplo de diferentes lemas: $\quad$ arco $m$ (masculino), arch; (elec) arc.

abrasión $f$ (femenino), abrasion, (hyd) scour.

abrasivo $m$ (masculino), a (adjetivo), abrasivo.

- Contenido lexicográfico, orden alfabético.

- Información Gramatical: indicación de género en sustantivos en español $(m, f)$.

- Inflexiones: abrasión $f$, abrasivo $a$.

- Definición: evita las definiciones (el autor cree que están fuera de lugar en un diccionario técnico bilingüe). Excepcionalmente se utilizan para definir términos «al carecer de un equivalente satisfactorio, (p.ej. abetunar, to coat or impregnate with pitch) y en algunos casos para evitar ambigüedades». 
- Sinónimos: ajuste sin holgura, snug or wringing or tunking or push or working fit

- Colocaciones (Incluye 51 colocaciones de la entrada arco): -a regla,-acarreador de trozas,-adintelado, ...,-- de la hélice,--de radio constante,-de tres centros, ...,tricéntrico o carpanel.

- Ejemplos: no incluye.

- Representación no verbal: no incluye.

3. ILLUSTRATED DICTIONARY OF MECHANICAL ENGINEERING: ENGLISH, GERMAN, FRENCH, DUTCH, RUSSIAN (1984).

- Diccionario: inglés, alemán, francés, holandés y ruso.

- Soporte: en papel.

- Contenido: términos equivalentes en cinco idiomas, el idioma llave es el inglés

- Objetivo: la asimilación de términos

- Destinatario: estudiantes de ingeniería mecánica en una segunda lengua y puede ser útil para traductores

- Necesidades: necesidad de información orientada a la comunicación

- Situación: adquisición de conocimiento, traducción

- Habilidades, no se especifican, pero se deduce que son personas iniciadas en el ámbito profesional con conocimientos técnicos

- Contenido lexicográfico: está agrupado en 14 temas, la mayoría son unidades pluriverbales

- Información Gramatical: indicación de género $(m, f, n)$, número $(p /)$

- Sinónimos: diagram of distributed load, load diagram; (toothed) gearing, gear set, gear train; storage cell, accumulator.

- Representación no verbal: las ilustraciones tienen la función informativa ayudar a recordar los términos, actuar como intermediario universal entre lenguas

- Tipo: dibujos simplificados o ilustraciones informativas del objeto, diagramas de procesos (figura 4.11) y esquemas (figura 4.12) que forman parte del significado, representaciones normalizadas de objetos

- Frecuencia: todas las entradas del diccionario tienen componente gráfico

- Ejemplos:

- Ejemplo 1: el componente gráfico incluye la representación normalizada de una rosca exterior y una imagen informativa del objeto (ver fig. 4.9). 
- Ejemplo 2: representación normalizada de una rosca métrica acotada (ver fig. 4.10).

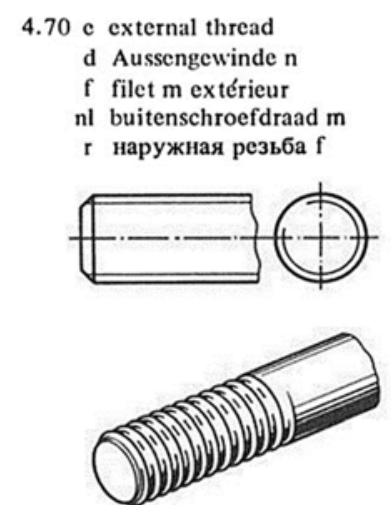

Figura 4.9. Representación normalizada e imagen informativa

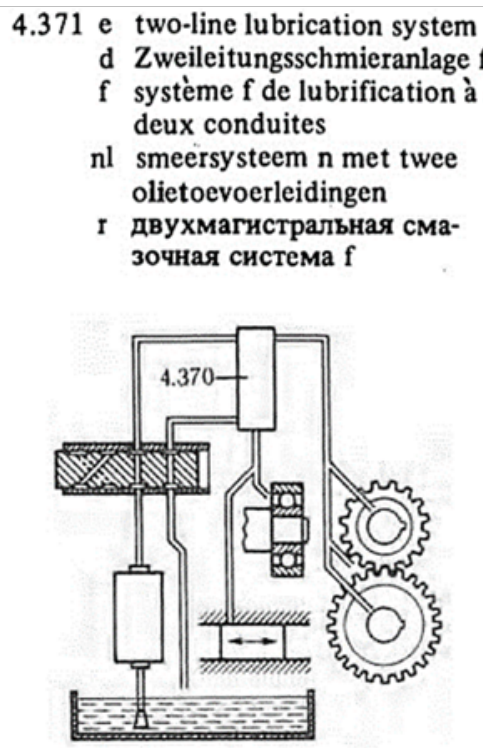

Figura 4.11. Representación simplificada de un proceso

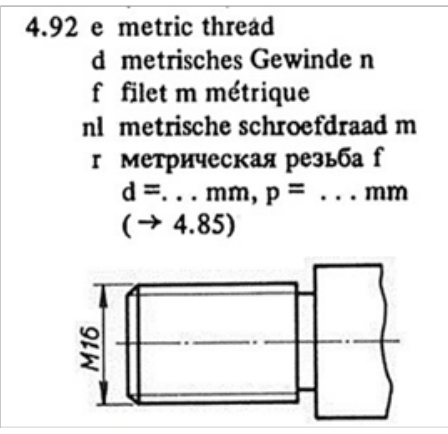

Figura 4.10. Representación normalizada de una rosca métrica acotada
d offener Stromkreis m
f circuit m ouvert
$\mathrm{nl}$ geopende stroomkring $\mathrm{m}$
$\mathrm{r}$ разомкнутая цепь $\mathrm{f}$

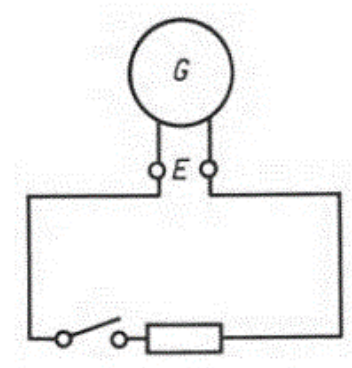

Figura 4.12. Esquema eléctrico

\section{UNIVERSAL DICTIONARY OF MECHANICAL DRAWING (1906).}

- Diccionario: monolingüe en inglés.

- Soporte: en papel.

- Contenido: convencionalismos sobre tipos de líneas, rotulación, acotación, proyecciones, secciones y representación de materiales en secciones, bloque de títulos y lista de materiales, formatos y datos normalizados.

- Objetivo: mostrar el dibujo mecánico como lenguaje, manual de consulta de apoyo a la escritura especializada y asegurar una uniformidad razonable en los dibujos realizados por personas diferentes en lugares diferentes.

- Destinatario: estudiantes, profesores y profesionales delineantes.

- Necesidades: necesidad de información. 
- Situación: adquisición de conocimiento, realizar tareas e interpretar la representación gráfica.

- Habilidades: no se especifican.

- Contenido lexicográfico: introduce conceptos que apoya con figuras, problemas, análisis descripciones y aspectos normalizados del dibujo técnico.

- Representación no verbal: mostrar uniformidad en los tipos de dibujos.

- Tipo: dibujos simplificados o ilustraciones informativas del objeto, representaciones normalizadas de objetos, indicaciones de aspectos normalizadas en dibujos.

- Frecuencia: el $5 \%$ de entradas tienen figuras que en superficie ocupan el $50 \%$.

- Ejemplos:

- Ejemplo 1: indicación normalizada de la acotación (ver figura 4.13).

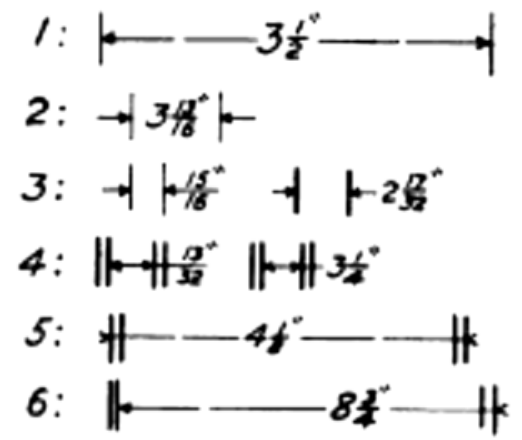

FIG. 26. SIX DIMENSION CONSTRUCTIONS.

Figura 4.13. The Application of Dimensions, indicación normalizada de la acotación

- Ejemplo 2: proyecciones diédricas de los sistemas de tercer y primer diedro (Fig 4.14).
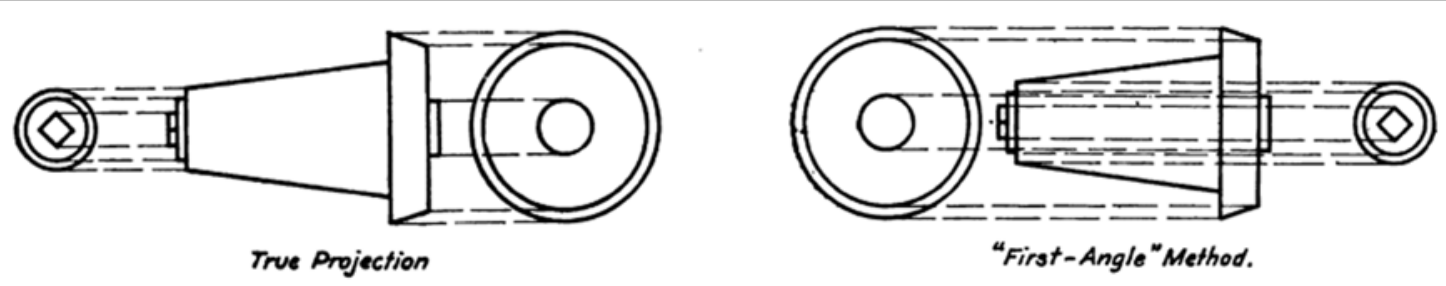

FIG. 13. FIRST ANGLE PROJECTION AND TRUE PROJECTION CONTRASTED.

Figura 4.14. First angle projection and true projection contrasted, representa en proyecciones diédricas, una comparación entre el primer y el tercer diedro.

- Comentario: el autor (Follows, 1906) define el dibujo mecánico en el capítulo primero como «un lenguaje de líneas, vistas, dimensiones, signos y abreviaturas, notas y material explicativo, todo para la transmisión positiva de información exacta». Presenta el diccionario como un libro de texto que trata sobre el dibujo mecánico como lenguaje. 
Expresa la analogía entre el dibujo mecánico como lenguaje y la lengua inglesa de manera que: las líneas serían las letras, las vistas serían las palabras, las proyecciones ortogonales serían las oraciones, los dibujos serían los capítulos y los dibujos de conjuntos serían los libros (traducción nuestra). El objetivo «it has been written with the hope that the drafting fraternity, as well as teachers and students of mechanical drawing, will accept it, as far as it goes, and use it as a basis for the writing of the language.».

\section{DICCIONARIO ESPAÑOL DE INGENIERÍA. REAL ACADEMIA DE INGENIERÍA (2014)}

- Diccionario: en español con algunos equivalentes en inglés.

- Soporte: electrónico en línea

- Contenido: Astronáutica, naval y transportes; Agroforestal; Construcción; Tecnologías de la información y las comunicaciones; Seguridad y defensa; Química industrial; Energía; Ingeniería biomédica; Ingeniería general; Nueve ramas de la ingeniería divididas en treinta y dos campos de conocimiento.

- Objetivo: facilitar términos equivalentes en español y en inglés.

- Destinatario: profesionales de ámbitos de ingeniería de distintas ramas.

- Necesidades: información orientada al conocimiento y a la comunicación.

- Situación, manejo de documentos e información textual, con interés en traducción o interpretación y adquisición de conocimiento.

- Habilidades: no se especifican.

- Contenido lexicográfico: identifica el campo de conocimiento especializado a modo de organización para ubicar las entradas y contextualizar los términos.

- Información Gramatical: no incluye.

- Definición, se describe con precisión los objetos.

- Incluye algunos términos equivalentes en inglés (no de forma generalizada).

- Colocaciones: tuerca, tuerca almenada, tuerca autoblocante, tuerca autofrenante, tuerca cilíndrica ranurada, tuerca de mariposa, tuerca de prensaestopas, tuerca del avance, tuerca hexagonal.

Representación no verbal: los lemas susceptibles de representación gráfica son escasos y ni en el caso de objetos ni en el caso de conceptos se incluye un campo destinado a información gráfica

Ejemplos de capturas de pantalla de la web de la Real Academia de Ingeniería [Consulta: miércoles, 15 de abril de 2020]: se eligen ejemplos del ámbito de la ingeniería industrial (aunque este campo no está identificado) referidos a conceptos y objetos susceptibles de representación gráfica y objetos cuya representación gráfica está normalizada. Son ejemplos representativos del tipo de información presentada. 
- Ejemplo 1, lema Proyecto, incluye el dominio, el equivalente en inglés y dos definiciones (fig. 4.15).

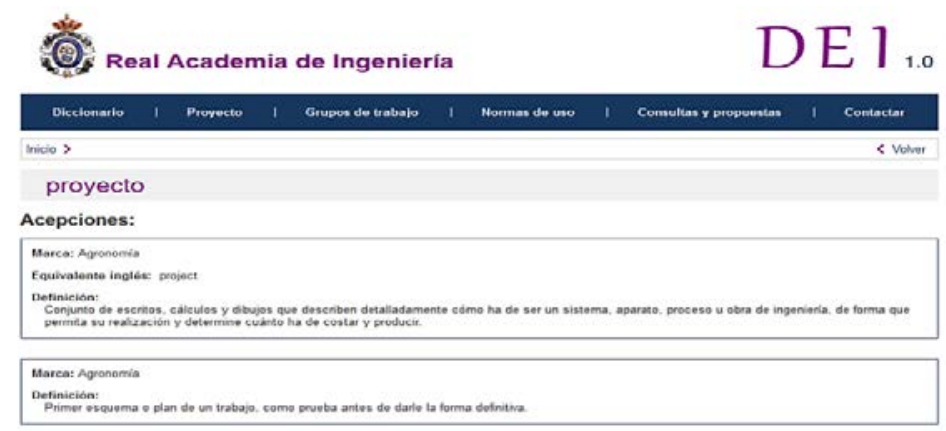

Figura 4.15. Lema: proyecto, incluye dos definiciones (DEI 1.0)

- Ejemplo 2, lema: Rugosidad superficial, incluye el dominio, el equivalente en inglés y la definición (fig. 4.16.)

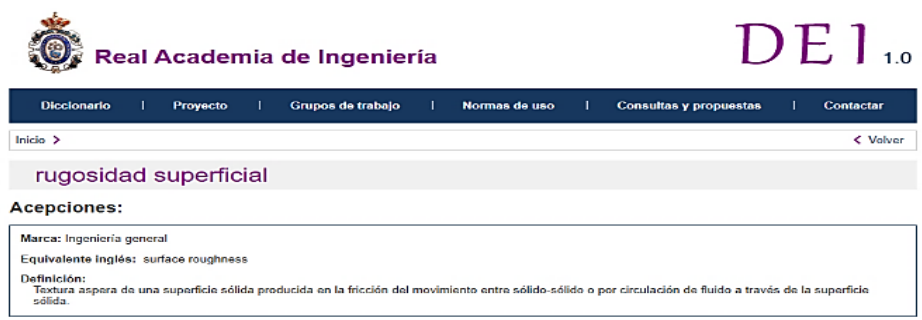

Figura 4.16. Lema: rugosidad superficial (DEI 1.0)

- Ejemplo 3, lema: Rosca, incluye el dominio y la definición (fig. 4.17)

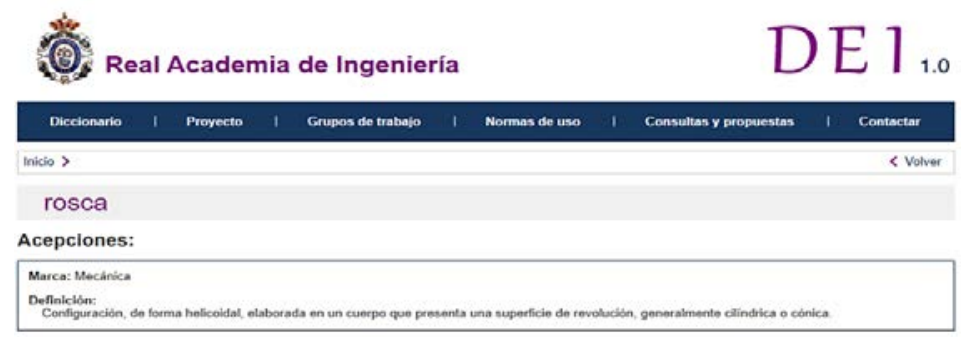

Figura 4.17. Lema: rosca (DEI 1.0)

- Ejemplo 4, lema: Roscado, incluye el dominio, el equivalente en inglés y la definición (fig. 4.18).

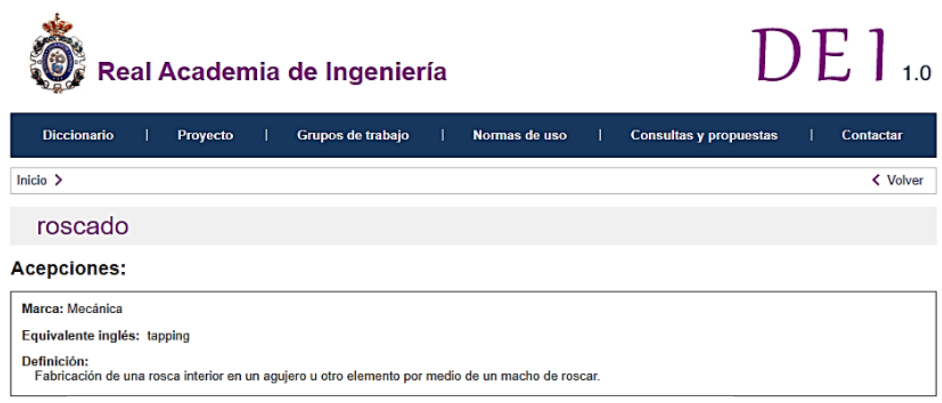

Fiqura 4.18. Lema: roscado (DEI 1.0) 
- Ejemplo 5, lema: Tuerca almenada, incluye el dominio y la definición (fig. 4.19)

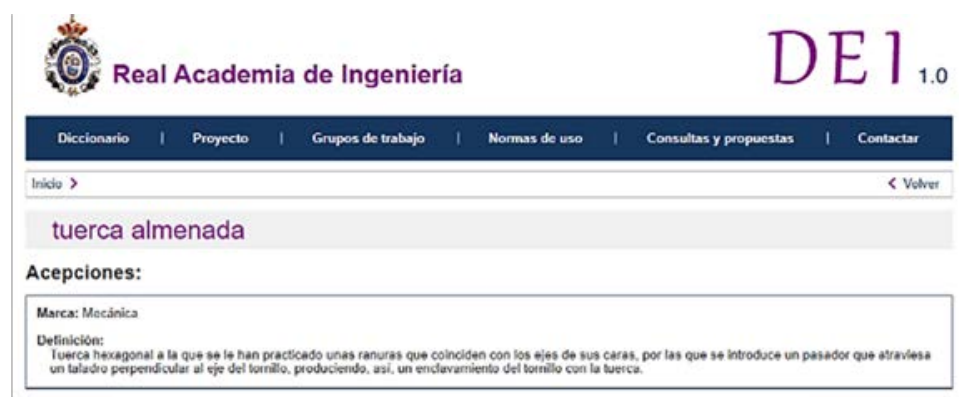

Figura 4.19. Lema: tuerca almenada (DEI 1.0)

- Ejemplo 6, lema: Sección transversal, incluye el dominio y la definición (fig. 4.20)

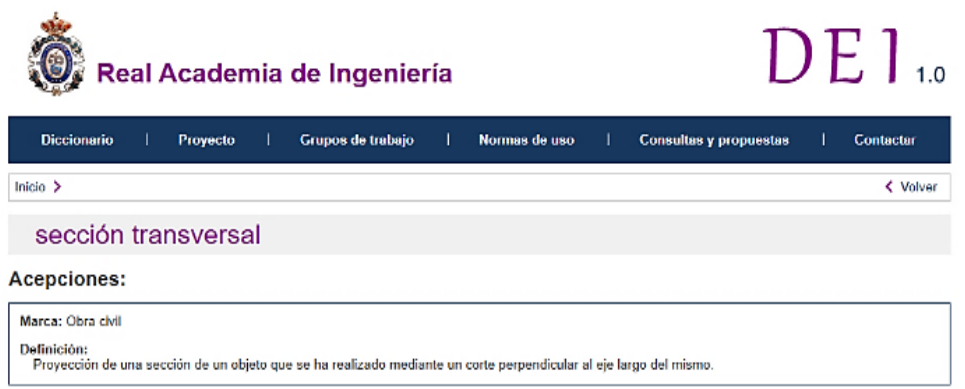

Figura 4.20. Lema: sección transversal (DEI 1.0)

\section{ATKINS, T., \& ESCUDIER, M. (2013). A DICTIONARY OF MECHANICAL ENGINEERING}

- Diccionario: monolingüe en inglés.

- Soporte: papel.

- Contenido: términos y definiciones de ingeniería mecánica. Incluye términos en inglés británico e inglés de US cuando hay diferencias esenciales de significado. Recoge definiciones de diferentes fuentes como libros de texto, diccionarios, páginas web de fabricantes, publicaciones y artículos científicos (también los publicados en internet). No incluye elementos de geometría métrica, si incluye elementos normalizados y sus correspondientes conceptos.

- Objetivo: definición de términos, contrastando diferentes fuentes para asegurar la veracidad.

- Destinatario: especialistas en ingeniería mecánica, estudiantes, investigadores y profesionales de la ingeniería. También para periodistas, abogados, políticos y otros que necesiten la definición de términos de ingeniería mecánica. Para nativos y no nativos de la lengua inglesa.

- Necesidades: definición de términos de ingeniería mecánica, de información orientada a la adquisición de conocimiento y a la comunicación.

- Situación: adquisición de conocimiento, manejo de documentos e información textual, con interés en traducción o interpretación. 
- Habilidades: se requieren conocimientos de matemáticas, física y química, o en su defecto la habilidad de acceder a ellos en libros de textos y mediante especialistas.

- Contenido lexicográfico, en orden alfabético con referencias a otros lemas

- Información gramatical: no incluye.

- Inflexiones: no incluye.

- Sinónimos: circlip, snap ring.

- Definición: define el término y aporta una descripción física del objeto y una descripción funcional.

- Ejemplos:

- Ejemplo de unidad verbal, circlip, snap ring: an external or internal retaining ring that locates parts of circular cross section in an axial direction. It consists of an incomplete ring, with holes on either side of the gap that may be expanded by a plier-like tool to pass into a groove in a shaft or contracted to pass into a groove in a bore.

- Representación no verbal:

- Tipo: imagen de objeto, figura de análisis con indicación de parámetros necesarios para definir el elemento, representación normalizada de símbolos que figurarán en un plano sobre un objeto.

- Forma parte de la definición: refuerza la definición y concreta la interpretación.

- Frecuencia: en número de entradas con componente gráfico es inferior al 10\%.

- Ejemplos:

- Ejemplo 1, circlip el componente gráfico representa un elemento normalizado (figura. 4.21).

- Ejemplo 2, right-handed thread la imagen representa un elemento roscado con rosca a derechas, identificados los parámetros que definen la elaboración helicoidal (figura. 4.22).

- Ejemplo 3, símbolos normalizados de indicación de calidad superficial (fig. 4.23).

- Ejemplo 4, toothed gearing, en la figura que relacionan los términos con su representación gráfica (fig. 4.24)

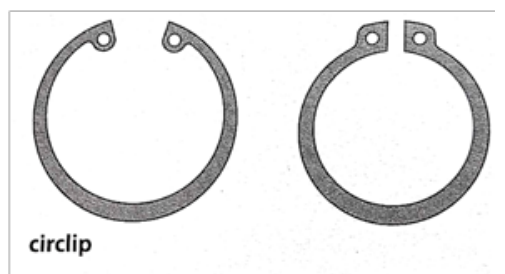

Figura 4.21. Anilla elástica exterior e interior

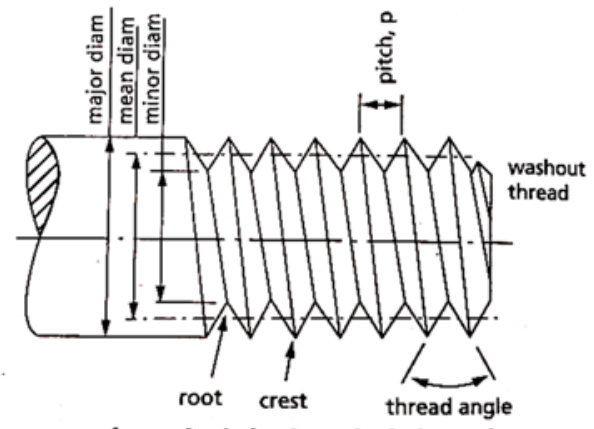

screw thread: right-handed thread

Figura 4.22. Extremo roscado con rosca de perfil triangular 


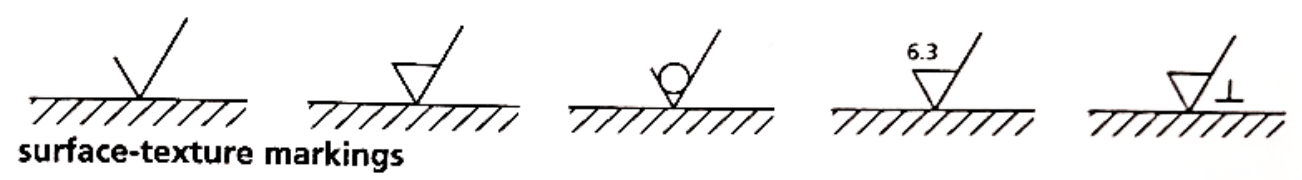

Figura 4.23. Símbolos normalizados de indicación de calidad superficial

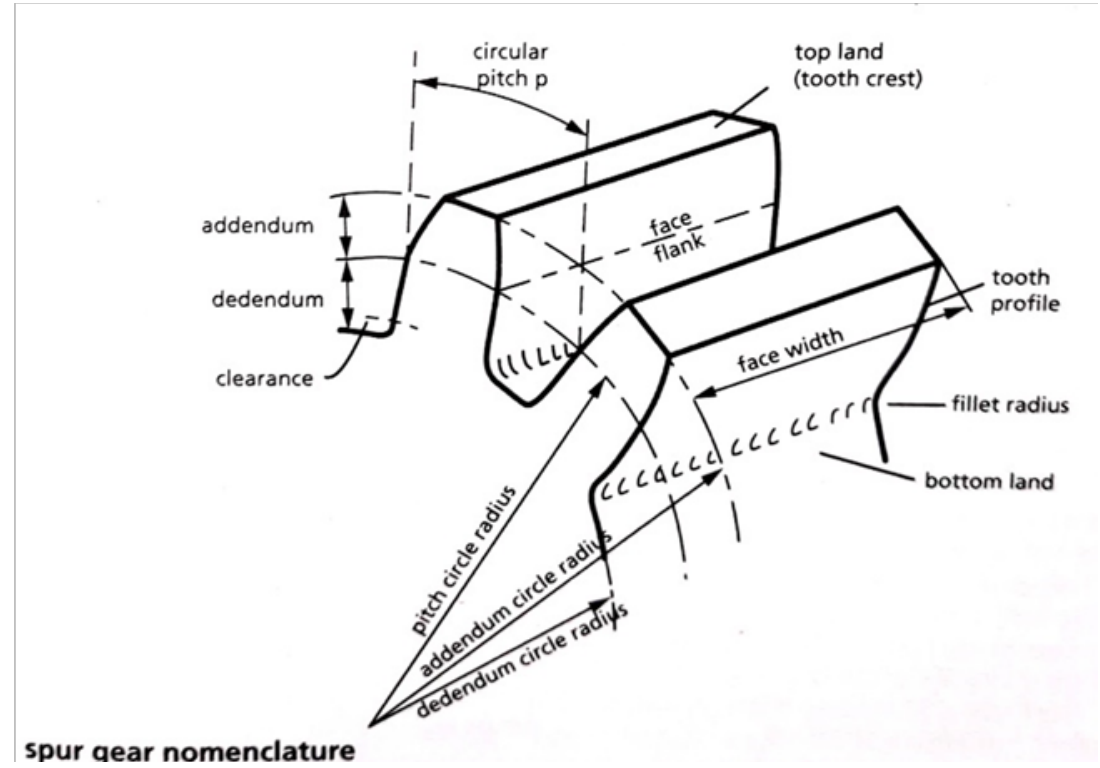

Figura 4.24. Visualización de la nomenclatura de una rueda dentada

\section{DICTER 2.0. DICCIONARIO DE LA CIENCIA Y DE LA TÉCNICA DEL RENACIMIENTO}

- Diccionario: en español del siglo XVI y primer cuarto del XVII.

- Soporte: electrónico en línea.

- Contenido: vocabulario especializado de la ciencia y la técnica del siglo XVI y primer cuarto del XVII en España con alguna prolongación en el Nuevo Mundo en las áreas: Arte militar, Artillería, Fortificación, Astronomía, Arquitectura, Cantería, Cosmografía, Geografía, Destilación, Comercio, Ingeniería hidráulica y mecánica, Matemáticas (Aritmética, Geometría, Álgebra), Metalurgia, Minería y Óptica.

- Objetivo: aportar datos para la comprensión de los conceptos científicos y de las técnicas del Renacimiento; aportar testimonios textuales para facilitar la interpretación de la historia de la ciencia y de la técnica; conectar dos culturas: humanidades y ciencia y tecnología.

- Destinatarios: filólogos, lingüistas, historiadores de la ciencia y de la técnica, lexicógrafos (con orientación diacrónica), filósofos de la ciencia, personas con inquietudes culturales históricas.

- Necesidades: información orientada a la comunicación.

- Situación, descodificación de textos históricos.

- Habilidades: no se especifican. 
- Ejemplo de lema: arco.

- Contenido lexicográfico:

- Variantes: alco, arco.

- Etimología, [del latín arcus 'id.' (DRAE, 2001)]

- Familia léxica: arca, arcada, arcador, arcar, arcual, arqueado, enarcado.

- Categoría gramatical: sustantivo

- Marca diatécnica: geometría.

- Definición 1: porción continua de una curva (DRAE, 2001).

- Ejemplo 1: "Pues qualquier derecha línea que esté en el círculo y no passe por el centro se suele llamar cuerda, bien assí como la parte de la cincunferentia que le cabe se llama arco. (Girava, Fineo, Geometría práctica, 1553, pág.17).»

- Ejemplo 2: «Será, luego, a.b.e. medio círculo, y porque, sacando d'esse arco a.b., el qual es la tercia parte de la cincumferencia del mismo círculo, lo que queda es el sexto de la misma circunferencia del círculo. (Núñez, Álgebra en Arithmética, 1567, fol. 278v).»

- Ejemplo 3: «Esta línea se llamará cuerda, como sobre el punto G, hecha la línea EGF, será cuerda; y la parte del círculo que mira la tal cuerda que con ella está determinada se llama arco, como la circunferencia FAE. (Álaba, Perfeto capitán, 1590, fol. 202r).»

- Representación no verbal:

- Tipo: dibujo o figura de análisis, todas las figuras están enlazadas y la ruta está accesible y es opcional.

- Forma parte de la definición: refuerza la definición y concreta la interpretación

- Frecuencia: en total incluye 1050 figuras, en número de entradas con componente gráfico es elevado.

- Ejemplos:

- Ejemplo 1, el componente gráfico representa un concepto (ver figura 4.25)

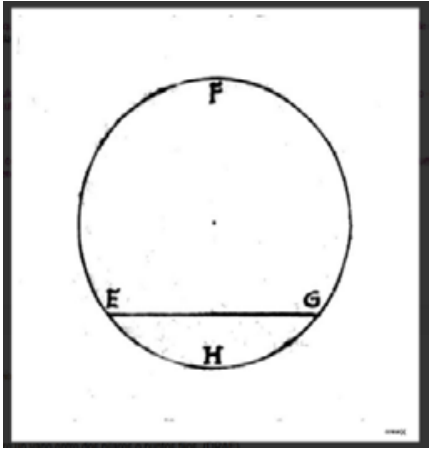

Figura 4.25. Lema: arco (Girava, Fineo, Geometría práctica, 1553, pág. 17) DICTER $2.0<$ http://dicter.usal.es/> [7 de junio 2020]. 
- Ejemplo 2: lema rosca. Captura de pantalla DICTER 2.0 (ver figura 4.26)

\section{DICTER}

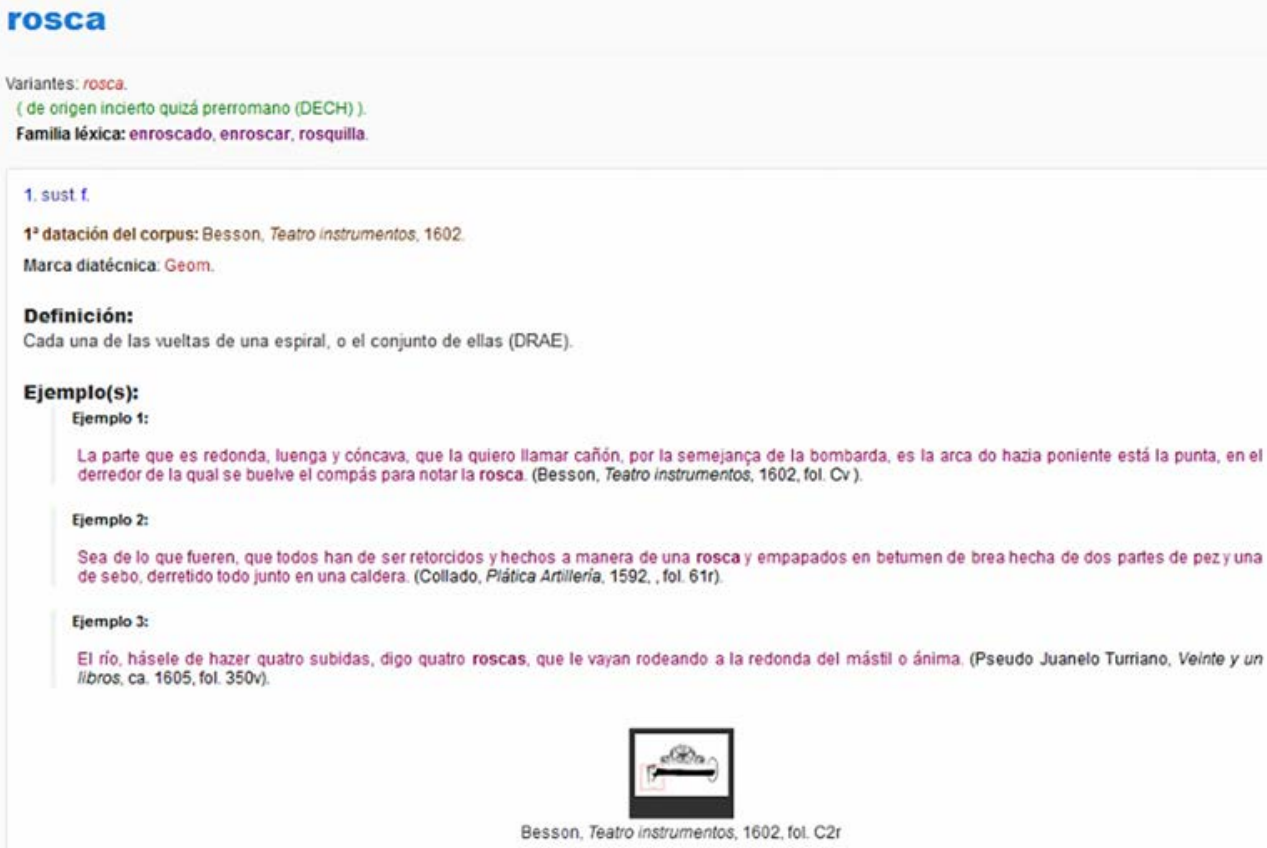

Figura 4.26. Lema: rosca. DICTER $2.0<$ http://dicter.usal.es/> [7 de junio 2020]. 


\subsubsection{Resumen y consideraciones generales}

Es frecuente y necesaria la convivencia de distintos lenguajes presentes en la comunicación técnica: el lenguaje verbal o textual; la representación gráfica; los modelos matemáticos y analíticos; y los números. Todos ellos pueden coexistir en el proceso de definición de un objeto de carácter industrial. En EGI el lenguaje verbal es necesario para describir conceptos, definir las características sin representación formal y facilitar la comunicación mediante documentos; la representación gráfica para obtener planos de definición, las representaciones tridimensionales y renderizados; los modelos analíticos se utilizan para simular situaciones de funcionamiento; los números para acotar piezas y establecer relaciones entre ellas y sus posiciones.

Los diccionarios técnicos que hemos presentado constituyen una representación de los diccionarios en línea y en papel que tratan temas relacionados con la geometría, con los elementos normalizados, con el vocabulario técnico y en los que sería factible el empleo de figuras de representaciones de elementos y objetos. Son el tipo de recursos lexicográficos que pueden consultar los alumnos de EGI y sólo en parte cumplen las expectativas de un diccionario con funciones comunicativa, cognitiva, operativa e interpretativa. A pesar de ciertas carencias, desde el punto de vista de los objetivos que hemos planteado, incorporan distintas categorías de datos y utilizan un formato de presentación con unidades lingüísticas y gráficas interesantes para nuestra propuesta. Se han elegido entradas al diccionario del mismo lema, cuando ha sido posible, o de lemas correspondientes a ejemplos que aparecen en distintos apartados en este trabajo.

Todas las características de estos diccionarios técnicos analizados se muestran en la Tabla 4.2. Hemos incluido la última fila para especificar si estos diccionarios especializados han sido concebidos como herramientas de referencia o, como bien precisa Agerbo (2019: 107) «only as books of words». El diccionario 3, es un diccionario 'de palabras' pero las disposiciones de las figuras junto con el vocabulario completan el significado de una forma rápida y fácil de entender y el conjunto se percibe como una herramienta. El diccionario 7 se percibe como un 'extraordinario diccionario de palabras' de fácil acceso, pero la posibilidad de acceder de forma opcional y aislada a las figuras les confiere un tratamiento periférico y provoca que se disocien del significado. 
Expresión Gráfica en la Ingeniería

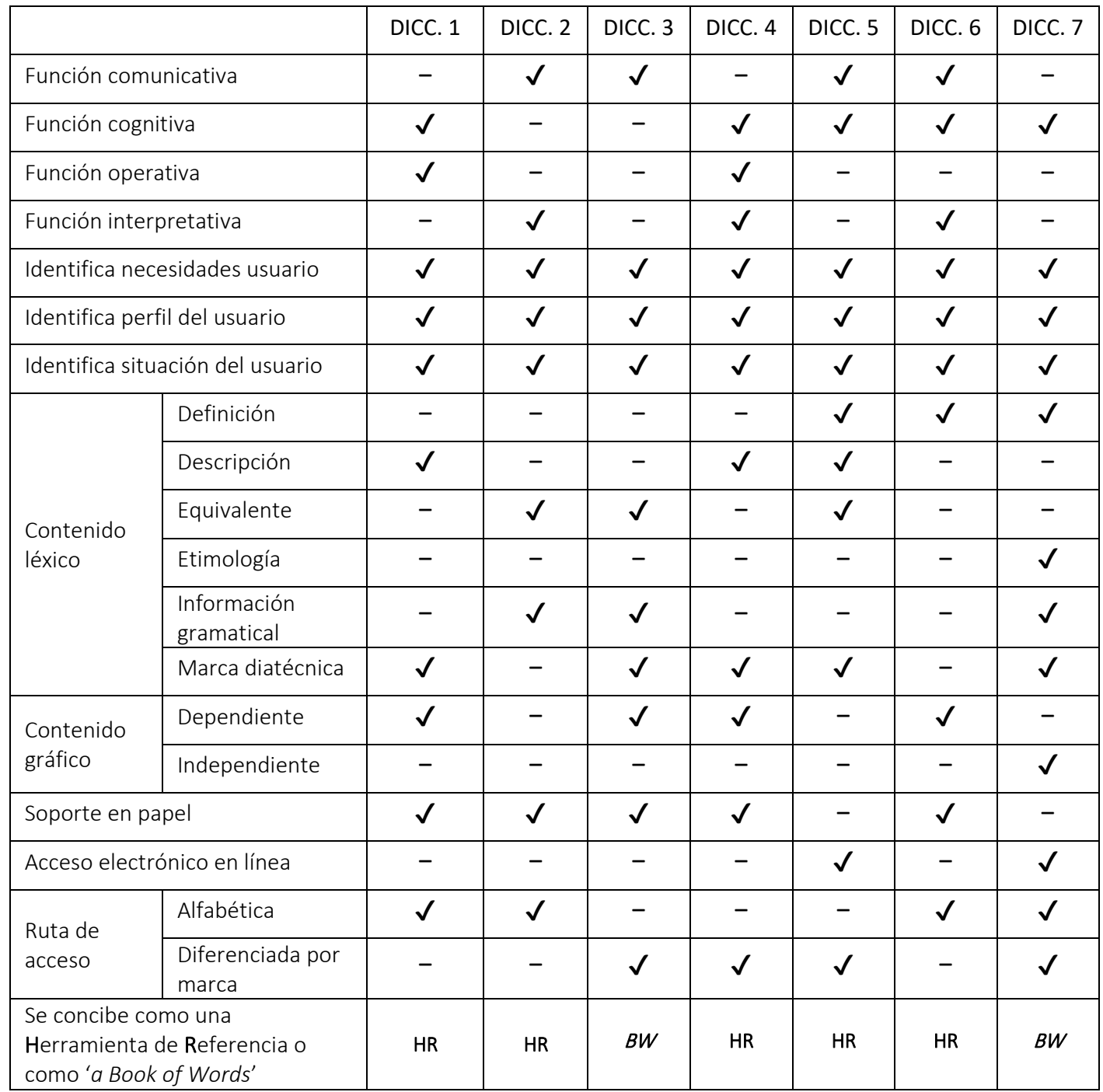

Tabla 4.2. Características relativas a las funciones, el usuario, el contenido, soporte y ruta de acceso de los diccionarios técnicos analizados

Desde el punto de vista de las funciones del diccionario cabe destacar que los diccionarios 3 y 7 son diccionarios monofuncionales, los diccionarios 1, 2, 4, 5 y 6 son polifuncionales. El diccionario 5 es polifuncional de acceso monofuncional al tener formato electrónico desde el punto de vista del usuario son diccionarios monofuncionales.

\subsection{El usuario de una herramienta lexicográfica de EGI}

La TFL (Bergenholtz y Tarp 2002; Tarp 2002; Tarp 2008; Tarp 2013, Fuertes-Olivera y Tarp 2014) constituye el marco teórico y metodológico de nuestra propuesta que pretende ser una herramienta lexicográfica de consulta puntual en línea, dirigida a estudiantes universitarios y 
profesionales de EGI. Para identificar el perfil del usuario, las necesidades y las situaciones de uso, siguiendo los postulados de la TFL, se ha tenido en cuenta la experiencia de un panel de expertos en $\mathrm{EGI}$.

El propósito con el que se compila un diccionario se configura teniendo en cuenta que se dirige a un usuario con un perfil concreto, se conocen las situaciones en las que se produce la consulta y por último se conocen las necesidades de información que provocan la consulta. Todas estas variables condicionan el contenido de los datos. Además, para tener éxito en esta empresa, se tienen en cuenta las habilidades de referencia del usuario, se facilita el acceso a los datos y se presentan solamente los datos relevantes.

En este apartado nos centramos, por una parte, en el perfil del usuario potencial -sus habilidades y sus competencias- $y$, por otra parte, en las situaciones en las que se encuentra y las necesidades que motivan la consulta al diccionario en un proceso, bien de adquisición de conocimiento especializado, bien de aplicación del mismo.

\subsubsection{El perfil del usuario}

El perfil de usuario de un diccionario pivota alrededor, de su lengua nativa y muchos diccionarios especializados presuponen el mismo grado de competencia en su lengua nativa a todo el perfil tipo, al margen del conocimiento culturalmente dependiente y de las influencias que aportan las diferentes nacionalidades al conocimiento enciclopédico (Bergenholtz y Tarp 1995: 20). Por nuestra experiencia constatamos que los grupos de aprendizaje no son homogéneos en ningún aspecto y probablemente el usuario del diccionario especializado pertenece a un tipo de perfil con diferentes singularidades, al margen del hecho de ser inexperto, semiexperto y experto en una disciplina concreta.

La experiencia previa que puede tener un usuario de diccionarios monolingües tradicionales será útil en nuestra propuesta de diccionario en línea especializado, al que se supone la comprensión e interpretación adecuada (Battaner, 2008: 15). Por una parte, al usuario se le atribuye cierto conocimiento, ciertas habilidades para extraer la información requerida, y cierta capacidad para interpretar los datos y la materia. Sin embargo, la competencia del sujeto es limitada, y afectará a la presentación de los datos ofrecidos al usuario: «[...] Por eso mismo 
también, lo expuesto aquí parece una base atendible para diccionarios de aprendizaje, que siempre exigen más explicitación y mayor coherencia en la información ofrecida, al no contar sus usuarios con toda la disponibilidad del hablante competente» (ibid., p. 22).

Dado que el conocimiento especializado se adquiere sobre la base previa de un mínimo de conocimiento general y especializado previo, se pueden identificar algunas características del usuario de un diccionario en las respuestas a las siguientes cuestiones (Bergenholtz y Nielsen, 2006: 285, Tarp 2015):

- ¿Cuál es su lengua materna?

- ¿A qué nivel domina su lengua materna?

- ¿A qué nivel dominan una lengua extranjera?

- ¿A qué nivel dominan la disciplina o ciencia en cuestión?

- ¿A qué nivel dominan la disciplina en su cultura o país?

- ¿A qué nivel dominan la disciplina en la cultura o país extranjero?

- ¿A qué nivel dominan el lenguaje especializado en su lengua materna?

- ¿A qué nivel dominan el lenguaje especializado en la lengua extranjera?

- ¿Cuál es su experiencia en la traducción especializada?

El perfil del usuario potencial de nuestra propuesta de diccionario es el de un estudiante o el de un egresado de Ell con experiencia en EGI, con conocimientos de ingeniería gráfica y con cierto grado de desarrollo en las competencias que los estudiantes de ingeniería industrial van a desarrollar durante su vida académica. Estas competencias configuran una parte importante del perfil del alumno y, por tanto, del perfil del usuario potencial de un diccionario en línea pedagógico de EGI. Las competencias, generales y específicas, que se han seleccionado (ver Tabla 4.3) provienen de asignaturas de los planes de estudios de ingenierías industriales de la Universidad de Valladolid evaluadas por el programa Verifica de la ANECA. Los grados que se imparten son: en Ingeniería en Tecnologías Industriales (plan de abril 2018); en Ingeniería Mecánica (plan de abril 2018); en Ingeniería en Electrónica Industrial y Automática (plan abril 2018); en Ingeniería en Diseño Industrial y Desarrollo de Producto (plan de abril 2015); en Ingeniero/a en Organización Industrial (plan de abril 2015); en Ingeniería Química (plan de julio 2017); en Ingeniería Eléctrica (plan de abril 2018). 


\section{Competencias}

\section{GENÉRICAS}

- Capacidad de análisis y síntesis

- Capacidad de organización y planificación del tiempo

- Capacidad de expresión oral

- Capacidad de expresión escrita

- Capacidad para aprender y trabajar de forma autónoma

- Capacidad de resolución de problemas

- Capacidad de razonamiento crítico/análisis lógico

- Capacidad para aplicar los conocimientos a la práctica

\section{ESPECÍFICAS}

- Comprensión y dominio de los conceptos básicos sobre las leyes generales de la mecánica, termodinámica, campos y ondas y electromagnetismo y su aplicación para la resolución de problemas propios de la ingeniería

- Conocimientos básicos sobre el uso y programación de los ordenadores, sistemas operativos, bases de datos y programas informáticos con aplicación en ingeniería

- Capacidad de visión espacial y conocimiento de las técnicas de representación gráfica, tanto por métodos tradicionales de geometría métrica y geometría descriptiva, como mediante las aplicaciones de diseño asistido por ordenador

- Conocimiento aplicado para la elaboración de Proyectos Técnicos Mecánicos

- Conocimientos y capacidades para aplicar las técnicas de ingeniería gráfica

- Conocimientos y capacidades para el cálculo, diseño y ensayo de máquinas

- Conocimiento aplicado de sistemas y procesos de fabricación, metrología y control de calidad

- Diseño, redacción y dirección de proyectos relacionados con el Diseño Industrial y Desarrollo de Producto

- Elaboración y presentación de informes relacionados con la especial.

- Realizar mediciones, cálculos, valoraciones, peritaciones, informes, planos y otros trabajos análogos

- Fundamentos científico-técnicos

- Capacidad para la comunicación en lenguajes formales gráficos y simbólicos

- Comprender y aplicar las principales teorías de semiótica

- Aplicar normas, reglamentos y especificaciones de obligado cumplimiento

- Comprender y aplicar conocimientos de Tecnologías de la Información
- Capacidad para trabajar en equipo de forma eficaz

- Capacidad para la creatividad y la innovación

- Capacidad para la motivación por el logro y la mejora continua

- Capacidad para actuar éticamente y con compromiso social

- Capacidad de evaluar

- Capacidad para el manejo de especificaciones técnicas y la elaboración de informes técnicos

- Conocimiento de herramientas tecnológicas de acceso y difusión de la información

- Aplicar y dominar conocimientos culturales, tecnológicos y de comunicación.

- Capacidad para actuar con responsabilidad social en base al conocimiento de las relaciones entre ingeniería y sociedad, en los aspectos de ética, historia, legislación, seguridad y riesgos laborales e impacto social de la ingeniería

- Capacidad de comprensión del espacio tridimensional, los elementos básicos que lo ocupan y las relaciones entre estos

- Capacidad de diseñar respondiendo a las necesidades de la empresa, el mercado y los usuarios. Marketing

- Reconocimiento de las relaciones material-formaproceso-coste

- Conocimiento de los principios de máquinas y mecanismos

- Conocimientos y capacidades para diseño de máquinas.

- Capacidad para el ejercicio de la docencia en sus diversos grados en los casos y términos previstos en la normativa correspondiente

- Conocimiento de la realidad industrial Capacidad para trabajar en un contexto internacional

- Capacidad para la redacción e interpretación de documentación técnica

- Conocimiento en materias básicas y tecnológicas, que les capacite para el aprendizaje de nuevos métodos y teorías, y les dote de versatilidad para adaptarse a nuevas situaciones

- Capacidad de resolver problemas con iniciativa, toma de decisiones, creatividad, razonamiento crítico y de comunicar y transmitir conocimientos, habilidades y destrezas en el campo de la Ingeniería Industrial.

- Capacidad para el manejo de especificaciones, reglamentos y normas de obligado cumplimiento 


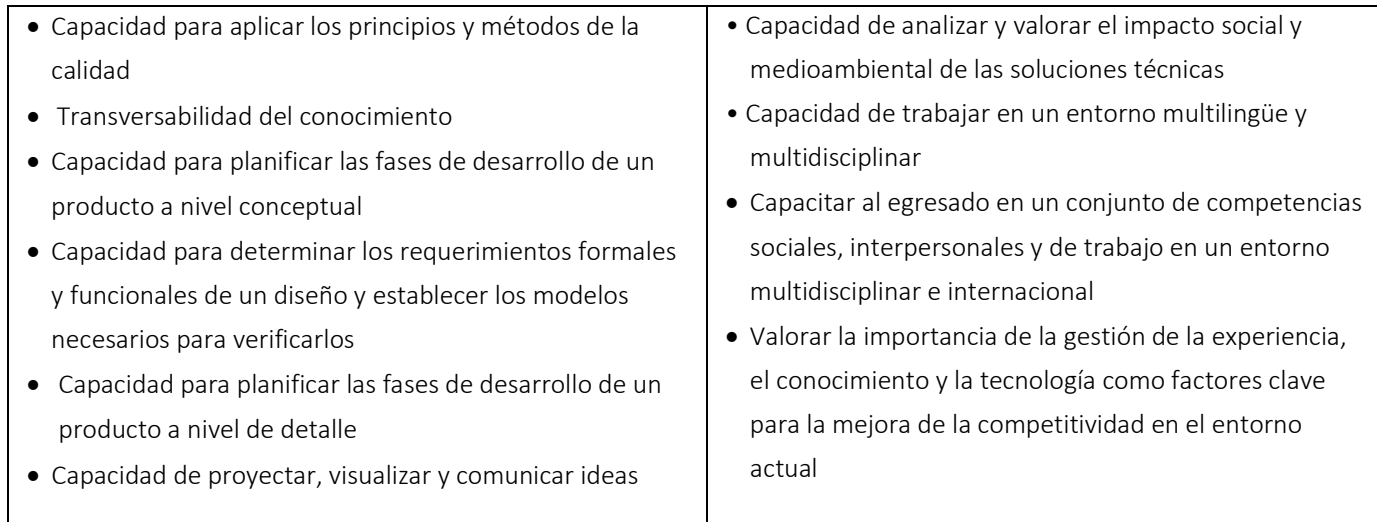

Tabla 4.3. Selección del compendio de competencias profesionales establecidas por la Comisión de Elaboración de Planes de Estudio en el Ámbito de las Ingenierías Industriales y de EGI de la Universidad de Valladolid. Competencias Genéricas y Competencias Específicas

De forma general e interesada se puede determinar que, como consecuencia del desarrollo de estas competencias (en la Tabla 4.3 se muestran aquellas competencias que directa o indirectamente pueden influir en nuestro estudio) el alumno de la Ell de la UVa debe demostrar un alto nivel de rendimiento en la comunicación oral, escrita y gráfica de ideas. En el apartado 5.2 se presentan las implicaciones de estas competencias a la hora de determinar el perfil del usuario.

Se ha de facultar al alumno de EGI para adquirir las habilidades y el conocimiento necesario para resolver construcciones y problemas de Geometría Descriptiva y para consignar especificaciones normalizadas a 'mano alzada' o delineadas. La cultura visual en la ingeniería es de mayor importancia que la simple suma de sus partes. Los 'dibujos' constituyen la comunicación entre profesionales en el mundo del diseño, Henderson (1998) lo denomina conocimiento tácito, en este trabajo se ha designado como un 'conocimiento instrumental', imprescindible en el dibujo y diseño asistidos por ordenador y su contribución es importante para comprender la tecnología contemporánea.

El alumno actual, en su período académico y en su desarrollo profesional realiza tareas asistido por un ordenador, por lo que hoy en día es necesaria tanto la ingeniería basada en la práctica, como la ingeniería basada en la ciencia (Meyers, 2009). Apoyando un punto de vista tecnológico, Phillips (1997) considera necesaria la capacidad de comunicarse de manera efectiva y la capacidad de utilizar técnicas, habilidades y herramientas modernas de ingeniería necesarias para la práctica de la ingeniería. Los fundamentos de ingeniería gráfica que el alumno va a tener 
que adquirir incluyen: la visualización espacial, las vistas ortogonales, la perspectiva (frecuentemente isométrica), los cortes y secciones, la acotación, las tolerancias, los estados superficiales, los planos de trabajo normalizados (2D), el modelado de piezas (3D), etc.

\subsubsection{Las situaciones}

Con respecto a la situación de un potencial usuario en un entorno académico universitario, es conocida, en parte, por los expertos ya que dirigen el proceso de aprendizaje. Caso distinto será la situación de un egresado en el desempeño de una actividad profesional. A pesar de encontrarse ambos perfiles en una situación extralexicográfica esperan ser asistidos puntualmente en tareas relacionadas con el lenguaje. Por lo tanto, las consultas están relacionadas con el lenguaje como vehículo conductor, siendo más complejas que si se comparan con el uso de un diccionario no especializado ya que, en este caso, se debe activar un componente gráfico de forma simultánea. Nos proponemos diseñar una herramienta digital de acceso en línea, en una situación de aprendizaje, operativa e interpretativa sobre una temática de especialidad que requiere del lenguaje verbal y gráfico para conceptualizar su campo de conocimiento.

Dictionaries are usually made by scholars and many, as a result, are made FOR scholars. Perhaps we can define a scholar as a man of insatiable curiosity for whom, wisely or unwisely, time is infinitely expendable. A student, on the other hand, can be defined as a person who enjoys a curiosity that is specific and limited, and who must husband his time well if he is to survive. A machine can then be defined as a very fast but dumb student, with a literal mind and a nagging insistence on explicit directions and forced choices (Martin, 1962: 153).

Nuestra propuesta de diccionario en línea especializado con objetivo pedagógico será una herramienta complementaria en un proceso de aprendizaje y/o autoaprendizaje. Las decisiones relativas al acceso y a la presentación de datos se justifican pensando en un usuario aprendiz. Teniendo en cuenta que los diccionarios de un campo de conocimiento especializado están dirigidos a usuarios con cierto conocimiento previo de dicho campo (Bergenholtz y Tarp, 1995), la presentación se simplifica si inicialmente se ofrece un orden secuencial (o dirigido) de acceso a datos y a continuación, se ofrece la información completa en casos en que exista ambigüedad, pero con la posibilidad adicional de una selección intuitiva u obedeciendo a criterios del usuario. 
También es posible elegir entre las distintas opciones que ofrece la descripción y la representación de un concepto, lo que en lexicografía general y especializada se conoce como equivalencia. En nuestro caso la equivalencia se produce entre definición o descripción verbal y la figura de trazado gráfico o 'figura de análisis'.

\subsubsection{Las necesidades de un usuario tipo en relación con el área de conocimiento}

Para satisfacer las necesidades cognitivas relacionadas con el área de conocimiento es preciso la inclusión de datos enciclopédicos, que se ocupan de la descripción del conocimiento específico y de la realidad extralingüística. Estos datos suelen aparecer en notas enciclopédicas, en los artículos del diccionario especializado, en etiquetas referidas al lema individual o equivalentes y en componentes independientes de la materia externa denominados 'introducciones sistemáticas', 'componentes del campo temático', 'secciones enciclopédicas', o 'sistemas de términos de campo de asignatura' (Bergenholtz y Nielsen, 2006: 284; FuertesOlivera, 20010: 161).

Los diccionarios especializados con carencias en datos enciclopédicos no resuelven las necesidades de comunicación y aprendizaje de LSP de los usuarios (Fuertes-Olivera y Tarp, 2011: 152) que se derivan de las competencias a desarrollar. Por otra parte, hemos detallado en el apartado 5.4.3 la reformulación necesaria para adaptar la información a situaciones, a un tipo específico de receptor y de acuerdo con acciones determinadas.

El proceso de reformulación incluye dos transformaciones paralelas verbal y gráfica que implica la incorporación de datos gráficos a modo de instrucciones que el usuario va a poder aplicar para cubrir sus necesidades en situaciones operativas.

La representación normalizada de objetos requiere del conocimiento de los convencionalismos adoptados internacionalmente para facilitar la comunicación técnica. El dominio de la producción y recepción de documentos técnicos normalizados forma parte de la formación del ingeniero. La competencia en normalización gráfica implica tres aspectos: que se es capaz de interpretar símbolos gráficos de forma inequívoca, que se es capaz de interpretar un plano concebido con un fin determinado, y que de toda la información que contiene un plano se puede realizar una 'lectura' a distintos niveles. Esta lectura e interpretación a distintos niveles 
de un plano es lo que hemos denominado 'interpretación interesada de un plano' en la que es necesaria una intervención personal con una finalidad concreta. La normalización provoca una serie de necesidades externas, es decir, son necesidades originadas, a veces impuestas, por agentes externos.

En nuestro caso, el usuario potencial es un estudiante o un profesional iniciado en expresión gráfica en la ingeniería, es decir, con experiencia y en situación académica de aprendizaje y/o de puesta en práctica de conocimientos de ingeniería industrial gráfica. Para definir con precisión y seguridad al usuario al que nos dirigimos, consideramos conveniente tomar como punto de partida la experiencia profesional de docentes de dicho ámbito en la Universidad de Valladolid. En el apartado 5.3 veremos la incidencia en este trabajo de estos encuentros con docentes de EGI. Los profesionales de la docencia en ingeniería gráfica pueden aportar información fiable sobre las necesidades presentes y futuras que puede tener un alumno de Expresión Gráfica en la Ingeniería, que suele ser un alumno de primeros cursos de ingeniería.

Para disponer además de información directa sobre las necesidades de un usuario potencial, se realizó una encuesta a alumnos de EGI. En el apartado 5.5 se incluyen los resultados de una encuesta realizada a los alumnos y la confrontación de las opiniones de expertos y estudiantes. Este análisis condujo a un conjunto de conceptos a incluir en una herramienta 'cognitiva operativa interpretativa pedagógica' utilizada para definir lo más precisamente posible el punto de partida y cumplir con éxito la tarea de satisfacer las necesidades de los usuarios potenciales.

\subsection{La selección de lemas en lexicografía especializada}

Los métodos utilizados para la selección de lemas de un diccionario especializado tienen bases teóricas marcadas por diferentes tradiciones investigadoras. Las fuentes tradicionales que el lexicógrafo utiliza como recurso léxico son los diccionarios, la documentación existente sobre el tema y el conocimiento e intuición del lexicógrafo.

La lexicografía tradicional se basa en la elaboración de un corpus a partir de recursos textuales reales y la obtención de evidencias procedentes de esos corpus mediante herramientas informáticas que faciliten el acceso y la cuantificación (Pérez, Moreno y Faber 
1999: 206). La consulta de diccionarios previos facilita muchísimo la labor del lexicógrafo, pero aportan una visión, no actualizada, en cuanto a la selección de lemas, la definición de los mismos.

A penas hay alternativa al uso de corpus como recurso léxico primario y principal (Čermak, 2003: 18-20). Una parte importante de los trabajos enfocados a la creación de herramientas lexicográficas y al análisis del lenguaje, inicia el proyecto basándose en un corpus y aplican mecanismos de análisis de corpus para comprobar las evidencias que, con criterios de representatividad y frecuencia, deben constituir una entrada en un diccionario. Bowker y Pearson (2002: 9) adoptan la siguiente definición de corpus: «a large collection of authentic texts that have been gathered in electronic form according to specific criteria».

El prestigio de la utilización de corpus a gran escala para la elaboración de diccionarios desde los años 80 radica en la utilización del lenguaje natural en uso. Como muestran las obras lexicográficas: The Collins Cobuild Dictionary of English, (Sinclair, 1987) y Oxford-Hachette English-French/French-English (Corréard et al., 2001 (citado en Verlinde y Selva, 2009)). Una de las claves del enfoque lingüístico de Sinclair consiste en determinar las regularidades subyacentes mediante el análisis de la evidencia en el corpus. La experiencia adquirida a través del estudio de los datos del corpus constata su idea 'idiom principle', es decir, en la práctica las elecciones léxicas son limitadas y la recurrencia es más relevante que la aleatoriedad (Rundell, 2012: 65). La aportación y estrecha colaboración lingüista- lexicógrafo se lleva a la práctica en el proyecto COBUILD (1980s) que se ha mencionado, en el proyecto DELIS (en la década de 1990) y en el archivo Euralex, entre otros.

En el proyecto Oxford Dictionaries, los equipos de lexicógrafos determinaron las prioridades para la inclusión de palabras en base a evidencias de cada palabra, actualizando y creando definiciones, traducciones, pronunciaciones y etimologías. Hoy en día se utilizan los principios de la lingüística del corpus para sistematizar y objetivar las tareas que el lexicógrafo realiza para identificar unidades léxicas y patrones de uso.

El trabajo del lexicógrafo implica una larga serie de juicios y toma de decisiones. El análisis del corpus permite al lexicógrafo experimentado ser sistemático al identificar patrones subyacentes en lugar de confiar en sus intuiciones (Rundell, 2012: 66). El análisis del corpus y la intuición del lexicógrafo son compatibles si se tiene en cuenta que las intuiciones del lexicógrafo 
experimentado suelen ser certeras porque están dirigidas y condicionadas positivamente por la experiencia y conocimiento acumulados. En todo caso la aleatoriedad de la intuición del lexicógrafo debe ser reducida. Verlinde y Selva comparan dos enfoques lexicográficos: «Corpusbased versus intuition-based lexicography» llegando a la conclusión de que la lexicografía basada en corpus brinda a la intuición personal del lexicógrafo una evidencia empírica importante y necesaria, no obstante, esta intuición sigue siendo útil para llenar los vacíos que puedan producirse en un corpus (Verlinde y Selva, 2009: 598).

Para ciertos diccionarios especializados los criterios para componer un corpus en la lexicografía tradicional requieren una adaptación. Las fuentes primarias no siempre aportan datos e información representativa, disponible y suficiente para cualquier diccionario de especialidad, en estos casos se recurre a fuentes secundarias como los trabajos de campo, internet y diccionarios y enciclopedias existentes y se busca información pragmática sobre el uso, la aclaración o la definición de un elemento como ocurre en los campos técnicos especializados (Čermak, 2003: 18).

Las fuentes secundarias utilizadas en este tipo de proyectos lexicográficos utilizan cuestionarios, encuestas ( $p$. ej. ICTIOTERM), trabajos de campo, consulta a expertos y consulta a obras lexicográficas como diccionarios y enciclopedias ( $p$. ej. LEXILOGON) y son especialmente útiles cuando se trabaja en un primer diccionario. Estos documentos serían considerados fuentes secundarias en algunos proyectos lexicográficos, pero son documentos esenciales en la comunicación especializada. León, Faber y Montero (en EcoLexicon) utilizan como fuente para la extracción de conocimiento de un dominio los textos especializados y knowledge-rich context (León, Faber y Montero, 2012:101). Este último designa un contexto que indica al menos un elemento (o una característica conceptual, bien sea atributo o relación) del dominio de conocimiento que podría ser útil para el análisis conceptual (Meyer 2001: 281).

El proyecto MeteoTrad de diccionario especializado propone una metodología mixta entre la dependencia del corpus especializado (TBM) y la dependencia del experto (TFL) e introduce el concepto del perfil profesional del término-lexicógrafo: un iniciado en la materia y familiarizado con su público objetivo (García Aragón, 2016: 278). Este perfil profesional facilita la comunicación con el experto durante la extracción de términos de un corpus especializado. Otro ejemplo serían OncoTerm (2000-2003) que se basa en un sistema de información, en el 
subdominio biomédico de la oncología clínica, integrado en Internet, y que utiliza la información extraída de diccionarios, de corpus de textos especializados y la proporcionada por expertos. En ambos casos el corpus es la herramienta principal de la labor del lexicógrafo.

Fuertes-Olivera y Tarp (2014: 190) proponen una metodología alternativa a la lingüística del corpus para la selección de lemas: la estrecha colaboración del experto en la materia con el lexicógrafo para la descripción de conceptos y del lenguaje de especialidad. Esto implica que el corpus es una herramienta auxiliar en tareas como la selección de lemas, las definiciones de términos y las descripciones gramaticales.

Fuertes-Olivera y Bergenholtz (2015), en el marco de la teoría funcional de la lexicografía, inician la selección de lemas con rastreadores de internet (crawler) e indexadores y el programa informático "Lemma loader" para completar y ampliar de forma continua el lemario del diccionario como parte del proceso dinámico de la lexicografía de internet. De esta manera se facilita y agiliza el proceso de búsqueda (Fuertes-Olivera y Bergenholtz, 2015: 81).

Es posible la utilización de una muestra de población de expertos que no excluye la utilización de un corpus en formato electrónico especialmente en los casos en que el volumen del campo de conocimiento especializado hace que el corpus no permita deducir valoraciones de relevancia muy válidas de las evidencias halladas. Las herramientas informáticas más avanzadas aplican herramientas de inteligencia artificial y big-data pero solo proporcionan resultados válidos para grandes volúmenes de términos o en campos en los que desde hace muchos años se vienen aplicado estás técnicas a áreas muy concretas de la medicina y de la física. Para el resto de casos hay que recurrir a un plantel de expertos en el campo de conocimiento concreto.

Para León, Faber y Montero (2012: 101) la aportación de un grupo de expertos es intuitiva y se corren riesgos al estructurar un campo de conocimiento basado en un conjunto restringido de opiniones por muy expertas que sean. Esos riesgos se pueden reducir drásticamente con una cuidadosa selección de expertos. Selección que debe de hacerse no solo en función de su conocimiento de la materia sino, principalmente, en función su conocimiento del usuario y las funciones y necesidades que pretende la búsqueda de ese usuario. En esta dirección, es posible sustituir el corpus y los diccionarios organizados como elementos centrales y de contenido, más o menos fijo, por la exploración dinámica de funciones y de la subsiguiente organización de un 
producto flexible, adaptable y en permanente proceso de construcción y actualización (Díaz García y Mas Álvarez, 2008: 669).

En el caso de EGI, la búsqueda de lemas en los textos especializados implica el conocimiento de las diferentes materias del área de conocimiento y la identificación del componente gráfico asociado o constitutivo de significado.

\subsection{Determinación de unidades de conocimiento en EGI}

En las lenguas especializadas se produce la asignación de una noción a un signo no lingüístico y, desde el punto de vista formal, en los enunciados especializados hay lugar para los signos no lingüísticos (Lerat, 1995: 34-35). Entendido que:

- una noción es una unidad de conocimiento constituida por abstracción a partir de propiedades reconocidas a un conjunto de objetos (p.ej. la noción de perpendicularidad);

- un signo no lingüístico puede jugar el papel de una palabra, tener una pronunciación o una grafía en una legua ( $\varnothing 5$ : 'diámetro cinco'; R5: 'radio cinco');

- en un texto especializado la lógica de la organización del conocimiento puede ser más fuerte que la lógica de la lengua (traducción nuestra).

Desde el punto de vista del estudio semiológico, el análisis del texto técnico incluye todos los elementos -textuales e icónicos- de información que contribuyen directa o indirectamente a la producción del significado. De hecho, en un texto técnico «l'image n'est plus une illustration mais une unité d'information à part entière.», la imagen es una unidad de información por derecho propio y se considera un documento combinatorio (Pétroff, 1984: 56-57) de elementos textuales y elementos visuales o gráficos que ocupan un espacio y una disposición razonada en un documento. Por otra parte, la percepción del discurso y del texto científico y técnico ha cambiado debido a los medios actuales para su publicación y divulgación, también en el ámbito que nos ocupa, la representación gráfica industrial.

El enfoque lexicográfico de EGI que se plantea está motivado, en parte, por la posibilidad de realizar una contribución lexicográfica en este campo, dada la escasa investigación, sobre su valor lexicográfico. 
Entre los estudios previos hay que destacar el realizado por Sadowski y Sorby tanto por el método utilizado como por los resultados alcanzados en la obtención de un inventario de conceptos de ingeniería gráfica (Sadowski y Sorby, 2012, 2015) que permitieron identificar aquellos conceptos críticos que los estudiantes no comprenden y los que 'creen comprender' pero que constituyen los errores recurrentes. El propósito de su trabajo consistió en el desarrollo de un instrumento que valore el conocimiento de conceptos de comunicación gráfica de los estudiantes y que permita a los profesores cuantificar la comprensión de esos conceptos por parte de los estudiantes. Como conclusión, se recomiendan en las programaciones docentes los ajustes que consideran necesarios.

Pasamos a describir brevemente el método utilizado y los resultados obtenidos por estas investigadoras porque suponen un antecedente importante y establecen puntos de referencia con nuestro trabajo:

- El panel de expertos procede de la universidad, de instituciones educativas, institutos de educación secundaria y la industria.

- Los cuestionarios incluyen definiciones con componente verbal y gráfico.

- Se parte de un conjunto de conceptos (80) agrupados por temas.

- Se realizan tres rondas de encuestas anónimas pudiéndose aportar comentarios.

- Se analizan y se retroalimentan los resultados para concluir con 39 conceptos que son los que presentan mayor dificultad a los estudiantes. Se parte de un cuestionario con 80 proposiciones en la primera ronda, después de analizar los resultados y los comentarios de los informantes desaparecen algunas proposiciones y aparecen otras nuevas, se conforma un segundo cuestionario. La segunda ronda contiene 63 proposiciones agrupados en 12 grandes temas, con el procedimiento citado se conforma un cuestionario final (ronda tercera) con un conjunto de 39 conceptos agrupados en 10 temas.

- La fuente utilizada por Sadowski y Sorby es Fundamentals of Graphics Communications de los autores Bertoline \& Wiebe \& Hartman \& Ross (2010), un manual de referencia internacional en comunicación gráfica industrial de nivel universitario.

- La última parte consiste en valorar la dificultad de los 39 conceptos y decidir los integrantes de concept inventory.

Los conceptos obtenidos (Sadowski y Sorby, 2015: 8) ordenados de mayor a menor dificultad se presentan en la tabla 4.4: 
Expresión Gráfica en la Ingeniería

\begin{tabular}{|l|l|l|}
\hline 1.Aligned section & 14.True length & 27.View alignment \\
\hline 2.Revolved section & 15.Cutting plane & 28.Interpreting 3D images \\
\hline 3.Auxiliary view & 16.Sweeping & 29.Assembly \\
\hline 4.Offset section & 17.Creating 2D images & 30.Isometric \\
\hline 5.Removed section & 18.Size description & 31.Line of sight \\
\hline 6.Interpreting 2D images & 19.Inclined surfaces & 32.Callouts \\
\hline 7.Projection plane & 20.Shape description & 33. Revolving \\
\hline 8.Creating 3D images & 21. Half section & 34.Annotations and notes \\
\hline 9.Dimension placement & 22.Edge view & 35. Features \\
\hline 10.Reference plane & 23.Plane of projection & 36.Exploded \\
\hline 11.Datum plane & 24.View direction & 37.Full section \\
\hline 12.Location description & 25.True shape and size & 38.Normal views \\
\hline 13.Orthographic & 26.Edge view & 39.Extrusion \\
\hline
\end{tabular}

Tabla 4.4. Conceptos 'críticos' integrantes de concept inventory ordenados de mayor a menor dificultad (Sadowski y Sorby, 2015)

Desde nuestro punto de vista, este trabajo es muy destacable por: el objetivo del trabajo; el panel de expertos como fuente informante; el método Delphi utilizado para la obtención datos; la utilización de definiciones con dos componentes, verbal y gráfico y los resultados obtenidos consistentes en la identificación de conceptos 'críticos'.

La identificación de conceptos en el área de conocimiento de EGI a partir de recursos documentales que se utilizan en un entorno académico supone un desafío. La dificultad radica en la identificación y la asociación de los dos componentes verbal y gráfico como única entidad, para lo que es imprescindible un conocimiento especializado. A partir de la identificación siguiendo la metodología de la teoría funcional es posible tratar los datos lexicográficamente y presentarlos a los alumnos mediante una herramienta lexicográfica que cubra con éxito sus necesidades de información.

La unidad de conocimiento en EGI requiere de un componente verbal y otro gráfico, ambos integrantes de una misma entidad. Esta unidad de conocimiento está condicionada por los convencionalismos necesarios para la difusión internacional del conocimiento en ingeniería, por la precisión en un mensaje en el que se trasladan detalles de forma, dimensiones y fabricación de objetos dentro de un proceso de diseño.

Much of the creative thought of the designers of our technological world is non-verbal, not easily reducible to words; [...] Technologists, converting their nonverbal knowledge into objects directly (as when an artisan fashioned an 
American ax) or into drawings that have enabled others to build what was in their minds, have chosen the shape and many of the qualities of our man-made surroundings. (Ferguson, 1977)

El rol que asume cada uno de los dos componentes depende de cada concepto y define el grado de dependencia entre ellos. El componente no lingüístico responde a estos cuatro tipos de figuras o dibujos:

- Símbolo gráfico, es el elemento de trazado gráfico al que las normas nacionales e internacionales asignan un significado convencional y reconocido por instituciones y colectivos de profesionales.

- Figura de análisis, es una representación de un proceso tridimensional de resolución o tratamiento de problemas que evidencia la reversibilidad de las proyecciones diédricas

- Representación diédrica, es la representación de elementos geométricos y de objetos sobre un plano según el Sistema Diédrico de representación.

- Representación normalizada, es la representación diédrica de objetos según unas normas (generalmente UNE, UNE-EN ISO, ISO, DIN...)

Algunos ejemplos aclarativos de conceptos y unidades gráficos de EGI que aparecen en manuales, en normas, libros de texto, artículos científicos con carácter pedagógico y catálogos de fabricantes y no tienen un tratamiento lexicográfico son los siguientes:

Ejemplo 1. símbolo gráfico: se utiliza un símbolo convencional para la «Indicación del proceso de fabricación y requisito para la rugosidad de la superficie resultante» UNE-EN ISO 1302. Esta información se compone de un elemento gráfico, una indicación textual y un significado. El elemento gráfico es el representado en la Figura 4.27; la indicación textual: «MRR torneado Rz 3,1»; el significado: el símbolo indica que se requiere retirada de material y además «el método de fabricación es el torneado, límite superior de especificación unilateral, banda de transmisión por defecto, perfil-R, máxima altura de rugosidad 3,1 mm, longitud de evaluación de cinco longitudes de muestreo (por defecto), "regla del $16 \%$ " (por defecto)»

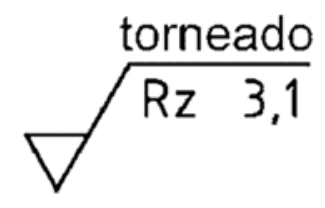

Figura 4.27. Símbolo del requisito para la rugosidad. UNE-EN ISO 1302 
Ejemplo 2. figura de análisis y representación diédrica: el ejemplo de la figura representa las posiciones relativas de dos rectas (en este caso las rectas se cortan). Este ejemplo consta de dos elementos gráficos que son una figura de análisis y una representación diédrica y una descripción verbal. La figura de análisis (suele preceder a la representación diédrica) representa la posición relativa de dos rectas que se cortan (ver figura 4.28). La representación diédrica (ver figura 4.56) representa en proyecciones dos rectas que se cortan en el punto $P$.

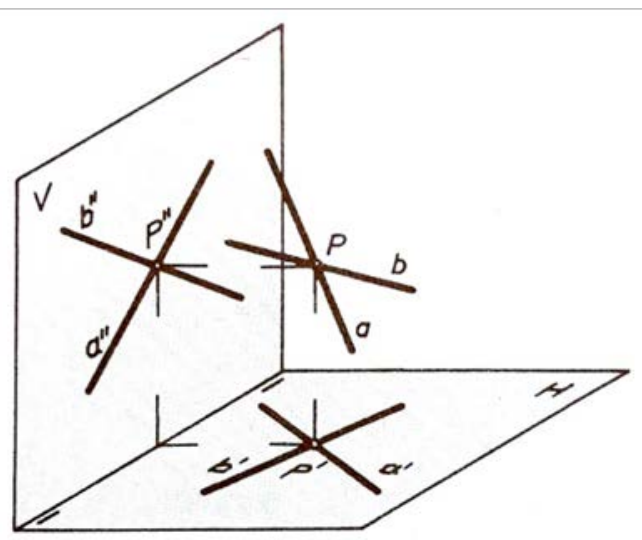

Figura 4.28. Figura de análisis que representa dos rectas que se cortan (González et al.,1982:30)

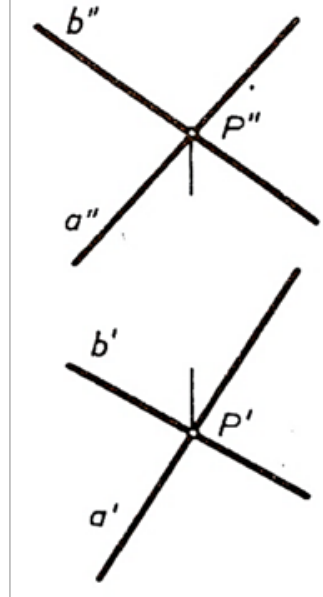

Figura 4.29. Representación diédrica de dos rectas que se cortan (González et al.,1982: 30)

La única indicación textual corresponde a ambas figuras 4.55 y 4.56 :

«Si dos rectas $\mathbf{a}$ y $\mathbf{b}$ se cortan en un punto $\mathbf{P}$, este punto pertenece a ambas y, por tanto, las proyecciones del punto estarán sobre las proyecciones homónimas de las rectas.» y se añade «Esto sólo será posible, cuando los puntos de corte de las proyecciones horizontal y vertical de las dos rectas, estén sobre la misma línea de referencia de P'-P", condición necesaria y suficiente.» (González et al.,1982:30)

En este ejemplo se observan dos aspectos destacables: por una parte, el nivel de abstracción que se establece al concebir los tres componentes (dos gráficos y uno verbal) como similares o equivalentes $y$, por otra parte, que es posible eliminar la rigidez o linealidad de la secuencia de la forma verbal. Las representaciones verbales sugieren un procesamiento lineal de la información, mientras que las representaciones gráficas permiten un procesamiento flexible de la información (Maton, 2007: 46). 
Cuando un usuario realiza una consulta lexicográfica, algunos indicadores en la estructura y presentación del artículo de diccionario (subtítulos, encabezados...) pueden ser útiles para lograr un acceso más rápido, pero es importante tener en cuenta que el consultante que busca información no actúa de manera lineal (Bergenholtz, Bothma y Gouws, 2015: 23).

Ejemplo 3, representación normalizada de un objeto normalizado, un tornillo prisionero DIN6332. Esta información se compone de la representación normalizada (ver la figura 4.31.), una imagen del objeto (ver la figura 4.30), la descripción del objeto y una tabla en la que las variables representadas en el dibujo toman valores que concreta el fabricante. La información textual es una descripción del objeto «El punto de empuje de los tornillos prisioneros DIN 6332 está diseñado para ser utilizado con y sin almohadilla de empuje para la sujeción. El diámetro de la punta de estos tornillos prisioneros es más pequeño que el diámetro central del espárrago, lo que les permite atornillarse en el lado de la punta. El anillo de retención /resorte de retención es un método simple y rápido para conectar la almohadilla de empuje al tornillo prisionero.»

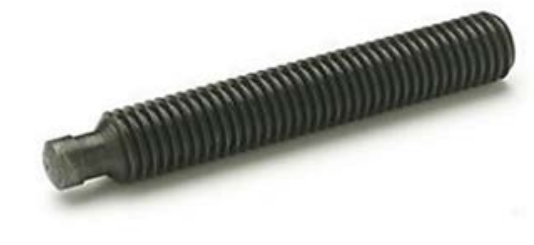

Figura 4.30. Imagen de tornillo prisionero DIN 6332 <https://www.jwwinco.com>

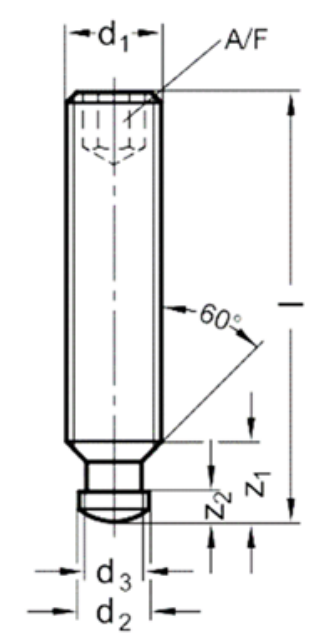

Figura 4.31. Representación normalizada del tornillo de la figura 4.30 $<$ https://www.jwwinco.com>

\subsection{Análisis de las funciones lexicográficas del diccionario de EGI}

Los diccionarios se especializan en relación con los datos que incluyen para satisfacer las demandas de información de los usuarios con una intención que viene determinada por la función del diccionario. Como apuntan Bergenholtz, Bothma y Gouws (2015) y Tarp (2008a) estas herramientas de información son aquellas que contienen datos destinados a usuarios en situaciones comunicativas relacionadas con textos, en situaciones cognitivas que brindan 
información para aprender conocimientos generales o especiales, en situaciones interpretativas para reconocer el significado atribuído a signos no lingüísticos y en situaciones operativas para llevar a cabo ciertas acciones. Al igual que Bergenholtz y Agerbo (2017: 24) se entiende por situación «it refers to a time at which a certain information need occurs. Such a situation may occur as a result of another situation and thereby be a part of a course of events». Se adopta la definición de función lexicográfica de un diccionario, entendido este como una herramienta destinada para realizar una actividad "the satisfaction of the specific types of punctual information need that may arise in a specific type of potencial user in a specific type of extralexicographical situation» (Fuertes-Olivera y Tarp, 2014: 62). La información que un usuario extrae de un diccionario y que va a poder utilizar en situaciones lexicográficas y extralexicográficas depende, entre otros factores, de los datos puntuales presentados y accesibles en el diccionario. Los datos contenidos en un diccionario se ajustan a las necesidades tipo que surgen en situaciones tipo a un perfil tipo de usuario y estos datos son «datos lexicográficos explícitamente preparados» (Tarp, 2015) para cumplir una o varias funciones declaradas de un diccionario en una disciplina gráfica instrumental como EGI.

La intervención de las variables usuario, necesidades que dependen de la situación extra-lexicográfica concreta determina la función del diccionario. En la TFL se considera predominante la situación social en la que se encuentra el usuario (sobre las otras dos variables) y dentro de las posibles situaciones es preciso identificar las situaciones lexicográficamente relevantes: comunicativa, cognitiva, operativa e interpretativa y con esta misma denominación las funciones del diccionario. No obstante, al más alto nivel de abstracción las situaciones en las que una persona puede experimentar necesidad de información (Fuertes-Olivera y Tarp, 2014: 51) son: cognitiva, interpretativa y operativa:

- Situación cognitiva, en la que puede presentarse la necesidad de adquirir conocimiento sobre un tema o disciplina, o se requiere un conocimiento previo para realizar una tarea (Fuertes-Olivera y Tarp, 2014; Tarp, 2015).

- Situación interpretativa, en la que puede presentarse la necesidad de interpretar y comprender un signo, señal, símbolo o sonido que no es lingüístico (Tarp, 2015).

- Situación operativa, en la que puede presentarse la necesidad de llevar a cabo una acción de naturaleza física, mental o lingüística (Fuertes-Olivera y Tarp 2014). 
El tipo de situación está claramente predeterminado en las fuentes de información monofuncionales. No obstante, en las fuentes de información polifuncionales, especialmente en las bases de datos electrónicas, el usuario puede formular las cadenas de búsqueda y acceder a una parte (no al 'todo') p. ej., de un artículo de diccionario, que parece relevante para satisfacer una necesidad específica de acuerdo con alguna de las funciones propuestas (Bergenholtz, Bothma y Gouws, 2015: 21), en este caso se amplían las posibles situaciones que pueden ser momentáneamente únicas, pero diferentes a cada paso. En el caso de nuestra propuesta de diccionario electrónico en línea no se espera que el usuario reaccione de una forma concreta y anticipada en todo momento, en cada situación. Se tiene en cuenta que un mismo usuario (en caso del estudiante) puede adoptar distintos roles ( $p$. ej., semiexperto o lego), incluso decidir adoptar distintos roles. El invariante es el tipo específico de necesidad de información del usuario potencial:

- las necesidades puntuales de información están asociadas a ciertos tipos de usuarios potenciales y no son abstractas (Fuertes-Olivera y Tarp, 2014: 62);

- el tipo de necesidades del usuario determina la asistencia que debe proporcionar cualquier diccionario (Tarp, 2008: 82). El acceso y la presentación de datos, en respuesta a una demanda de un usuario en una herramienta en línea, permite que la oferta oculta sea amplia y la respuesta visible sea concreta y relevante.

Antes de anticipar esta propuesta de diccionario y sus funciones se sopesa la dificultad que puede provocar un diccionario multifuncional en relación con la sobrecarga de información cuando el usuario accede a los datos para obtener la información deseada. «INFORMATION OVERLOAD. If overstimulation at the sensory level increases the distortion with which we perceive reality, cognitive overstimulation interferes with our ability to "think"» (Toffler, 1970: 350). Fuertes-Olivera y Tarp (ibid. 62-63) proponen reducir este problema, en lexicografía especializada, con una nueva generación de diccionarios en línea del tipo:

- monofuncionales puros,

- multifuncionales consintiendo el acceso monofuncional a los datos,

- monofuncionales consintiendo el acceso individualizado a los datos,

- multifuncionales consintiendo el acceso individualizado a los datos. 
Las funciones son elementos básicos de la teoría y práctica lexicográfica e influyen en mayor o menor medida en la forma y el contenido de un diccionario (Bergenholtz y Tarp, 2003: 177). La determinación de los tipos y la cantidad de datos necesarios en relación con cada función es objeto del marco teórico y metodológico de la TFL.

Presentamos una propuesta de diccionario pedagógico en línea de EGI con las funciones destacadas cognitiva, interpretativa y operativa. Si bien se considera que todo proceso de enseñanza-aprendizaje es un proceso de comunicación, esta propuesta no contempla explícitamente la función comunicativa.

\subsubsection{Función Cognitiva}

Las situaciones cognitivas se refieren a situaciones en las que el usuario necesita ampliar su conocimiento previo y pasar de un estado de conocimiento a otro superior por etapas fundamentadas en el nivel de conocimiento previo. Pétroff entiende que un estado de conocimiento se define como una red de relaciones entre elementos de información, desde este punto de vista, una propuesta lexicográfica muestra una red de elementos, de relaciones y de elementos con sus relaciones (Pétroff, 1984: 54).

Después de consultar una herramienta de información, en el caso de una consulta con éxito, el usuario puede memorizar la información adquirida para siempre o para aplicarla en el momento. Este conocimiento se puede utilizar en otra situación posterior, pero sería en una nueva situación cognitiva o una nueva situación operativa o una nueva situación interpretativa. La necesidad de adquirir conocimiento de un destinatario surge en situaciones relacionadas con: un programa de enseñanza reglada que requiere adquirir gradualmente conocimiento sobre un área específica de conocimiento; un curso de profundización sobre un tema (Tarp, 2008: 45) (énfasis añadido); una situación de aplicación práctica de un conocimiento teórico que requiere solución inmediata. Para facilitar la adquisición gradual de conocimiento especializado se proponen entradas al diccionario a distintos 'niveles'. Contemplando las necesidades de un usuario inexperto, de un usuario semi-experto y de un usuario experto. En este caso los dos primeros corresponden al perfil de un estudiante o alumno de EGI y el tercero a un ingeniero profesional. 
Para satisfacer las necesidades cognitivas, relativas a un determinado campo de conocimiento, los diccionarios especializados incluyen datos enciclopédicos descriptivos y detallados. Estos datos enciclopédicos se presentan generalmente en forma de notas o de etiquetas enciclopédicas adjuntas al lema o como elementos externos (introducción sistemática) (Bergenholtz y Nielsen, 2006: 284). Los datos enciclopédicos incluidos intentan satisfacer las necesidades cognitivas relacionados con el área de conocimiento y tratan la descripción del conocimiento específico y la realidad extra-lingüística. Algunos diccionarios especializados ofrecen soluciones incompletas para satisfacer las necesidades de los usuarios en términos de comunicación y aprendizaje de LSP debido a la ausencia de datos enciclopédicos (FuertesOlivera y Tarp, 2011: 152).

La realidad 'extra-lingüística' de carácter gráfico es parte integrante del concepto al presentarse dos componentes de distinta naturaleza (verbal y gráfica) simultáneamente. Los dos componentes del concepto son necesarios para alcanzar la precisión y la eficacia requerida en un proceso cognitivo mental y gráfico. El peso de cada componente del concepto depende del nivel de conocimiento de la materia y de la situación del usuario, esto es, si se precisa aplicar el conocimiento adquirido o se aprende para progresar en el conocimiento.

EGI es tanto una materia instrumental como una materia de aplicación práctica directa. En ambos casos los conceptos forman parte de un proceso cognitivo constructivo, se apoyan en el conocimiento previo y están cumpliendo una función cognitiva. Si el usuario está inmerso en una situación extralexicográfica que requiere información de aplicación práctica directa, los conceptos deben ser presentados para cumplir una función cognitiva activa. Los datos que contiene el diccionario se diseñan y se disponen para cumplir esta función en situaciones tipo.

\subsubsection{Función Interpretativa}

Hay situaciones en las que se surgen necesidades relacionadas con signos y conceptos que no son verbales y no suelen tratarse en los diccionarios. Esto puede dificultar una consulta puntual, rápida y el acceso a una información requerida. El tratamiento lexicográfico de unidades para su presentación en obras de consulta que contienen signos, como parte integrante de su expresión, 
o que contienen símbolos, a los que se les ha atribuido un significado, es una opción razonable para satisfacer estas necesidades.

La necesidad de información ha existido siempre a pesar de que es, hoy en día, cuando se denomina 'sociedad de la información'. Dado el interés que siempre ha existido por adquirir conocimiento, experiencia y habilidades en comunicación, para aprender, para ejecutar acciones y para comprender signos con intención de actuar. Al definir los elementos importantes en la teoría funcional Tarp (2008a) considera posible una situación interpretativa en la que el usuario requiera interpretar 'signos y símbolos' del mundo que le rodea. Lo novedoso en la sociedad de la información es la facilidad, la extensa cantidad de datos y la complejidad de sus relaciones que se puede manejar en poco tiempo y que requiere otro tipo de conocimiento y de aprendizaje. Bergenholtz, Bothma and Gouws (2015: 2) mencionan el conocimiento interpretativo necesario para actuar, en consecuencia, en determinadas situaciones. El proceso necesario para adquirir conocimiento en estas situaciones conduce a diseñar herramientas lexicográficas de consulta y a disponer de ellas.

Durante su formación los alumnos de ingeniería deben manejar signos, símbolos y conceptos no verbales, y es frecuente que se encuentran en situaciones interpretativas. La consulta a una obra de referencia facilita, a partir de los datos obtenidos: la interpretación de símbolos; la comprensión de conceptos complejos; la resolución de problemas gráficamente; la documentación de un proceso de fabricación...

El proceso interpretativo, en este caso, coincide con la formulación respecto a la necesidad de interpretar signos no lingüísticos que se plantea en Bergenholtz, Bothma y Gouws (2015) y Agerbo (2019) las dos opciones -que mostramos en una- se adaptan a las situaciones en $E G I$, se entiende que una vez obtenida la información, se requiere una fase de 'toma de decisiones' se decida actuar o no:

- problema del conocimiento del significado de un signo no lingüístico y posiblemente actuar en consecuencia / problema para actuar al reaccionar a un signo o símbolo

- fuente de información,

- después de obtener la información, actuar o no actuar,

- reflexión sobre el proceso y los resultados. 
A continuación, se presenta un ejemplo seleccionado de Generalidades sobre los cortes de la norma UNE 1-032-82. Es un caso tipo en el que el alumno debe interpretar, por sí mismo o con 'ayuda', el significado preciso de la indicación en la norma: «Cuando es evidente la localización del plano de corte, no es necesaria ninguna indicación de su posición o su identificación (véanse las figuras 24 y 35).» y es el receptor quien debe llegar a la única interpretación posible al analizar las figuras 24 y 35 de dicha norma.

Las figuras 24 y 25 de la norma UNE (véase la Figura 4.32 y la Figura 4.33) respectivamente son necesarias para completar el significado al que hace referencia la norma para identificar «cuando es evidente la localización del plano de corte». En la figura 24 la interpretación es necesaria y única: la localización del plano de corte es evidente porque coincide con el plano de simetría de la pieza. En la figura 35 la interpretación es única (más obvio que en el caso anterior): las localizaciones de los planos de corte son evidentes porque las trazas de los planos de corte están unidas a los ejes de las secciones respectivas.

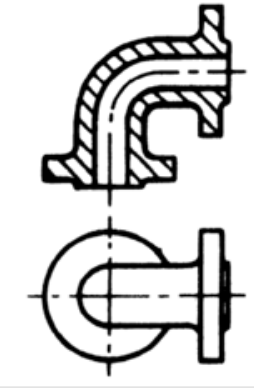

Figura 4.32. Figura 24 de la norma UNE 1-032-82

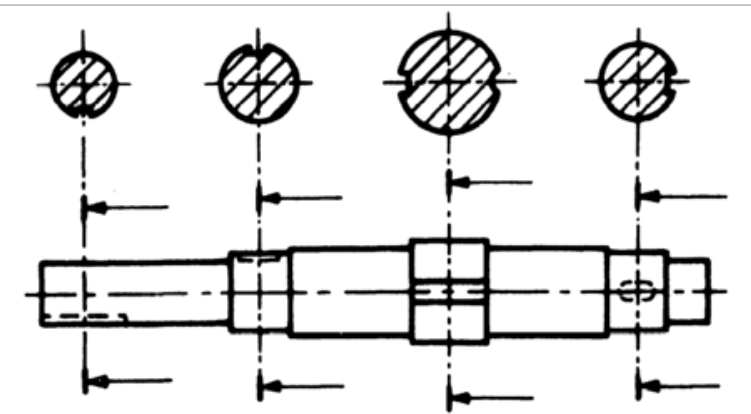

Figura 4.33. Figura 35 de la norma UNE 1-032-82

Para García Aragón (2016: 210) la función interpretativa en una obra de referencia facilita al usuario realizar la tarea interpretativa de adquirir un conocimiento a corto o largo plazo con el fin de interpretar un fenómeno cognitivo, comunicativo u operativo.

A la pregunta que formula Agerbo (2017: 5): «Question 1: Do you need to understand the given sign in order to carry out a certain act? "

- En nuestra opinión, en EGI, sí es necesario interpretar el contenido gráfico en un plano o dibujo técnico para llevar a cabo acciones (p.ej. en los planos de montaje de un mecanismo). Además, se debe tener en cuenta que hay organismos responsables del 
desarrollo de las normas técnicas que incluyen en sus documentos símbolos y les atribuyen un significado convencional que no se puede deducir, ni de una forma intuitiva, ni del contexto.

Dado que existen situaciones y necesidades interpretativas, es posible que un diccionario se proyecte con una función interpretativa. Agerbo (2016) apoya la incorporación de la función interpretativa en la teoría de funciones y aporta sugerencias sobre cómo tratar los signos no lingüísticos en artículos específicos del diccionario. Sin embargo, su investigación sobre las definiciones de función interpretativa se resume en Agerbo (2017:5) y le lleva a considerar que, la función interpretativa no debe considerarse una función principal individual -puesto que no está relacionada con la actuación-. En Agerbo (2019:75) plantea si la necesidad de actuar existe de forma autónoma o es parte de una necesidad interpretativa. Entre las definiciones que recoge se aproximan a la función interpretativa de un diccionario de EGI las de los autores:

- Fuertes-Olivera y Tarp (2014: 51), «...to understand or interpret a specific phenomenon, sign, symbol, text, etc.»

- Bergenholtz, Bothma and Gouws (2015: 2) «...to be able to understand certain nonlinguistic signs and to act accordingly»

A la pregunta que formula Agerbo (ibid., p.5): "Question 2: What types of sign are relevant for the interpretive function? "

- Los signos relevantes en EGI para la función interpretativa: «El signo inventado o producido y transmitido por humanos de manera consciente y creativa para transmitir un mensaje (intencional y motivado). Los símbolos relativos al campo especializado de la geometría gráfica y a sus elementos. El signo que imita lo que representan, p.ej. un dibujo de un automóvil.» Agerbo menciona estos signos no lingüísticos extraídos de la tipología de signos de Pierce (traducción nuestra, énfasis añadido) que constituyen la esencia de la representación gráfica en la ingeniería.

Toda acción interpretativa tiene un componente subjetivo que supone concebir la realidad de un modo personal. En EGI cuando se lee un plano se está interpretando, depende del objetivo del plano y del cometido del interpretante en un proyecto, la información que se extrae de esa lectura es particular e interesada. El dibujo técnico esta codificado e 
intuitivamente no tiene sentido y se requiere una capacitación (cf. 4.8) que hace posible construir su significado. "Cuando se trata de crear el significado de un dibujo técnico, debe hacerse con un propósito de acción para lograr un objetivo. La creación de significado no se limita al dominio puramente "cognitivo" (de razonamiento, de comprensión), sino que también implica una emergencia movilizadora del individuo en su relación con el mundo que está construyendo en el camino.» (Labour, Martin, \& Leleu-Merviel, 2010:12).

La propuesta de una función lexicográfica interpretativa en un diccionario debe favorecer la construcción del significado de un dibujo técnico.

\subsubsection{Función Operativa}

Un diccionario cumple con la función operativa, cuando el usuario debe realizar una tarea no lingüística (Fuertes-Olivera y Tarp, 2014: 51) en una situación en la que necesita consejos e instrucciones para realizar cualquier tipo de acción mental o manual (Tarp 2008a:185) y consulta un diccionario para obtener información. Las obras de referencia lexicográficas pueden asistir en procesos de almacenamiento de información procedimental y en situaciones operativas que requieren llevar a cabo un determinado acto (cómo hacer) o saber qué acto llevar a cabo (qué hacer) (Bergenholtz y Agerbo, 2017: 36). Se identifican situaciones operativas en las que una persona realiza una búsqueda de información, bien porque precisa asesoramiento sobre lo que debe hacer, o bien porque necesita instrucciones para resolver un problema.

En el apartado 5.4, se identifica la situación operativa que motiva una consulta puntual para llevar a cabo una acción. Las subfunciones de la función operativa, las acciones comunicativas y no comunicativas (Agerbo, 2019: 89); las acciones físicas o mentales sobre signos lingüísticos y no lingüísticos, evidencian un rango amplio de necesidades posibles en esta situación. El objeto de esta tesis es una obra de referencia en un ámbito especializado (EGI) con vocación de satisfacer necesidades operativas en el fondo y en la forma. El fondo son los fundamentos geométricos de la representación gráfica industrial, la forma son las técnicas y sistemas de representación utilizadas y ambos se reflejan en los convencionalismos internacionales adoptados. 
Se tienen en cuenta las siguientes consideraciones en una situación operativa:

- La entrada al diccionario está formada por una sucesión de palabras clave. En la reunión de expertos de EGI se llega a la conclusión de que el inicio pluriverbal como elemento de búsqueda limita o anula la ambigüedad, objetivo perseguido en este campo. Como consecuencia se plantea un sistema de gestión de acceso a la información en un diccionario electrónico que permita estas unidades.

- En las situaciones operativas en EGI es imprescindible el conocimiento y ciertas habilidades relativas al campo especializado para llevar a cabo algún tipo de acción (saber- saber hacer), lógicamente en distinto grado dependiendo del nivel de conocimiento del usuario. La respuesta a una consulta podría ser, como en el caso de Agerbo diferentes "acciones" a llevar a cabo en conexión con un núcleo (Agerbo, 2019: 108).

- Se exponen ejemplos de las necesidades operativas concretas respecto al trazado o construcciones geométricas.

- La reformulación de definiciones y formulación de acciones adaptadas a distintos perfiles de usuario y distintas necesidades. El término reformulación utilizado por Pétroff (1984: 54) implica un acto, en el discurso científico y técnico, que recoge la información en su totalidad o en parte para adaptarla a una nueva situación o a otros destinatarios. Para Sánchez Martín (2009: 2170) «la reformulación permite las operaciones de explicación y denominación de la terminología geométrica».

Agerbo (2019: 126) define una herramienta con función operativa como: «an information tool that is to be applied to help a person act in a non-communicative way; it provides the person with data in the form of advice or instructions that are quick and easy to access, understand and apply». En una obra de referencia con elementos, relaciones y unidades conceptuales geométricas la función operativa que se precisa se ajusta a esta definición.

\subsection{Conclusiones}

La combinación en un diccionario de EGI en línea de los dos componentes procedentes de: el lenguaje especializado y el 'lenguaje gráfico’ supone un reto lexicográfico novedoso que ofrece al usuario un repertorio de datos lexicográficos junto con un repertorio integrado de datos gráficos. Además, lo hace apoyándose en un lenguaje especializado de naturaleza gráfica y un conocimiento especializado de aplicación técnica. 
La propuesta pedagógica de este diccionario implica tener en cuenta desde el inicio del proyecto el contenido, el acceso y la presentación de los datos, de manera que permita al usuario avanzar en el conocimiento de la materia. De este carácter pedagógico se deriva también que sea fundamental el determinar las características del usuario y las necesidades que este busca satisfacer con la consulta.

A la hora de determinar las funciones del diccionario (cf. 4.6) es necesario tener en cuenta el referente visual, la estructura y las funciones de la representación gráfica y su relación funcional con la parte verbal con la que se complementa.

Se ha comprobado la secuenciación de la función interpretativa y la función operativa tal y como lo entiende Agerbo (2019:74). La interpretación de ciertos signos no lingüísticos conduce a la acción (resolver un problema geométrico), al incremento de conocimiento y utilizar lo aprendido para aumentar el conocimiento sobre un tema, en ese momento o más adelante (determinar una recta perpendicular a un plano para, en otro momento determinar el segmento mínima distancia entre dos rectas que se cruzan), en un claro ejemplo de sucesión de funciones lexicográficas. Por lo que se deduce que las funciones del diccionario no son excluyentes.

Las fuentes documentales que hemos consultado y las carencias funcionales que han evidenciado los diccionarios técnicos (cf. 4.7.1) respecto a nuestros objetivos, justifican nuestra propuesta lexicográfica que incluye además las funciones interpretativa y operativa.

Por último, queremos destacar algunas capacidades disciplinares a desarrollar por los alumnos que también contribuyen a esa justificación:

- La precisión, la optimización en los dibujos normalizados y la relación unívoca entre el objeto representado y el objeto real

- La aparente reducción determinada por los principios de limitación, restricción, selección y simplificación en la utilización de recursos (lingüísticos y no lingüísticos), no es privativa de este lenguaje de especialidad, en alguna medida también corresponde al campo de conocimiento (Esandi et al., 2007).

- Los ingenieros deben ser usuarios competentes en la lengua y la adquisición de las habilidades lingüísticas y la competencia léxica deben ser una parte importante de la capacitación y la formación en ingeniería (debido a la deslocalización geográfica de los proyectos y de las tareas de ingeniería).

El usuario al que nos dirigimos está habituado al uso de herramientas informáticas, siendo esta su primera opción en cualquier tipo de consulta o búsqueda de información sobre 
un tema, el significado de una palabra o de una expresión, 'saber hacer' cualquier cosa... Hemos considerado interesante comprobar de qué manera resuelve una búsqueda de un elemento de EGI la principal herramienta mundial de búsqueda de información: Google. Una búsqueda (14 de julio de 2020) por imágenes en Google, utilizando figuras de algunos ejemplos que estamos utilizando en esta tesis para comprobar el grado de identificación de las entidades gráficas o símbolos. Es posible «Pegar el URL de imagen» o "Subir una imagen», el resultado es decepcionante.

Utilizando la Figura 4.27 que corresponde a un símbolo normalizado de requisito para la rugosidad, Google devuelve las imágenes de la Figura 4.34. Se encuentran similitudes gráficas entre el símbolo de requisito para la rugosidad y el signo matemático de la 'raíz cuadrada'.

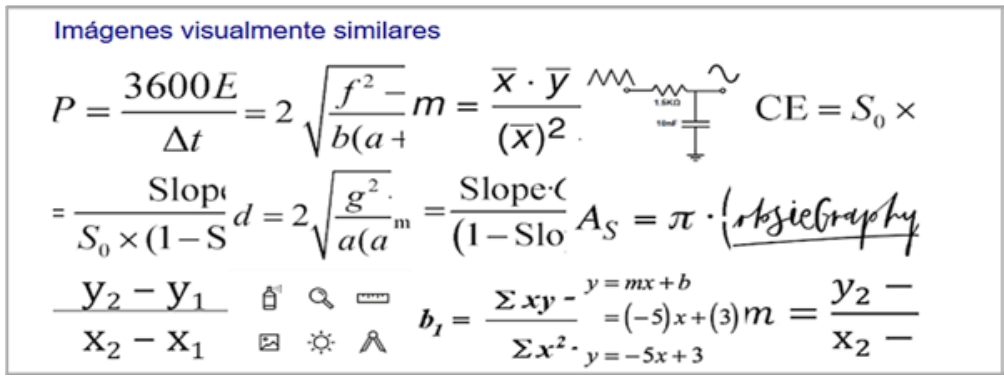

Figura 4.34. Captura de pantalla de la búsqueda por imagen 4.27 en Google $<$ https://www.google.com/> [consultado 14-07-2020]

Utilizando la Figura 4.28 que corresponde a una figura de análisis, Google devuelve las imágenes de la Figura 4.35. Sería interesante que, al menos, identificara los planos coordenados

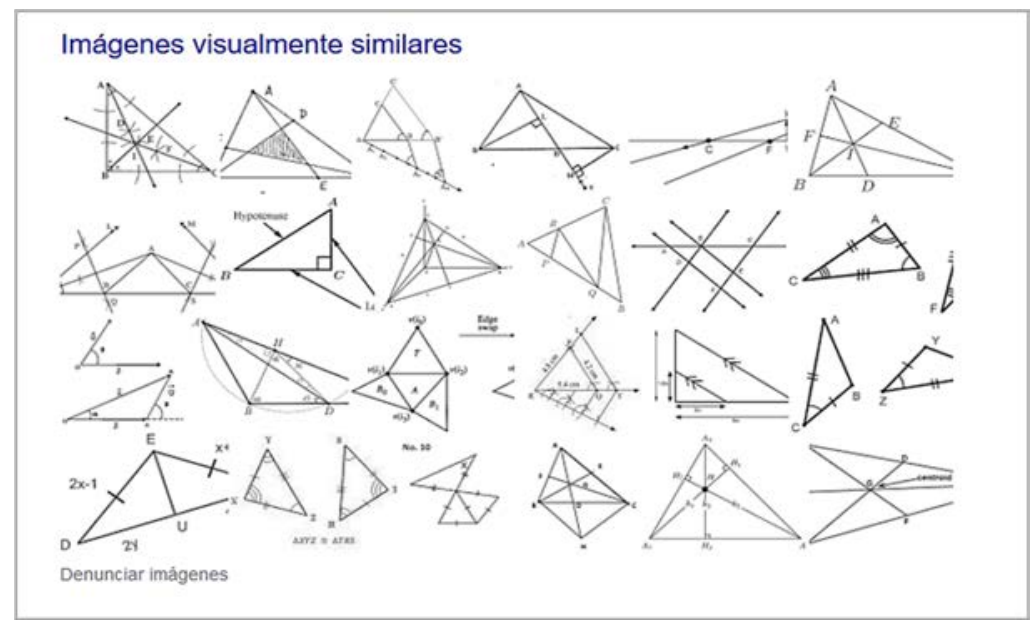

Figura 4.35. Captura de pantalla de la búsqueda por imagen 4.28 en Google

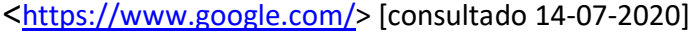


$(\mathrm{H}$ y $\mathrm{V})$ y las dos rectas que se cortan en un punto. Sin embargo, se identifican diversos elementos geométricos relacionados con problemas y propiedades de los ángulos.

Nada tienen que ver con las figuras 'de entrada' y ningún interés para un semiexperto, esperamos que tengan poco interés para un inexperto en EGI. Esta se debe a dos razones: el modo de búsqueda de imágenes de Google y al tratamiento informático de los sistemas de dibujo asistido por ordenador que son los utilizados en ingeniería para la generación y empleo de imágenes. Google hace un, relativamente simple, reconocimiento de imágenes a partir de ficheros de imagen y devuelve imágenes topológicamente parecidas y reconoce similitudes de formas y de colores, pero nada más. Los sistemas de CAD o DAO tratan con gráficos vectorizados, es decir, que entienden, clasifican y relacionan entidades geométricas a las que dan un tratamiento gráfico solo cuando se muestran en la pantalla, pero internamente el tratamiento es matemático. Los ficheros de 'dibujo' generados por los programas de CAD son de un formato específico para cada programa, aunque existen ficheros de 'intercambio' o aplicaciones de traducción de ficheros entre los programas de CAD del mercado. De momento, Google no rastrea este tipo de ficheros. 


\section{MATERIALES Y MÉTODOS}

5.1 Introducción

5.2 Metodología

5.3 Caracterización del usuario tipo

5.3.1 Características del perfil del usuario de un diccionario de EGI

5.4 Sesión de Expertos

5.4.1 Aportaciones de los expertos

5.5 Lista inicial consensuada de conceptos, el Método Delphi

5.5.1 Metodología Delphi

5.5.2 Las fuentes

5.5.3 Los cuestionarios

5.5.4 Realización de los cuestionarios

5.5.5 Interpretación del consenso

5.5.6 Importancia asignada al concepto

5.5.7 Encuesta realizada a los alumnos

5.5.8 Análisis de los resultados

5.5.9 Discusión

5.6 Conclusiones 


\section{MATERIALES Y MÉTODOS}

\subsection{Introducción}

En el capítulo 1 dedicado a la Introducción de este estudio, se declara el objetivo principal de la presente tesis y se enuncia una serie de preguntas de investigación. Con la intención de responder estas preguntas se llevan a cabo una serie de acciones, se aplican metodologías y se toman las siguientes decisiones:

1. Definir el perfil tipo de usuario e identificar las necesidades de información lexicográficas en este campo especializado. Para ello es necesario identificar entre las competencias a desarrollar en la vida académica del usuario las que les conducen a realizar tareas que precisan conocimiento especializado, habilidades y destrezas generales y específicas relacionadas con el ámbito especializado y con la consulta a obras de referencia.

2. Una sesión con expertos docentes sobre su experiencia académica, la naturaleza de la Expresión Gráfica en la Ingeniería y el ámbito industrial profesional. Los expertos aportan información sobre el perfil del usuario y sobre sus necesidades en este contexto. Finalmente, esta sesión ha sido el punto de partida:

2.1 para la aplicación de una metodología que, mediante cuestionarios, permite extraer conceptos de unas fuentes que agrupan y relacionan conceptos que incluyen un componente gráfico y una lista consensuada inicial de conceptos (Método Delphi);

2.2 para la recogida de información de los alumnos sobre estos conceptos y sobre ciertas necesidades del usuario potencial.

\subsection{Metodología}

Esta tesis se perfila siguiendo los criterios de la teoría funcional para concretar una propuesta de diccionario especializado en línea. 
Siguiendo los principios de la teoría funcional y el razonamiento del método deductivo se inicia el proceso centrado en el usuario del diccionario, su situación y sus necesidades. Una vez identificadas estas premisas, la naturaleza del campo de conocimiento especializado condiciona su tratamiento lexicográfico. Entre las tareas del lexicógrafo está reconocer las unidades léxicas y proporcionar definiciones, en el caso en un campo especializado, que contribuyan a la desambiguación de conceptos, es decir, a determinar el sentido de una palabra en su contexto (cf. Wilks et al.,1996: capítulo 11 (Fellbaum, 1998b:239-240)). De forma que, una vez identificadas (extraídas de textos), diseccionadas (analizadas pormenorizadamente) y expuestas sus nociones, se buscan soluciones y se realiza una propuesta lógica que alcance nuestro objetivo principal. Una propuesta para una obra de referencia de consulta puntual en línea que satisfaga las necesidades de información de un potencial usuario y que incremente su conocimiento especializado de EGI. En consecuencia y por la estrategia adoptada, se tienen en cuenta:

- las características del perfil del usuario;

- las situaciones extra-lexicográficas de la consulta;

- las necesidades del usuario;

- la identificación y la extracción de nociones propias del campo de conocimiento que incluyen unidades textuales y unidades -representaciones- gráficas de manuales, normas, libros de texto, etc.

- las funciones del diccionario;

- la disposición de estos datos convenientemente en un diccionario;

- una lista inicial de unidades (después de realizar un análisis empírico de recogida de datos);

- solución y propuesta de concepto lexicográfico en EGI;

- una ruta de acceso y la presentación de los datos lexicográficos en el diccionario.

\subsection{Caracterización del usuario tipo}

El futuro usuario del diccionario en línea pedagógico propuesto es un estudiante de «Expresión gráfica en la ingeniería» o un profesional, es decir, con experiencia y en situación académica de aprendizaje y/o de puesta en práctica de conocimientos de ingeniería industrial gráfica. El catálogo de competencias a desarrollar por estos estudiantes a lo largo de su vida académica nos permite una aproximación al perfil del usuario potencial de un diccionario en línea de EGI. 
Teniendo en cuenta que el nivel máximo competencial se alcanza al final de este período de formación.

Respecto a las competencias a desarrollar del estudiante de EGI, se señala el compendio seleccionado que se presenta en la Tabla 4.3 y que corresponde fundamentalmente a materias de primer curso (revelando el grado de desarrollo competencial de un alumno universitario en este momento de su formación). Las competencias aparecen diferenciadas en genéricas y específicas. El desarrollo de las competencias genéricas predispone a un correcto uso y aprovechamiento de un diccionario general y de un diccionario especializado, ya que hacen referencia a la madurez académica de los estudiantes. Dentro de las competencias específicas cabe destacar:

- visualización espacial;

- las técnicas de visualización gráfica, geometría métrica, geometría descriptiva y aplicaciones de diseño asistidas por ordenador;

- la aplicación de normas, reglamentos y especificaciones de obligado cumplimiento;

- la realización de planos y definición de producto a nivel de detalle;

- la comunicación en lenguajes formales gráficos y simbólicos;

- la comprensión y aplicación de las principales teorías de semiótica;

- la visualización y comunicación de ideas;

- la comprensión del espacio tridimensional, los elementos básicos que lo ocupan y sus relaciones;

- la identificación de especificaciones normalizadas;

- la redacción de proyectos relacionados con el diseño industrial y desarrollo de producto;

- la redacción e interpretación de documentación técnica;

- el diseño de máquinas e instalaciones industriales;

- la aplicación de sistemas y procesos de fabricación, metrología y control de calidad;

- los fundamentos científico-técnicos;

- la aplicación y dominio de conocimientos culturales, tecnológicos y de comunicación;

- la aplicación de herramientas tecnológicas de acceso y de difusión de la información;

- la actuación responsable en base a la relación entre la ingeniería y la sociedad;

- el Diseño, respondiendo a las necesidades de la empresa, el mercado, la sociedad y los usuarios;

- el trabajo en un contexto internacional;

- el dominio de materias básicas y tecnológicas, que le capacite para el aprendizaje de nuevos métodos y teorías y le dote de versatilidad para adaptarse a nuevas situaciones;

- el trabajo en un entorno multilingüe y multidisciplinar.

Este usuario tiene ciertas características de la llamada generación de nativos digitales que le predisponen para una utilización de las herramientas en línea en lo que a destrezas y 
habilidades se refiere y sin prejuicios hacia el soporte. Sin embargo, de las conclusiones expuestas en el capítulo 3, se deduce que presenta una relación compleja y no homogénea entre el uso de tecnologías digitales y los hábitos de aprendizaje productivo (Thompson, 2013); tiene un conocimiento sofisticado de las tecnologías de la información y el contacto con ellas ha modificado su estilo de aprendizaje (Bennett et al., 2008) y mejora la autosuficiencia en su proceso de aprendizaje. Además, desde el punto de vista académico se puede concluir que el tipo de usuario: requiere formación para un uso eficaz de una herramienta pedagógica (Thompson, 2013); tiende a una asociación de la tecnología digital con el ocio; es un agente receptivo, pocas veces activo en aportaciones personales respecto a la información; su actitud ante el aprendizaje está influenciada por la actitud de su docente (Margaryan et al., 2011).

La formación técnica universitaria contiene un conjunto de conocimientos y habilidades que deben organizarse y estructurarse para conducir a una formación coherente y profesional. Siendo imprescindible para los futuros ingenieros, en nuestra opinión, una formación sólida en dibujo industrial.

\subsubsection{Características del perfil del usuario de un diccionario de EGI}

El nivel competencial del usuario es consecuencia de su experiencia previa y de las capacidades a desarrollar según el plan de estudios que definen un entorno universitario técnico y gráfico que ya se ha detallado. Según este plan docente estas capacidades configuran el perfil de:

- un usuario predispuesto lexicográficamente con tareas de redacción e interpretación de documentos familiarizado con áreas y herramientas de información y comunicación;

- un usuario que forma parte de un colectivo con el que comparte un conocimiento especializado y una terminología propia de la ingeniería industrial, pero no siempre con el rigor necesario;

- un usuario consciente de la dispersión geográfica del conocimiento en ingeniería en entornos multilingües y multidisciplinares;

- un nativo digital motivado, pero un usuario de tecnología digital que requiere formación en la utilización de una herramienta lexicográfica;

- un usuario activo-receptivo de la información visual;

- un usuario acostumbrado a la inmediatez en la respuesta;

- un usuario acostumbrado a vídeos y presentaciones animadas. 
Dado que, el usuario es un estudiante o un profesional iniciado en Expresión Gráfica en la Ingeniería, es decir, con cierta experiencia y en situación académica de aprendizaje y/o de puesta en práctica de conocimientos de ingeniería industrial gráfica. Se toma en consideración la metodología propuesta por Fuertes-Olivera y Tarp (2014), esto es, 'la estrecha colaboración del experto en la materia con el lexicógrafo para la descripción de conceptos del lenguaje de especialidad', también para la identificación y selección de conceptos (cf. 4.9). A continuación, se presenta el encuentro de docentes que comparten su experiencia y reflexiones profesionales en el área de conocimiento de EGI de la Universidad de Valladolid y la experiencia de las investigaciones en la utilización del método y la técnica Delphi, en el ámbito de conocimiento EGI.

\subsection{Sesión de Expertos}

Se pretende obtener los primeros indicios sobre los conceptos importantes a incluir en una propuesta de diccionario en línea, el contenido y la presentación de los datos y, las necesidades de los usuarios según la opinión de los expertos en base a su experiencia. El 19 de febrero de 2019 tuvo lugar una sesión de 'tormenta de ideas' semiestructurada de un panel de expertos docentes en EGI por sugerencia y bajo la dirección del tutor de la presente tesis. Una sesión grabada de $1 \mathrm{~h}$ y $17^{\prime}$ en la que se planteó el tema de investigación, pero abierto a otros temas relacionados con esta investigación: la Lexicografía (bajo el prisma de la TFL) y la EGI. Se presentó el diccionario como una herramienta de información con utilidad para obtener el punto de vista del experto sobre las necesidades que debe cubrir una herramienta diseñada con el objetivo de facilitar el conocimiento de EGI, sobre la organización y presentación de los datos y sobre el uso y el usuario.

El panel de expertos está compuesto por cinco profesores a tiempo completo del área de conocimiento Expresión Gráfica en la Ingeniería con experiencia docente en EGI entre 27 y 40 años (a tiempo completo) y un profesor novel con 2 años de experiencia (a tiempo parcial). El

perfil del experto está configurado por la docencia en asignaturas de primero, segundo y tercer curso en los grados de ingeniería industrial y en disciplinas como la geometría métrica, los sistemas de representación, el dibujo técnico y el dibujo y diseño asistidos por ordenador. Este perfil se completa con la experiencia en el ámbito profesional, bien por el ejercicio activo de la 
ingeniería, bien por el contacto como tutores de prácticas en empresa de alumnos y de titulados. Este panel de expertos EGI constituye el 50\% de la plantilla de EGI de la Escuela de Ingenierías Industriales de la UVa.

El encuentro se plantea como un debate para definir temas fundamentales en la instrucción y el aprendizaje de la ingeniería gráfica bajo un formato de 'tormenta de ideas', en el que se introducen temas y cuestiones para suscitar el debate en el grupo de profesionales y motivar la aportación de ideas. Los temas tratados son:

1. La normalización en el ámbito industrial y en EGI en sus dos variantes descriptiva o dispositiva y prescriptiva o impositiva

2. Las fuentes de información utilizadas: Wikipedia, libros y manuales

3. El contenido de un concepto: definición, figura de análisis y aplicación o ejemplo

4. Lema verbal o lema gráfico y acceso al diccionario mediante lema verbal

5. El usuario potencial puede ser un alumno (entorno teórico y práctico) y/o un profesional (entorno laboral)

6. Lengua en que el usuario recibe los datos

7. El uso adecuado del lenguaje, la precisión en la comunicación especializada

8. Diferencias culturales relevantes en la EGI

9. La o las funciones del diccionario

10. La ambigüedad y la precisión en el lenguaje y en la representación gráfica industrial

11. La presencia de organismos oficiales que imponen normas y crean necesidades concretas ( $p . e j$. , un plano en una licencia de obra)

\subsubsection{Aportaciones de los expertos}

1. Las aportaciones con respecto a la identificación del tipo de usuario conducen a:

- un usuario potencial, un alumno que se prepara para un entorno profesional, pero en un entorno académico o un profesional en activo. Ambos contextos tienen consecuencias en las entradas al diccionario y en su contenido;

- un usuario puede ser una institución o una empresa que impone unas normas de representación por encima de un usuario (del individuo) y que tiene una necesidad concreta. Es decir, hay agentes externos que crean necesidades que hay que satisfacer; 
- un usuario que tiene conciencia sobre el retorno económico de la normalización. La normalización en EGI tiene al menos dos aplicaciones: los documentos que reflejan una norma (UNE, ISO...) y, los componentes normalizados (un tornillo, una arandela...) que se publican y difunden en documentos. El trasfondo de la normalización industrial es abaratar el coste de un producto, porque asegura la 'comunicación' y reduce el coste del producto;

- un usuario que utiliza los términos con precisión "piensa con claridad" -en opinión de un experto-. Este usuario si domina los términos en su idioma y tiene apoyo gráfico puede asimilar información en otras lenguas;

- un usuario con distintas referencias culturales o geográficas (p. ej., Los sistemas de primer y tercer diedro, utilizados en Europa y Estados Unidos respectivamente). Estas diferencias no existen a nivel conceptual, sí a nivel de representación gráfica

- un usuario consciente de que la falta de precisión y la ambigüedad tienen consecuencias económicas negativas.

2. Identifican las situaciones que en las que se puede encontrar el usuario:

- Adquisición de conocimiento

- Aplicación del fundamento teórico de un problema

- Interpretación de las normas

- Cómo se aplica una norma, con qué intención

- Representación normalizada que requiere la Geometría Descriptiva para la representación de formas geométricas (p.ej., horizontales de plano en vistas auxiliares)

- Consulta puntual para recuperar aspectos ya memorizados

- Pasos a dar en un procedimiento de resolución de un problema y su justificación

3. Identifican ciertas necesidades de un usuario tipo:

- Información puntual sobre trazado geométrico, sobre símbolos convencionales en el trazado y la definición de objetos 
- Información sobre procesos de resolución de problemas gráficos mediante construcciones geométricas

- Refuerza la noción de conveniencia de la aplicación de las Normas de representación en Dibujo Técnico

- Aplicación de construcciones geométricas de un caso académico a la resolución de un problema del mundo real

- Trasladar un concepto a una aplicación de la vida real: los expertos plantean dos opciones:

1. partir de conceptos básicos y añadir las aplicaciones;

2. partir de un caso práctico real y ofrecer la aplicación gráfica básica o los conceptos básicos para resolver la duda o problema

- Interacción entre lo teórico, lo práctico (académico) y lo profesional (laboral)

- Desde el punto de vista formativo es necesario plantear una solución a problemas genéricos mediante figuras de análisis para que el usuario pueda aplicar el concepto y el método de resolución gráfica a un caso particular

- El alumno necesita resolver un problema mediante construcciones geométricas

- Un profesional se encuentra en un entorno laboral y necesita un plano para fabricar un objeto y un fundamento teórico conceptual para resolver un problema

- Definiciones formal y conceptualmente precisas y concisas

- Definiciones formal y conceptualmente unívocas, sin ambigüedad para evitar diferentes interpretaciones

- Existen necesidades de usuarios que están condicionadas o dirigidas por entidades externas y por intereses externos.

4. Las aportaciones con respecto al contenido los conceptos y la presentación de los datos de una herramienta en línea que ofrece datos puntuales que el usuario convierte en información:

- debe contener conceptos teóricos abstractos y sus aplicaciones prácticas;

- debe contener definiciones, aplicaciones prácticas y ejemplos; 
- en el caso de incluir ejemplos se debe contemplar dos casos: que el usuario sea un estudiante o que el usuario sea un profesional. El ejemplo dirigido al alumno puede ser un problema gráfico teórico con resolución geométrica. El ejemplo dirigido a un profesional debe indicar con precisión 'cómo se hace' (p.ej., necesita un plano de un desarrollo con medidas reales para cortar y soldar una chapa);

- debe incluir normalización, debe ser 'exportable' a un entorno industrial y precisa Normas;

- el diccionario electrónico en línea permite hipervínculos a elementos gráficos y léxicos y enlaces a temas relacionados dentro y fuera del mismo diccionario.

5. El diccionario en línea:

- El acceso en línea a los datos debe permitir variar la ruta dependiendo de las necesidades y realizar una selección por funciones.

- Entre las funciones que el diccionario debe cumplir está la indicación de procedimientos de resolución que se inician mediante la explicación conceptual de un problema con una figura de análisis, instruye sobre conceptos (función cognitiva). La explicación debe activar en el alumno los mecanismos necesarios para aplicar el concepto general para utilizar el método adecuado en un caso particular. Entre los datos se incluyen las instrucciones para resolver un problema mediante construcciones geométricas (función operativa).

- Recomienda sobre la interpretación convencional de los símbolos en el contexto de un dibujo técnico (función interpretativa)

- El formato de diccionario electrónico en línea permite hipervínculos a elementos gráficos y léxicos, a materiales procedentes de otras fuentes y enlaces dentro del mismo diccionario

- La incorporación de equivalentes en otros idiomas

6. En el debate se introducen sugerencias sobre temas de los que se requiere información y/u opinión, en forma de preguntas. Estas observaciones se trasladan a la propuesta de diccionario o se proponen en acciones futuras. Transcripción de la grabación: 
- «¿Conoces un diccionario de EGI? Los expertos no conocen diccionarios de EGI, se mencionan tres obras impresas de referencia que se puede relacionar con nuestra propuesta por contenido, Universal Dictionary of Mechanical Drawing (1906), The Essentials of Descriptive Geometry (1908), Illustrated Dictionary of Mechanical Engineering: English, German, French, Dutch, Russian (2013) y un diccionario online Diccionario Español de Ingeniería (2014) no conocen;

- ¿Utilizas algún tipo de enciclopedia? Se destaca la riqueza de las respuestas que enciclopedias como Wikipedia ofrece al usuario con enlaces a todo tipo de documentos como textos, figuras, archivos de vídeo, archivos de sonido...

- ¿Qué os gustaría encontrar en un diccionario EGI? El usuario es un alumno y su situación es la resolución de un problema en un entorno académico

- Soluciones a dudas, poder manejar la aplicación para adecuar la búsqueda a la demanda del usuario lo máximo posible. Una entrada gráfica dinámica para poder introducir los datos de un problema concreto.

- Estrategias para abordar un problema, premisas y planteamientos para abordar un problema y que se pueda sistematizar. Poder apreciar que pueden darse casos prácticos con un fundamento geométrico, que existe un orden. Método para desarrollar un proceso.

- Definición (verbal + figura de análisis)

- Incluir tridimensionalidad 3D. Poder tener un elemento tridimensional manipulable gráficamente. Importante una búsqueda gráfica por imagen que sea eficaz o por ente gráfico que todavía no existe

- Conceptos teóricos claros de geometría tanto plana como del espacio, las definiciones deben recoger todos estos conceptos teóricos, figuras de análisis.»

7. Las preguntas y respuestas sobre los usuarios. Transcripción de la grabación:

- «¿Cuál es la lengua materna de los usuarios? Español, pero se observan diferencias culturales presentes en el lenguaje de especialidad y hay hablantes bilingües (españolchino)

- ¿En qué medida dominan su lengua materna? Son hablantes nativos de español

- ¿En qué medida dominan una lengua extranjera específica? Inglés con nivel medio-bajo

- ¿Hasta qué punto dominan un lenguaje de especialidad determinado en su lengua materna? Nivel bajo 
- ¿En qué medida dominan un lenguaje de especialidad determinado en un idioma extranjero? Los alumnos de primero no dominan, los alumnos de tercer curso trabajan con software en inglés

- ¿Cuánta experiencia tiene en traducción? Si tienen experiencia en traducción

- ¿Cuánto conocimiento cultural general tiene? No se sabe

- ¿Cuánto conocimiento cultural en un área específica (de una lengua extranjera) tiene? No se sabe

- ¿Cuánto saben sobre un tema específico o ciencia? Depende del Grado, de nada a un conocimiento básico

- ¿Cuánto saben los usuarios sobre lexicografía? Nada o poco

- ¿Qué experiencia general tienen en el uso del diccionario? Diccionario en papel ninguna, vía internet y teléfono móvil sí.

- ¿Crees que, si hubiera un diccionario EGI, los alumnos lo utilizarían? En papel NO, en internet sí, utilizarían un diccionario antes que un libro o un manual.»

\subsection{Lista inicial consensuada de conceptos, el Método Delphi}

Se ha utilizado la técnica Delphi para identificar y obtener un consenso de un panel de expertos sobre los conceptos fundamentales presentes en los documentos fuente seleccionados relacionados con la ingeniería gráfica. Esta técnica no es una novedad en el dominio de la ingeniería gráfica, la experiencia y los resultados de Sadowski y Sorby (2015) que utilizan esta técnica para desarrollar Engineering Graphics Concept, constituyen un referente mencionado en el apartado 4.10.

Con este objetivo se obtiene un consenso de expertos que produce pérdida de subjetividad y proporciona una lista inicial de conceptos evitando errores sistemáticos. Es un ejemplo de utilización del método deductivo alternativo con una relación estrecha con el conocimiento experto (Fuertes-Olivera y Tarp 2014).

El método Delphi (Linstone y Turoff, 1975) conlleva la estructuración de un proceso de comunicación de un grupo de expertos que funcionan como un conjunto a los que se solicita su opinión a través de cuestionarios sucesivos. Este método enfatiza la comunicación anónima estructurada entre individuos que poseen experiencia en un tema determinado con el objetivo 
de llegar a un consenso en un área determinada, permite identificar convergencias de opiniones y deducir consensos provisionales para finalmente, determinar y cuantificar el consenso del grupo. El investigador puede utilizar técnicas cuantitativas con el método Delphi (Rowe \& Wright, 1999) y técnicas cualitativas cuando está interesado en la interpretación, comprensión y experimentación en un contexto social dentro del cual se recopilan los datos para producir entendimientos (Mason, 1996). La investigación cualitativa debe dar sentido o interpretar los fenómenos en términos de la relevancia que les asignan los participantes (Creswell, 1998) y debe llevarse a cabo estratégicamente, pero de forma flexible y contextual (Mason, 2002:7). En campos como los negocios, la industria y especialmente la medicina son numerosos los estudios que utilizan esta técnica (Flume et al. 2010; Powell 2003) para formalizar el consenso de expertos y, en el caso de cuidados médicos, desarrollar recomendaciones de atención explícitas para una mayoría de pacientes, pero adaptable a las necesidades específicas de individuos, sus familias y sus cuidadores.

El objetivo de esta parte del estudio de investigación es la identificación y cuantificación de los conceptos fundamentales sobre ingeniería gráfica. Son interesantes para este trabajo los conceptos fundamentales, bien por la dificultad que presentan, bien por la importancia que tienen dentro del ámbito de conocimiento, bien porque satisfacen las necesidades del usuario. En nuestro caso, no se puede recurrir a un posible análisis de los mismos en diccionarios de EGI porque, como sea mencionado, no existen. Para llevar a cabo esta labor se cuenta con informantes elegidos entre profesionales docentes del área de conocimiento EGI para identificar los conceptos fundamentales. Se cuenta con la aportación adicional de informantes estudiantes de la Ell de la UVa. El objetivo final de este proceso es diseñar una herramienta de consulta, que necesariamente incluya estos conceptos identificados, para cumplir con éxito la tarea de satisfacer las necesidades de los usuarios, inicialmente en el ámbito académico y posteriormente en el ámbito profesional.

El proceso Delphi existe en dos formatos diferentes: la versión paper-and-pencil conocida como "Delphi Exercise» o conventional Delphi y la versión "Delphi Conference» o real-lucre Delphi (Linstone y Turoff, 1975: 5). Las diferencias entre ambas radican en la utilización de un soporte físico o uno informático y en la utilización de software para el análisis de datos en el segundo caso. Este último permite actualizar y desarrollar un nuevo cuestionario dirigido al 
grupo, pero requiere que las características de la comunicación estén definidas antes de iniciar el proceso Delphi. Sin embargo, en un ejercicio Delphi con "papel y lápiz" se pueden ajustar, para la siguiente ronda, estas características en función de las respuestas obtenidas en la ronda previa. En esencia, la técnica Delphi consta de una serie de cuestionarios secuenciales, intercalados por retroalimentación controlada, utilizados para obtener el consenso de opinión de un panel de expertos (Powell, 2002: 377).

\subsubsection{Metodología Delphi}

Se decide llevar a cabo dos rondas con cuestionarios anónimos y se utiliza la opción paper-andpencil. Una vez que se completa el primer cuestionario en papel, los participantes remiten el documento para que se analicen los resultados y se puedan realizar los ajustes necesarios en función de los comentarios recibidos. De acuerdo con los resultados y las contribuciones, se prepara un segundo cuestionario basado en la evaluación de la respuesta grupal. Los panelistas, al responder el segundo cuestionario, tienen la oportunidad de reevaluar sus propias respuestas a la luz de las respuestas grupales. No se utiliza un método Delphi estándar ya que se incluyen, en la segunda ronda, no solo los conceptos identificados por los expertos, sino también algunos de los identificados en el estudio realizado por Sadowski y Sorby (2015) sobre ingeniería gráfica. Estos elementos se introducen en el cuestionario y se tratan junto con el resto de conceptos. Esta modificación del método se justifica porque amplía el espectro de nuestro estudio con conceptos ya extraídos en investigaciones previas y porque los elementos incluidos entran dentro del alcance de nuestro estudio, de forma que se integran perfectamente entre los seleccionados por los expertos en la primera ronda.

\subsubsection{Las fuentes}

Los enunciados proceden de dos compendios de prácticas utilizadas en el proceso de aprendizaje de los alumnos de ingeniería de la Ell; un manual teórico sobre sistemas de representación y la norma UNE sobre los principios generales de presentación en dibujos técnicos. Se considera que es necesario utilizar la norma como recurso documental, ya que se 
considera de obligado cumplimiento en un contexto académico de aprendizaje e introducen recomendaciones publicadas que proporcionan datos comunicativos. Las fuentes de los enunciados del cuestionario de la ronda I son los siguientes:

- Nieto Oñate, M., González García V., López Poza, R. (1970). Prácticas programadas de Dibujo Técnico. Delineantes industriales. Valladolid: DITEC

- Álvarez S., Reboto E., Rodríguez Q., Escribano Negueruela M. (2018) Prácticas de Expresión Gráfica III

- La norma UNE 1-032-82 (1982) que corresponde a ISO 128

- González García, V., López Poza, R., \& Nieto Oñate, M. (1982). Sistemas de representación. Sistema diédrico.

\subsubsection{Los cuestionarios}

El proceso Delphi consta de dos rondas realizadas con el panel de expertos y una evaluación final. El cuestionario I no está estructurado, busca una respuesta abierta (Powell, 2003: 378) y consta de 111 declaraciones $(12+22+64+13)$; los encuestados primero deben identificar los conceptos relevantes y luego evaluar, en una escala de 1 (poco) a 5 (mucho), la importancia estimada y la dificultad prevista para un estudiante universitario semiexperto en el EGI. A los participantes se les plantea, en todos los enunciados, la opción de aceptar (responder), rechazar (no responder), aportar los comentarios e incluir los conceptos que consideren interesantes y que no figuren en los enunciados. Los resultados permitirán identificar, relacionar y reformular el siguiente cuestionario. Con respecto a las cuatro fuentes, las dos primeras muestran

- Croquizar la pieza facilitada al mayor tamaño posible. Las medidas de las vistas serán proporcionales a las dimensiones de la perspectiva.
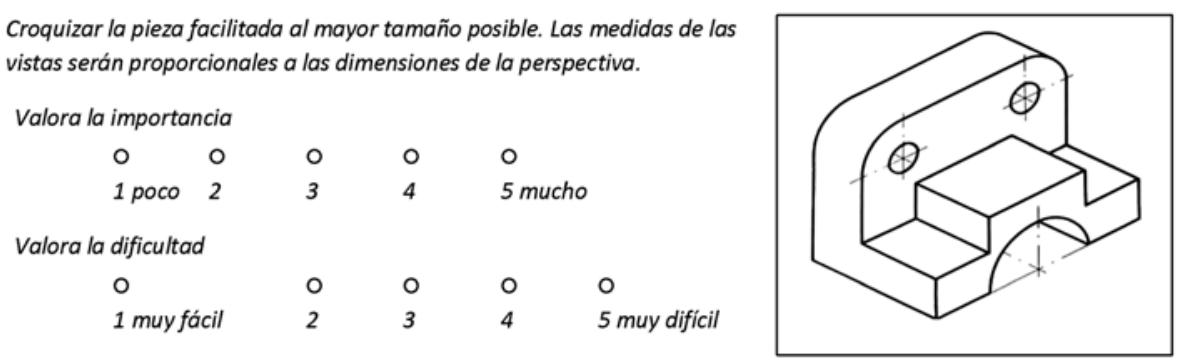

Figura 5.1. Ejemplo del cuestionario / con enunciado no estructurado, de respuesta abierta con componente verbal y gráfico (Nieto Oñate et al., 1970). 
características idénticas: enunciado verbalizado descriptivo-informativo y componente gráfico (ver el ejemplo de la Figura 5.1).

En cuanto a los enunciados correspondientes a la norma UNE, los conceptos están previamente identificados en la fuente y se utiliza la denominación verbal normalizada exclusivamente (ver el ejemplo de la Figura 5.2).

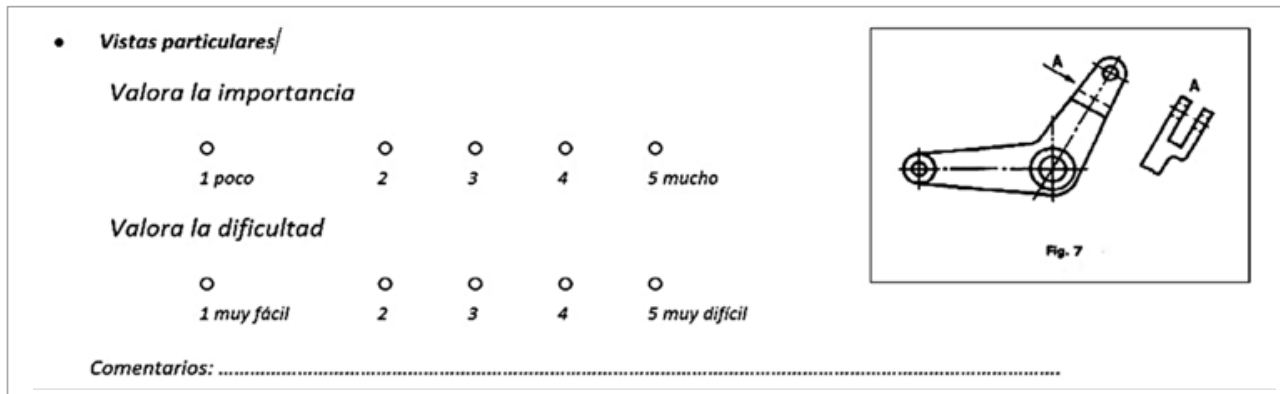

Figura 5.2. Ejemplo del cuestionario I, enunciado de la norma UNE 1-032

La cuarta fuente corresponde a los sistemas de representación, en este caso los conceptos previamente identificados por un experto son el resultado de la división o descomposición en construcciones geométricas simples partiendo de construcciones geométricas más complejas (ver el ejemplo de la Figura 5.3). Las construcciones se describen pormenorizadamente y dan lugar a nuevos conceptos reformulados. Cabe señalar que en estos ítems el componente verbal y el componente gráfico son equivalentes, destacando la expresividad del componente gráfico.

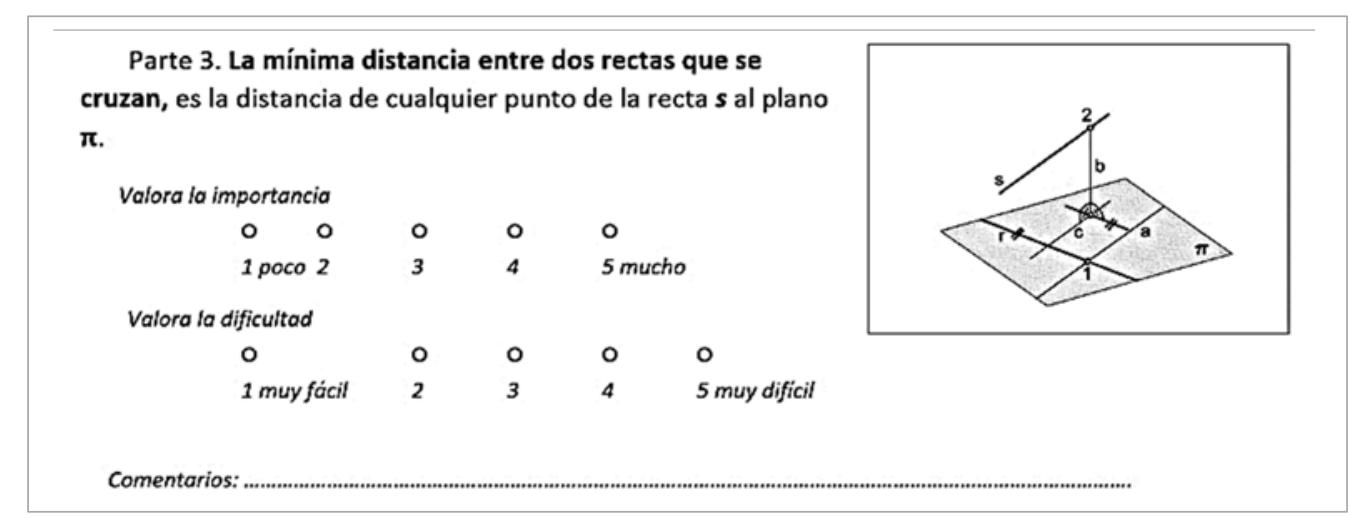

Figura 5.3. Ejemplo del cuestionario $I$, de un concepto geométrico complejo identificado en el enunciado, descrito con precisión y componentes verbal y gráfico equivalentes. (González et al., 1982) 
El cuestionario I/ es más concreto (ver Figura 5. 4) con el objetivo de que los expertos revisen $y$, confirmen o no, los resultados de la primera vuelta. Se planifica evitando la ambigüedad en los enunciados de forma que los conceptos identificados por los informantes expertos sean inequívocos y fidedignos. Se presentan 54 conceptos identificados anteriormente, clasificados en orden de mayor a menor y aceptados al menos por tres expertos, a los que se han añadido 14 conceptos procedentes del mencionado estudio de Sadowski y Sorby (2012, 2015).

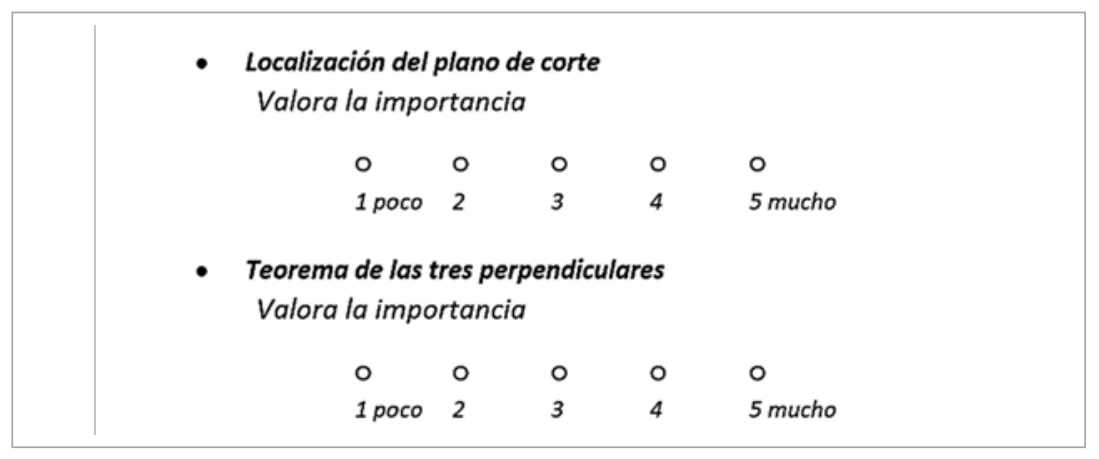

Figura 5.4. Ejemplo perteneciente al cuestionario II, enunciado con componente verbal.

\subsubsection{Realización de los cuestionarios}

Se entregan ambos cuestionarios en distintos momentos y en mano de forma que se garantice el anonimato en la realización de cada cuestionario y no haya comunicación entre los informantes mientras se realiza la prueba. Una vez recogidos los cuestionarios y analizadas las respuestas, los resultados de la primera ronda se comunican a los participantes que reciben los conceptos identificados y ordenados de mayor a menor importancia según la opinión del grupo, esto constituye el segundo cuestionario. Es necesario realizar algunos ajustes porque en las fuentes literarias aparecen denominaciones anacrónicas del mismo concepto y en adelante aparecerán unificados y actualizados. Algunos conceptos son desestimados por el desinterés que muestran los expertos en ellos y se incorporan algunos conceptos procedentes del estudio sobre Concept inventory for Engineering Graphics (Sadowski y Sorby, 2012, 2015) que ya se ha mencionado. El segundo cuestionario se facilita y realiza de forma análoga al primero con una separación de dos meses. 


\subsubsection{Interpretación del consenso}

Se define el nivel de consenso en función del número de participantes que han identificado el concepto. Se establecen cuatro categorías (ver Tabla 5.1) y si el número de participantes que aceptan el concepto es superior o igual a tres, este se considera identificado.

Tabla 5.1: Grados que determinan el nivel de consenso

\begin{tabular}{ll}
\hline \hline Grado & Participantes que aceptan \\
\hline Consenso pleno & Todos los participantes (5) identifican el concepto \\
Muy buen consenso & Al menos 4 participantes identifican el concepto \\
Buen consenso & Al menos 3 participantes identifican el concepto \\
Algún consenso & 1 o 2 participantes identifican en consenso \\
Sin consenso & Ningún participante identifica el concepto \\
\hline
\end{tabular}

\subsubsection{Importancia asignada al concepto}

Se cuantifica la importancia asignada al concepto de entre los conceptos identificados al menos por tres expertos (ver Tabla 5.2).

Tabla 5.2: Grados que determinan la importancia asignada

\begin{tabular}{ll}
\hline \hline Importancia & Promedio \\
\hline Muy importante & Media $=5$ \\
Importante & Media $\geq 4$ \\
Algo importante & Media $\geq 3$ \\
Poco importante & Media $\geq 2$ \\
Sin importancia & $0 \geq$ Media $\geq 1$ \\
\hline
\end{tabular}

\subsubsection{Encuesta realizada a los alumnos}

Como complemento del proceso de Delphi y en relación con el objetivo que se persigue, se ha propuesto una encuesta que produce información adicional derivada de una comparación de opiniones de expertos y estudiantes.

Los conceptos se incluyen debido a su importancia o, debido a su dificultad y en este último sentido, tanto los expertos como los estudiantes tienen algo que aportar. En el momento 
de su realización (curso 2019-2020), los estudiantes consultados están cursando un grado de Ingeniería Industrial en la Ell de la UVa. Esto supone que están involucrados en un amplio espectro de estudios técnicos (no solo en el campo gráfico) en el que las asignaturas relacionadas con ingeniería gráfica están localizadas en el primer, tercer y quinto semestres.

Se invitó a los alumnos a responder voluntariamente al cuestionario de la segunda ronda Delphi accesible para estos estudiantes en el campus virtual de la universidad durante tres semanas y se obtuvieron ochenta y seis respuestas.

Las figuras 5.5. y 5.6. muestran dos ejemplos de la propuesta en línea. Un estudio comparativo y posterior reflexión sobre la dificultad asignada por los expertos y estudiantes se presenta, más adelante, en este mismo apartado. La figura 5.5 corresponde a una figura de análisis (González et al., 1982) y la figura 5.6 a un enunciado y su representación en la norma

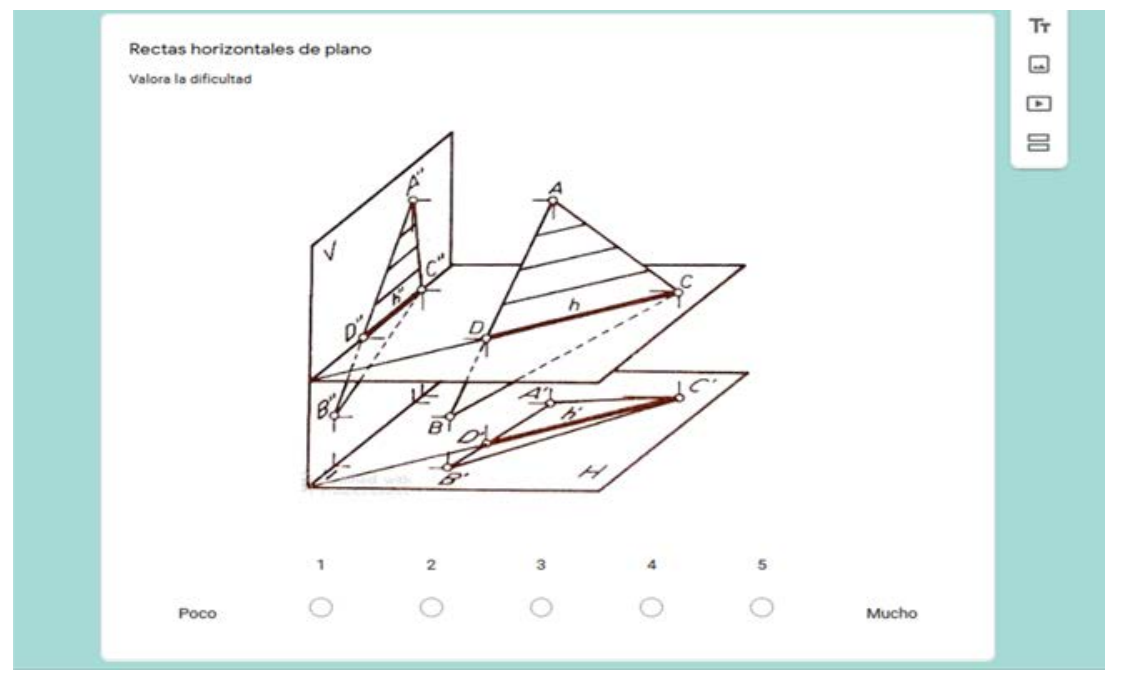

Figura 5.5. Ejemplo 1 de a la encuesta accesible a los alumnos vía campus virtual (UVa) (https://docs.google.com/forms/d/1ji-cYVLXSCgipRPzxShSIAX1QXAURW4vsegfBOZd5V4/edit?ts=5dd2590a)

UNE 1-032. 


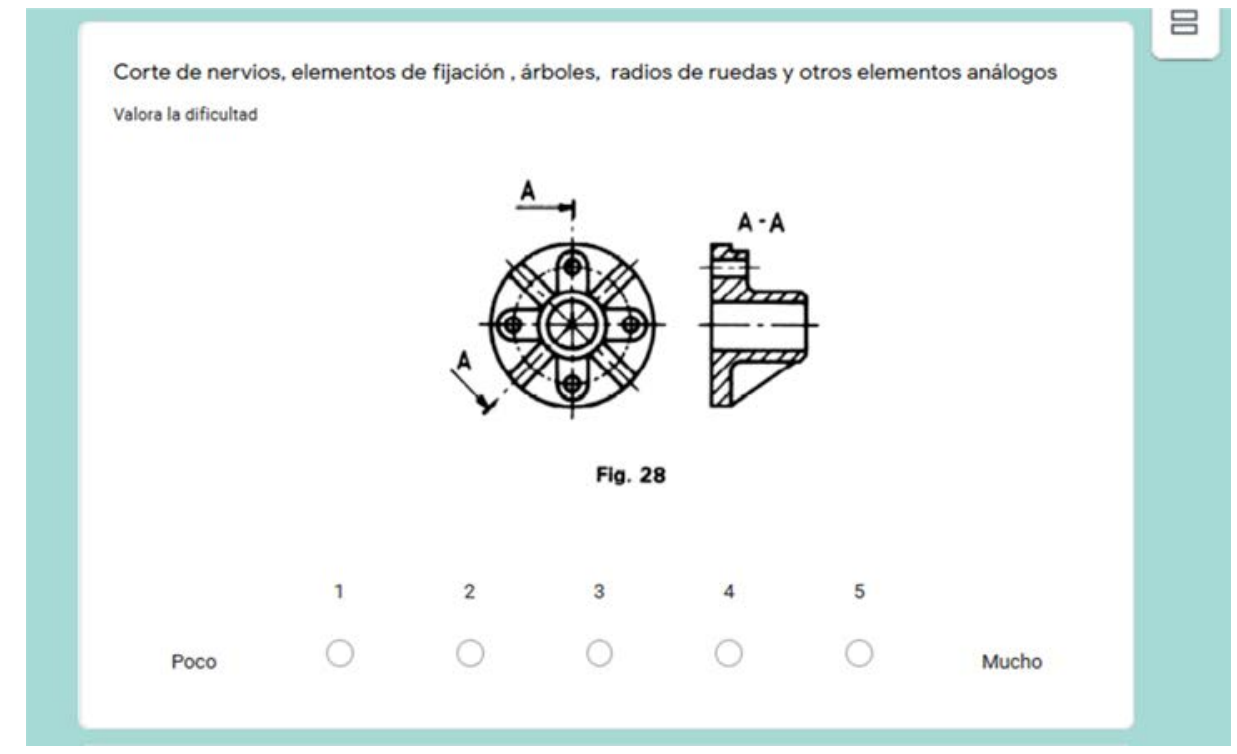

Figura 5.6. Ejemplo 2 de la encuesta accesible a los alumnos vía campus virtual (UVa) (https://docs.google.com/forms/d/1ji-cYVLXSCgipRPzxShSIAX1QxAURW4vseqfB0Zd5V4/edit?ts=5dd2590a)

\subsubsection{Análisis de los resultados}

Se presentan los resultados correspondientes a tres análisis: en primer lugar, los resultados de la primera ronda constituidos por los conceptos identificados al menos por tres expertos; en segundo lugar, la valoración de los expertos en un documento en el que los conceptos aparecen en orden de importancia decidido por el grupo (reafirmación de su evaluación inicial) son los resultados de la segunda ronda; finalmente, una comparación de las opiniones de expertos y estudiantes sobre la dificultad de estos conceptos.

Los resultados de la primera ronda muestran setenta y un conceptos identificados, aceptados por tres expertos o más, con un grado de importancia superior a 4 . El apéndice 1 muestra estos resultados y se añade el dato de la dificultad.

Los resultados de la segunda ronda (sesenta y siete conceptos) se muestran en el apéndice 2.

Para identificar y cuantificar el nivel de consenso entre expertos en esta serie de conceptos que pertenecen al campo de la expresión gráfica en ingeniería, se comparan los resultados de ambas etapas (apéndice 3) y se entiende que un alto grado de consenso viene determinado por una diferencia menor o igual a 0,2 puntos. Como resultado, se obtiene una 
lista inicial de 20 conceptos (ver la Tabla 5.3) acordados por los expertos junto con sus valoraciones.

Tabla 5.3: 20 conceptos consensuados por expertos y sus valoraciones

\begin{tabular}{|c|c|c|}
\hline Concepto & $\begin{array}{l}\text { Importancia } \\
\text { Ronda I }\end{array}$ & $\begin{array}{l}\text { Importancia } \\
\text { Ronda II }\end{array}$ \\
\hline 1. Acotar & 5 & 5 \\
\hline 2. Seguir las normas /Normalizado & 5 & 4,8 \\
\hline 3. Elección de las vistas & 4,8 & 4,8 \\
\hline 4. Corte /corte por un plano & 4,3 & 4,4 \\
\hline 5. Rectas horizontales de plano & 4,8 & 4,8 \\
\hline 6. Rectas frontales de plano & 4,8 & 4,8 \\
\hline 7. Posición relativa de las vistas & 4,71 & 4,6 \\
\hline 8. Disposición de los cortes & 4,6 & 4,4 \\
\hline 9. Teorema de las tres perpendiculares & 4,6 & 4,6 \\
\hline $\begin{array}{l}\text { 10. Disposición normalizada de las vistas/ } \\
\text { Seis vistas normalizadas }\end{array}$ & 4,25 & 4,2 \\
\hline $\begin{array}{l}\text { 11. Corte en ángulo/ Corte por dos planos } \\
\text { concurrentes }\end{array}$ & 4,4 & 4,3 \\
\hline 12. Método de proyección del primer diedro & 4,4 & 4,6 \\
\hline 13. Línea fina de trazos y puntos & 4,4 & 4,4 \\
\hline $\begin{array}{l}\text { 14. Rayado de diferentes partes cortadas de } \\
\text { una misma pieza }\end{array}$ & 4,4 & 4,4 \\
\hline $\begin{array}{l}\text { 15. Corte de nervios, elementos de fijación, } \\
\text { árboles, radios de ruedas y otros } \\
\text { elementos análogos }\end{array}$ & 4,4 & 4,2 \\
\hline 16. Recta perpendicular a un plano & 4,4 & 4,4 \\
\hline 17. Identificar el plano de corte & 4,33 & 4,2 \\
\hline 18. Sección abatida / sección transversal & 4,2 & 4 \\
\hline 19. Línea fina de trazos & 4,2 & 4 \\
\hline 20. Línea de máxima inclinación de un plano & 4,2 & 4 \\
\hline
\end{tabular}

\subsubsection{Discusión}

Esta lista de veinte conceptos constituye el aporte inicial de lemas de la propuesta de diccionario pensado con el objetivo de satisfacer las necesidades en EGI del usuario potencial.

La información adicional es el contraste de la opinión de los expertos con la opinión de los posibles usuarios que, como se ha mencionado, se consigue al facilitar el acceso en línea en el campus virtual de la UVa. La publicación de este cuestionario se hizo en varias asignaturas de la Ell de expresión gráfica. Ochenta y seis estudiantes respondieron el cuestionario de forma anónima (ver apéndice 4). Esto nos permite identificar los conceptos que involucran cierto grado de dificultad para los alumnos y que ponen de manifiesto distinto tipo de necesidades que pueden resolverse. Del mismo modo, la comparación del punto de vista del experto con el del 
usuario nos permite sacar conclusiones sobre la convergencia y la divergencia en la dificultad percibida por ambos grupos.

Una vez analizados los resultados se puede concluir:

1. Se ha obtenido la lista inicial de conceptos.

2. Es preciso el análisis algunos conceptos dada la dificultad apreciada por los alumnos.

1. Lista inicial de conceptos. La lista inicial de entradas del diccionario incluye veinte conceptos enfocados a estudiantes de ingeniería industrial semiexpertos, que pueden satisfacer sus necesidades de información. La inclusión de estos conceptos en nuestra propuesta de diccionario cubre las necesidades iniciales del usuario potencial. Esta lista promueve un proceso para dar visibilidad a conceptos de ingeniería gráfica: la parte verbal a futuros ingenieros y, la parte gráfica a lexicógrafos. En la lista inicial de veinte conceptos, con la excepción de uno, todos son pluriverbales. Esto supone una ruptura con el esquema de estructura clásica y el formato de los diccionarios tradicionales.

Se acredita que el método Delphi ha sido eficaz para fundar una lista esencial de conceptos y ampliarla a cualquier otra subdisciplina de la ingeniería gráfica, al tiempo que se satisfacen con éxito las necesidades de un usuario tipo de un diccionario especializado de EGI. El cuestionario continúa disponible en el campus virtual de la universidad de Valladolid y puede ampliarse y reutilizarse en el futuro.

Los conceptos iniciales son: 1. Acotar; 2. Seguir las normas /Normalizado; 3. Elección de las vistas; 4. Corte /corte por un plano; 5. Rectas horizontales de plano; 6. Rectas frontales de plano; 7. Posición relativa de las vistas; 8. Disposición de los cortes; 9. Teorema de las tres perpendiculares; 10. Disposición normalizada de las vistas/Seis vistas normalizadas; 11 . Corte en ángulo/ Corte por dos planos concurrentes; 12. Método de proyección del primer diedro; 13. Línea fina de trazos y puntos; 14. Rayado de diferentes partes cortadas de una misma pieza; 15. Corte de nervios, elementos de fijación, árboles, radios de ruedas y otros elementos análogos; 16. Recta perpendicular a un plano; 17. Identificar el plano de corte; 18. Sección abatida / sección transversal; 19. Línea fina de trazos; 20. Línea de máxima inclinación de un plano 
2. Se analiza la valoración de la dificultad de los conceptos (ver apéndice 3) al contrastar la opinión de seis expertos y ochenta y seis estudiantes. En el gráfico (figura 5.7) se observan las tendencias, convergencias, divergencias y valoración de ambos grupos en términos absolutos.

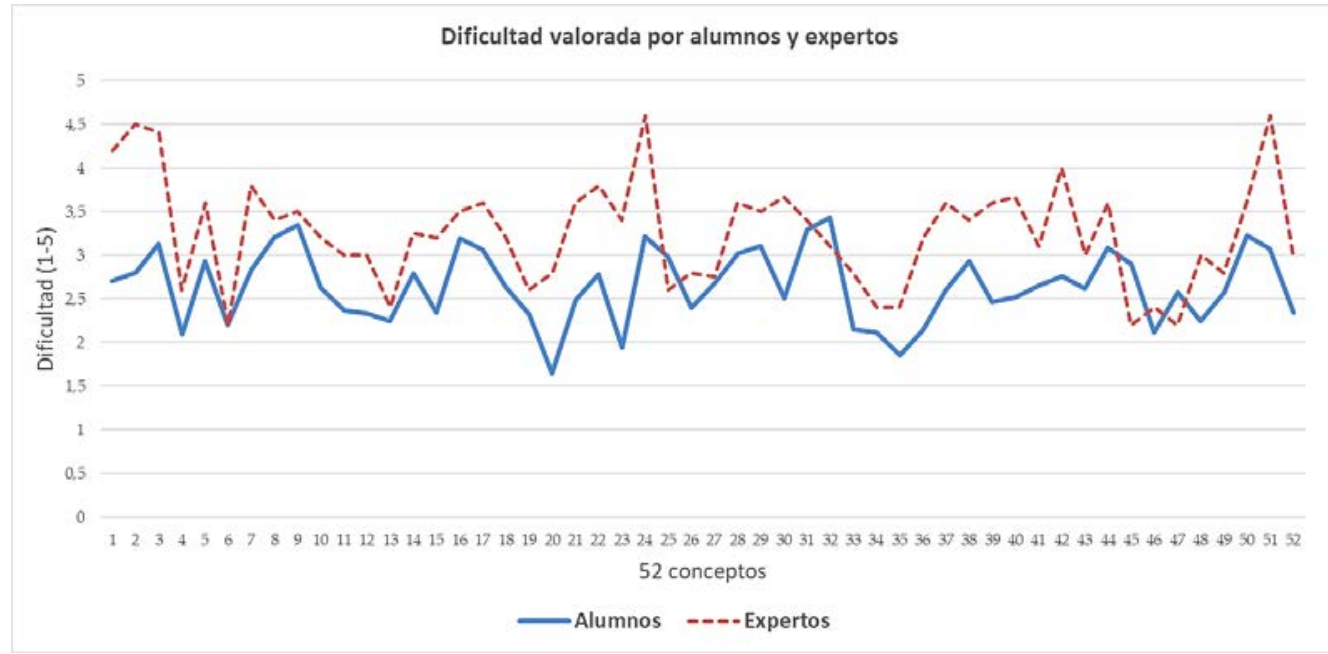

Figura 5.7. Estudio comparativo de la dificultad de los conceptos según expertos y estudiantes

Se presenta una representación gráfica de los datos obtenidos sobre la dificultad apreciada en 52 conceptos, en rojo y línea discontinua la opinión de los expertos, en azul y línea continua la opinión de los estudiantes. El primer análisis cualitativo del gráfico de la figura 5.7 destaca que los expertos generalmente asignan valores mayores de dificultad a los conceptos que los estudiantes. Las dos líneas son sensiblemente paralelas y se aprecia una aproximación cercana a la coincidencia en el $12 \%$ de los conceptos. Una explicación de por qué los expertos aprecian una mayor dificultad en los conceptos está relacionada con su comprensión más profunda de los mismos y la consideración de las implicaciones y las referencias externas e internas. Se observa una mayor oscilación en la calificación de conceptos por parte de expertos en comparación con la de los estudiantes que presentan menor oscilación. Los alumnos tienen una visión orientada de las dificultades que presentan los conceptos, debido al contacto profesor-alumno. Las dificultades se anticipan y se exponen, por lo que el grado de dificultad es menor y la percepción de la dificultad es más homogénea.

Ambos colectivos 'coinciden' al evaluar los siguientes conceptos: 6 -línea llena gruesa; 9 - corte longitudinal de una forma de revolución (que contiene detalles regularmente repartidos no situados en el plano de corte y siempre que no se produzca ambigüedad); 13- corte total o 
corte por un plano; 27- Disposición normalizada; 31- corte en ángulo o corte por dos planos concurrentes and 49- representación de elementos repetitivos. Todos estos conceptos provienen de la misma norma UNE (1032). Esta norma define los principios generales de representación aplicables a los dibujos técnicos realizados según los métodos de proyección ortogonales. La presentación actual de una norma es el resultado de continuas depuraciones a base de desprenderse de lo superfluo con el objetivo de presentar conceptos complejos de forma sencilla. Parece razonable que en estas condiciones la percepción de estos conceptos coincida en gran medida.

Las divergencias más prominentes aparecen en los siguientes conceptos: 25- segmento paralelo a un plano coordenado; 32- Sección múltiple abatida o disposición de las secciones sucesivas; 45- indicación del método de proyección and 47- Interrupción del rayado. Estos conceptos provienen de un contexto en el que se requiere bien una figura de análisis o un ejemplo de aplicación directa.

El experto reconoce las implicaciones externas de un concepto que es más complejo. Por ejemplo, en el concepto 32, un experto es consciente de que un objeto también puede ser seccionado por una superficie cónica y cilíndrica, mientras que un estudiante se centra solamente una superficie plana.

Se consideran los conceptos en los que los expertos perciben mayor dificultad y aquellos que son más difíciles para los estudiantes: cuatro provienen de la evaluación experta y ocho de los estudiantes y dos conceptos aparecen en ambos grupos.

Conceptos que, según los expertos, destacan por su dificultad:

- 2. Acotar

- 3. Seguir las normas/ normalizado

- 24. Teorema de las tres perpendiculares

- 51. Línea de máxima inclinación de un plano

Conceptos que, en opinión de los alumnos, son considerablemente más difíciles:

- 3. Seguir las normas/ normalizado

- 9. Corte longitudinal de una forma de revolución (que contiene detalles regularmente repartidos no situados en el plano de corte y siempre que no se produzca ambigüedad)

- 16. Planos no paralelos a los de proyección 
- 24. Teorema de las tres perpendiculares

- 29. Rosca métrica

- 32. Sección múltiple abatida o disposición de las secciones sucesivas

- 44. Sección abatida o sección transversal

- 50. Segmento mínima distancia

Se propone añadir estos conceptos que se consideran críticos, en una segunda fase, a los veinte conceptos de la lista inicial de lemas.

Finalmente, se citan los casos, hasta ahora no mencionados, en los que los estudiantes asignan mayor dificultad a un concepto que los expertos: 25- segmento paralelo a un plano coordenado; 45- Indicación del método de proyección; 47- interrupción del rayado. De hecho, en estos tres casos, la dificultad asignada tanto por los estudiantes como por los expertos es inferior a tres.

Finalmente se puede constatar que los conceptos especializados requieren códigos especializados para su definición y representación y, por lo tanto, los criterios para compilar un diccionario especializado requieren criterios discriminatorios. Este estudio se refiere a «un método experto respaldado por más expertos», utilizando la técnica Delphi para identificar y acordar una lista experta de conceptos que no se contemplan desde un punto de vista lexicográfico en la literatura sobre EGI. Se ha podido identificar ciertos conceptos que los estudiantes encuentran ligeramente o considerablemente difíciles y puede ser un factor que probablemente dificulte su aprendizaje. Los conceptos percibidos como más difíciles, identificados como tales por expertos y probados por estudiantes, deben incluirse en nuestra propuesta de diccionario para satisfacer sus necesidades cognitivas. Este estudio realizado con profesores y alumnos, así como las conclusiones que sirven para iniciar una propuesta de diccionario de EGI está pendiente de publicación (a 19 de mayo de 2020) (Esandi-Baztan y Fuertes-Olivera, 2020). 


\subsection{Conclusiones}

Se ha propuesto, en el presente trabajo, iniciar un procedimiento que permita a los lexicógrafos identificar conceptos, cuantificar el conocimiento conceptual de los usuarios e identificar las necesidades del usuario potencial. Se decide adoptar un método de experto refrendado por expertos y por tanto es un experto el que inicia el proceso y diseña el primer cuestionario que se hace llegar a un grupo de expertos.

Como resultado se ha obtenido una lista inicial consensuada de conceptos que satisfacen las necesidades del usuario, a criterio de los docentes. Para minimizar el sesgo experto se considera contrastar su opinión con la del usuario y esto amplía las oportunidades para sucesivas fases del proyecto lexicográfico.

El método Delphi se muestra idóneo porque permite una cuantificación de los resultados y aplicar el método deductivo.

Los enunciados para el cuestionario I, se han tomado directamente de las fuentes con una maquetación mínima. De esta experiencia se deduce que, no sólo para futuras versiones o ampliaciones del método Delphi, sino también para nuestra propuesta de diccionario, es necesario configurar una plantilla para la presentación de datos con los dos componentes verbal y gráfico.

Es preciso el análisis algunos conceptos dada la dificultad apreciada por los alumnos. Dado que existe una discrepancia motivada por una necesidad de los alumnos, se recomienda incluir estos elementos en fases sucesivas.

La aplicación de las estrategias que conducen a hacer que las funciones del diccionario sean eficaces; se especifican en el capítulo 6 . 
6. PROPUESTA DE DICCIONARIO EN LÍNEA DE EGI EN EL MARCO DE LA TEORIA FUNCIONAL

\subsection{Introducción}

6.2 Aplicación de las funciones lexicográficas del diccionario de EGI

6.3 Propuesta de concepto lexicográfico en EGI

6.3.1 Propuesta de definiciones para el diccionario de EGI

6.4 Presentación de los datos respaldando las funciones

6.4.1 Plantilla para la presentación de datos en el diccionario

6.4.2 Ejemplo de un concepto según la plantilla propuesta

6.4.3 Ejemplos de presentación de datos por funciones

6.5 Ruta de acceso en línea

6.5.1 Representación de la rutina de acceso

6.5.2 Ejemplo de la presentación de una consulta

6.5.3 Propuesta de consulta de usuarios con diferentes perfiles de conocimiento especializado

6.6 Conclusiones 
Propuesta de Diccionario en Línea de EGI en el marco de la Teoría Funcional. 
6. Propuesta de Diccionario en Línea de EGI en el marco de la Teoría Funcional

\subsection{Introducción}

El límite de este estudio se ha limitado a una parte del área de conocimiento EGI referida a los fundamentos de la geometría métrica, el sistema diédrico y la representación normalizada mediante proyecciones ortogonales. Como se ha mencionado con anterioridad los parámetros a considerar en nuestra propuesta de diccionario son el perfil de usuario, su situación y sus necesidades de información.

El perfil del usuario potencial es el de un alumno que cursa o ha cursado primer curso en Ell de la UVa. Este perfil de usuario tiene la trascendencia de ajustarse a un mínimo del $62,5 \%$ de los alumnos y futuros ingenieros de la Ell de la UVa será la única formación de EGI que reciban, el resto reciben formación adicional. También hemos mencionado que en otras escuelas de ingeniería en España la orientación, respecto a la formación de EGI recibida es similar. Tenemos en cuenta, como potenciales usuarios de la propuesta de diccionario que presentamos, sus necesidades y sus situaciones tanto en su vida académica como en su inmediato futuro profesional. Ser estudiante de primer curso implica iniciarse en nuevos conocimientos y materias que se consideran instrumentales porque fundamentan conocimientos posteriores.

Somos conscientes que se está planteando una propuesta de diccionario de EGI que no existe con estas características y que puede ser el inicio de futuros proyectos que sobrepasen los límites del trabajo actual y alcancen otras materias de EGI. Las situaciones cognitivas, interpretativas y operativas son aquellas en las que inicialmente se encuentra el potencial usuario que hemos identificado. Las situaciones comunicativas se plantean en una fase futura del proyecto, en la que el usuario, superados los conocimientos fundamentales de EGI se enfrente a situaciones de elaboración de proyectos, manejo de documentación en otros 
idiomas, etc., o cualquier situación que requiera dominio de EGI en las diferentes especialidades de ingeniería industrial.

Finalmente, las necesidades de información del futuro usuario, que han sido propuestas en la reunión de expertos, los resultados del método Delphi y el análisis de la comparativa de opiniones del grupo de expertos y el grupo de estudiantes, contribuyen a fundamentar nuestra propuesta que, como veremos, incide en los conceptos de aplicación práctica fundamentales de EGI. Los expertos han revelado la importancia de evocar e incidir más en las situaciones sobre casos reales. Esto implica incluir más ejemplos de la práctica profesional de la ingeniería.

Nuestra propuesta de diccionario pedagógico en línea de EGI con las funciones cognitiva, interpretativa y operativa en el marco teórico y metodológico de la TFL tiene en consideración la determinación de los tipos y la cantidad de los datos necesarios en relación con cada función del diccionario ya que las funciones son la raíz de la teoría y práctica lexicográfica e influyen en la forma y el contenido de un diccionario (Bergenholtz y Tarp, 2003: 177). Se han tomado las siguientes decisiones que afectan a su diseño:

- Aplicación de las funciones lexicográficas al diccionario de EGI

- Definir una propuesta de concepto lexicográfico en EGI adaptada al usuario

- Presentar los datos y el acceso a los mismos respaldando las funciones

- Definir una plantilla para la presentación de datos por funciones

- Facilitar que la ruta de acceso en línea a los datos permita: dos rutas posibles una dirigida y otra libre y la opción de que el usuario explore distintas funciones del diccionario con retorno a la situación inicial.

\subsection{Aplicación de las funciones lexicográficas al diccionario de EGI}

A continuación, a modo de ejemplo, se expone un caso en el que se aprecian las situaciones en las que se encuentra un posible usuario y que corrobora las funciones lexicográficas de un diccionario de EGI según los postulados de la teoría funcional.

Este caso presenta un concepto y, tal y como aconsejan los expertos, se traslada un concepto a una aplicación en la vida real. Son tres figuras del texto de Paré et al. (1997) y se han añadido las unidades léxicas asociadas: la Figura 6.1 corresponde a la representación gráfica del 
concepto o figura de análisis de un ángulo diedro o ángulo formado por dos planos desde dos puntos de vista; la Figura 6.2 corresponde a un ejemplo instrumental en el que se pide determinar, mediante construcciones gráficas, el ángulo formado por el plano MNO con el plano horizontal, la Figura 6.3 es un caso de aplicación práctica real en el que, para fabricar las piezas de unión de los cristales de la cabina de un avión, se precisan conocer los ángulos entre planos.

Las tres partes hacen referencia a un mismo concepto (es decir, una clave en nuestra propuesta, que es similar al lema de la lexicografía tradicional) que, en este caso, tiene tres definiciones diferentes, cada una de ellas asociada a una situación basada en una función. La situación primera, representada en la Figura 6.1, corresponde a una situación cognitiva e interpretativa. La situación segunda, que reflejamos en la Figura 6.2., muestra una situación interpretativa y operativa académica. Finalmente, la situación tercera, representada en la Figura 6.3., refleja una situación interpretativa y operativa profesional.

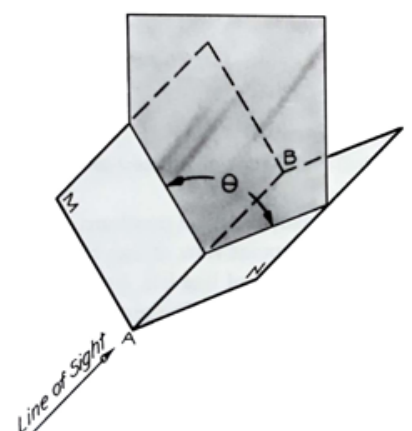

(a)

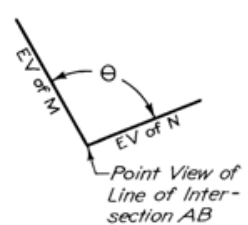

(b)

Figura 6.1, Ángulo diedro entre dos planos que se intersectan

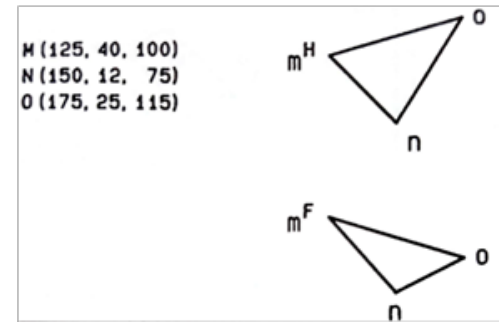

Figura 6.2, Ángulo formado por el plano MNO con el plano Horizontal

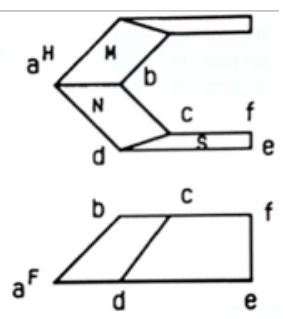

$A(60,140,215)$

B( 85, 165, 215)

C ( $-165,196)$

D( 85, 140, 190)

$E(135,140,190)$

$F(135,165,196)$

Figura 6.3, Ángulos formados por los planos $\mathrm{M}$ y N; y los planos $\mathrm{N}$ y $\mathrm{S}$ 
Son situaciones en las que un potencial usuario de diccionario de EGI puede requerir información en una obra de referencia lexicográfica. A las figuras y a las unidades léxicas del concepto ángulo formado por dos planos, para atender las necesidades de información de un usuario, se debe añadir una definición y tres interpretaciones junto a la figura 6.1 (Paré et al. 1997: 107):

- definición: «el ángulo formado por dos planos que se intersectan se denomina ángulo diedro».

- interpretación 1: «el ángulo diedro se observa en verdadera magnitud desde una dirección de observación en la que los dos planos son proyectantes, por lo que cada uno se representa por una línea».

- interpretación 2: «si el ángulo diedro se observa en verdadera magnitud, entonces, la línea intersección de los dos planos se proyecta como un punto».

- interpretación 3: "la dirección de visualización es la recta intersección de ambos planos».

Junto a la figura 6.2 se debe incluir también una definición y una descripción que permita interpretar el enunciado y las instrucciones para su resolución:

- descripción 3: «el plano MNO está definido en proyecciones diédricas por los puntos $\mathrm{M}, \mathrm{N}$ y $\mathrm{O}$, y cada uno de los puntos está definido por sus coordenadas en el espacio» (Paré et al. 1997: 113).

- instrucciones: «obtener la línea de máxima pendiente del plano y llevarla a verdadera magnitud».

Junto a la figura 6.3 se debe incluir la definición y una descripción que permita interpretar el enunciado y el acceso opcional a la información de los dos pasos anteriores:

- descripción 4: «los planos M, N, O están definidos en proyecciones diédricas por los puntos A, B, C, D, F y cada uno de ellos está definido por sus coordenadas en el espacio». «In order that support clips may be formed for the airplane windshield sections, determine the angles formed by planes $\mathrm{M}$ and N; N and S.» (Paré et al. 1997: 114)

- Enlace a 'ángulo formado por dos planos que se intersectan'

- Enlace a 'ángulo que forma un plano dado con el plano Horizontal' 
En este caso se ha tomado un ejemplo representativo de situaciones extralexicográficas de un usuario potencial de este diccionario de EGI y cabe extraer dos conclusiones:

1. "Language is the key» Barnard (2012: 83). El lenguaje especializado es el medio, el hilo conductor y agente imprescindible, en un área de conocimiento como Expresión Gráfica en la Ingeniería. El elemento léxico que inicia este proceso lexicográfico se denomina en este estudio 'clave', Agerbo (2019) 'action', Mancho Duque (2014) 'lema', Bowker (2003) 'lexical item', por citar algunos ejemplos;

2. El usuario potencial requiere una obra de consulta rápida, fácil y que se adapte a varias situaciones sucesivas a lo largo de la misma consulta. Cualquier combinación de las funciones cognitiva, operativa e interpretativa en esta propuesta de diccionario es posible y necesaria, ya que puede ser necesaria en una consulta.

\subsection{Propuesta de concepto lexicográfico en EGI}

Para configurar el concepto lexicográfico en EGI se tiene en cuenta el marco teórico y metodológico de la TFL y la aproximación gráfica y lexicográfica a la EGI con el alcance definido en este trabajo. Lo que supone:

1. Definir unidades léxicas relevantes para usuarios en diferente situación de aprendizaje: inexperto, semiexperto y experto.

2. Facilitar la adquisición gradual de conocimiento especializado con la propuesta de opciones de consulta al diccionario a distintos niveles y satisfacer las necesidades de un usuario inexperto, semiexperto o experto.

3. Proponer definiciones que contribuyan a la desambiguación de conceptos.

4. Utilizar la metodología de la TFL, por lo que hay que:

- presentar soluciones a las necesidades de los usuarios en situaciones de uso lexicográficas.

- presentar datos lexicográficos que respalden la función del diccionario (Nielsen \& Mourier 2007: 121). 
5. Utilizar todas las opciones tecnológicas disponibles para conseguir que el diccionario especializado en línea sea más fácil de consultar (Fuertes-Olivera y Tarp, 2011: 64) Esto implica:

- Evitar la sobrecarga de información y facilitar que el usuario pueda optimizar la toma decisiones ante la presentación de datos en un diccionario en línea. Evitando 'entornos cambiantes' que obligan a procesar más información para la toma de decisiones efectivas y racionales (Toffler, 1970: 351).

- Que los usuarios deben localizar los datos que necesitan lo más rápidamente posible.

- Un diccionario no es una base de datos. En una base de datos prima el registro y la indexación de la información sobre la comunicación.

- Una base de datos asociada a un diccionario debe incluir la mayor cantidad de datos relevantes (Fuertes-Olivera, 2019).

- Un diccionario concreto debe ser capaz de contener (para presentar si fuera necesario) la mayor de datos posible para satisfacer cualquier consulta.

- Presentar en pantalla una cantidad de datos ajustada (la menor posible) para satisfacer las necesidades del usuario en cada situación.

- Presentar propuestas de avance en el conocimiento mediante enlaces, opción 'para saber más', otros ejemplos relacionado...

6. Son necesarios conceptos con dos componentes de distinta naturaleza y un mismo referente. Estos dos componentes tienen una relación unas veces en equilibrio y otras, con un claro predominio de un componente sobre el otro, con el objetivo de optimizar y precisar, en este caso, un concepto.

\subsubsection{Propuesta de definiciones para el diccionario de EGI}

Se proponen definiciones precisas adaptadas al usuario. Esto implica reformular la definición según sus necesidades y su situación. La colaboración entre el lexicógrafo y el experto en la materia permite una definición de concepto adaptada al usuario como resultado de un conocimiento sólido del campo temático (Fuertes-Olivera, 2014:25). Estas necesidades surgen en una situación extralexicográfica que implica la adquisición de principios y fundamentos técnicos para los que se requiere conocimiento previo. 
La situación en la que se requiere la adquisición de conocimiento para ampliar el conocimiento es una situación cognitiva. Sin embargo, el propósito de los dibujos utilizados y de los elementos geométricos involucrados se puede referir, en el caso de la figura 6.3 o 6.5, a una situación extralexicográfica interpretativa-operativa o, en el caso de la figura 6.18, a una situación extralexicográfica operativa.

Se presenta el concepto acotar y una definición propuesta disgregada en caso de que algún conocimiento previo deba aclararse o hacerse accesible (a cada necesidad se puede y se debe responder con una propuesta que incluya un componente verbal y uno gráfico):

Acotar: proceso de consignar sobre la representación de un objeto sus dimensiones reales, definiendo con precisión el tamaño, la ubicación y la geometría (si fuera necesario) teniendo en cuenta el proceso de fabricación y las recomendaciones normalizadas para la representación

- consignar sobre la representación de un objeto, hace referencia por una parte a que se debe reservar un espacio para disponer las cotas, por otra, a que son necesarios ciertos elementos que sitúan y definen las cotas con precisión y finalmente a que la representación puede ser sobre una representación plana o una perspectiva

- consignar: destinar un lugar o sitio para poner o colocar en él algo (RAE)

- dimensiones reales de un objeto, el objeto puede estar representado a escala por lo que los valores de las cotas han de ser los correspondientes al objeto real

- definir con precisión, hace referencia por una parte que se deben unir con esmero las líneas de cota al elemento geométrico y por otra parte que se debe acotar sin ambigüedad lo que implica no dar información dimensional que pueda conducir a una indeterminación de la geometría

- definir el tamaño implica definir los elementos geométricos que conforman el objeto y sus características y, conocer de antemano las cotas necesarias para definir el objeto

- definir la ubicación de los elementos geométricos situados en relación a otros

- puede ser necesario definir, aclarar, precisar la geometría; se refiere a los símbolos que preceden a la cifra de cota y que "permiten la identificación de las formas y mejoran la interpretación del dibujo" (UNE 1-039)

- se disponen las dimensiones con aplicación directa en la fabricación del objeto, no las que son fruto o se derivan del proceso de fabricación

- las pautas para consignar las dimensiones y los elementos que intervienen en la acotación de un objeto sobre su representación está(n) especificado(s) en distintas Normas 


\subsection{Presentación de los datos respaldando las funciones}

Un diccionario electrónico facilita el acceso a los datos y amplia las opciones en la presentación de los mismos. En este formato de diccionario se debe definir la secuencia de acceso a los datos y finalmente la estructura de presentación de los mismos. Con el objetivo expresado por Nielsen (1995), citado por Bergenholtz, Botma y Gouws (2015: 5) «The access structure may be realised in a number of ways, all of which are intended to direct the user to the information required in the shortest possible consultation time (1995: 219).». Los parámetros que condicionan el acceso, la presentación y el tiempo necesario para obtener los datos son:

- La estructura de almacenamiento de datos ha de ser un registro lexicográfico que tiene un formato de plantilla organizada en campos que alojan unidades textuales y gráficas que han de estar etiquetadas juntas (siempre que sea posible). Puede corresponder a definiciones ostensivas (cf. Ahumada, 2001) utilizando las ilustraciones para 'aprehender el referente'.

- El sistema debe reconocer unidades pluriverbales, unidades gráficas y las relaciones entre unidades del mismo tipo y también cruzadas.

- La ruta de acceso a los datos ha de ser intuitiva y comprensible a primera vista. En el proceso de búsqueda el usuario sí sabe que función o funciones del diccionario son relevantes en su situación y puede preseleccionar una u otra función ya que es un usuario motivado.

- La estructura de presentación de datos ha de ser adecuada para cada nivel de complejidad y presentar simultáneamente un componente verbal y un componente gráfico asociado (hasta llegar a nivel avanzado). A nivel de iniciación en EGI, ambos componentes son sencillos y directos textual y gráficamente. En un nivel intermedio ambos componentes son complejos, por lo que incluyen reformulaciones previas. En un nivel avanzado solo hay componente gráfico o el componente textual sería mínimo (sería muy complejo, impreciso, e incompleto verbalizar ciertos conceptos geométricos o verbalizar para definir con precisión un objeto que se va a fabricar en serie). 
- La relación de asociación entre en componente verbal y el componente gráfico varía en función del referente (más o menos complejo) y del conocimiento especializado de usuario. Se pasa de una relación de cooperación a una relación de rivalidad por representar al referente.

- El nivel de conocimiento previo lo determina el usuario con la elección de opciones y la propuesta de datos tiene el objetivo de facilitarle el paso de un estado de conocimiento a otro estado para que pueda realizar una acción específica (Pétroff, 1984: 54). La diferencia de niveles existe desde el punto de vista del lexicógrafo o experto, pero desde el punto de vista del usuario (iniciado en EGI) son referencias a un conocimiento previo o posterior.

\subsubsection{Plantilla para la presentación de datos en el diccionario}

Con todos los parámetros mencionados se ha diseñado una plantilla de presentación de los lemas en el diccionario propuesto. Se configura una plantilla con el objetivo de presentar de forma directa la información pertinente para satisfacer las necesidades del usuario y proporcionar un repositorio eficiente con funciones de acceso.

El modelo de plantilla base (ver figura 6.4) está organizada en cinco bloques relativos a: concepto, lema (clave) y su familia léxica; representación gráfica; información gramatical; función y definiciones.

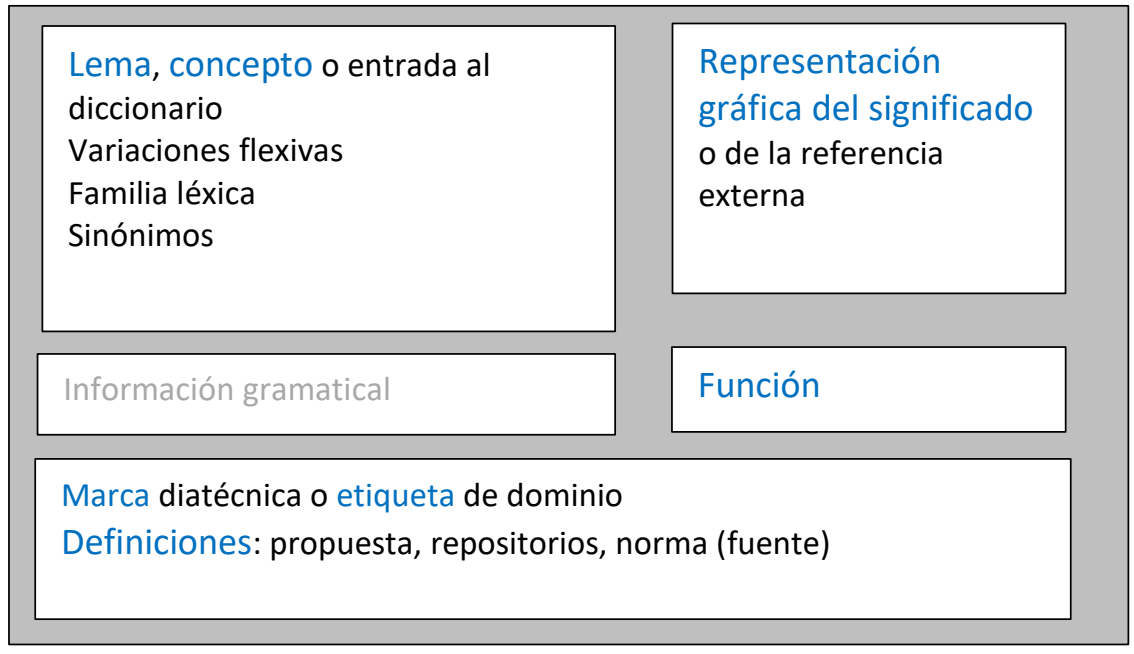

Figura 6.4. Estructura básica de la presentación de los datos 
Las entradas del diccionario se realizan a través de una clave, que puede ser una unidad pluriverbal, que identifica un concepto en EGI (equivalente a lema) y que, a su vez, conduce a otras unidades (o familias léxicas). Las diferentes definiciones e interpretaciones gráficas de cada entrada están condicionadas por la etiqueta de dominio dentro de EGI.

El campo gráfico no es opcional como ocurre en otros diccionarios, sino obligatorio. Para cada concepto identificado en el diccionario, se muestra a primera vista la representación gráfica que completa, que porta el significado o a modo de ejemplo. La aproximación a un concepto en EGI se realiza vinculando las definiciones y la representación gráfica. Las disciplinas técnicas se caracterizan por la correspondencia unívoca entre el significante y el significado y entre un signo no lingüístico a una noción (Lerat, 1995 :34).

La representación gráfica incluye representaciones normalizadas, representaciones de conceptos y ejemplos de aplicación práctica. Está adaptada a la consulta, según dos vías: dirigida por el experto y elegida por el usuario. Los conceptos gráficos complejos se disgregan y se presentan mediante conceptos sencillos.

Se incluye una opción de acceso por función que será necesario seleccionar. En cierto modo es un 'cruce de caminos' antes de avanzar: en una situación y con una función cognitiva; en una situación interpretativa y con una función interpretativa, y en una situación operativa y con una función operativa. Los tres 'caminos' discurren de forma separada, pero no distante, de forma que el usuario tiene la opción de_cambiar de ruta, explorar cualquiera de los dos caminos y regresar al camino inicial para finalizar un proceso o para seguir avanzando. En este sentido una situación evoca a un usuario ('agente' que demanda) una función evoca a un diccionario ('agente' que responde a la demanda).

Se incluye un campo de información gramatical, colocaciones, relaciones léxicas (antónimos, sinónimos, etc.), pero no es prioritaria para el usuario y únicamente será relevante en situaciones puramente comunicativas.

La primera propuesta de definición a la que se accede es la formulada o reformulada por nosotros y opcionalmente se pueden consultar definiciones de autores reconocidos y la definición normalizada. Con las definiciones se pretende el rigor y la precisión terminológica, así como la comprensión de los conceptos, esto supone que hay definiciones escuetas y otras, necesariamente enciclopédicas. 
La marca es una información que restringe el uso de las unidades léxicas y señala la pertenencia del lema a un determinado campo especializado (Sánchez Martín, 2009: 342). En esta propuesta figura una etiqueta de dominio a modo de marca diatécnica que indica la materia (o subcampo especializado) dentro de EGI y restringe el significado.

\subsubsection{Ejemplo de un concepto según la plantilla propuesta}

Ejemplo del concepto acotar. Es un concepto complejo y complicado con multitud de aplicaciones y acepciones que presenta dificultad conceptual y práctica. Es el primer concepto en la lista consensuada por expertos ( $c f .5 .4 .7)$. Este caso se presenta en una estructura de datos dividida en tres secciones y subsecciones:

Clave: acotar

\section{CONCEPTO}

Categoría gramatical: Verbo

-Variaciones flexivas: acotación, cota, acotado.

-Familia léxica: unidades pluriverbales agrupadas por etiqueta de dominio.

-Dibujos técnicos. (Marca) ACOTACIÓN: acotación funcional directa; acotación funcional indirecta; elementos de acotación; método de acotación; acotación de radios; acotación de cotas superpuestas; acotación en serie; acotación a partir de un elemento en común; acotación en paralelo; acotación por coordenadas; acotación combinada; acotación de elementos equidistantes; acotación de elementos equidistantes dispuestos angularmente a intervalos; acotación simplificada de chaflanes; acotación de conjuntos; acotación de las tolerancias; cota; cota funcional; cota no funcional; cota auxiliar; cota lineal; cota angular; cifra de cota; línea auxiliar de cota; línea de cota; líneas de cota oblicuas; cota fuera de escala;; disposición de las cotas; cadenas de cotas; línea de cota del radio; cota angular; cota de altitud; cota de nivel.

-Dibujos técnicos. (Marca) Tolerancias de cotas lineales y angulares: cota con tolerancia; cota nominal; cota superior; cota inferior; cota con límite superior; cota con límite inferior; cota del agujero; cota del eje, etc.

-Especificaciones geométricas de producto (GPS). (Marca) Acotado geométrico: acotado geométrico; acotación geométrica; acotación geométrica de piezas; elemento geométrico acotado; cilindro acotado; superficie media acotada; característica a acotar; figuras acotadas.

-Dibujos técnicos. (Marca) Métodos de proyección. Parte 3: Representaciones axonométricas: acotados.

-Dibujos técnicos. Roscas y piezas roscadas: Acotación de piezas roscadas, acotar la longitud del roscado, acotar la profundidad del agujero ciego. 


\section{DEFINICIÓN}

Se propone en primer lugar la definición a.-

-Definiciones de autores de prestigio, repertorios de la especialidad y la definición normalizada:

a. proceso de consignar sobre la representación de un objeto sus dimensiones reales, definiendo con precisión el tamaño, la ubicación y la geometría (si fuera necesario) teniendo en cuenta el proceso de fabricación y las recomendaciones normalizadas de la representación

b. señalar las magnitudes que determinan la geometría o características geométricas de un objeto atendiendo a aspectos tales como funcionamiento, fabricación, montaje o verificación de las magnitudes (A. Valin)

c. el proceso de situar las medidas de la pieza sobre el plano, y los elementos que reflejan las medidas reales de la pieza se denominan cotas (Félez \& Martínez, 2008)

d. acotar es dimensionar, las dimensiones y notas describen el tamaño, el terminado y otros procesos de fabricación en el dibujo, de tal forma que el objeto quede total y precisamente definido. Las dimensiones describen el tamaño y la ubicación de los elementos de un objeto (Giesecke et al., 2006)

e. (De «cota», número.) Poner números o cotas en un plano (Moliner, M., 1985).

\section{REPRESENTACIÓN GRÁFICA}

Corresponde a las figuras 6.5 y 6.6 una parte de la representación acotada de un objeto.

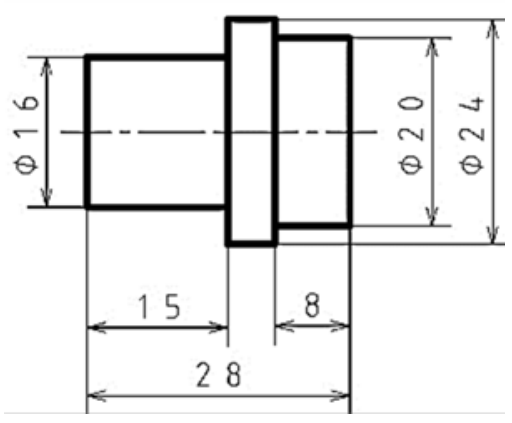

Figura 6.5. Ejemplo de aplicación práctica. El dibujo define, con precisión, la geometría y las dimensiones de un objeto

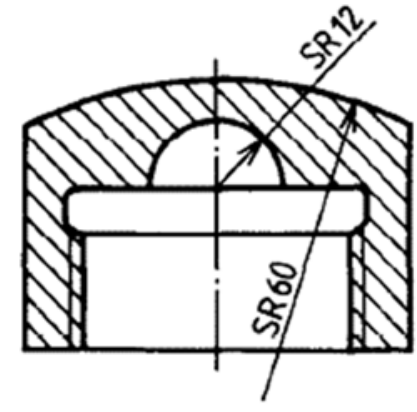

Figura 6.6. Representación normalizada de la acotación de un elemento esférico UNE 1-039-94

\subsubsection{Ejemplos de presentación de datos por funciones}

Las figuras $6.7,6.8$ y 6.9 muestran las propuestas de datos que se muestran al iniciar una consulta con la clave acotar según las funciones cognitiva, interpretativa y operativa respectivamente. 


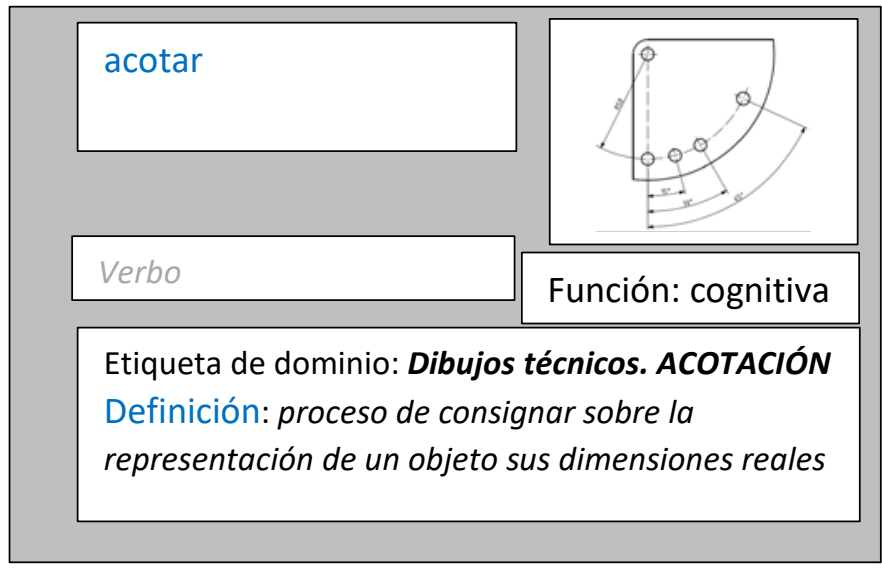

Figura 6.7. Clave acotar, función cognitiva (BS ISO 129-1:2004)

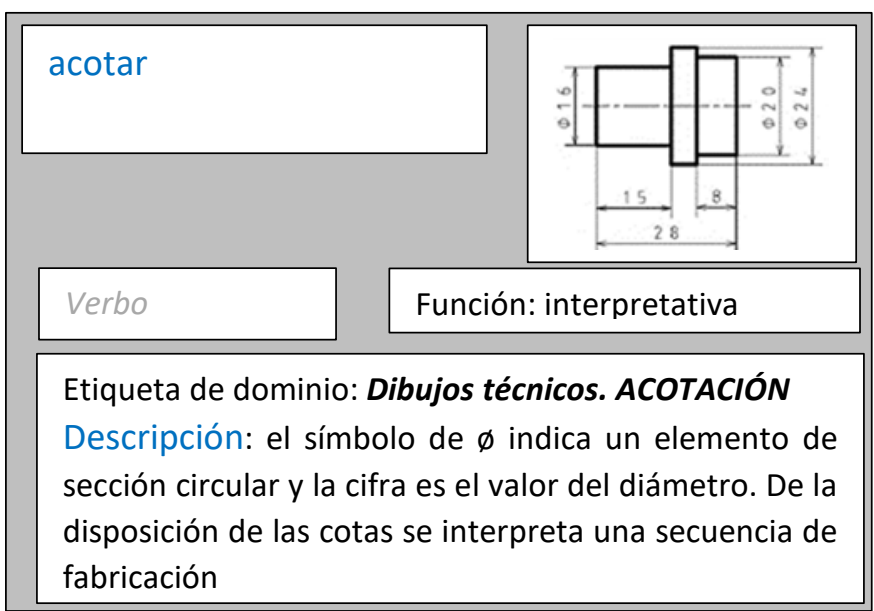

Figura 6.8. Clave acotar, función interpretativa

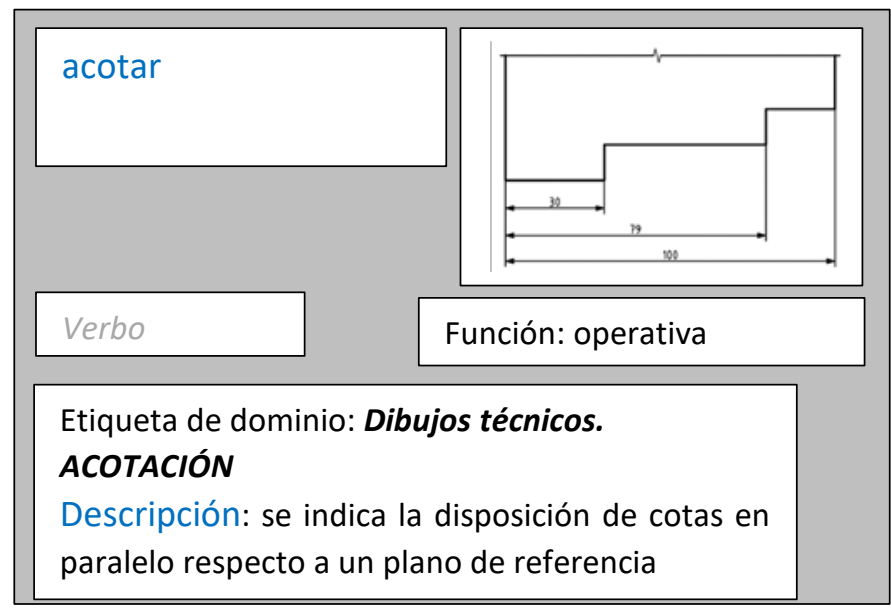

Figura 6.9. Clave acotar, función operativa para la acotación en paralelo (BS ISO 129-1:2004) 


\subsection{Ruta de acceso en línea}

A través de la interfaz el usuario, la navegación y ruta de acceso a los datos en la herramienta lexicográfica de una consulta sigue el esquema de la figura 6.10. siendo necesaria al menos una palabra para iniciar el proceso de búsqueda. Se propondrá la utilización de una interzfaz gráfica de usuario que actúe de interfaz de usuario «utilizando un conjunto de imágenes y objetos gráficos para representar la información y acciones disponibles en la interfaz. Su principal uso, consiste en proporcionar un entorno visual sencillo» para permitir la comunicación con la herramienta lexicográfica (https://es.wikipedia.org).

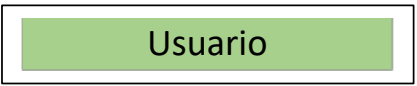

1.Teclea la palabra clave (su percepción de palabra clave)

2. Selecciona la pestaña o etiqueta de campo: Norma, figura de análisis, ejemplo gráfico

4. el usuario selecciona para avanzar, bien la unidad léxica, bien la unidad gráfica y a continuación...

\section{Selecciona la función para avanzar comprender (f. cognitiva) interpretar (f. interpretativa) trazar (f. operativa)}

Herramienta lexicográfica
3. Devuelve una lista de unidades léxicas, que incluyen la clave y presentan una descripción o definición del concepto junto con una representación gráfica inicial asociada (que no se pueden desvincular)
6. Devuelve una unidad léxica vinculada a una representación gráfica presentada por niveles, en la que la opción recomendada aparece visualmente destacada, pero en la que otras opciones de distinto nivel son visualmente accesibles, de forma que el usuario es libre de seguir la recomendación.

7. Amplia la visualización de la opción elegida y finaliza la búsqueda o

8. Elige otra unidad léxica o gráfica correspondiente a nivel previo o posterior.

Figura 6.10. Ruta de acceso y propuesta para la interfaz de usuario 


\subsubsection{Representación de la rutina de acceso}

Se presentan dos casos, a modo de ejemplo, sobre las rutinas de acceso en consultas con dos claves distancia y estado superficial. Las rutinas muestran opciones de decisiones que ha de tomar el usuario, condicionadas por su situación, su perfil y su conocimiento especializado. Los datos proporcionados por el diccionario dependen de la función preselecionada.

Caso 1: clave distancia

- Activada la función cognitiva en la herramienta

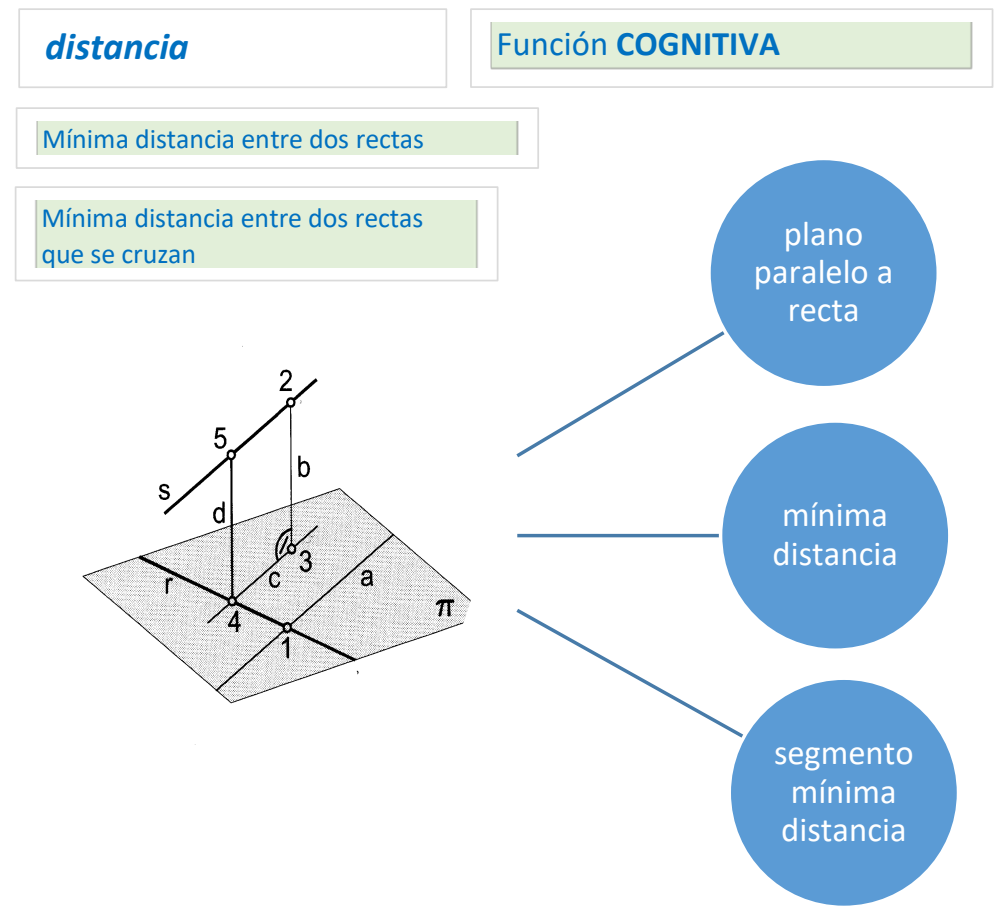

Figura 6.11. Rutina de acceso con clave distancia y activada la función cognitiva

El esquema de la figura 6.11 es un ejemplo de la ruta iniciada a partir de una palabra clave distancia, dos unidades pluriverbales y una unidad gráfica. Las opciones muestran la función cognitiva. Como se ha mencionado, cada definición y cada descripción están asociadas a una representación gráfica en este caso respaldando la función cognitiva (figura de análisis). El nivel asignado en la estructura del registro para el diccionario sería semiexperto-experto. 
- Activada la función operativa en la herramienta

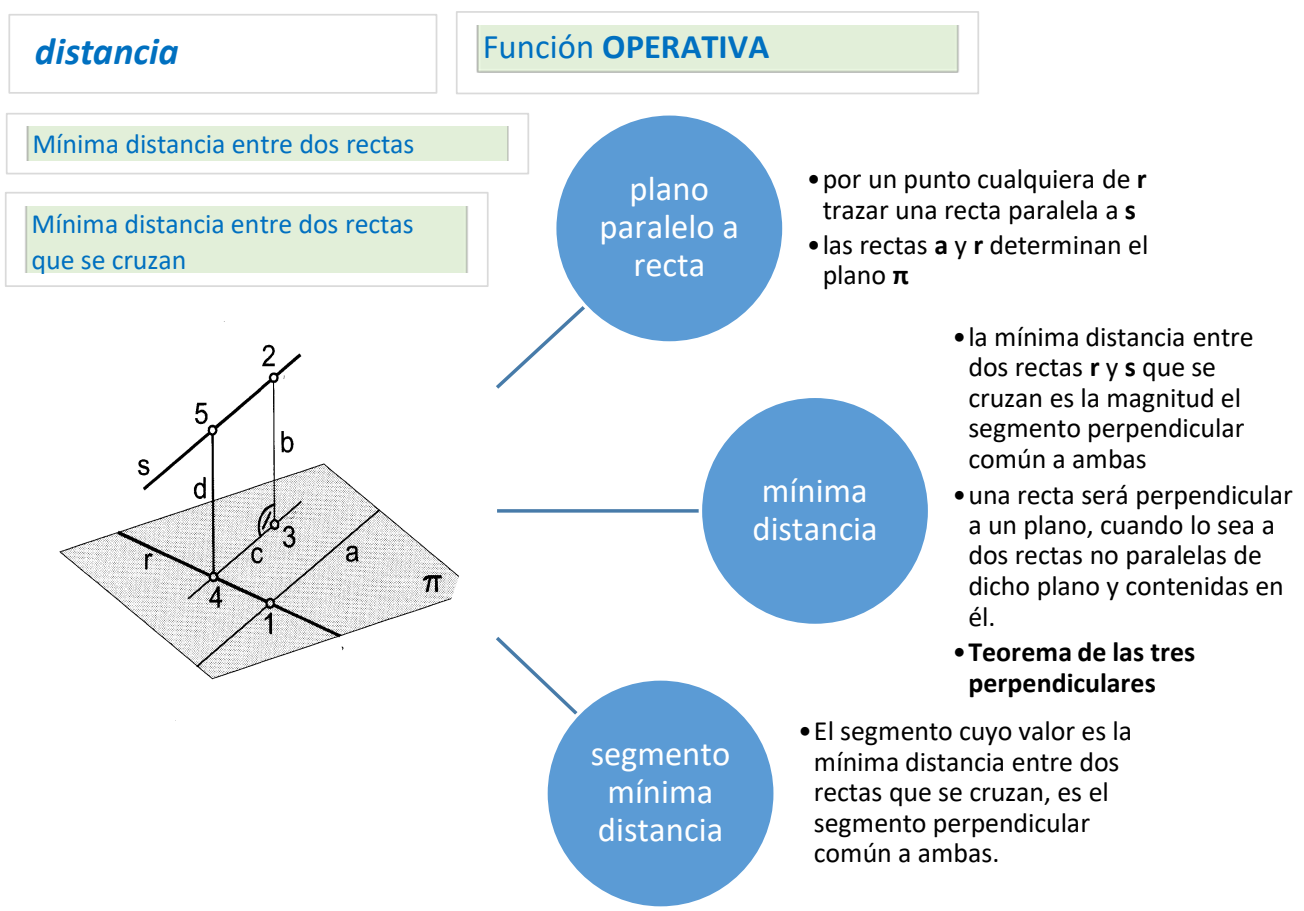

Figura 6.12. Rutina de acceso con clave distancia y activada la función operativa

El esquema de la figura 6.12 es un ejemplo de la ruta iniciada a partir de una palabra clave distancia, dos unidades pluriverbales y una unidad gráfica. Las opciones muestran la función operativa. Como se ha mencionado, cada definición y cada descripción están asociadas a una representación gráfica en este caso respaldando la función operativa (representación diédrica). El nivel asignado en la estructura del registro para el diccionario sería semiexperto-experto. 
Caso 2, clave calidad superficial

- Activada la función interpretativa en la herramienta

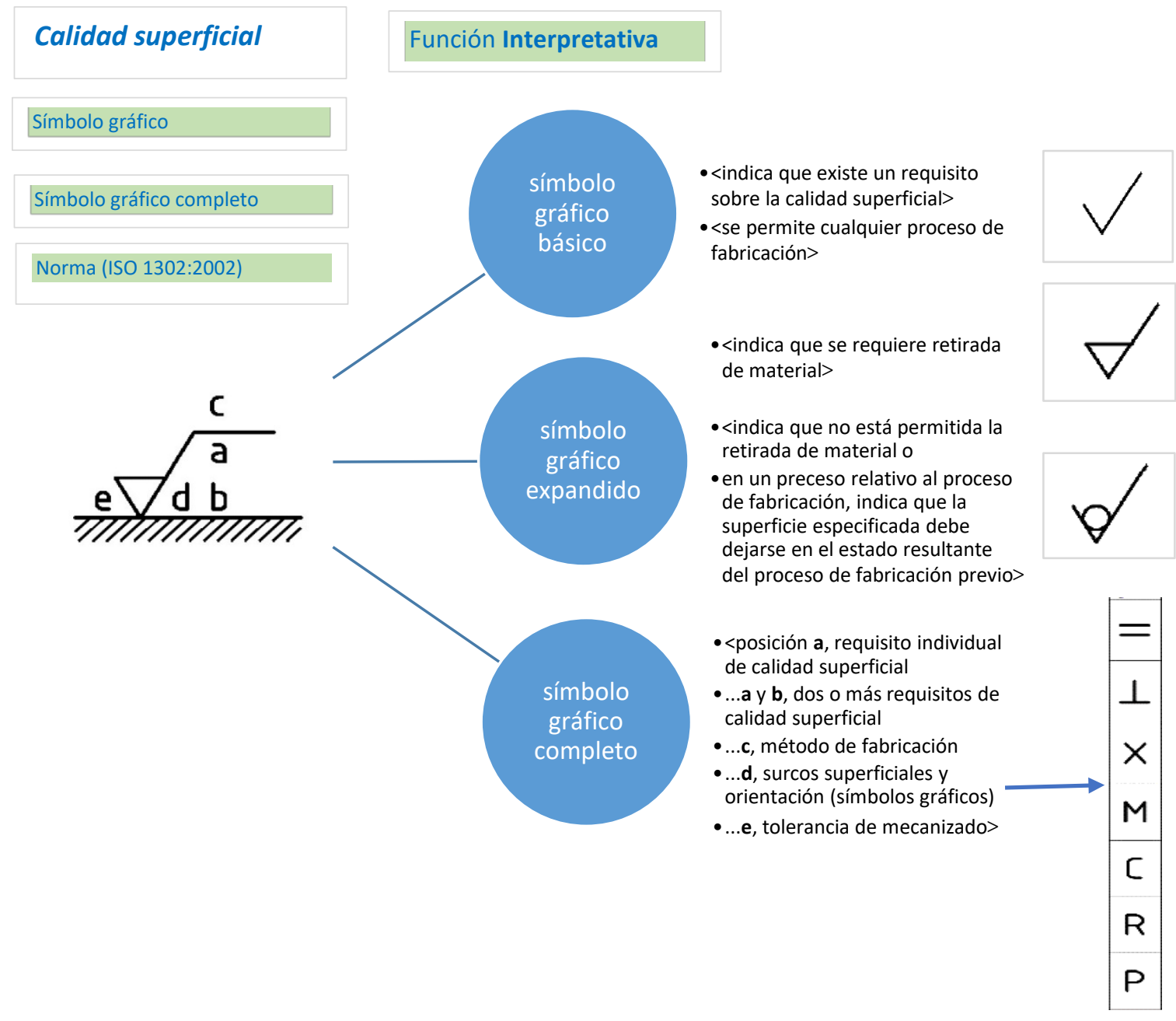

Figura 6.13. Rutina de acceso con clave calidad superficial y activada la función operativa

El esquema de la figura 6.13 es un ejemplo de la ruta iniciada a partir de una clave pluriverbal calidad superficial, una unidad pluriverbal, una unidad gráfica y una etiqueta de campo. Las opciones muestran la función interpretativa del diccionario. En este caso la figura permite visualizar de forma conjunta los símbolos gráficos y las indicaciones textuales necesarias. El nivel asignado en la estructura del registro para el diccionario sería iniciadosemiexperto. Constituye un ejemplo de un signo que sólo tiene significado en un contexto junto a otros signos. 


\subsubsection{Ejemplo de la presentación de una consulta}

Se propone una estructura de consulta que en ningún caso sea nula y que alcance el mayor grado de satisfacción del usuario. Se presenta el contenido completo disponible con la clave acotar, en concreto acotación con tolerancias dimensionales (acotación + tolerancias + dimensionales).

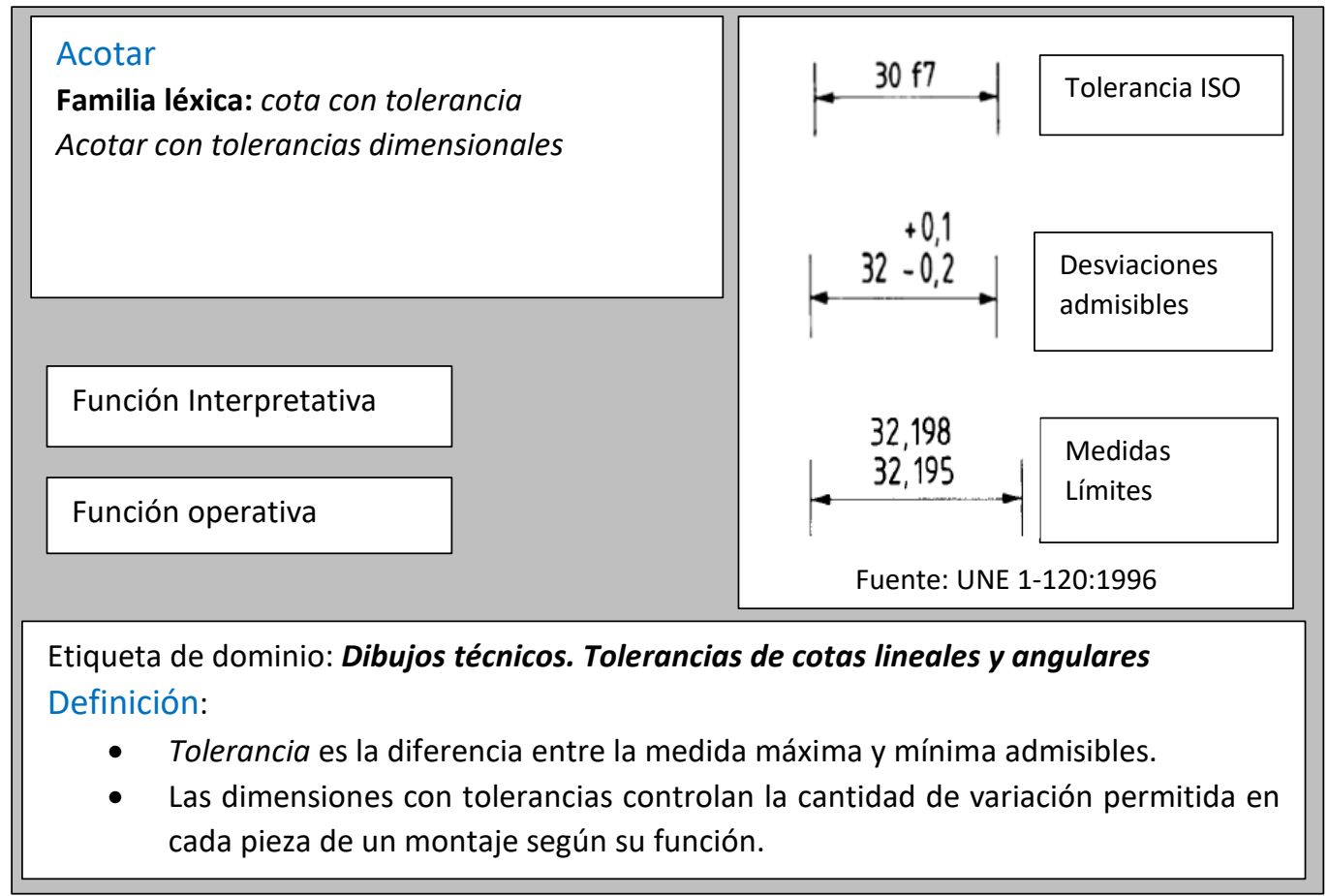

Figura 6.14. Datos disponibles para la clave acotar

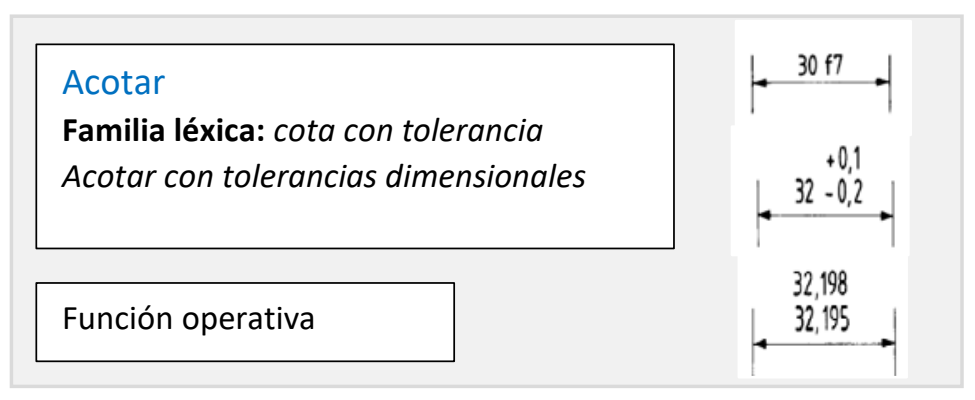

Figura 6.15. Datos presentados para un usuario en situación operativa

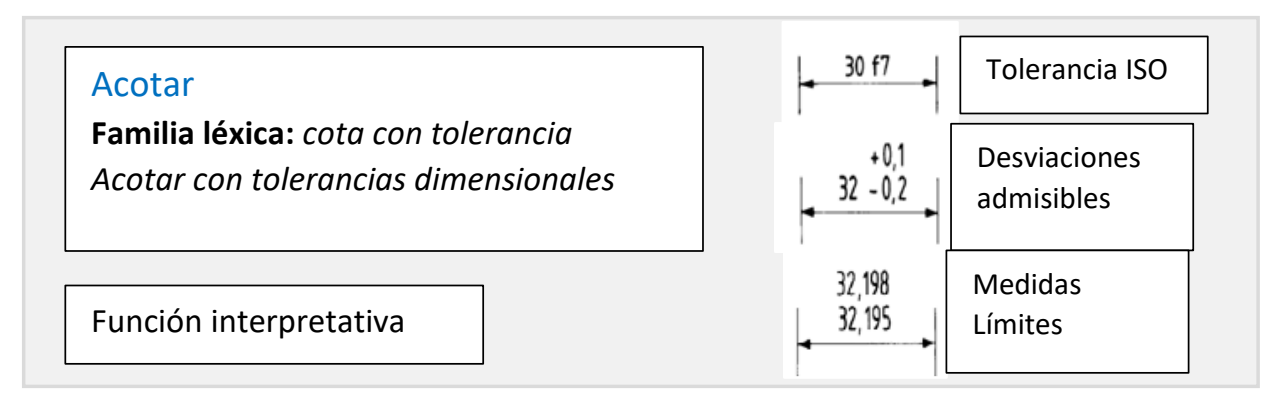

Figura 6.16. Datos presentados para un usuario en situación interpretativa 
El ejemplo de la figura 6.14 corresponde a un nivel intermedio que puede requerir conocimientos previos, en este caso se debe indicar el significado de la notación ISO (posición y calidad IT de la tolerancia) o casos más avanzados como el cálculo de ajustes o ejemplos prácticos de representación en piezas reales aisladas o en un montaje. La figura 6.15 representa los datos aportados en una situación operativa y la figura 6.16 representa los datos aportados en una situación interpretativa.

\subsubsection{Propuesta de consulta de usuarios con diferentes perfiles de conocimiento especializado}

\section{Consulta de un usuario lego o inexperto:}

- Paso 1: se introduce palabra clave.

Nivel 1: se visualiza destacada la representación gráfica y se presenta una definición sintética y clara (propuesta por el experto); (nivel 1).

- Paso 2: seleccionar definición por figura o ampliar la clave.

Nivel 2: se presenta definición descriptiva y pormenorizada (propuesta por el experto) y representación gráfica asociada (nivel 2).

Nivel 3: seleccionar definición por función. Esta puede requerir información textual y gráfica correspondiente a procesos intermedios (nivel 3).

\section{Consulta de un usuario semiexperto:}

- Paso 1: se introduce palabra(s) clave y se selecciona la etiqueta del dominio.

Nivel 1: se presenta una definición sintética y clara (propuesta por el experto); simultáneamente se visualiza la representación correspondiente asociada (determinada por el concepto, la etiqueta de dominio y nivel 1).

- Paso 2: seleccionar definición por función.

Nivel 2: se presenta definición descriptiva y pormenorizada (propuesta por el experto) y representación gráfica asociada (nivel 2). Opcional acceso a definiciones y representaciones propuestas por distintos autores.

Nivel 3: la función seleccionada puede requerir información textual y gráfica correspondiente a procesos intermedios (nivel 3). 


\section{Consulta de un usuario experto:}

Paso 1: seleccionar definición por función

Nivel 2: se presenta definición descriptiva y pormenorizada (propuesta por el experto) y representación gráfica asociada (nivel 2).

Opcional definiciones y representaciones propuestas por distintos autores

Nivel 3: la función seleccionada puede requerir información textual y gráfica correspondiente a procesos intermedios (nivel 3).

Nivel 4: la función seleccionada puede requerir información textual y gráfica correspondiente a procesos avanzados y ejemplos gráficos prácticos (nivel 4).

\section{Ejemplo detallado de la presentación de datos en el nivel 3: Determinar la mínima} distancia entre dos rectas que se cruzan (González et al., 1982)

En una situación cognitiva y operativa (ver la figura 6.11) que requiere la descomposición de un concepto complejo en conceptos simples, es decir, la división o descomposición en construcciones geométricas simples de problemas complejos. Se reformulan tanto las definiciones como las construcciones gráficas y la descomposición implica una secuencia en el proceso.

Se plantea un ejemplo de un caso genérico en los pasos 1 a 5, el punto 6 refiere un caso real en posición favorable. En este caso, para determinar la mínima distancia entre dos rectas que se cruzan, la reformulación requiere los siguientes conceptos previos:

1. Visualizar gráficamente dos rectas que se cruzan y el concepto mínima distancia entre ellas (figuras 6.11 y 6.17 )

2. La acción necesaria para realizar el cálculo gráficamente se inicia al definir un plano $\pi$ paralelo a una de las rectas y que contiene a la otra. Todos los puntos, en este caso de la recta $\mathbf{s}$ distan lo mismo de $\boldsymbol{\pi}$

3. Trazar una Recta perpendicular a un plano. Una recta es perpendicular a un plano, cuando lo es a dos rectas no paralelas de dicho plano y contenidas en él

4. El Teorema de las tres perpendiculares se puede enunciar de la siguiente manera: «si dos rectas son perpendiculares en el espacio -cruzándose o cortándose- y una de ellas 
es paralela a un plano y las proyecciones ortogonales de las dos rectas, sobre dicho plano, son perpendiculares entre sí.» (González et al. 1982: 89).

5. Obtener gráficamente el Segmento mínima distancia. El segmento cuyo valor es la mínima distancia entre dos rectas que se cruzan, es el segmento perpendicular común a ambas.

6. Nivel 4: Enunciado de un caso real, en posición favorable puesto que las dos tuberías son perpendiculares. Se necesita obtener la «separación mínima de dos tuberías que se cruzan» (https://docplayer.es/21775335-Ing-luis-basadre-berrios.html)

\section{Pasos Ejemplo Nivel 3:}

- Paso 1. La mínima distancia entre dos rectas $r$ y $s$ que se cruzan es la magnitud del segmento perpendicular común a ambas. (Figura 6.17)

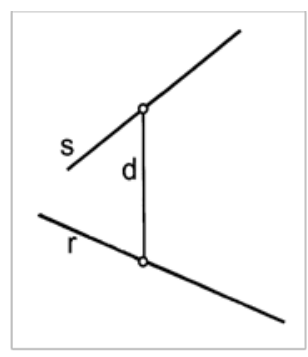

Figura 6.17. Representación de la mínima distancia entre dos rectas que se cruzan

- Paso 2. Definir el plano $\boldsymbol{\pi}$ paralelo a $\mathbf{s}$ y pasa por $\mathbf{r}$. El plano $\boldsymbol{\pi}$ está definido por las rectas a y $\mathbf{r}$. Todos los puntos de la recta $\mathbf{s}$ distan lo mismo de del plano $\boldsymbol{\pi}$. Trazar la recta a por el punto $\mathbf{1}$

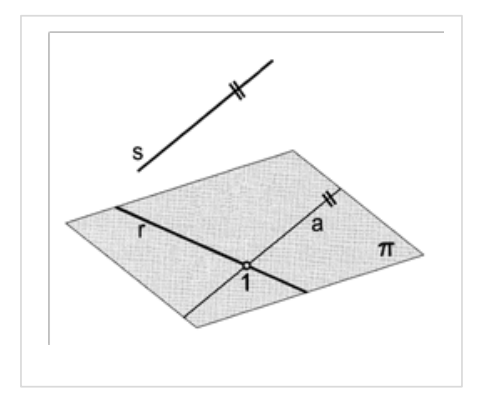

Figura 6.18. Por el punto 1 trazar la recta a (es paralela a s) 
Propuesta de Diccionario en Línea de EGI en el marco de la Teoría Funcional.

- Paso 3. Recta perpendicular a un plano. Una recta será perpendicular a un plano, cuando lo sea a dos rectas no paralelas de dicho plano y contenidas en él. Trazar la recta $\mathbf{b}$ por el punto $\mathbf{2}$

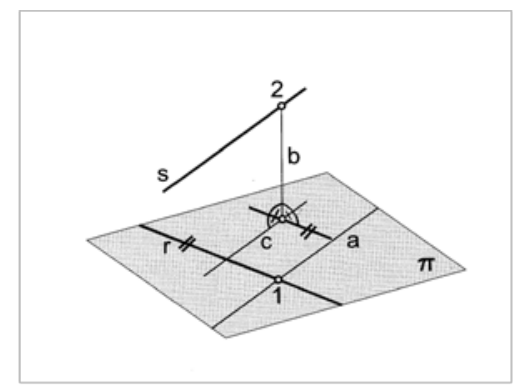

Figura 6.19. Recta perpendicular a un plano

- Paso 4: Teorema de las tres perpendiculares. Si dos rectas son perpendiculares en el espacio, cruzándose o cortándose y una de ellas es paralela a un plano, las proyecciones ortogonales de las dos rectas, sobre dicho plano, son perpendiculares entre sí (González et al. 1982: 89).

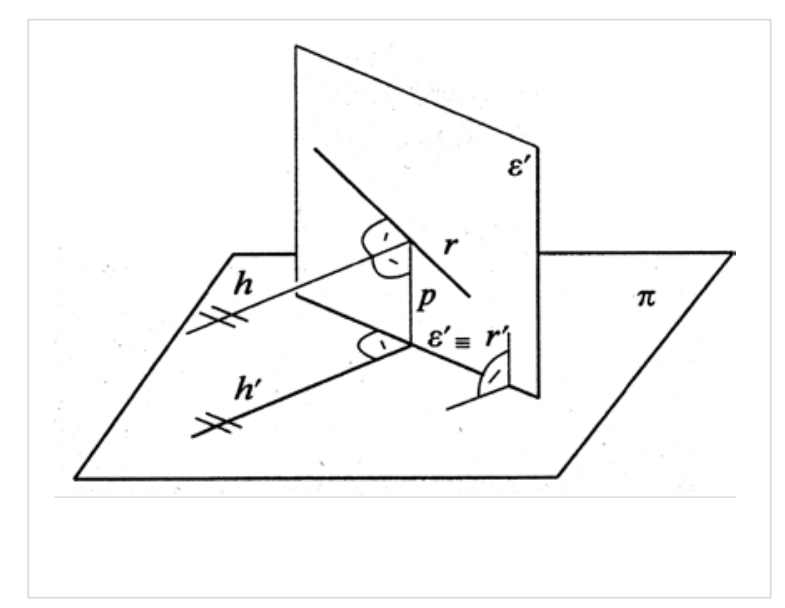

Figura 6.20. Teorema de las tres perpendiculares (Arroyo, 1997: 46)

- Paso 5: Intersección de la recta b con el plano $\boldsymbol{\pi}$. Justificación geométrica: La magnitud del segmento formado por un punto (2) exterior a un plano $(\pi)$ y el pie de la recta (3) perpendicular a un plano desde ese mismo punto exterior es la distancia de ese punto (2) al plano (ver la figura 6.21) 
5. Ejemplo de presentación de datos en el nivel 4 (constituyen los paso 6 y 7): Determinar el segmento mínima distancia entre dos rectas que se cruzan.

\section{Pasos Ejemplo Nivel 4:}

Paso 6. Segmento mínima distancia. El segmento cuyo valor es la mínima distancia entre dos rectas que se cruzan, es el segmento perpendicular común a ambas. Una recta será perpendicular a un plano, cuando lo sea a dos rectas no paralelas de dicho plano y contenidas en él. Por el punto $\mathbf{3}$ se traza la recta c y se halla la intersección de $\mathbf{c}$ con $\mathbf{r}$ que es el punto 4 .

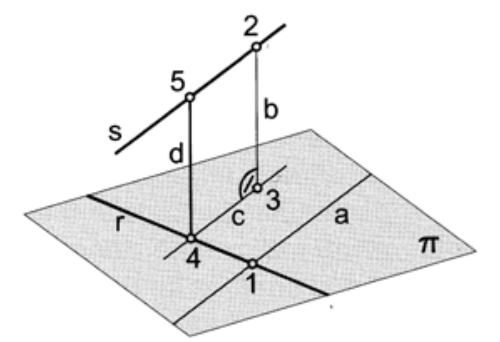

Figura 6.21. Segmento mínima distancia entre dos rectas que se cruzan $\overline{\mathbf{5 4}}$

Por el punto $\mathbf{4}$ se traza la recta $\mathbf{d}$ y se halla el punto $\mathbf{5}$ (punto de intersección de rectas $\mathbf{d}$ y $\mathbf{s}$ )

- Paso 7. Nivel 4: Aplicación práctica de trabajo. Dos tuberías cuyos ejes son perpendiculares, las rectas están en posición favorable al ser perpendiculares. Se necesita obtener la «separación mínima de dos tuberías que se cruzan»

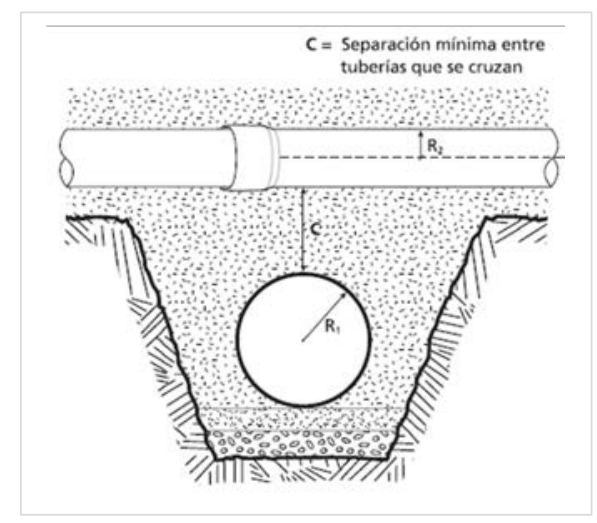

Figura 6.22. Separación mínima entre dos tuberías que se cruzan <https://docplayer.es/21775335-Ing-luis-basadre-berrios.html> 


\subsection{Conclusiones}

Una vez que el lexicógrafo ha identificado los conceptos (cf. 5.4), debe facilitar a los usuarios el acceso a datos de una forma fácil y rápida para optimizar el proceso de aprendizaje.

El usuario accede en dos modos opcionales, uno libre y otro dirigido al repertorio de datos lexicográficos y de datos gráficos. La elección en 'modo libre' permite el aprendizaje autogestionado, la elección en 'modo dirigido' facilita el aprendizaje premeditado secuencialmente por un experto.

Se ha comprobado que en Egi se produce la secuencia de las funciones interpretativa y operativa tal y como lo entiende Agerbo (2019:74). La interpretación de ciertos signos no lingüísticos conduce a la acción (resolver un problema geométrico), al incremento de conocimiento y utilizar lo aprendido para aumentar el conocimiento sobre un tema, en ese momento o más adelante (determinar una recta perpendicular a un plano para, en otro momento determinar el segmento mínima distancia entre dos rectas que se cruzan), en un claro ejemplo de sucesión de funciones lexicográficas. Por lo que se deduce que las funciones del diccionario de EGI no son excluyentes.

Para algunos usuarios potenciales el acceso a una herramienta lexicográfica de EGI como la que se propone en este trabajo puede ser de gran importancia. Nos referimos a los alumnos que tienen el primer contacto con este conocimiento especializado en el primer cuatrimestre de primer curso y el 'segundo' cuando se enfrentan a situaciones de la vida profesional. De esta forma podríamos comprobar que resulta una obra de referencia es útil para que el usuario potencial adquiera mediante un lenguaje especializado de naturaleza gráfica un conocimiento aplicado especializado técnicamente.

Se plantea en acciones futuras la posibilidad de incorporar la variable tiempo, entendido que las necesidades del usuario se actualizan no solo en situaciones concretas sino en momentos concretos. También parece interesante explorar para acciones futuras la utilización de una Interfaz de enfoque del usuario (Zooming user interface $Z U I$ ) que es una interfaz de usuario de entorno gráfico, en el que los usuarios pueden ajustar el tamaño o detalle del área de visión 
Propuesta de Diccionario en Línea de EGI en el marco de la Teoría Funcional.

como forma de búsqueda o ámbito de interés. Los elementos de información aparecen directamente en un escritorio virtual infinito (generalmente creado con gráficos vectoriales) en lugar de en ventanas tal y como proponemos para una fase inicial del diccionario en línea de EGI. <https://es.wikipedia.org/wiki/Interfaz de enfoque del usuario>. 
Propuesta de Diccionario en Línea de EGI en el marco de la Teoría Funcional. 


\section{CONCLUSIONES}

\subsection{Conclusiones}

7.2 Respuestas a las preguntas de investigación

7.3 Contribuciones al conocimiento

7.4 Líneas de investigación futuras 


\section{CONCLUSIONES}

A partir de la elaboración de esta tesis nos ha sido posible obtener una serie de conclusiones que responden a las cuestiones planteadas al inicio de la misma y fijar unas pautas en las que apoyarnos para diseñar una herramienta lexicográfica especializada útil y adaptada al usuario. Además, permiten plantear una nueva serie de posibilidades que abren futuras líneas de estudio.

\subsection{Conclusiones}

1. Se ha cumplido el objetivo final del proyecto que nos ocupa: diseñar una propuesta de diccionario especializado en EGI de orientación pedagógica en el marco teórico y metodológico de la Teoría de las Funciones Lexicográficas o Teoría Funcional de la Lexicografía. Para lograrlo se han cumplido los objetivos intermedios y que consisten en: la identificación de conceptos y de las unidades de información en el dominio de EGl; la determinación del perfil y de las necesidades del usuario potencial; la configuración de las entradas para cada concepto con los datos relevantes para cada situación; la determinación de los datos contenidos de los cuales extraer la información necesaria, y la adaptación del acceso y la presentación de los datos a las funciones que desempeña el diccionario.

2. La teoría de las funciones lexicográficas se presenta como el marco teórico más adecuado para elaborar la propuesta lexicográfica de un diccionario especializado en línea con el propósito de crear una herramienta útil y eficiente. Útil porque alcanza el objetivo que se persigue y eficiente porque lo hace con un alto rendimiento. Esta adecuación se fundamenta en que permite: 
- establecer el perfil del grupo potencial de usuarios determinado por ciertas características comunes del grupo; las situaciones en las que se encuentra; las necesidades de información y definir las funciones del diccionario;

- contemplar que una unidad conceptual tenga un componente gráfico constitutivo de significado especializado;

- que el acceso a los datos requiera la introducción de una unidad léxica y la selección de una función;

- que los componentes verbal y gráfico de los datos que están asociados formando una única unidad, se muestren simultáneamente, pero haciendo posible avanzar simultáneamente por la vía verbal o por la gráfica. Ambas vías forman una unidad indivisible más precisa y completa;

- elaborar diccionarios estructuralmente complejos, con imágenes no alfabéticas, pero de fácil comprensión y consulta por parte del estudiante de ingeniería. Estos estudiantes, al consultar el diccionario, deben comprender su estructura, interpretar encabezados temáticos y predecir los conjuntos léxicos subordinados que un diccionario electrónico en línea permite potenciar y organizar dinámicamente.

3. Presentamos una herramienta polifuncional cognitiva, operativa e interpretativa, de acceso monofuncional.

4. En este diccionario se registran unidades léxicas pluriverbales que corresponden a una unidad conceptual.

5. La propuesta de estructura de datos del diccionario de EGI tiene el valor lexicográfico amplio y riguroso, capaz de satisfacer las necesidades de información de un usuario. Emplea la tecnología disponible que permite, facilitar el acceso y la presentación de datos con interés lexicográfico para la consecución del objetivo. Este soporte tecnológico es el más potente, actual y con el que el usuario está acostumbrado a la consulta.

6. El diccionario en línea propuesto hace posible la individualización, en la satisfacción de las necesidades del usuario, mediante las decisiones y selección de opciones la ruta de 
acceso a los conceptos demandados en la consulta. El usuario accede al repertorio de datos lexicográficos y de datos gráficos en dos modos opcionales. La elección en 'modo libre' permite el aprendizaje autogestionado e independiente, la elección en 'modo dirigido' facilita el aprendizaje premeditado secuencialmente por un experto.

7. Este diccionario es una herramienta complementaria a otras labores docentes, pero muy útil y eficiente, a utilizar durante la realización de tareas propias de EGI. Es una obra de referencia de acceso en línea que ofrece solo los datos más relevantes para lograr así una consulta puntual y ágil. El soporte electrónico en línea aumenta la flexibilidad en la presentación de los datos lexicográficos, permite el acceso a los mismos gráficos con detalle y calidad y ser a la vez, fácilmente actualizable, revisable y modificable.

8. La combinación en un diccionario de EGI en línea de los componentes procedentes del lenguaje especializado y del lenguaje gráfico supone un reto lexicográfico novedoso. Ofrece al usuario un repertorio de datos lexicográficos junto a un repertorio integrado de datos gráficos basándose en un lenguaje especializado de naturaleza gráfica y un conocimiento especializado de aplicación técnica. Constituye un aprendizaje de doble código (Mayer \& Sims, 1994).

9. La propuesta pedagógica de este diccionario conlleva tener necesariamente en cuenta y desde el inicio del proyecto el contenido, el acceso y la presentación de los datos, de manera que permita al usuario progresar en el conocimiento de la materia. De este carácter pedagógico se deriva también que sea fundamental el concretar el perfil del usuario y las necesidades que busca satisfacer con una consulta.

10. La determinación de las funciones del diccionario hace necesario tener en cuenta el referente visual, la estructura y las funciones de la representación gráfica y su relación funcional con la parte verbal con la que se complementa. El marco teórico de la TFL facilita este trabajo de forma muy importante.

11. Se ha comprobado la secuenciación de las funciones interpretativa, operativa y cognitiva, pero en un entorno que combina dos lenguajes: el verbal y el gráfico. Se ha 
comprobado que la interpretación de ciertos signos lingüísticos y no lingüísticos, conduce a la acción, al incremento de conocimiento y a aplicar lo aprendido para resolver un problema práctico, en un claro ejemplo de sucesión de las funciones lexicográficas formando secuencias marcadas por cada necesidad concreta. Por lo que se deduce que las funciones del diccionario no son excluyentes, tampoco con la combinación de los lenguajes verbal y gráfico.

12. La función interpretativa de un diccionario de EGI tiene un componente subjetivo que favorece la construcción de significado. En un campo de conocimiento altamente codificado se requiere una capacitación que haga posible la construcción del significado.

13. Las carencias funcionales que han evidenciado los diccionarios técnicos consultados, respecto a nuestros objetivos en el dominio de EGI, justifican nuestra propuesta lexicográfica. Este diccionario es una obra de referencia para que el usuario potencial adquiera mediante un lenguaje gráfico especializado, un conocimiento aplicado especializado técnicamente actualizado y vigente.

14. Se ha propuesto y adaptado un procedimiento que permite a los lexicógrafos identificar conceptos con componente gráfico fundamentales para el diccionario de EGI. Este es el método Delphi que se muestra idóneo ya que permite una cuantificación de los resultados y la aplicación del método deductivo a la selección de conceptos especializados. Se ha obtenido una lista inicial consensuada de conceptos que satisfacen las necesidades del usuario, a criterio de los docentes. Una vez que el lexicógrafo ha identificado los conceptos se facilita a los usuarios el acceso a datos de una forma fácil y rápida para optimizar la consulta.

15. Se ha comprobado la conveniencia de contrastar la opinión del experto con la del usuario para obtener así los conceptos críticos. Dado que existe una discrepancia motivada por una necesidad de los alumnos, se recomienda incluir estos elementos en fases sucesivas del proyecto lexicográfico. 


\subsection{Respuestas a las preguntas de investigación}

P 1. ¿Cómo debe ser la aproximación pedagógico-lexicográfica a la expresión gráfica en la ingeniería que dé como resultado un diccionario en línea?

Responder a esta pregunta es relevante porque el sustrato teórico necesario para llevar a cabo el proyecto de diccionario nos va a ayudar enormemente en el desafío que nos hemos impuesto. Hemos descubierto en el transcurso de nuestra investigación que no hay ningún diccionario pedagógico de EGI y, por lo tanto, no podemos partir del análisis de obras hechas, ver sus puntos fuertes y débiles y ofrecer una propuesta que mejore los puntos fuertes y elimine los débiles. Nosotros hemos tenido que empezar buscando un marco teórico que nos guíe y nos oriente en nuestra propuesta. Es por ello que la primera pregunta debe responder que el marco teórico elegido es adecuado para nuestra propuesta de diccionario.

Por otra parte, el carácter altamente codificado de la EGI requiere, que cuando un experto o semiexperto en EGI tiene una necesidad de información relativo a signos y símbolos no lingüísticos, realice un proceso de búsqueda de datos y acuda a herramientas lexicográficas. Estos signos no lingüísticos, hasta el momento no están incorporados a las herramientas lexicográficas porque no son alfabetizables.

La aproximación pedagógico-lexicográfica debe realizarse en un marco teórico y metodológico que solucione las necesidades del usuario facilitando el acceso puntual solo a los datos justificados por las funciones.

P 2. ¿Por qué el marco teórico de la Teoría Funcional de la Lexicografía (TF) es válido para nuestra propuesta de desarrollo de un diccionario de EGI?

Aunque esta pregunta es muy general, creemos necesario indicar que la TF ofrece planteamientos muy dinámicos que son necesarios porque nuestro diccionario debe ir más allá de las funciones cognitivas. Como vemos a lo largo de la tesis, otras funciones, como las operativas e interpretativas, son básicas para nuestros usuarios potenciales.

En este marco teórico (TF) es posible la simbiosis de dos lenguajes (por naturaleza) independientes para adquirir, en el formato de un diccionario en línea, el conocimiento, 
las instrucciones y la orientación interpretativa, que realmente tiene posibilidades de éxito para el usuario (cuyo perfil, situaciones y necesidades contemplamos). La TF ofrece un soporte teórico adecuado para introducir una dimensión pedagógica dual en el diccionario especializado.

Hemos mencionado en las conclusiones que la teoría de las funciones lexicográficas se presenta como el marco teórico más adecuado para elaborar la propuesta lexicográfica de un diccionario especializado en línea porque permite establecer el perfil del grupo potencial de usuarios; las situaciones en las que se encuentra; las necesidades de información y definir las funciones del diccionario.

\section{P 3. ¿Cómo debe guiarnos la TF a la hora de diseñar una herramienta lexicográfica sobre} los fundamentos geométricos, gráficos y técnicos en el ámbito de la Expresión Gráfica en la Ingeniería?

La TF es una teoría dinámica y abierta que ha ido adaptándose a los desarrollos lexicográficos y tecnológicos, especialmente a los derivados de la introducción y generalización de las Tecnologías de la Información y la Comunicación. Esta adaptación nos obliga a valorar los elementos de la TF que podemos usar y los que podemos dejar a un lado a la hora de diseñar el diccionario en línea objeto de esta tesis. En otras palabras, puede ser necesario ampliar, modificar, cambiar algunos planteamientos teóricos de la TF si se considera necesario. Por ejemplo, hemos visto que en una situación como la que tiene la EGI (no hay ningún diccionario ni corpus, hecho que se pueda consultar), puede ser conveniente recurrir a experiencias externas a la lexicografía y a la terminología para solucionar alguno de los problemas iniciales que se presentan. Se ha visto un ejemplo de esta problemática al aplicar y adoptar el "método Delphi", usado en esta tesis para seleccionar el lemario inicial y básico al que se pueden incorporar todos los demás lemas.

Hemos mencionado en las conclusiones que la teoría de las funciones lexicográficas se presenta como el marco teórico más adecuado para elaborar la propuesta lexicográfica de un diccionario especializado en línea porque permite: 
- que una unidad conceptual tenga un componente gráfico constitutivo de significado especializado;

- que el acceso a los datos requiera la introducción de una unidad léxica y la selección de una función y que los componentes verbal y gráfico de los datos que estén asociados como una única unidad, se muestren simultáneamente y formen una unidad indivisible más precisa y completa.

\section{P 4. ¿Qué datos debe contener una herramienta lexicográfica de contenido gráfico industrial en el marco de la TFL?}

Aunque esta pregunta parece obvia, conviene responder a la misma desde una perspectiva aplicada. Cualquier diccionario tiene limitaciones de espacio, tiempo, recursos económicos, tecnológicos, etc. Es por ello conveniente justificar la elección de los datos concretos que se han elegido para nuestra propuesta de diccionario. Esto supone la combinación en un diccionario de EGI en línea de un repertorio de datos lexicográficos junto a un repertorio integrado de datos gráficos formando unidades indivisibles más precisas y completas.

\section{P 5. ¿Qué funciones lexicográficas son necesarias en un diccionario pedagógico en línea en EGI?}

Las funciones lexicográficas necesarias en un diccionario pedagógico en línea de EGI están condicionadas por el perfil del usuario que tenemos en mente y son la función cognitiva, interpretativa y operativa. Incluir estas dos últimas funciones como esenciales en el diccionario de EGI, aumenta el alcance de la teoría funcional y estimula el desarrollo de nuevas herramientas de información. Es viable la ampliación a una cuarta función lexicográfica la comunicativa con un coste asumible, para ello sería necesario ampliar los objetivos de un futuro estudio, que no se contemplan en este trabajo porque nos hemos centrado en cubrir las necesidades fundamentales inmediatas del usuario. 


\section{P 6. ¿Qué implicaciones futuras puede tener este trabajo de investigación?}

Todas las tesis son trabajos inacabados. La nuestra también y creemos por ello necesario preguntarnos por los límites actuales de nuestro trabajo al tiempo que fijamos posibles líneas de trabajo futuras. Avanzamos lo desarrollado a continuación en el apartado 7.4 sobre las implicaciones en futuras líneas de investigación: la introducción de la función lexicográfica de comunicación; la posibilidad de aplicar el marco teórico de las funciones lexicográficas solo al lenguaje gráfico; la ampliación de las fuentes literarias dentro del campo de estudio (sistema dieléctrico, sistema axonométrico, estandarización UNE e ISO), otros campos dentro de EGI (CAD); la utilización del método Delphi con ingenieros expertos y el cuestionario en el campus virtual con futuros estudiantes; integrar la consulta a un diccionario de EGI en un programa de CAD 2D o CAD 3D.

Con anterioridad a este trabajo de investigación, en el estudio realizado sobre el discurso de la EGI en el Trabajo de Investigación Tutelado (Esandi, 2006: 59-60) se plantearon dos cuestiones que quedaron pendientes y que ahora podemos responder a la luz del trabajo presente:

¿Existen este tipo de unidades con componente verbal y gráfico? Hemos probado que sí existen, que son necesarias y que están incluidas en nuestra propuesta de diccionario para satisfacer de forma completa las necesidades del potencial usuario que tenemos en mente.

Si existen este tipo de unidades, ¿responden a una necesidad de hacer más comprensible o más eficaz la comunicación en un entorno académico y/o profesional (industrial)?Efectivamente responden a la necesidad demanda por el usuario para hacer más comprensible, más eficaz la comunicación técnica, tanto en un entorno académico, como en un entorno profesional. 


\subsection{Contribuciones al conocimiento}

1. La teoría de las funciones lexicográficas puede aplicarse a lenguajes de distinta naturaleza que son independientes entre sí. Esto supone una novedad. Al poner en contacto ambos lenguajes, es decir, permite que ambos cooperen funcionalmente. Este contacto entre dos lenguajes es posible en el marco de la teoría funcional, porque permite que un lenguaje apoye a otro lenguaje. En el marco de esta teoría es posible integrar un contenido gráfico conceptual y un concepto verbalizado en un contexto lexicográfico.

2. Se amplía la función interpretativa que conocemos de la TF al contemplar la parte subjetiva de la interpretación. Como hemos mencionado, la función interpretativa de un diccionario de EGI tiene un componente subjetivo que favorece la construcción de significado. En un campo de conocimiento altamente codificado se requiere una capacitación que haga posible esta construcción del significado.

3. Cuando un experto o semiexperto en EGI tiene una necesidad de información relativa a la interpretación de signos y símbolos no lingüísticos inicia un proceso de búsqueda, análisis y síntesis de datos acudiendo a herramientas lexicográficas. Estos signos no lingüísticos, hasta el momento no están incorporados a las herramientas lexicográficas porque no son alfabetizables.

4. En EGI un verdadero experto no necesita apoyo verbal para recibir un mensaje gráfico, lo recibe directamente sin el apoyo de una lengua. Un semiexperto necesita o puede necesitar, dependiendo de la situación, el apoyo verbal para comprender, interpretar o actuar sobre un concepto gráfico. También requiere ese apoyo para comunicar, pero no es objeto de esta tesis. 
5. Un diccionario pedagógico en línea de EGI es novedoso, no existe, en la actualidad, sin embargo, hemos comprobado que sí existe la necesidad en un usuario en formación (y de algunos en el ejercicio profesional) de consultar una herramienta lexicográfica pedagógica en EGI. La posibilidad de ofrecer y acceder a los datos, gráficos y verbales, en formato digital y en línea, tiene ventajas para el potencial usuario, en primer lugar, la inmediatez (el consumo de tiempo es mínimo), en segundo lugar, la presentación de datos (una figura compleja) con el detalle, con el rigor y con la calidad que se necesita en un entorno industrial, y en tercer lugar, no hace una lectura lineal de los datos, sino que se percibe como un conjunto visual, verbal y gráfico. Un usuario aborda un concepto lexicográficamente, este se hace extensivo a un lenguaje gráfico y se aplican conjuntamente.

\subsection{Líneas de investigación futuras}

El presente estudio abre la posibilidad de introducir en el diccionario la función lexicográfica de comunicación para atender la demanda de un usuario que necesite producir o manejar textos y manuales en otros idiomas y producir documentación textual en un proyecto. Este usuario tendría un perfil correspondiente al $37,5 \%$ de los estudiantes de ingeniería (cf. 6.1).

Otra posible línea de investigación sería la aplicación del marco teórico de las funciones lexicográficas solo al lenguaje gráfico y destinado solo a un usuario experto.

Además, en un futuro cercano, puede ser necesario ampliar las fuentes literarias dentro del campo de estudio (simbología técnica especializada, sistema axonométrico, estandarización UNE e ISO), otros campos dentro de EGI (CAD). A la luz de los resultados de este trabajo es posible y aconsejable continuar con el método Delphi con ingenieros expertos y el cuestionario en el campus virtual con futuros estudiantes, ampliando así los resultados y el contenido del diccionario.

Otra línea de investigación posible para un diccionario de EGI en línea, cuando existan rastreadores de ficheros de gráficos vectorizados, realizar enlaces a ejemplos de EGI en la web y referencias cruzadas a los mismos desde un futuro diccionario. 
Finalmente, ya es una realidad que los diccionarios han sido absorbidos por herramientas digitales más amplias que facilitan la asistencia en comunicación, expresión y búsqueda de información. En este sentido, otra posible línea de trabajo sería el integrar o vincular un diccionario de $E G I$ con un programa de $C A D 2 D$ y $3 D$, de manera que al usuario de dicho programa le sea posible realizar una consulta a un diccionario en línea de EGI del mismo modo que hace una consulta a un manual en línea. 
En coherencia con el valor de la igualdad de género asumido por la Universidad de Valladolid, todas las denominaciones que en este escrito se efectúan en género masculino, cuando no hayan sido sustituidos por términos genéricos, se entenderán hechas indistintamente en género femenino. 
8. BIBLIOGRAFÍA
A. Diccionarios
B. Bibliografía General
C. Otras Referencias 
8. BIBLIOGRAFÍA

\section{A. Diccionarios}

Atkins, A. G., Atkins, T., \& Escudier, M. (2013). A dictionary of mechanical engineering. Oxford University Press.

DICTER. Diccionario de la ciencia y de la técnica del Renacimiento. Mạ Jesús Mancho Duque (dir.), Ediciones Universidad de Salamanca. Disponible en: $\langle\underline{h t t p}: / /$ dicter.usal.es/> [Consulta: 3 de febrero de 2020].

Follows, G. H. (1906). Universal Dictionary of Mechanical Drawing. Engineering news publishing Company. Disponible en: $<$ https://archive.org/details/universaldictio00follgoog> [Consulta: 3 de febrero de 2020].

Illustrated Dictionary of Mechanical Engineering: English, German, French, Dutch, Russian. Springer Science \& Business Media, 2013.

Moliner, M., \& Moliner, M. (1998). Diccionario de uso del español (Vol. 2). Madrid: Gredos

Real Academia de Ingeniería (España). (2014). Diccionario Español de Ingeniería. Real Academia de Ingeniería. Disponible en: < http://diccionario.raing.es/es > [Consulta: 15 de abril de 2020].

REAL ACADEMIA ESPAÑOLA: Diccionario de la lengua española, 23.. ed., [versión 23.3 en línea]. Disponible en: <https://dle.rae.es/ > [Última consulta: 09 de agosto de 2020].

Robb, L. A. (1979). Diccionario para ingenieros: español-inglés e inglés-español (No. 03) 62 ROB). Disponible en: <http://fullseguridad.net/wp-content/uploads/2017/02/DICCIONARIOPARA-INGENIEROS.pdf> [Consulta: 3 de febrero de 2020].

Stulpnagel, P. (1906). The Elements of Machinery and the tools most frequently used in metal and wood working. En Deinhardt, K., \& Schlomann, A. Illustrated technical dictionary in six 
languages, English, German, French, Russian, Italian, Spanish. VOL.I. Disponible en: <https://ia800203.us.archive.org/27/items/bub gb tcs3AAAAMAAJ/bub gb tcs3AAAAM AAJ.pdf $>$ [Consulta: 12 de abril de 2020].

Toms, W. H. \& Devoto, J. (1734). The Builder's Dictionary: or, Gentleman and Architect's Companion. London: Bettesworth \& Hitch. Disponible en: $<$ https://ia800504.us.archive.org/2/items/buildersdictiona01toms/buildersdictiona01tom

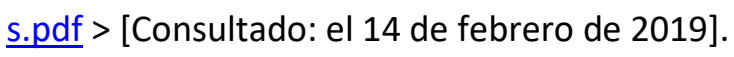

\section{B. Bibliografía General}

Agerbo, H. (2016). The incorporation of specialised data in lexicographical meaning explanations: A discussion based on sports and fitness terms. Lexikos, 26(1), 1-35.

Agerbo, H. (2017). The interpretive function: To be or not to be, that is the question. Lexikos, 27(1), 1-15.

Agerbo, H. (2019). A Theoretical Description of the Operative Function and its Implementation in the Conceptualisation of Danish Lexicographical Tools in Physical Training. Tesis doctoral inédita, Universidad de Aarhus. Departamento de estudios Germánicos y lenguas Romances, 2019.

Ahumada, I. (2001). Problemas de la definición enciclopédica en las palabras especializadas. Universidad Rovira i Virgili.

Alvar Ezquerra, M. A. (2002). De antiguos y nuevos diccionarios del español. Arco Libros, SL.

Álvarez Garrote S., Reboto Rodríguez E., Rodríguez Ovejero Q., Escribano Negueruela M. (2018) Prácticas de Expresión Gráfica III. Valladolid: los autores.

Andersen, B., \& Fuertes-Olivera, P. A. (2009). The application of function theory to the classification of English monolingual business dictionaries. Lexicographica, 25, 213-240. 
Arntz, R., \& Picht, H. (1995). Introducción a la terminología. Fundación Germán Sánchez Ruipérez.

Arroyo, J. A. A. (1997). Ejercicios de geometría descriptiva en sistema diédrico. José Amadeo Alonso Arroyo.

Ashwin, C. (1984). Drawing, design and semiotics. Design Issues, 42-52.

Atkin, A., "Peirce's Theory of Signs", The Stanford Encyclopedia of Philosophy (Summer 2013 Edition), Edward N. Zalta (ed.). Disponible en: <https://plato.stanford.edu/archives/ sum2013/entries/peirce-semiotics/> [Consulta: 29 de junio de 2020].

Atkins, B. T. S. (1996). Bilingual dictionaries: Past, present and future. EURALEX'96 Proceedings. Göteborg: Department of Swedish, Göteborg University, 515-546.

Atkins, T., \& Escudier, M. (2013). A dictionary of mechanical engineering. Oxford University Press.

Atkins, B. S., \& Rundell, M. (2008). The Oxford guide to practical lexicography. Oxford University Press.

Atkins, B. T., \& Varantola, K. (1997). Monitoring dictionary use. International Journal of Lexicography, 10(1), 1-45.

Barnard, A. (2012). Genesis of symbolic thought. Cambridge University Press.

Battaner, P. (2008). El fenómeno de la polisemia en la lexicografía actual: otra perspectiva. Revista de lexicografía, 14, 7-25.

Béjoint, H. (2010). The lexicography of English. OUP Oxford.

Bennett, S., Maton, K., \& Kervin, L. (2008). The 'digital natives' debate: A critical review of the evidence. British journal of educational technology, 39(5), 775-786.

Bergenholtz, H., \& Agerbo, H. (2017). Types of lexicographical information needs and their relevance for information science. Journal of Information Science Theory and Practice, 5(3), 15-30. 
Bergenholtz, H., \& Bothma, T. J. (2011). Needs-adapted data presentation in e-information tools. Lexikos, 21, 53-77.

Bergenholtz, H.; Bothma, T.J.D.; Gouws, R. H. (2015) Phases and steps in the access to data in information tools. Lexikos, vol. 25, p. 1-30.

Bergenholtz, H., \& Johnsen, M. (2005). Log Files as a Tool for Improving Internet Dictionaries. Hermes. Journal od Language and Communication Studies, 34, 117-141.

Bergenholtz, H., \& Kaufmann, U. (1997). Terminography and lexicography. A critical survey of dictionaries from a single specialised field. HERMES-Journal of Language and Communication in Business, (18), 91-125.

Bergenholtz, H., \& Nielsen, S. (2006). Subject-field components as integrated parts of LSP dictionaries. Terminology. International Journal of Theoretical and Applied Issues in Specialized Communication, 12(2), 281-303.

Bergenholtz, H., \& Tarp, S. (Eds.). (1995). Manual of specialised lexicography: the preparation of specialised dictionaries (Vol. 12). John Benjamins Publishing.

Bergenholtz, H., \& Tarp, S. (2003). Two opposing theories. On HE Wiegand's recent discovery of lexicographic functions. HERMES-Journal of Language and Communication in Business, (31), 171-196.

Bertin, J. (1967). Sémiologie graphique. Paris, Mouton/Gauthier-Villars.

Bertin, J. (1977). La graphique et le traitement graphique de l'information (No. 91 (084.21) BER).

Bertoline, G. R., \& Urbina Medal, E. G. (1999). Dibujo en ingeniería y comunicación gráfica.

Bertoline, G. R., Wiebe, E. N., Miller, C. L., \& Nasman, L. O. (2002). Fundamentals of Graphics Communications. McGraw-Hill. Disponible en: <http://aylin.gurkok.net/Fundamentals\%20of\%20Graphics\%20Communication.pdf> [Consulta: 6 de junio 2020].

Bertoline, G. R., Wiebe, E. N., Hartman, N. W., \& Ross, W. A. (2010). Fundamentals of graphics communication. McGraw-Hill Higher Education. 
Boardman, D. (1990). Graphicacy revisited: Mapping abilities and gender differences. Educational Review, 42(1), 57-64.

Booker, P. J. (1961). Gaspard Monge (1746-1818) and his Effect on Engineering Drawing and Technical Education. Transactions of the Newcomen Society, 34(1), 15-36.

Borlund, P. (2000). Experimental components for the evaluation of interactive information retrieval systems. Journal of documentation, 56(1), 71-90.

Borlund, P. (2003). The concept of relevance in IR. Journal of the American Society for information Science and Technology, 54(10), 913-925.

Bothma, T. J. (2011). Filtering and adapting data and information in an online environment in response to user needs. Fuertes-Olivera, PA and H. Bergenholtz (Eds.), 2011, 71-102.

Bothma, T. J., \& Tarp, S. (2012). Lexicography and the relevance criterion. Lexikos, 22, 86-108.

Boulanger, J. C. (1995). Présentation: images et parcours de la socioterminologie. Meta: journal des traducteurs/Meta: Translators' Journal, 40(2), 194-205.

Bowker, L. (2003). Specialized lexicography and specialized dictionaries. A Practical Guide to Lexicography, Sterkenburg, Piet van (ed.), 154-164.

Bowker, L., \& Pearson, J. (2002). Working with specialized language: A practical guide to using corpora. Routledge.

Cabezas, L. y Ortega, L.F. (2002). Análisis gráfico y representación geométrica. Barcelona: Edicions Universitat de Barcelona.

Cabré, M. T., \& i Castellví, M. T. C. (1993). La terminología: teoría, metodología, aplicaciones. Editorial Antártida/Empúries.

Cabré, M. T. (1999). Terminology: Theory, methods, and applications (Vol. 1). John Benjamins Publishing.

Cabré Castellví, M. T. (2003). Theories of terminology: Their description, prescription and explanation. Terminology, 9(2), 163-199. 
Casares, J. (1951). Qué es lo" moderno" en lexicografía. Boletín de la Real Academia Española, 31(132), 7-22.

Castro, A. (1991). Glosarios latino-españoles de la Edad Media (Vol. 22). Editorial CSIC-CSIC Press.

Čermák, F. (2003). 1.2 Source materials for dictionaries. In A practical guide to lexicography (pp. 18-25). John Benjamins.

Corréard, M. H., Grundy, V., \& Ormal-Grenon, J. B. (2001). The Oxford-Hachette French Dictionary. Oxford University Press, USA.

Cosijn, E., \& Ingwersen, P. (2000). Dimensions of relevance. Information Processing \& Management, 36(4), 533-550.

Cosijn, E. (2003). Relevance judgements in information retrieval. Pretoria (Doctoral dissertation, RSA: University of Pretoria, Dept. of Information Science).

Cosijn, E., \& Bothma, T. (2005, June). Contexts of relevance for information retrieval system design. In International Conference on Conceptions of Library and Information Sciences (pp. 47-58). Springer, Berlin, Heidelberg. Disponible en: <ftp://nozdr.ru/biblio/> [Consulta: 18 de mayo de 2017].

Cvetković, I. D., Stojićević, M. D., Stachel, H., Milićević, R. G., \& Popkonstantinović, B. D. (2019). The man who invented descriptive geometry. FME Transactions, 47(2), 331-336.

De Schryver, G. M., \& Joffe, D. (2004). On How Electronic Dictionaries are Really Used. In G. Williams S. Vessier (Eds.), Proceedings of the Eleventh EURALEX International Congress, Lorient France, July 6th -10th (pp. 187 -196). Lorient: Universite de Bretagne Sud.

Díaz y Díaz, M. C. (1981). El cultivo del latín en el siglo X.

Díaz García, T., \& Mas Álvarez, I. M. (2008). Construir un diccionario de derivación del español en el siglo XXI. La arquitectura de la información al servicio de la lexicografía. In Proceedings of the XIII EURALEX International Congress (Barcelona, 15-19 July 2008), Barcelona, Institut Universitari de Lingüística Aplicada, Universitat Pompeu Fabra (pp. 669-678). 
Domínguez, R. J. (1878). Diccionario nacional o Gran diccionario clásico de la lengua española: Al (Vol. 1). Imp. de Miguel Guijarro.

Ducrot, O. (1982). Decir y no decir: principios de semántica lingüística. Anagrama.

Dürer, A. (1525) Underweysung der Messung, mit dem Zirckel und Richtscheyt, in Linien, Ebenen unnd gantzen corporen. Disponible en: $<$ https://digital.slubdresden.de/werkansicht/dlf/17139/5/ > [Última consulta: 05 de abril de 2020].

Durkin, P. (Ed.). (2016). The Oxford handbook of lexicography. Oxford University Press.

Esandi-Baztan, M.A. Estudio Crítico de la Terminología de un Manual de Instrucción Universitario. Director: Pedro Antonio Fuertes-Olivera. Trabajo de Investigación Tutelado, Universidad de Valladolid. Departamento de Filología Inglesa, 2006.

Esandi-Baztan, M., Fuertes-Olivera, P.A. y Valin Ortega, A. (2007). Trasmisión de conocimiento científico-técnico en un entorno académico en EGI. Libro de actas del 15 Congreso de Innovación Educativa en las Enseñanzas Técnicas (15 CUIEET), Valladolid: Universidad de Valladolid, 1-10. ISBN 978-84-690-7547-0

Esandi-Baztan, M., Fuertes-Olivera, P.A. (2020). Selecting an Initial Lemma List in Specialised Lexicography: A case study in the Field of Graphic Engineering (en revisión).

Espejo, E. C. (1999). Aspectos generales de la Lexicografía. Thesaurus: Boletín del instituto Caro y Cuervo, 54(2), 412-432.

Faaß, G. (2017). Lexicography and corpus linguistics. In The Routledge Handbook of Lexicography (pp. 123-137). Routledge.

Faber Benítez, P., Márquez Linares, C., \& Vega Expósito, M. (2005). Framing Terminology: A process-oriented approach. Meta: journal des traducteurs/Meta: Translators' Journal, 50(4).

Faber, P., Martínez, S. M., Prieto, M. R. C., Ruiz, J. S., Velasco, J. A. P., Arauz, P. L., ... \& Expósito, M. V. (2006). Process-oriented terminology management in the domain of Coastal 
Engineering. Terminology. International Journal of Theoretical and Applied Issues in Specialized Communication, 12(2), 189-213.

Faber, P., Araúz, P. L., Prieto Velasco, J. A., \& Reimerink, A. (2007). Linking images and words: the description of specialized concepts. International Journal of Lexicography, 20(1), 39-65.

Faber Benítez, P. (2009). The cognitive shift in terminology and specialized translation.

Faber, P. (Ed.). (2012). A cognitive linguistics view of terminology and specialized language (Vol. 20). Walter de Gruyter.

Farina, D. M. C. (1995). LV Shcherba: Towards a General Theory of Lexicography. International Journal of Lexicography, 8(4), 314-350.

Félez, J., \& Martinez, M. L. (2008). Ingeniería gráfica y diseño. EDITORIAL SÍNTESIS SA.

Ferguson, E. S. (1977). The mind's eye: Nonverbal thought in technology. Science, 197(4306), 827-836.

Fontanille, J. (2017). Semiótica del discurso. Fondo Editorial Universidad de Lima.

Flume, P. A., Mogayzel Jr, P. J., Robinson, K. A., Rosenblatt, R. L., Quittell, L., \& Marshall, B. C. (2010). Cystic fibrosis pulmonary guidelines: pulmonary complications: hemoptysis and pneumothorax. American journal of respiratory and critical care medicine, 182(3), 298-306.

Fuertes Olivera, P. (2007). El lenguaje de la ciencia y la tecnología. Las lenguas profesionales y académicas, 205-217.

Fuertes-Olivera, P. A. (Ed.). (2010). Specialised dictionaries for learners (Vol. 136). Walter de Gruyter.

Fuertes-Olivera, P. A. (2011). Equivalent selection in specialized e-lexicography: A case study with Spanish accounting terms. Lexikos, 21.

Fuertes-Olivera, P. A. (2012). Lexicography and the Internet as a (Re-) source. Lexicographica, 28(1), 49-70. 
Fuertes-Olivera, P. A. (2013). E-lexicography: The continuing challenge of applying new technology to dictionary making. Bloomsbury Companion to Lexicography. Londres/Nueva York/Nueva Delhi y Sidney: Bloomsbury, 323-340.

Fuertes-Olivera, P. A. (2016). A Cambrian explosion in lexicography: Some reflections for designing and constructing specialised online dictionaries. International Journal of Lexicography, 29(2), 226-247.

Fuertes-Olivera, P. A. (2019). Designing and making commercially driven integrated dictionary portals: the Diccionarios Valladolid-UVa. Lexicography, 6(1), 21-41. Disponible en: <https://doi.org/10.1007/s40607-019-00056-8> [Consulta: 24 de junio de 2020].

Fuertes-Olivera, P. A., \& Bergenholtz, H. (2015). Los Diccionarios en Línea de Español" Universidad de Valladolid. Estudios de lexicografía, 4, 71-98.

Fuertes-Olivera, P. A., Niño Amo, M., y Sastre Ruano, Á. (2019). Tecnología con fines lexicográficos: Su aplicación en los Diccionarios Valladolid-UVa. Revista Internacional de Lenguas Extranjeras/International Journal of Foreign Languages, 1(10), 75-100.

Fuertes-Olivera, P. A., \& Tarp, S. (2008). La Teoría Funcional de la Lexicografía y sus consecuencias para los diccionarios de economía del español. Revista de lexicografía, (14), 75-95.

Fuertes-Olivera, P. A., \& Tarp, S. (2011). Lexicography for the third millennium: Cognitiveoriented specialised dictionaries for learners. Ibérica, Revista de la Asociación Europea de Lenguas para Fines Específicos, (21), 141-161.

Fuertes-Olivera, P. A., \& Tarp, S. (2014). Theory and practice of specialised online dictionaries: Lexicography versus terminography (Vol. 146). Walter de Gruyter GmbH \& Co KG.

Fuertes-Olivera, P. A., Tarp, S., \& Sepstrup, P. (2018). New insights in the design and compilation of digital bilingual lexicographical products: the case of the Diccionarios Valladolid-UVa. Lexikos, $28,152-17$ 
Galinski, C., \& Picht, H. (1997). 1.2. 2 Graphic and Other Semiotic Forms of Knowledge Representation in Terminology Management. Handbook of Terminology Management: Volume 1: Basic Aspects of Terminology Management, 42.

García Aragón, A. (2016). Lexicografía especializada para traductores: Una propuesta multidisclipinar para el diseño de diccionarios a medida del usuario (inglés-español-griego).

García Llamas, B. I. (2016). La Teoría Funcional de la Lexicografía y su aplicación a la construcción de diccionarios especializados. Una propuesta de Diccionario de Comercio Internacional.

Gelpi, C. (2007, December). Reliability of online bilingual dictionaries. In Dictionary Visions, Research and Practice: Selected Papers from the 12 th International Symposium on Lexicography, Copenhagen (Vol. 2004, p. 5).

Giesecke, F. E. (2006). Dibujo y comunicación gráfica. Pearson Educación.

González García, V., López Poza, R., \& Nieto Oñate, M. (1982). Sistemas de representación. Sistema diédrico. Valladolid. Texgraf.

Gouws, R. (2007). A transtextual approach to lexicographic functions. Lexikos, 17(1).

Gouws, R. H. (2009). Sinuous lemma files in printed dictionaries Access and lexicographic functions. Lexicography in the 21st Century: In Honour of Henning Bergenholtz, 12, 3.

Gouws, R. H. (2011). Learning, unlearning and innovation in the planning of electronic dictionaries.

Grinev, S., \& Klepalchenko, I. (1999). Terminological approach to knowledge representation. In TKE'99: Proceedings of the 5th International Congress on Terminology and Knowledge Engineering (pp. 147-151). Viena: TermNet.

Haensch, G., Omeñaca, C. (2004). Los diccionarios del español en el siglo XXI (Vol. 10). Universidad de Salamanca.

Hanks, P., Dykstra, A., \& Schoonheim, T. (2010). Lexicography, printing technology, and the spread of Renaissance culture. In Proceedings of the XIV Euralex International Congress. Leeuwarden: Fryske Akademy (pp. 988-1016). 
Hartmann, R. R. K. (1989). Sociology of the dictionary user: Hypotheses and empirical studies. Hausmann, FJ et al. (Eds.), 1991, 102-111.

Hartmann, R. R. K. (2001). Teaching and Researching Lexicography. Pearson Education.

Hartmann, R. R. K., \& James, G. (2002). Dictionary of lexicography. Routledge.

Hegarty, M., \& Kozhevnikov, M. (1999). Types of visual-spatial representations and mathematical problem solving. Journal of educational psychology, 91(4), 684.

Henderson, K. (1998). On line and on paper: Visual representations, visual culture, and computer graphics in design engineering. MIT press.

Hernández, H. (1991). De la teoría lexicográfica al uso del diccionario. España: ASELE. Disponible en: $\quad<$ https://cvc.cervantes.es/ensenanza/biblioteca ele/asele/pdf/03/03 0187.pdf> [Consulta: 21 de junio de 2017].

Hood (Jüssen) George J. (1926). Geometry of Engineering Drawing: Descriptive Geometry by the Direct Method. McGraw-Hill book Company, Incorporated.

Householder, F. W. (1967). Problems in Lexicography: Edited by Fred W. Householder and Sol Saporta. Indiana University.

Hausmann, F. J. (1989): «Kleine Weltgeschichte der Metalexikographie», en H. E. Wiegand, ed., Wörterbücher in der Diskussion. Vorträge aus dem Heidelberger Lexikographischen Kolloquium, Tubinga, Niemeyer, pp. 75-109 (= Lexicographica Series Maior 27).

Ingwersen, P., \& Järvelin, K. (2005, December). Information retrieval in context: IRiX. In ACM Sigir Forum (Vol. 39, No. 2, pp. 31-39). New York, NY, USA: ACM.

Johnson, S. (1747). The plan of a dictionary of the English language. Longman.

Kersey, J. (1739). A New English Dictionary... The Fourth Edition, Carefully Revised... By JK [ie John Kersey.]. J. \&J. Bonwicke; H. Knaplock.

Kockaert, H. J., \& Steurs, F. (Eds.). (2015). Handbook of terminology (Vol. 1). John Benjamins Publishing Company. 
Kocourek, R. (1991). La langue française de la technique et de la science: vers une linguistique de la langue savante. Brandstetter.

Kromann, H. P., Riiber, T., \& Rosbach, P. (1984). Überlegungen zu Grundfragen der zweisprachigen Lexikographie. Studien zur neuhochdeutschen Lexikographie $V$. Hildesheim/New York: Olms, 159-238.

Kruyt, J. G. (1995). Technologies in computerized lexicography. Lexikos, 5, 117-137.

Kudashev, I. (2007). Terminography vs. lexicography opposition revisited. Oversattningsteori, facksprak och flersprakighet. Publikationer av VAKKI, (4), 157-166.

Labour, M., Martin, M., \& Leleu-Merviel, S. (2010). Dessin technique et émergence de sens. Apport de la complexité dans une médiation d'apprentissage.

Landau, S. (2001). Dictionaries: the art and craft of lexicography. Cambridge: Cambridge University Press.

Larkin, J. H., \& Simon, H. A. (1987). Why a diagram is (sometimes) worth ten thousand words. Cognitive science, 11(1), 65-100.

León Araúz, P., Faber, P., \& Martínez, S. M. (2012). 3.1 Specialized language semantics. A cognitive linguistics view of terminology and specialized language, 20, 95.

Lerat, P. (1995). Les langues spécialisées. FeniXX.

Lew, R. (2013). Online dictionary skills. Disponible en: <http://repozytorium.amu.edu.pl:8080> [Consulta: 07 de febrero de 2019].

Linstone, H. A., \& Turoff, M. (1975). Introduction. In H. A. Linstone, \& M. Turoff (Eds.). The Delphi method: Techniques and applications (pp. 3-12). Reading, MA: Addison-Wesley Publishing Company.

López Rodríguez, C. I., Faber, P., Araúz, P. L., Velasco, J. A. P., \& Tercedor, M. (2010). La Terminología basada en marcos y su aplicación a las Ciencias Ambientales: los proyectos MARCOCOSTA y ECOSISTEMA. Arena Romanistica, 7(10), 52-74. 
Lorentzen, H. (2012). Online dictionaries - how do users find them and what do they have? In L. Theilgaard (Ed.), Proceedings of the 15th EURALEX International Congress 2012, Oslo, Norway, 7- 11 August 2012 (pp. 654 - 660). Oslo: Universitetet i Oslo, Institutt for ligvistiske og nordiske studier. Disponible en: <http:// www.euralex.org/elx proceedings/Euralex 2012/pp626 -639\%20Sharifi.pdf> [Consulta: 18 de 2013].

Macdonald-Ross, M. (1977). 2: Graphics in Texts. Review of research in education, 5(1), 49-85.

Mancho-Duque, M. J. (2014). La difusión del léxico científico y técnico español del Renacimiento

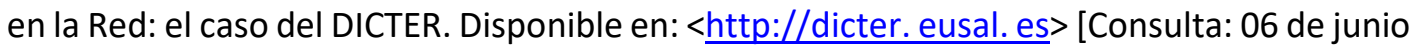
de 2020].

Margaryan, A., Littlejohn, A., \& Vojt, G. (2011). Are digital natives a myth or reality? University students' use of digital technologies. Computers \& education, 56(2), 429-440.

Marsá, F. (Ed.). (1982). Diccionario Planeta de la lengua española usual. Planeta Publishing Corporation.

Martí, E. (2003). Representar el mundo externamente. La adquisición infantil de los sistemas externos de representación. Madrid: Antonio Machado Libros.

Martin, S. E. (1962). Selection and presentation of ready equivalents in a translation dictionary. INTERNATIONAL JOURNAL OF AMERICAN LINGUISTICS, 28(2), 153-159.

Mason, J. (1996). Qualitative researching. Thousand Oaks, USA: Sage Publications.

Mason, J. (2002). Linking qualitative and quantitative data analysis. In Analyzing qualitative data (pp. 103-124). Routledge.

Maton, E. (2007). Représentation graphique et pensée managériale, le cas de la Harvard Business Review de 1922 à 1999 (Doctoral dissertation). Disponible en: <https://pastel.archivesouvertes.fr/pastel-00003632/> [Consulta: 1 mayo de 2020].

Mayer, R. E., \& Sims, V. K. (1994). For whom is a picture worth a thousand words? Extensions of a dual-coding theory of multimedia learning. Journal of educational psychology, 86(3), 389. 
Meier, H. H. (2003). Lexicography as Applied Linguistics. Hartmann, RRK (Ed.). Lexicography: Critical Concepts: 307-318.

Menéndez Pidal, R. (2018). Las glosas-CODERA, FRANCISCO (1910).

Meyer, I. (2001). Extracting knowledge-rich contexts for terminography. Recent advances in computational terminology, 2, 279.

Meyers, F. D. (2009). First year engineering graphics curricula in major engineering colleges. Engineering Design Graphics Journal, 64(2).

Molina Sangüesa, I. (2017). La confección del" Glosario de aritmética y álgebra en el Renacimiento hispano" como instrumento para el estudio del léxico matemático del siglo XVI. Etudes romanes de Brno, (2), 51-68.

Molina Sangüesa, I. (2018). Una propuesta de organización semántica del léxico aritméticoalgebraico renacentista. In Actas del X Congreso Internacional de Historia de la Lengua Española: Zaragoza, 7-11 de septiembre de 2015 (pp. 1229-1240). Institución Fernando el Católico.

Monfasani, R., \& CURZEL, M. F. (2008). Usuarios de la información. Formación y desafíos. Buenos Aires: Alfagrama.

Monge, G. (1822). Géométrie descriptive. Disponible en: <https://archive.org/details/ geodescaugmdune01 mongrich/page/n3/mode/2up> [Consulta: 08 de abril de 2020].

Müller-Spitzer, C., Koplenig, A., \& Töpel, A. (2011). What makes a good online dictionary? Empirical insights from an interdisciplinary research project.

Nebrija A. de (1492). Lexicon hoc est Dictionarium ex sermone latino in hispaniensem. Diccionario latino-español. Salamanca.

Nesi, H. (1999). The specification of dictionary reference skills in higher education. Dictionaries in language learning. Recommendations, national reports and thematic reports from the thematic network project in the area of languages, sub-project, 9, 53-67. Disponible en: <http://curve.coventry.ac.uk/open> [Consulta: 30 de abril de 2019]. 
Nielsen, S. (1995). Access Structure. In Manual of Specialised Lexicography: The Preparation of Specialised Dictionaries (pp. 219-223). John Benjamins Publishing Company.

Nielsen, S., \& Mourier, L. (2007). Design of a function-based internet accounting dictionary. H. Gottlieb, \& JE Mogensen, Dictionary visions, research and practice, 119-138.

Nielsen, S. (2011). Function-and user-related definitions in online dictionaries. Ivanovskaya leksikografischeskaya shkola: traditsii i innovatsii [Ivanovo School of Lexicography: Traditions and Innovations]: A Festschrift in Honour of Professor Olga Karpova. Ivanovo: Ivanovo State University, 197-219.

Nieto Oñate, M., González García V., López Poza, R. (1970). Prácticas programadas de Dibujo Técnico. Delineantes industriales. Valladolid: DITEC

Niño Amo, M. (2015). Conceptualización y descripción de la contabilidad: propuesta de una introducción sistemática para los diccionarios de contabilidad. [Consulta: Consulta: jueves, 16 de abril de 2020]. Disponible en: < https://uvadoc.uva.es/> [Consulta: 26 de febrero de 2018].

Niño Amo, M., \& Fuertes-Olivera, P. A. (2017). La introducción sistemática en el diccionario especializado. Revista de lexicografía, 23, 137-156.

Ortega Mohedano, F. (2008). El método Delphi, prospectiva en ciencias sociales. Revista Ean, 65, 31-64.

Ortega Valín, A. Proyecto Docente. (1992). Docencia en: Dibujo Geométrico, Sistemas de Representación y Dibujo Técnico. Dibujo Asistido por Ordenador. Departamento Expresión Gráfica en la Ingeniería

Paré, E.G., Loving, R. O., Hill, I. L., Paré, R. C. (1997). Descriptive Geometry. Prentice-Hall

Pérez Hernández, C.; Moreno Ortiz, A.; Faber Benítez, P. (1999). “Lexicografía computacional y lexico-grafía de corpus". Revista española de lingüística aplicada 1. 175-214.

Pétroff, A. J. (1984). Sémiologie de la reformulation dans le discours scientifique et technique. Langue française, (64), 53-67. 
Picht, H. (2011). Non-verbal graphic representation of concepts. Ivanovo School of Lexicography: Traditions and Innovations. A Festschrift in Honour of Professor Olga Karpova, 220-236.

Postlethwayt, M. (1774). The Universal Dictionary of Trade and Commerce, with Large Additions and Improvements, Adapting the Same to the Present State of British Affairs in America Since the Last Treaty of Peace Made in the Year 1763; with Great Variety of New Remarks and Illustrations Incorporated Throughout the Whole: Together with Every Thing Essential that is Contained in Savary's Dictionary: Also, All the Material Laws of Trade and Navigation Relating to These Kingdoms and the Customs and Usages to which All Traders are ... (Vol. 1). W. Strahan.

Powell, C. (2003). The Delphi technique: myths and realities. Journal of advanced nursing, 41(4), 376-382.

Prensky, M. (2001). Digital natives, digital immigrants part 1. On the horizon, 9(5), 1-6.

Riggs, F. W. (1989). Terminology and lexicography: their complementarity. International Journal of lexicography, 2(2), 89-110.

Romero-Pérez, I., Alarcón-Vásquez, Y., \& García-Jiménez, R. (2018). Lexicometría: enfoque aplicado a la redefinición de conceptos e identificación de unidades temáticas. Biblios, (71), 68-80.

Rondeau, G. (1983). Introduction à la terminologie. Chicoutimi (Quebec): Gaëtan Morin.

Rossi, A., \& da Silva Brito, G. (2003). LANDAU, Sidney I. (2001). Dictionaries: the art and craft of lexicography. Cambridge University Press. Fórum Linguístico, 3(2), 241-255. Disponible en: <https://periodicos.ufsc.br/> [Consulta: 26 de febrero de 2020].

Rowe, G. \& Wright, G. (1999). The Delphi technique as a forecasting tool: Issues and analysis. International Journal of Forecasting, 15(4), 353 - 375.

Rundell, M. (2012, August). It works in practice but will it work in theory? The uneasy relationship be-tween lexicography and matters theoretical. In Proceedings of the 15th 
EURALEX international Congress (pp. 47-92). Oslo, Norway: Department of Linguistics and Scandinavian Studies, University of Oslo

Sadoski, M., Paivio, A., \& Goetz, E. T. (1991). Commentary: A critique of schema theory in reading and a dual coding alternative. Reading research quarterly, 463-484.

Sadowski, M. A., \& Sorby, S. A. (2012). A Delphi study as a first step in developing a concept inventory for engineering graphics. In 66th Mid-Year Meeting Proceedings, ASEE Engineering Design Graphics Division (pp. 126-132).

Sadowski, M. A., \& Sorby, S. A. (2014, October). Defining Concepts for an Engineering Graphics Concept Inventory: A Delphi Study. In Proceedings of the 69th Midyear Conference of the Engineering Design Graphics Division of ASEE, Normal, IL.

Sadowski, M. A., \& Sorby, S. A. (2015). Engineering graphics concepts: A Delphi study. In Proceedings of the Annual Conference of ASEE, Seattle, WA.

Sager, J. C., Dungworth, D., \& McDonald, P. F. (1980). English special languages: principles and practice in science and technology. Wiesbaden: Brandstetter.

Sager, J. C. (1990). Practical course in terminology processing. John Benjamins Publishing.

Sager, J. C. (2007). La evolución de los lenguajes de especialidad y la terminología. Estudis de lingüística i de lingüística aplicada en honor de M. Teresa Cabré Castellví, 1, 105-122.

Salvá, V. (1846). Nuevo diccionario de la lengua castellana: que comprende la última edición íntegra, muy rectificada y mejorada: del publicado por la Academia española: y unas veinte y seis mil voces, acepciones, frases y locuciones entre ellas muchas americanas. Librería de don Vicente Salvá.

Sánchez Martín, F. J. (2008). Aproximación al léxico de la práctica mensuradora en el Renacimiento: el cuerpo humano como base del sistema metrológico.

Sánchez Martín, F. J. (2009). Estudio del léxico de la geometría aplicada a la técnica en el Renacimiento Hispano (Vol. 235). Salamanca: Universidad de Salamanca. ISBN 978-847800-271-9 
Santos Borbujo, A., Real, E., Jiménez, D., Pujante, D., \& Cortijo, A. (2001). Terminología y socioterminología. Écrire, traduire et représenter la fête, 657-664.

Saussure, Ferdinand de. 1974 [1916]. Course in general linguistics (edited by Charles Bally and Albert Sechehaye, translated by Wade Baskin). Glasgow: Fontana/Collins

Schamber, L., \& Eisenberg, M. (1988). Relevance: The Search for a Definition.

Schierholz, S. J. (2015). Methods in lexicography and dictionary research. Lexikos, 25, 323-352.

Sevilla Muñoz, M., \& Sevilla Muñoz, J. (2003). Una clasificación del texto científico-técnico desde un enfoque multidireccional. Language design: journal of theoretical and experimental linguistics, 5, 0019-38.

Shcherba L.V. (1940). Towards a General Theory of Lexicography. (Traducido por Farina, D. M. C. ,1995). International Journal of Lexicography, 8(4), 314-350.

Silverman, K. (1983). The subject of semiotics. Oxford University Press.

Sinclair, J. M. (1984). Lexicography as an academic subject. Hartmann, RRK (Ed.), 1984, 3-12.

Sinclair, J. M. (Ed.). (1987). Looking up: An account of the COBUILD project in lexical computing and the development of the Collins COBUILD English language dictionary. Collins Elt.

Stein, G. (1984). The English dictionary: past, present and future. Exeter UP.

Taibo Fernández, Á. (1966). Geometría descriptiva y sus aplicaciones. Tomo I. PUNTO, RECTA Y PLANO

Tarp, S. (2003). Basic Elements of Lexicographic Theory/Éléments de base de la théorie lexicographique. Emejulu, James Duplessis (Ed.). 2003. Éléments de lexicographie gabonaise. Tome II, 7-35.

Tarp, S. (2007). Lexicography in the information age. Lexikos, 17(1).

Tarp, S. (2008). Lexicography in the borderland between knowledge and non-knowledge: general lexicographical theory with particular focus on learner's lexicography (Vol. 134). Walter de Gruyter. 
Tarp, S. (2008a). Revival of a dusty old profession. HERMES-Journal of Language and Communication in Business, (41), 175-188.

Tarp, S. (2009). Reflections on lexicographical user research. Lexikos, 19(1).

Tarp, S. (2011). Lexicographical and other e-tools for consultation purposes: Towards the individualization of needs satisfaction. In E-lexicography (pp. 54-70). Bloomsbury Academic.

Tarp, S. (2015). La lexicografía y su relación con otras disciplinas independientes como la lingüística y la ciencia de la información. In Lingüística y diccionarios (pp. 9-31). Universidade da Coruña.

Tarp, S. (2015a). La teoría funcional en pocas palabras. Estudios de Lexicografía, 4, 31-42.

Tarp, S. (2018). Lexicography as an independent science. The Routledge handbook of lexicography, 19-33.

Tarp, S. T., \& Fuertes-Olivera, P. A. (2016). Advantages and disadvantages in the use of internet as a corpus: The case of the online dictionaries of Spanish Valladolid-UVa. Lexikos, 26(1), 273-295.

Temmerman, R. (1998). Why traditional terminology theory impedes a realistic description of categories and terms in the life sciences. Terminology. International Journal of Theoretical and Applied Issues in Specialized Communication, 5(1), 77-92.

Temmerman, R. (Ed.). (2000). Towards new ways of terminology description: The sociocognitiveapproach (Vol. 3). John Benjamins Publishing.

Temmerman, R., \& Kerremans, K. (2003). Termontography: Ontology building and the sociocognitive approach to terminology description. Proceedings of CIL17, 1-10.

Thompson, P. (2013). The digital natives as learners: Technology use patterns and approaches to learning. Computers \& Education, 65, 12-33.

Toffler, A. (1970). Future shock, 1970. Sydney. Pan. 
Tono, Y. (1991). 18 A GOOD DICTIONARY USER: WHAT MAKES THE DIFFERENCE?. Disponible en: <http://www.tufs.ac.jp/ts/personal/tonolab/papers/tono1991a.pdf> [Consultado: el 03 de mayo de 2019].

Tono, Y. (2011). Application of eye-tracking in EFL learners' dictionary look-up process research. International Journal of Lexicography, 24(1), 124-153. Disponible en: <https://academic.oup.com> [Consultado: el 03 de mayo de 2019].

Töpel, A. (2014). Review of research into the use of electronic dictionaries. Using online dictionaries, 13-54.

van Sterkenburg, P. (Ed.). (2003). A practical guide to lexicography (Vol. 6). John Benjamins Publishing.

Verlinde, S., \& Binon, J. (2010). Monitoring Dictionary Use in the Electronic Age. In A. Dykstra \& T. Schoonheim (Eds.), Proceedings of the XIV Euralex International Congress (pp. 11441151) Ljouwert: Afûk.

Verlinde, S., \& Selva, T. (2009). Corpus-based versus intuition-based lexicography: defining a word list for a French learners' dictionary. coach, 83, 1424.

Weill-Fassina, A., \& Rabardel, P. (1985). Le dessin technique un instrument graphique de pensée et de communication professionnel: points de repères. Le travail humain, 48(4), 301-305.

Wiegand, H. E. (1984). On the structure and contents of a general theory of lexicography. Hartmann, RRK (ed.), 1984, 13-30. Disponible en: <https://www.euralex.org/> [Última consulta: el 26 de febrero de 2020].

Wiegand, H. E. (1998). Wörterbuchforschung: Untersuchungen zur Wörterbuchbenutzung, zur Theorie, Geschichte, Kritik und Automatisierung der Lexikographie. Walter de Gruyter.

Wiegand, H. E. (2002). Über textuelle Strukturen der Wörterbuchartikel und Artikelnischen im" de Gruyter Wörterbuch Deutsch als Fremdsprache". Zugleich ein Beitrag zur Weiterentwicklung einer Theorie der Wörterbuchform. Wiegand, HE (Ed.). 2002. Perspektiven der pädagogischen Lexikographie des Deutschen II. Untersuchungen anhand des, 497-595. 
Winkler, B. (1998). Electronic Dictionaries for Learners of English. Disponible en: http://web.warwick.ac.uk/fac/soc/CELTE/PG conference/B Winkler.htm [Consulta: 18 de 2013].

Wolf, H. J., \& Ruhstaller, S. (1996). Las glosas emilianenses (Vol. 6). Universidad de Sevilla.

\section{Otras Referencias}

Ell de la UVa. Grado en: Ingeniería en Tecnologías Industriales, 2018. Disponible en:

<https://www.eii.uva.es/titulaciones/grados/planes/493.pdf> [última consulta: lunes, 01 de julio de 2019].

Ell de la UVa. Grado en: Ingeniería Mecánica, 2018. Disponible en:

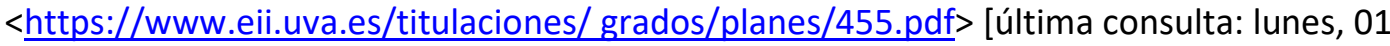
de julio de 2019].

Ell de la UVa. Grado en: Ingeniería en Electrónica Industrial y Automática, 2018. Disponible en: <https:// www.eii.uva.es/titulaciones/grados/planes/452.pdf> [última consulta: lunes, 01 de julio de 2019].

Ell de la UVa. Grado en: Ingeniería en Diseño Industrial y Desarrollo de Producto, 2015. Disponible en: <https:// www.eii.uva.es/titulaciones/grados/planes/448.pdf.> [última consulta: lunes, 01 de julio de 2019].

Ell de la UVa. Grado en: Ingeniero/a en Organización Industrial, 2015. Disponible en:

$<$ https://www.eii.uva.es/titulaciones/grados/planes/447.pdf. $>$ [última consulta lunes, 01 de julio de 2019].

Ell de la UVa Grado en: Ingeniería Química, 2017. Disponible

en:<https://www.eii.uva.es/titulaciones/grados/planes/442.pdf.> [última consulta: lunes, 01 de julio de 2019]. 
Ell de la UVa Grado en: Ingeniería Eléctrica, 2018. Disponible en:<https://www.eii.uva.es/titulaciones/grados/planes/439.pdf.> [última consulta: lunes, 01 de julio de 2019].

Ontology Engineering Group, Escuela Técnica Superior de Ingeniería Informática de la Universidad Politécnica de Madrid. Disponible en: <https://www.oeg-upm.net/> [última consulta: 05 de febrero de 2019].

Tarp, S. (2014). «Homo hodiernus, homo durus: ¿Cómo pueden adaptarse los diccionarios?» [Conferencia]. Recuperado de:< https://www.youtube.com/watch?v=kcBW$\underline{\text { UXSd68\&list=PLAc67Zs0vicKTLBhUicDMaLCovnx61cMk\&index }=6 \& \mathrm{t}=0 \mathrm{~s} \text { > }}$

UNE 1032:1982. Dibujos técnicos. Principios generales de representación (ISO 128, Technical drawings)

UNE 1039, Dibujos técnicos. Acotación. Principios generales, definiciones, métodos de ejecución e indicaciones especiales. (ISO 129-1:2018, Technical drawings -- Indication of dimensions and tolerances -- Part 1: General principles);

UNE 1120:1996, Dibujos técnicos. Tolerancias de cotas lineales y angulares;

UNE-EN ISO 1302, Especificación geométrica de productos (GPS) Indicación de la calidad superficial en la documentación técnica de productos;

UNE-EN ISO 6410-1, Dibujos técnicos. Roscas y piezas roscadas. Parte 1: Convenios generales;

UNE-EN ISO 1101:2017, Especificación geométrica de productos (GPS). Tolerancia geométrica. Tolerancias de forma, orientación, localización y alabeo (ISO 1101:2017). 


\section{APÉNDICES}

Apéndice 1: Resultados obtenidos en la primera ronda del método Delphi, se incluye el grado de consenso

Apéndice 2: Resultados obtenidos en la segunda ronda del método Delphi

Apéndice 3: Comparación de los resultados con respecto a la importancia percibida por los expertos de las rondas I y II

Apéndice 4: Resultados de las opiniones de los alumnos 
Apéndice 1: Resultados obtenidos en la primera ronda del método Delphi, se incluye el grado de consenso.

RESULTADOS Ronda I

\begin{tabular}{|c|c|c|c|}
\hline Concepto identificado & $\begin{array}{l}\text { Importancia* } \\
\text { concedida (1-5) }\end{array}$ & Consenso** & $\begin{array}{c}\text { Dificultad } * * * \\
\text { apreciada (1-5) }\end{array}$ \\
\hline Croquizar & 4.5 & Bueno & 2.8 \\
\hline Posición relativa de las vistas & 4.71 & Bueno & 3.2 \\
\hline Mínimas vistas necesarias & 4.66 & Bueno & 4.2 \\
\hline Sección & 4.6 & Pleno & 3.6 \\
\hline Sección total & 4.75 & Muy bueno & 3.25 \\
\hline Media sección & 4 & Bueno & 3.5 \\
\hline Media sección con giro & 4 & Muy bueno & 4 \\
\hline Sección en ángulo & 4.4 & Pleno & 3.6 \\
\hline Sección múltiple abatida & 4.4 & Pleno & 3.2 \\
\hline Secciones auxiliares & 4 & Bueno & 3.6 \\
\hline Planos no paralelos a los de proyección & 4.66 & Bueno & 3.5 \\
\hline Escala & 4.42 & Bueno & 3.66 \\
\hline Seis vistas normalizadas & 4.25 & Muy bueno & 2.75 \\
\hline Croquis de la perspectiva & 4.33 & Bueno & 3.66 \\
\hline Medio corte & 4,13 & Pleno & 3 \\
\hline Corte quebrado & 4.5 & Muy bueno & 4 \\
\hline Identificar el plano de corte & 4.33 & Bueno & 3.1 \\
\hline Sección abatida & 4.2 & Pleno & 3.6 \\
\hline Acotar & 5 & Pleno & 4.5 \\
\hline Seguir las normas & 5 & Pleno & 4.4 \\
\hline Rosca métrica & 4.5 & Muy bueno & 3.5 \\
\hline Coeficiente de reducción & 4.33 & Bueno & 4 \\
\hline Croquis de definición & 4.33 & Bueno & 3 \\
\hline Rosca métrica de paso fino & 4 & Muy bueno & 4 \\
\hline Croquis de producto terminado & 4.75 & Muy bueno & 3.25 \\
\hline 3/8 de pulgada & 4 & Bueno & 3.6 \\
\hline Denominación de las vistas & 4.4 & Pleno & 2.6 \\
\hline Método de proyección del primer diedro & 4.8 & Pleno & 2.8 \\
\hline Indicación del método de proyección & 4.2 & Pleno & 2.2 \\
\hline Elección de las vistas & 4.8 & Pleno & 3.6 \\
\hline Vistas parciales & 4 & Pleno & 2.4 \\
\hline Línea llena gruesa & 4.8 & Pleno & 2.2 \\
\hline Línea llena fina & 4.4 & Pleno & 2.4 \\
\hline Línea llena fina a mano alzada & 4 & Pleno & 2.2 \\
\hline Línea fina de trazos & 4.2 & Pleno & 2.4 \\
\hline Línea fina de trazos y puntos & 4.4 & Pleno & 2.4 \\
\hline Traza del plano de corte & 4.6 & Pleno & 3.2 \\
\hline Anchura de la línea & 4.6 & Pleno & 2.6 \\
\hline Orden de prioridad de líneas coincidentes & 4.8 & Pleno & 3.8 \\
\hline Líneas de referencia & 4 & Pleno & 2.4 \\
\hline Rayado & 4.6 & Pleno & 2.8 \\
\hline $\begin{array}{l}\text { Rayado de diferentes partes cortadas de } \\
\quad \text { una misma pieza }\end{array}$ & 4.4 & Pleno & 3.2 \\
\hline Interrupción de rayado & 4.2 & Pleno & 2.2 \\
\hline Corte & 4.8 & Pleno & 3.4 \\
\hline Plano de corte & 4.6 & Pleno & 3.6 \\
\hline Disposición de los cortes & 4.6 & Pleno & 3.8 \\
\hline
\end{tabular}


Localización del plano de corte

4.6

Corte de nervios, elementos de fijación,

Pleno

árboles, radios de ruedas y otros

Pleno

elementos análogos

Corte por un plano

Pleno

Corte por dos planos paralelos

4.2

Pleno

Corte por planos sucesivos

Pleno

Corte por dos planos concurrentes

Corte longitudinal de una forma de

Pleno revolución que contiene detalles regularmente repartidos y no situados en el plano de corte y siempre que no se produzca ambigüedad

Secciones abatidas con desplazamiento Secciones abatidas sin desplazamiento Corte local

Disposición de las secciones sucesivas Vistas interrumpidas

Representación de elementos repetitivos Detalles representados a escala mayor

Mínima distancia entre dos rectas que se cruzan

Recta perpendicular a un plano

$\begin{array}{ccc}4 & \text { Pleno } & 3.4 \\ 4 & \text { Pleno } & 2.8 \\ 4 & \text { Pleno } & 2.6 \\ 4.4 & \text { Pleno } & 3 \\ 4 & \text { Pleno } & 2.6 \\ 4.2 & \text { Pleno } & 2.8 \\ 4 & \text { Pleno } & 2.4 \\ 4.3 & \text { Pleno } & 3.4\end{array}$

Teorema de las tres perpendiculares

Segmento mínima distancia

Pleno

Segmento paralelo a un plano

coordenado

Pleno

Pleno

Verdadera magnitud de un segmento a

Pleno partir de sus proyecciones

Ángulo recta-plano

Rectas horizontales de plano

Pleno

Rectas frontales de plano

Pleno

Pleno

Pleno

Pleno

* La importancia concedida (de 1 a 5) es el criterio utilizado para pertenecer a la lista inicial de lemas.

** Se considera que está consensuado si al menos tres panelistas identifican ese concepto.

*** La dificultad apreciada (de 1 a 5) permite una comparación de dos puntos de vista: el de los expertos y el de los estudiantes. 
Apéndice 2: Resultados obtenidos en la segunda ronda del método Delphi.

\section{RESULTADOS Ronda II}

\begin{tabular}{|c|c|}
\hline Concepto & $\begin{array}{l}\text { Importancia concedida } \\
(1-5)\end{array}$ \\
\hline $\begin{array}{l}\text { Vistas suficientes / Mínimas vistas necesarias / Vistas necesarias } \\
\text { para definir... }\end{array}$ & 4,8 \\
\hline Acotar & 5 \\
\hline Seguir las normas /Normalizado & 4,8 \\
\hline Mecanizar superficies & 3.6 \\
\hline Denominación de las vistas & 4,4 \\
\hline Elección de las vistas & 4,8 \\
\hline Línea llena gruesa & 4,4 \\
\hline Orden de prioridad de líneas coincidentes & 4 \\
\hline Corte /corte por un plano & 4,4 \\
\hline $\begin{array}{l}\text { Corte longitudinal de una forma de revolución que contiene detalles } \\
\text { regularmente repartidos y no situados en el plano de corte y } \\
\text { siempre que no se produzca ambigüedad }\end{array}$ & 3,8 \\
\hline Verdadera magnitud de un segmento a partir de sus proyecciones & 4,4 \\
\hline Rectas horizontales de plano & 4,8 \\
\hline Rectas frontales de plano & 4,8 \\
\hline Corte total/ Corte por un plano & 4,4 \\
\hline Croquis de producto terminado & 4,4 \\
\hline Posición relativa de las vistas & 4,6 \\
\hline Planos no paralelos a los de proyección & 4 \\
\hline Sección & 3,8 \\
\hline Traza del plano de corte & 4,2 \\
\hline Anchura de la línea & 3,8 \\
\hline Rayado & 4 \\
\hline Plano de corte & 4,2 \\
\hline Disposición de los cortes & 4,4 \\
\hline Localización del plano de corte & 4 \\
\hline Teorema de las tres perpendiculares & 4,6 \\
\hline Segmento paralelo a un plano coordenado & 4,4 \\
\hline Croquizar & 4,2 \\
\hline Disposición normalizada de las vistas/Seis vistas normalizadas & 4,2 \\
\hline Corte quebrado/Corte por planos sucesivos & 4,2 \\
\hline Rosca métrica & 4,2 \\
\hline Escala & 4,8 \\
\hline Corte en ángulo/Corte por dos planos concurrentes & 4,3 \\
\hline Sección múltiple abatida/Disposición de las secciones sucesivas & 4 \\
\hline Método de proyección del primer diedro & 4,6 \\
\hline Línea llena fina & 3,8 \\
\hline Línea fina de trazos y puntos & 4,4 \\
\hline Rayado de diferentes partes cortadas de una misma pieza & 4,4 \\
\hline $\begin{array}{l}\text { Corte de nervios, elementos de fijación, árboles, radios de ruedas y } \\
\text { otros elementos análogos }\end{array}$ & 4,2 \\
\hline Mínima distancia entre dos rectas que se cruzan & 3 \\
\hline Recta perpendicular a un plano & 4,4 \\
\hline Croquis de la perspectiva & 3,8 \\
\hline Identificar el plano de corte & 4,2 \\
\hline Coeficiente de reducción & 3,6 \\
\hline Croquis de definición & 5 \\
\hline Sección abatida / sección transversal & 4 \\
\hline Indicación del método de proyección & 3,4 \\
\hline
\end{tabular}


Línea fina de trazos $\quad 4$

Interrupción de rayado $\quad 3,4$

$\begin{array}{ll}\text { Corte por dos planos paralelos } & 3,6\end{array}$

Representación de elementos repetitivos $\quad 3,8$

$\begin{array}{ll}\text { Segmento mínima distancia } & 3,8\end{array}$

Línea de máxima inclinación de un plano 4

Medio corte o corte al cuarto $\quad 4,6$

Plano de proyección $\quad 4,4$

$\begin{array}{lr}\text { Plano de referencia } & 3,8\end{array}$

Plano Datum $\quad 3,5$

Cota de situación $\quad 4,4$

Ortogonal, perpendicular, normal $\quad 4,6$

Plano representado por una línea, plano proyectante 4

Dirección y sentido de la visual/ Línea (dirección) de observación $\quad 4,8$

Verdadera forma $\quad 5$

Verdadera dimensión-magnitud

Elemento de revolución $\quad 4$

Alineamiento de las vistas $\quad 5$

Perspectiva estallada $\quad 5$

Proyección cilíndrica ortogonal/vistas ortogonales $\quad 4,8$

$\begin{array}{ll}\text { Oblicuo/ NO ortogonal } & 3,6\end{array}$ 
Apéndice 3. Comparación de los resultados con respecto a la importancia percibida por los expertos de las rondas I y II.

\begin{tabular}{|c|c|c|c|}
\hline & Concepto & $\begin{array}{l}\text { Importancia } \\
\text { en la ronda I }\end{array}$ & $\begin{array}{l}\text { Importancia en } \\
\text { la ronda II }\end{array}$ \\
\hline 1 & $\begin{array}{l}\text { Vistas suficientes / Mínimas vistas necesarias / Vistas } \\
\text { necesarias para definir... }\end{array}$ & 4,8 & 4,8 \\
\hline 2 & Acotar & 5 & 5 \\
\hline 3 & Seguir las normas /Normalizado & 5 & 4,8 \\
\hline 5 & Denominación de las vistas & 4,8 & 4,4 \\
\hline 6 & Elección de las vistas & 4,8 & 4,8 \\
\hline 7 & Línea llena gruesa & 4,8 & 4,4 \\
\hline 8 & Orden de prioridad de líneas coincidentes & 4,8 & 4 \\
\hline 9 & Corte /corte por un plano & 4,3 & 4,4 \\
\hline 10 & $\begin{array}{l}\text { Corte longitudinal de una forma de revolución que } \\
\text { contiene detalles regularmente repartidos y no } \\
\text { situados en el plano de corte y siempre que no se } \\
\text { produzca ambigüedad }\end{array}$ & 4,8 & 3,8 \\
\hline 11 & $\begin{array}{l}\text { Verdadera magnitud de un segmento a partir de sus } \\
\text { proyecciones }\end{array}$ & 4,8 & 4,4 \\
\hline 12 & Rectas horizontales de plano & 4,8 & 4,8 \\
\hline 13 & Rectas frontales de plano & 4,8 & 4,8 \\
\hline 15 & Croquis de producto terminado & 4,75 & 4,4 \\
\hline 16 & Posición relativa de las vistas & 4,71 & 4,6 \\
\hline 18 & Sección & 4,6 & 3,8 \\
\hline 19 & Traza del plano de corte & 4,6 & 4,2 \\
\hline 20 & Anchura de la línea & 4,6 & 3,8 \\
\hline 21 & Rayado & 4,6 & 4 \\
\hline 22 & Plano de corte & 4,6 & 4,2 \\
\hline 23 & Disposición de los cortes & 4,6 & 4,4 \\
\hline 24 & Localización del plano de corte & 4,6 & 4 \\
\hline 25 & Teorema de las tres perpendiculares & 4,6 & 4,6 \\
\hline 26 & Segmento paralelo a un plano coordenado & 4,6 & 4,4 \\
\hline 27 & Croquizar & 4,5 & 4,2 \\
\hline 28 & $\begin{array}{l}\text { Disposición normalizada de las vistas/Seis vistas } \\
\text { normalizadas }\end{array}$ & 4,25 & 4,2 \\
\hline 29 & Corte quebrado/Corte por planos sucesivos & 4,45 & 4,2 \\
\hline 30 & Rosca métrica & 4,5 & 4,2 \\
\hline 31 & Escala & 4,42 & 4,8 \\
\hline 32 & Corte en ángulo/ Corte por dos planos concurrentes & 4,4 & 4,3 \\
\hline 33 & $\begin{array}{l}\text { Sección múltiple abatida/ Disposición de las secciones } \\
\text { sucesivas }\end{array}$ & 4,4 & 4 \\
\hline 34 & Método de proyección del primer diedro & 4,4 & 4,6 \\
\hline 35 & Línea llena fina & 4,4 & 3,8 \\
\hline 36 & Línea fina de trazos y puntos & 4,4 & 4,4 \\
\hline 37 & $\begin{array}{l}\text { Rayado de diferentes partes cortadas de una misma } \\
\text { pieza }\end{array}$ & 4,4 & 4,4 \\
\hline 38 & $\begin{array}{l}\text { Corte de nervios, elementos de fijación, árboles, } \\
\text { radios de ruedas y otros elementos análogos }\end{array}$ & 4,4 & 4,2 \\
\hline 39 & Mínima distancia entre dos rectas que se cruzan & 4,3 & 3 \\
\hline 40 & Recta perpendicular a un plano & 4,4 & 4,4 \\
\hline 42 & Identificar el plano de corte & 4,33 & 4,2 \\
\hline 46 & Sección abatida / sección transversal & 4,2 & 4 \\
\hline 47 & Indicación del método de proyección & 4,2 & 3,4 \\
\hline 48 & Línea fina de trazos & 4,2 & 4 \\
\hline
\end{tabular}


Apéndices

49 Interrupción de rayado

50 Corte por dos planos paralelos

4,2

51 Representación de elementos repetitivos

4,2

3,8

52 Segmento mínima distancia

4,2

3,8

53 Línea de máxima inclinación de un plano

4,2 
Apéndice 4: Resultados de las opiniones de los alumnos.

Valoración por parte de los estudiantes de la dificultad de los conceptos en la ronda II de Delphi

\begin{tabular}{|c|c|}
\hline Concepto & Dificultad (1-5) \\
\hline Vistas suficientes/Mínimas vistas necesarias/Vistas necesarias para definir & 2,70 \\
\hline Acotar & 2,80 \\
\hline Seguir las normas / Normalizado & 3,13 \\
\hline Mecanizar superficies & 3,22 \\
\hline Denominación de las vistas & 2,10 \\
\hline Elección de las vistas & 2,93 \\
\hline Línea llena gruesa & 2,20 \\
\hline Orden de prioridad de líneas coincidentes & 2,83 \\
\hline Corte & 3,20 \\
\hline $\begin{array}{l}\text { Corte longitudinal de una forma de revolución que contiene detalles } \\
\text { regularmente repartidos y no situados en el plano de corte; y siempre } \\
\text { que no se produzca ambigüedad }\end{array}$ & 3,34 \\
\hline Verdadera magnitud de un segmento a partir de sus proyecciones & 2,63 \\
\hline Rectas horizontales de plano & 2,37 \\
\hline Rectas frontales de plano & 2,33 \\
\hline Corte total / Corte por un plano & 2,25 \\
\hline Croquis de producto terminado & 2,79 \\
\hline Posición relativa de las vistas & 2,35 \\
\hline Planos no paralelos a los de proyección & 3,19 \\
\hline Sección & 3,06 \\
\hline Traza del plano de corte & 2,64 \\
\hline Anchura de la línea & 2,32 \\
\hline Rayado & 1,65 \\
\hline Plano de corte & 2,49 \\
\hline Disposición de los cortes & 2,78 \\
\hline Localización del plano de corte & 1,94 \\
\hline Teorema de las tres perpendiculares & 3,21 \\
\hline Segmento paralelo a un plano coordenado & 2,99 \\
\hline Croquizar & 2,40 \\
\hline Disposición normalizada & 2,67 \\
\hline Corte quebrado / Corte por planos sucesivos & 3,02 \\
\hline Rosca métrica & 3,11 \\
\hline Escala & 2,51 \\
\hline Corte en ángulo / Corte por dos planos concurrentes & 3,29 \\
\hline Sección múltiple abatida / Disposición de las secciones sucesivas & 3,43 \\
\hline Método de proyección del primer diedro & 2,15 \\
\hline Línea llena fina & 2,12 \\
\hline Línea fina de trazos y puntos & 1,86 \\
\hline Rayado de diferentes partes cortadas de una misma pieza & 2,14 \\
\hline \multicolumn{2}{|l|}{ Corte de nervios; elementos de fijación ; árboles; radios de ruedas y otros } \\
\hline elementos análogos & 2,60 \\
\hline Mínima distancia entre dos rectas que se cruzan & 2,93 \\
\hline Recta perpendicular a un plano & 2,46 \\
\hline Croquis de la perspectiva & 2,52 \\
\hline Identificar el plano de corte & 2,65 \\
\hline Coeficiente de reducción & 2,76 \\
\hline Croquis de definición & 2,62 \\
\hline Sección abatida / sección transversal & 3,08 \\
\hline Indicación del método de proyección & 2,90 \\
\hline Línea fina de trazos & 2,12 \\
\hline Interrupción de rayado & 2,57 \\
\hline
\end{tabular}


Corte por dos planos paralelos

Representación de elementos repetitivos

Segmento mínima distancia

Línea de máxima inclinación de un plano

Medio corte o corte al cuarto

Plano de proyección

Plano de referencia

Plano Datum (de medidas)

Cota de situación

Ortogonal; perpendicular; normal

Plano representado por una línea; plano proyectante

Dirección y sentido de la visual/ Línea (dirección) de observación 2,80

Verdadera forma

Verdadera dimensión

Elemento de revolución

Alineamiento de las vistas 